\title{
RAFAEL DARIOLLI
}

\section{Efeito aditivo do transplante de células-troncos adultas sobre a perfusão cardíaca pós-infarto em porcos tratados com beta-bloqueador e inibidor da enzima conversora de angiotensina}

Tese apresentada à Faculdade de Medicina da Universidade de São Paulo para obtenção do título de Doutor em Ciências

Programa de Ciências Médicas

Área de concentração: Distúrbios Genéticos de Desenvolvimento e Metabolismo

Orientador: Prof. Dr. José Eduardo Krieger

São Paulo 
Dados Internacionais de Catalogação na Publicação (CIP)

Preparada pela Biblioteca da

Faculdade de Medicina da Universidade de São Paulo

Creprodução autorizada pelo autor

Dariolli, Rafael

Efeito aditivo do transplante de células-troncos adultas sobre a perfusão cardíaca pós-infarto em porcos tratados com beta-bloqueador e inibidor da enzima conversora de angiotensina / Rafael Dariolli. -- São Paulo, 2015.

Tese(doutorado)--Faculdade de Medicina da Universidade de São Paulo.

Programa de Ciências Médicas. Área de concentração: Distúrbios Genéticos de Desenvolvimento e Metabolismo.

Orientador: José Eduardo Krieger.

Descritores: 1.Células-tronco 2.Suínos 3.Transplante alogênico 4.Tecido adiposo 5.Infarto do miocárdio

USP/FM/DBD-060/15 
A meus pais, Odair e Isete, sem os quais e por motivos não tão óbvios, eu jamais teria chegado tão longe. Acima de tudo, por me ensinarem a ter persistência, a qual me impediu de desistir quando tudo parecia perdido. 


\section{Agradecimentos}

Este trabalho foi desenvolvido com o apoio financeiro da Fundação de Amparo à Pesquisa do Estado de São Paulo - FAPESP.

Primeiramente, gostaria de agradecer ao Prof. Dr. José Eduardo Krieger, sem o qual este trabalho não teria acontecido. Muito obrigado pela a oportunidade, e confiança a mim depositada nestes últimos sete anos e pelos exemplos de determinação, dedicação e competência com os quais tem me orientado.

Ao Prof. Dr. Luiz Francisco Poli de Figueiredo (in memoriam) e Prof. Dr. Luiz Alberto Soares e os funcionários Santana, Cláudio e Sueli, da Disciplina de Cirurgia da FMUSP pelas infinitas oportunidades durante meu período de treinamento e manipulação com suínos.

Aos funcionários Edna, Sueli, Eduardo, Liliane, Nelson, Richard, Elenice, Annelise, Pedro, Dario entre outros tantos, da Divisão de Experimentação do InCor, por toda ajuda com os experimentos realizados com os porcos.

À Leonora Loppnow pelas ajuda prestada durante todo o processo de desenvolvimento e padronização do modelo percutâneo de infarto em porcos entre outras colaborações.

Ao Núcleo de Transplantes do InCor e seus funcionários e pesquisadores, em especial Dr. Fernando Bacal, os quais fizeram parte integral de minha vida neste último ano de doutorado. Muito obrigado pela oportunidade e confiança em participar desta brilhante equipe.

Ao CEPEC, em especial, Dr. Wilson Mathias Jr., Dra. Jeane Mike Tsutsui e Telma, pela oportunidade impar de formar um não médico como um "ecocardiografista". O empenho e confiança de vocês permitiram não apenas que esta fase de minha trajetória profissional fosse finalizada, mas que novas oportunidades como participar da Equipe de Ecocardiografia do Transplante Cardíaco - InCor, fossem realizações verdadeiras. Dr. Wilson, muito obrigado pelo convite e pela confiança a mim depositada.

Ao Dr. Pedro Alves Lemos Neto pelo suporte científico, acadêmico, técnico que tem me dado desde nossa primeira reunião, nosso primeiro experimento com porcos. 
A todos os amigos e colegas do LGCM que de alguma maneira tiveram participação direta ou indireta na realização deste trabalho.

À Maria de Lourde, Silvana, Rosangela, Felícia, Juliana, Luciana, Sileide, Ana Maria, Lúcia, Marcelly, Márcio Chaves, Arruda, Janilton, Andréia e Brendo pelo apoio técnico e a amizade de sempre.

À Ayumi, Luciene, Samantha, Thais, Juliana, Valério, Newton, Flávio, Tiago, pela colaboração importante e indispensável para a geração do banco de célulastronco de porcos.

À Giovana Gonçalves, Juliana Sanajotti Nakamuta, Maria Elena Danoviz e Vinicius Bassaneze por terem me recebido tão bem, me engajado no grupo de terapia celular e me ensinado a dar os "primeiros passos". Pelas discussões que me ensinaram muito e me permitiram escrever meu primeiro projeto neste mundo infinito de possibilidades que são a terapia celular e a cardiologia.

Ao Luís Felipe Neves do Santos, um grande amigo que surgiu na hora certa para ajudar de forma considerável no manejo com os porcos e, além disso, por me fazer lembrar os grandes amigos que já fiz nessa vida.

Ao Dr. Euclydes Fontegno Marques, mestre, professor, exemplo, pai, amigo, figura sem a qual, esse trabalho teria sido extremamente menos interessante e também menos prazeroso. Por todas as horas que passamos no campo cirúrgico operando, ensinando e aprendendo. O senhor não só faz parte de minha vida acadêmica pelo grande profissional que é, mas parte de minha vida pessoal, como o exemplo de um grande homem a ser seguido.

Ao Dr. Celso Kiyochi Takimura, que com sua brilhante habilidade com os cateteres e sua paciência e educação oriental, me ajudou a seguir sempre confiante do trabalho que estávamos desenvolvendo. Muito obrigado por tantas horas dedicadas aos meus experimentos. Virão muitas mais.

Aos meus grandes e eternos amigos Leonardo Jensen e Marcus Vinícius por toda a colaboração profissional que tem dado a mim nos últimos anos, mas especialmente por todas as horas extra laboratório. Vocês são muito mais que colegas de trabalho, portanto nem todas as palavras serão capazes de agradecer e enaltecer meu sentimento por vocês. Obrigado. 
À Gabriela Venturini, pelo apoio científico e técnico, sem os quais essa trajetória teria sido muito mais dura. Você é meu ponto de equilíbrio emocional e racional. O termômetro que me ajuda a julgar meus excessos e faltas. Meu portoseguro. Muito obrigado pela amizade, companheirismo, dedicação e carinho, mas principalmente pela paciência que tem tido comigo nos últimos anos. Seu lugar é cativo. Muito obrigado por trilhar esse caminho a meu lado.

A minha irmã Nicole, a qual diz as quatro ventos me seguir como um bom exemplo de ser humano, eu também te agradeço, por ser um ser humano iluminado, diferenciado, forte, racional e emocional tudo na dose certa. Você também é meu exemplo a ser seguido. Seu caráter, sua perseverança, sua competência e sua transparência me dão a noção de segurança que procuro, sempre que é preciso um conselho de irmã mais nova.

A meus pais, Odair e Isete pela dedicação e trabalho que tiveram para me proporcionar a chance de estar aqui hoje correndo atrás de meus sonhos. Pelos exemplos de dignidade, respeito, educação, perseverança, força e garra que demonstram em tudo que fazem. Estes exemplos me motivam a continuar para fazer a diferença. Além disso, pela fé e confiança inabalável que sempre depositaram em mim e em minhas decisões. 
Esta tese está de acordo com as seguintes normas, em vigor no momento desta publicação:

Referências: adaptado de International Committee of Medical Journals Editors (Vancouver)

Universidade de São Paulo. Faculdade de Medicina. Serviço de Biblioteca e Documentação. Guia de apresentação de dissertações, teses e monografias. Elaborado por Anneliese Carneiro da Cunha, Maria Julia de A. L. Freddi, Maria F. Crestana, Marinalva de Souza Aragão, Suely Campos Cardoso, Valéria Vilhena. 2a ed. São Paulo: Serviço de Biblioteca e Documentação; 2005.

Abreviaturas dos títulos dos periódicos de acordo com List of Journals Indexed in Index Medicus. 



\section{Sumário}

Lista de Abreviações ........................................................................................... $\mathrm{i}$

Lista de Símbolos...........................................................................................ii

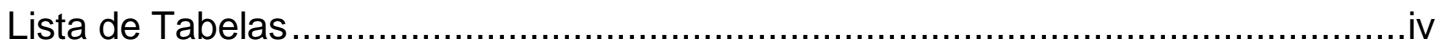

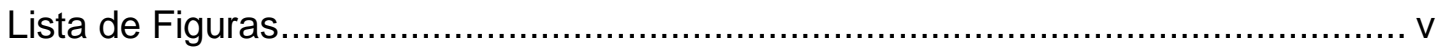

Resumo

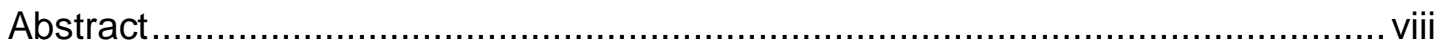

1. INTRODUÇÃO

1.1. Infarto do Miocárdio: Epidemiologia e Fisiopatologia ……............................... 3

1.2. Células-tronco adultas - renovação e manutenção dos tecidos ....................... 4

1.3. O tecido adiposo - uma fonte rica de células-tronco mesenquimais ............... 6

1.4. Influência da idade e comorbidades: perfil imunológico de ASCs ................... 7

1.5. A terapia celular e o porco como um modelo pré-clínico relevante em

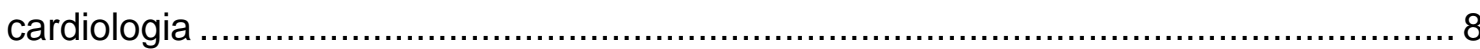

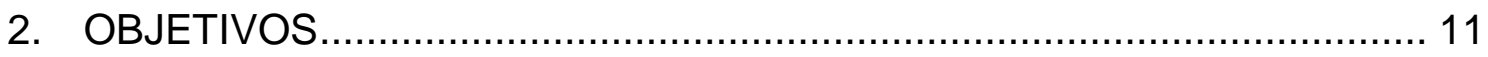

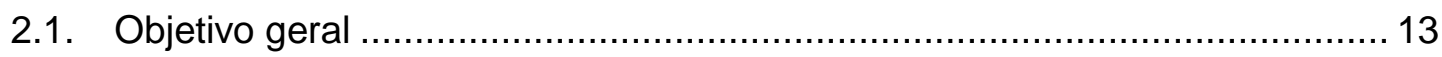

2.2. Objetivos específicos............................................................................. 13

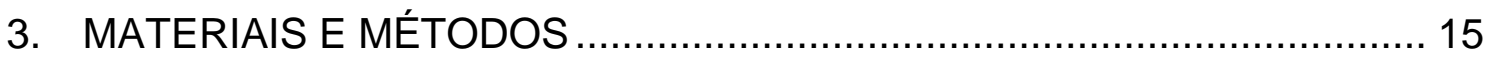

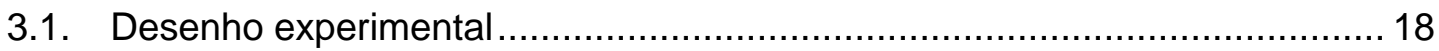

3.2. Extração, caracterização e geração do banco de pASCs .............................. 21

3.3. Modelo de infarto do miocárdio de artéria fechada em porcos .......................21

3.4. Procedimentos de injeção intramiocárdica de pASC..................................... 22

3.5. Ecocardiografia transtorácica ................................................................. 22

3.5.1. Ecocardiografia com perfusão miocárdica em tempo real .................................. 22

3.5.2. Determinação quantitativa da perfusão miocárdica ........................................... 24

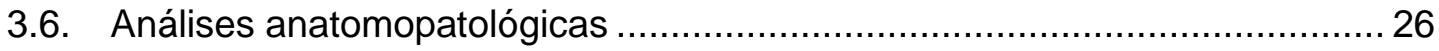

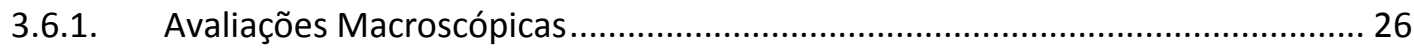

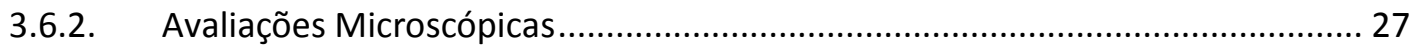

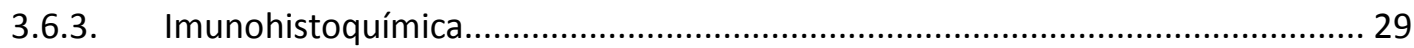




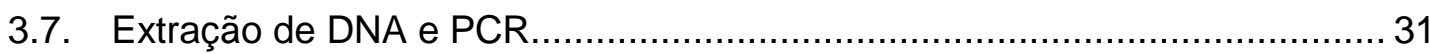

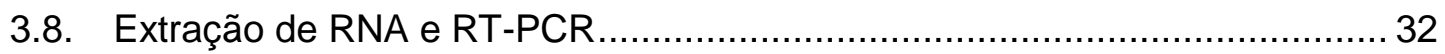

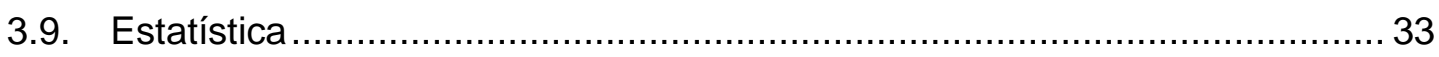

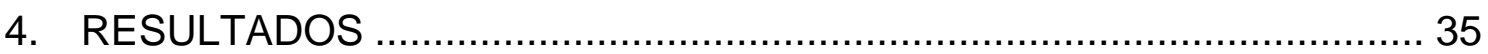

4.1. pASCs alogênicas não foram encontradas no coração dos porcos 30 dias após a injeção.

4.2. Altas doses de pASCs alogênicas estimulam um aumento na perfusão miocárdica 38

4.3. Altas doses de pASC alogênicas estimulam o aumento no número de vasos na borda e áreas remotas ao infarto 46

4.4. Altas doses de pASC alogênicas reduziram a área de lesão do VE 48

4.5. Altas doses de pASCs alogênicas não provocaram um aumento da resposta inflamatória celular no coração 54

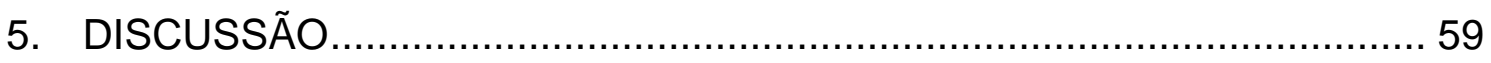

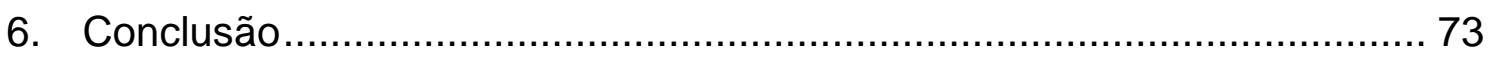

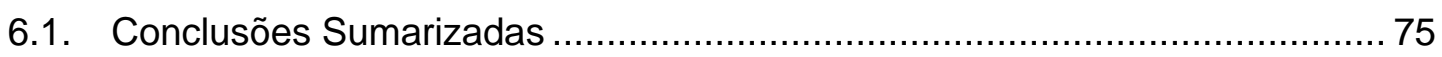

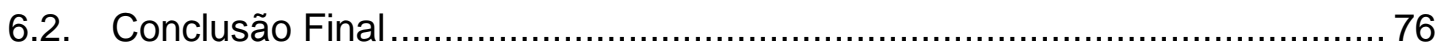

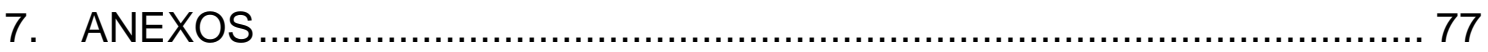

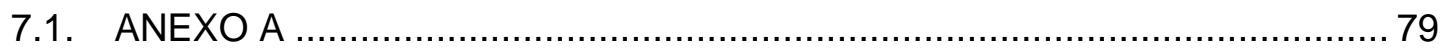

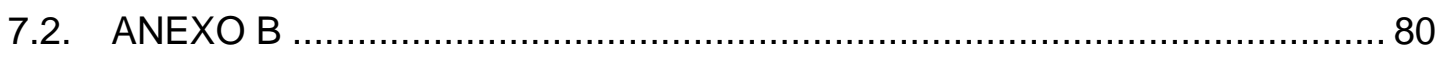

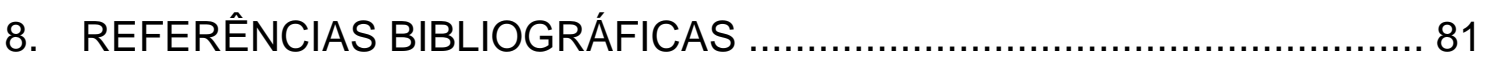

APÊNDICE A - Modelos de Infarto em Porcos

APÊNDICE B - Geração de piPSCs e CM-piPSCs 


\section{Lista de Abreviações}

\begin{tabular}{|c|c|}
\hline ACX & - Artéria Coronária Circunflexa Esquerda \\
\hline $\mathrm{AE}$ & - Átrio Esquerdo \\
\hline AMC & - Ameróides Constritores \\
\hline ASC & - do inglês, Adipose Derived Stem Cell \\
\hline BM-MSC & - do inglês, Bone Marron Mesenchymal Stem Cell \\
\hline BSA & - do inglês, Bovine serum albumin \\
\hline CAPPesq & - Comissão de Ética para Análise de Projetos de Pesquisa \\
\hline cDNA & - DNA Complementar \\
\hline CKMB & - Isoenzima MB de Creatina Quinase \\
\hline CM & - Cardiomiócito \\
\hline $\mathrm{CO}_{2}$ & - Dióxido de Carbono \\
\hline Ctrl & - Controle \\
\hline DA & - Artéria Coronária Descendente Anterior \\
\hline DAB & - Diaminobenzidina \\
\hline DAPI & - 2-(4-Amidinophenyl)-1 H-Indole-6-Carboxamidina \\
\hline DDF & - Diâmetro Diastólico Final \\
\hline DMEM & - do inglês, Dulbecco's Modified Eagle Medium \\
\hline DMEM-Low & - do inglês, Dulbecco's Modified Eagle Medium with Low glucose \\
\hline DMSO & - Dimetilsulfóxido \\
\hline DNA & - do inglês, Deoxyribonucleic acid \\
\hline dNTP's & - Desoxirribonucleotídeos Fosfatados \\
\hline DSF & - Diâmetro Sistólico Final \\
\hline EB & - do inglês, Embryoid Body \\
\hline ECG & - Elétrocardiograma \\
\hline ECM & - do inglês, Extracelular Matrix \\
\hline ECMTR & - Ecocardiografia com Perfusão Miocárdica em Tempo Real \\
\hline EDTA & - Ácido Etilenodiamino Tetra-Acético \\
\hline EPM & - Erro Padrão da Média \\
\hline ESC & - do inglês, Embryonic Stem Cell \\
\hline FEnVE & - Fração de Encurtamento do VE \\
\hline FEVE & - Fração de Ejeção do VE \\
\hline FGF-2 & - do inglês, Basic Fibroblast Growth Factor Type 2 \\
\hline FMUSP & - Faculdade de Medicina da Universidade de São Paulo \\
\hline FSM & - Fluxo Sanguíneo Miocárdico \\
\hline FV & - Fibrilação Ventricular \\
\hline FVI & - Fibrilação Ventricular Irreversível \\
\hline GAPDH & - Gliceraldeído 3 Desidrogenase \\
\hline $\mathrm{H} \& \mathrm{E}$ & - Hemotoxilina e Eosina \\
\hline $\mathrm{H} 2 \mathrm{O} 2$ & - Peróxido de Hidrogênio \\
\hline hASC & - do inglês, Human ASC \\
\hline HIF & - do inglês, Hypoxia-Inducible Factor \\
\hline hiPSC & - do inglês, Human Induced Pluripotent Stem Cell \\
\hline iECA & - Inibidor da Enzima Conversora de Angiotensina \\
\hline IGF-1 & - do inglês, Insulin Like Growth Factor Type 1 \\
\hline IM & - Infarto do Miodárdio \\
\hline
\end{tabular}




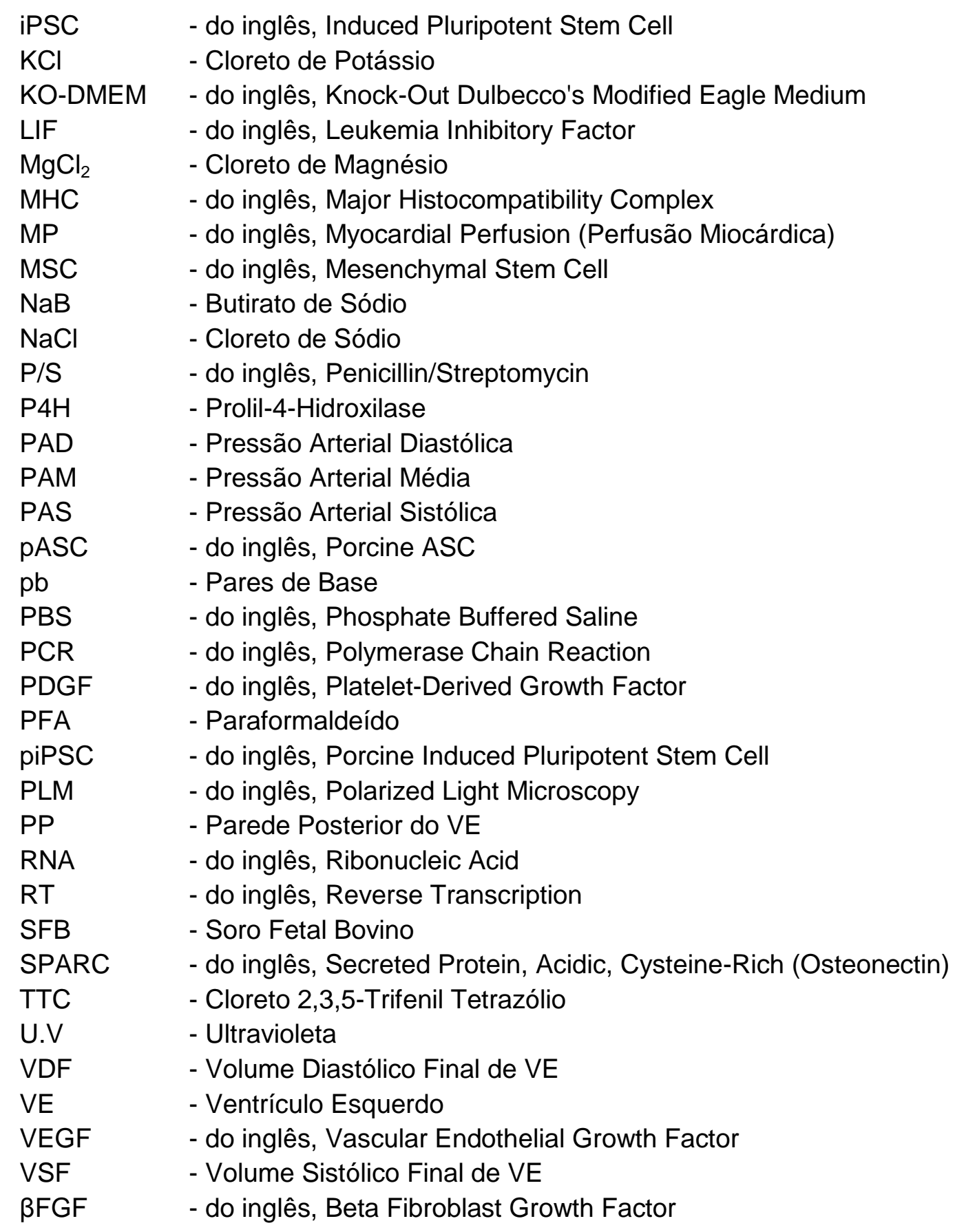




\section{Lista de Símbolos}

\begin{tabular}{|c|c|}
\hline$\%$ & - porcentagem \\
\hline${ }^{\circ} \mathrm{C}$ & - Graus Celsius \\
\hline$\mu g$ & - Micrograma \\
\hline$\mu \mathrm{L}$ & - Microlitro \\
\hline$\mu \mathrm{M}$ & - Micromolar \\
\hline $\mathrm{cm}$ & - Centímetros \\
\hline $\mathrm{cm}^{2}$ & - Centímetros Quadrados \\
\hline $\mathrm{cm}^{3}$ & - Centímetros Cúbicos \\
\hline $\mathrm{G}$ & - do inglês, Gauge (bitola) \\
\hline g & - Gramas \\
\hline $\mathrm{Hz}$ & - Hertz \\
\hline J & - Joules \\
\hline $\mathrm{kDa}$ & - Kilo daltons \\
\hline $\mathrm{Kg}$ & - Quilogramas \\
\hline M & - Molar \\
\hline $\mathrm{mg}$ & - Miligrama \\
\hline Min & - Minutos \\
\hline $\mathrm{mL}$ & - Mililitro \\
\hline $\mathrm{mm}$ & - Milímetro \\
\hline $\mathrm{mM}$ & - Milimolar \\
\hline $\mathrm{mm}^{2}$ & - Milímetro Quadrado \\
\hline $\mathrm{mmHg}$ & - Milímetros de Mercúrio \\
\hline $\mathrm{ng}$ & - Nanograma \\
\hline $\mathrm{nm}$ & - Nanômetro \\
\hline RPM & - Rotações por minuto \\
\hline S & - Segundos \\
\hline$\Delta$ & - Delta \\
\hline
\end{tabular}




\section{Lista de Tabelas}

Tabela 1: Anticorpos utilizados para realização das reações de imunohistoquímica

Tabela 2: Primers para análise do cromossomo $Y$ e para avaliação de expressão de VEGF

Tabela 3: Medidas lineares e derivações para acessar a função cardíaca de porcos via ecocardiografia transtorácica basal.

Tabela 4: Medidas lineares e derivações para acessar a função cardíaca de porcos via ecocardiografia transtorácica sob estresse farmacológico.

Tabela 5: Sistema de classificação para a rejeição das células alogênicas injetadas. 


\section{Lista de Figuras}

Figura 1: Desenho experimental do protocolo pASC/IM.

Figura 2: Regiões de interesse em imagem de Ecocardiografia com contraste.

Figura 3: Identificação do DNA de células de machos no tecido cardíaco de fêmeas

Figura 4: Função cardíaca ventricular esquerda medida através de ecocardiografia transtorácica.

Figura 5: A perfusão miocárdica (MP) foi melhorada no grupo de animais que recebeu 4 milhões de pASC/Kg.

Figura 6: O uso de 4 milhões de pASC alogênicas/Kg implica em um aumento no número de vasos e a expressão genica de VEGF nas bordas e área remota ao infarto do miocárdio.

Figura 7: A dose de 4 milhões de pASC/Kg é capaz de reduzir área lesada de VE 30 dias após tratamento

Figura 8: Parâmetros anatomopatológicos - Controles positivos para a redução da área de infarto e razão de afinamento das paredes de VE dos diferentes grupos tratados com pASC

Figura 9: A maior dose de células alogênicas testada tem influência sobre a maturação do colágeno presente na área de cicatriz

Figura 10: Altas doses de pASC alogênicas não provocam o aumento da infiltração de células inflamatórias no VE

Figura 11: Análise dos tipos de linfócitos presentes no infiltrado inflamatório presente nas diferentes áreas de tecido cardíaco dos porcos tratados com pASC nas diferentes doses testadas. 


\section{Resumo}

Dariolli R. Efeito aditivo do transplante de células-troncos adultas sobre a perfusão cardíaca pós-infarto em porcos tratados com beta-bloqueador e inibidor da enzima conversora de angiotensina [tese]. São Paulo: Faculdade de Medicina, Universidade de São Paulo; 2015.

Os efeitos benéficos associados à injeção intramiocárdica de células-tronco adultas, obtidos em roedores, não tem sido reproduzidos de modo consistente em modelos animais de grande porte e seres humanos. Neste trabalho testamos a hipótese que o transplante de células-tronco mesenquimais derivadas do tecido adiposo de porcos (pASC) aumenta a perfusão tecidual cardíaca em animais infartados e humanizados pelo tratamento com um inibidor da enzima conversora de angiotensina (iECA) e um $\beta$-bloqueador. Os animais foram submetidos a oclusão da artéria coronária circunflexa esquerda (ACX) e 4 semanas após o IM, 4 grupos foram randomizados para receber injeção intramiocárdica de PASC nas doses de 1, 2 ou 4×10^6 pASC/Kg de massa corporal ou placebo. A análise de perfusão miocárdica foi realizada através da ecocardiografia com perfusão miocárdica em tempo real (ECMTR) utilizando contraste de microbolhas comercialmente disponível antes da injeção de pASC e 4 semanas após o tratamento com as células. Avaliações anatomopatológicas foram realizadas para medir a área de IM e o remodelamento de VE. Oito semanas após o IM, os porcos tratados com a maior dose de pASC mostraram um aumento significativo do fluxo sanguíneo do miocárdio, tanto em áreas remotas (3,9 vezes) como na área de borda do infarto (3,7 vezes) vs. os outros grupos estudados. Neste mesmo grupo, um aumento significativo no número de vasos (cerca de 54 e $56 \%$, área remota e de borda respectivamente) foi observado ( $p>0,05$ vs. outros grupos). Curiosamente, a área de tecido não perfundido foi menor (em até $38 \%$ ), enquanto que a razão de afinamento da parede (25\%) e a percentagem de fibras de colágeno imaturas (verde/finas) foram maiores no grupo 4 que recebeu $4 \times 10^{\wedge} 6 \mathrm{pASC} / \mathrm{Kg}$ em comparação com os demais. Além disso, a dose mais elevada de pASCs alogênicas testadas não induziu um aumento da resposta inflamatória celular no VE.

Deste modo, os resultados mostram que a injeção intramiocárdica de pASCs alogênicas pósIM promove aumento da perfusão miocárdica e no número de vaso sanguíneos no VE na 
ausência de resposta inflamatória celular que podem contribuir para atenuar o remodelamento cardíaco adverso de VE 2 meses após o IM na presença de terapêutica farmacológica padrão.

Descritores: Células-tronco; Suínos; Transplante alogênico; Tecido adiposo; Infarto do miocárdio. 


\section{Abstract}

Dariolli R. Additive effect of transplantation of adult stem cells post-infarction on the cardiac perfusion in pigs treated with beta-blocker and angiotensin-converting enzyme inhibitor [thesis]. São Paulo: "Faculdade de Medicina, Universidade de São Paulo"; 2015.

The beneficial effects associated with intramyocardial injection of adult stem cells in rodents have not been consistently reproduced in larger animals and humans. We evaluated the dose of porcine adipose-tissue derived mesenchymal stem cells (pASC) to increase cardiac tissue perfusion in pigs treated with ace-inhibitors and $\beta$-blockers to mimic human management postMI. Animals were subjected to LCx occlusion and 4 weeks after MI blinded randomized in 4 groups to receive intramyocardial injection of pASC $\left(1,2\right.$ and $4 \times 10^{\wedge} 6 \mathrm{pASC} / \mathrm{Kg}$ bw) or placebo. Real time myocardial perfusion echocardiography (RTMPE) was conducted using commercial microbubbles before injection and 4 weeks after treatment with pASC. Anatomopathological assessments were performed to evaluated MI area, LV remodeling. Eight weeks after MI, the pigs treated with the highest dose of PASC showed a significant increase of myocardial blood flow in both remote (3.9 times) and border zone (3.7 times) versus the other groups, which was also in agreement with the increase in vessel numbers (about 54 and $56 \%$, respectively) compared to the other groups ( $p>0.05$ ). Interestingly, the non-perfused area was reduced (up to $38 \%)$ and the thinning ratio was higher $(25 \%)$ in the $4 \times 10^{\wedge} 6 \mathrm{pASC} / \mathrm{Kg}$.bw group compared with placebo or the other cell groups. In addition, the percentage of immature (thin/green) collagen fibers was greater in group 4 than in the placebo animals. The highest dose of allogeneic pASCs did not elicit an increased cellular inflammatory response in LV. Altogether, we provide evidence that intramyocardial injection of allogeneic PASC post-MI did not elicit cellular inflammatory response and also it increased cardiac perfusion and vessel number when in highest dose, which may have contributed to attenuate the LV adverse remodeling 2 months after the MI.

Descriptors: Stem cells; Swine; Allogeneic transplant; Adipose tissue, Myocardial infarction. 
1.INTRODUÇÃO 

Introdução

\subsection{Infarto do Miocárdio: Epidemiologia e Fisiopatologia}

Nas últimas décadas tem se discutido extensivamente sobre 0 desenvolvimento de terapias alternativas para $\circ$ tratamento de pacientes acometidos por doenças isquêmicas do coração como o infarto do miocárdio. As doenças cardiovasculares são as principais causas de morte em todo 0 mundo $(1,2)$. Estudos epidemiológicos recentes indicam que as mortes atribuídas às doenças cardiovasculares continuam a atingir percentuais de até $30 \%$ da população mundial, sendo cerca de 7 milhões destas mortes ocasionadas por infartos do coração (1-3). No Brasil, no ano de 2007 as doenças do aparelho circulatório somavam aproximadamente $32 \%$ das doenças causadoras de morte. Destas, cerca de 50\% referiam-se às doenças isquêmicas do coração (4).

O infarto do miocárdio é uma patologia isquêmica causada pela interrupção do fluxo sanguíneo coronariano. O tempo de isquemia bem como sua extensão, o estado do músculo cardíaco e a viabilidade da circulação colateral, irão definir se o dano causado pela falta de perfusão ao músculo implicará em prejuízo na função cardíaca $(5,6)$. Nesse cenário inicia-se uma resposta inflamatória para eliminação de células mortas residentes e preparação do microambiente para a recomposição tecidual. Em meio a uma resposta inflamatória importante, fibroblastos multiplicam-se na região atingida pela isquemia e lá sofrem alterações nos padrões fenotípicos e de expressão gênica e proteica diferenciando-se em miofibroblastos. Dá-se nesta fase o início da formação de um tecido fibroso rico em colágeno e com baixa capacidade contrátil o qual contribui de maneira negativa para a manutenção 
Introdução

da função cardíaca. A disfunção ventricular resulta em insuficiência cardíaca que irá acarretar no comprometimento funcional de outros sistemas orgânicos, como os rins, pulmões entre outros sistemas (7).

Avanços significativos têm sido obtidos nas últimas décadas no desenvolvimento de tratamentos para doenças cardíacas oclusivas. Novas terapias medicamentosas cada vez mais eficientes e técnicas de revascularização cirúrgica ou por angioplastia despontam como as estratégias mais utilizadas. Contudo, como evitar a perda de tecido contrátil, que acarreta no remodelamento ventricular e na falência cardíaca, ainda continua a ser o grande desafio.

\subsection{Células-tronco adultas - renovação e manutenção dos tecidos}

Tendo em vista a baixa capacidade regenerativa do coração adulto e as importantes alterações sofridas por este órgão pós-infarto, muito tem sido investido na busca de novas fontes terapêuticas capazes de auxiliar na regeneração do tecido cardíaco perdido. Neste cenário, nos últimos 20 anos, as células-tronco têm sido apresentadas como uma infindável fonte de material biológico com potencial para utilização terapêutica.

Células-tronco embrionárias (do inglês, ESCs) são células pluripotentes classicamente conhecidas por sua plasticidade (8,9). Estas células são apontadas como uma solução terapêutica para uma série de doenças onde a regeneração tecidual é essencial. Todavia, questões éticas, políticas e mesmo comerciais, tem retardado a utilização destas células em terapia. Além disso, questões técnicas de isolamento destas células, bem como a potencialidade de formação de teratomas e teratocarcinomas $(10,11)$, justificam a atenção e 
Introdução

cuidado excessivos no desenvolvimento de estudos de caracterização destas antes de seu uso como ferramenta terapêutica.

Por outro lado, o conceito consolidado de que em praticamente todos os tecidos de um organismo há constante renovação e assim substituição celular, sobretudo pela diferenciação de células-tronco residentes no tecido adulto (7), tem suportado uma série de extrapolações usando estes tecidos como fonte para extração de células-tronco denominadas de adultas. Neste contexto, os empecilhos éticos e políticos são minimizados e questões metodológicas como definir a melhor, mais fácil e mais abundante fonte de tecido adulto a ser explorado passam a ser as questões principais. Deste modo, as células-tronco adultas têm sido bastante exploradas para fins terapêuticos.

Diferentemente das ESCs, as células-tronco adultas apresentam um grau inferior de plasticidade quando comparadas as primeiras. Apesar disso, estas células ainda são capazes de gerar células maduras de órgãos distintos (12). Devido a plasticidade reduzida, não estão relacionadas com a formação de tumores quando injetadas em diferentes tecidos (13-15). Além disso, em determinados casos estas células são capazes de promover a manutenção da viabilidade celular ou ainda, em casos ainda mais restritos, regenerar alguns tipos de tecidos lesados $(16,17)$.

Dentre as células-tronco adultas mais exploradas no contexto da reparação de tecidos estão as de origem mesenquimal (do inglês, MSC) $(18,19)$. Estas apresentam marcadores de superfície como o CD29 (integrina beta-1) e o CD90 (Thy-1), que proteínas fundamentalmente relacionadas à adesão celular (20-23), e que quando em conjunto na membrana plasmática são utilizadas para caracterizar este tipo celular. Além disso, estas células têm 
Introdução

como principal apelo para aplicações clínicas sua facilidade de isolamento e a alta viabilidade em cultivos in vitro $(24,25)$.

\subsection{O tecido adiposo - uma fonte rica de células-tronco mesenquimais}

Devido à oportunidade ética proporcionada pelos transplantes de medula óssea em pacientes com leucemia, estudos terapêuticos pioneiros com célulastronco se utilizaram desta como a principal fonte para aquisição de células mesenquimais (26-28). A medula óssea é uma fonte de células-tronco heterogênea composta principalmente por células-tronco hematopoiéticas, células progenitoras sanguíneas, além de células-tronco mesenquimais não hematopoiéticas $(26,27,29,30)$.

O procedimento de obtenção das células da medula óssea causa dor e desconforto ao paciente, além de render baixa quantidade de células-tronco mesenquimais da medula (do inglês, BM-MSC). Além disso, tem como resultado uma população heterogênea e de difícil manutenção em cultura (31). Por isso, ao longo dos anos o foco sobre as células-tronco de medula tem sido dividido com outros tecidos que também fonte deste tipo celular.

Dentre as fontes mais exploradas está o tecido adiposo. Neste tecido é possível isolar uma população homogênea e abundante de células-tronco mesenquimais facilmente cultiváveis (31). As células-tronco mesenquimais derivadas do tecido adiposo (do inglês, ASC) foram isoladas pela primeira vez em tecido adiposo humano (hASC) através de lipoaspirado obtido de cirurgia plástica estética (32), um procedimento muito menos desconfortável e menos doloroso para o paciente, além de seu apelo estético. As ASC são facilmente mantidas por longos períodos em cultivo sem perda de estabilidade do 
Introdução

dobramento populacional e mantendo determinado potencial de diferenciação em linhagens celulares distintas $(12,33,34)$.

Estudos comparativos entre ASCs e MSCs demonstram que o padrão fenotípico dessas células é similar (23). Análises de expressão gênica demonstraram que menos do $1 \%$ dos genes destas células são expressos diferencialmente (35). Desta forma, estes dois tipos celulares são semelhantes no que diz respeito às características biológicas e de manutenção in vitro, justificando-se os vários estudos e possíveis aplicações terapêuticas.

\subsection{Influência da idade e comorbidades: perfil imunológico de ASCs}

Dados recentemente publicados demonstraram que existe uma relação negativa entre os índices de massa corporal elevado e a capacidade proliferativa e de diferenciação de ASCs humanas (36). Ademais, os efeitos negativos da idade do doador de hASC (37) e de células-tronco mesenquimais derivadas de líquido e membrana sinoviais (38) também já foram evidenciados.

Diversos estudos recentes têm demonstrado que as células-tronco mesenquimais, tanto de medula óssea (39-41), como de tecido adiposo (4244) apresentam baixa imunogenicidade, além de propriedades imunomodulatórias. Estas características estão possivelmente ligadas à ausência de expressão de moléculas de MHC de classe II na membrana estas células bem como sua capacidade de inibir a proliferação de células $\mathrm{T}$ $(29,39,45,46)$. Além disso, evidências sugerem que as células-tronco mesenquimais podem manter suas características fenotípicas, proliferativas e de plasticidade mesmo após serem submetidas a longos períodos de congelamento $(34,47-50)$. 
Introdução

As propriedades imunológicas somadas à manutenção de suas características após longo período de congelamento permitem extrapolações para o uso de células de fontes alogênicas (51), as quais podem ser mantidas criopreservadas. Esta é uma abordagem clinicamente custo efetiva, pois, torna possível a construção de bancos de células-tronco, garantindo tempo hábil para aplicação terapêutica e o controle de qualidade destas células. Para comprovar a eficácia destas práticas, bancos de células animais como o porco, têm sido utilizados para fins terapêuticos e de padronização das rotinas laboratoriais (34).

\subsection{A terapia celular e o porco como um modelo pré-clínico relevante em cardiologia}

Estudos pré-clínicos em modelos animais como os ratos, têm apresentado dados positivos para o uso de células-tronco adultas no tratamento de doenças isquêmicas como o infarto do miocárdio (13-15). Embora estes estudos mostrem resultados animadores, questões seminais como a dose de células necessária, e mesmo se o uso de células-tronco pode gerar efeitos aditivos a tratamentos bem estabelecidos, como por exemplo, os medicamentosos, ainda permanecem obscuros.

Dados prévios publicados por este grupo demonstram que a despeito da realização de injeções intramiocárdicas, apenas pequenas quantidades de BMMSC $(13,15)$ ou ASC (14) permanecem aderidas ao coração de ratos infartados após seu transplante. No entanto, os percentuais de retenção celular no miocárdio destes animais podem ser aumentados em 3 a 5 vezes quando as células são injetadas em associadas com biopolímeros $(13,14)$. Os animais tratados com essas células associadas à biopolimeros apresentaram melhora 
Introdução

da função cardíaca global, perfusão cardíaca, redução da área cicatricial, alteração da composição de colágeno na cicatriz, redução dos níveis de células apoptóticas, todos estes, eventos relacionados secundariamente a atividade parácrina destas células (13-15).

A despeito dos resultados obtidos até o momento em modelos animais de pequeno porte, onde uma série quase infinita de possibilidades pode ser testada; para a segura aplicação destes conhecimentos em seres humanos, o último teste de eficácia terapêutica pré-clínica deve ser realizado em modelos animais de grande porte em que a anatomia, fisiologia, habilidades técnicas de manipulação e cirurgia e, principalmente, a fisiopatologia do infarto do miocárdio sejam mais próximas às encontradas em pacientes (52).

Maxwell e colaboradores em 1987 (53) demonstraram o grande espectro de "fluxo colateral" existente entre diferentes espécies no coração de mamíferos. Este estudo demonstrou que o cão, um modelo muito utilizado em estudos de isquemia miocárdica, não foi o modelo de estudo mais adequado para esse fim, visto que este apresentava uma circulação colateral robusta e pré-existente à isquemia. Estes pré-colaterais são capazes de fornecer até $40 \%$ do fluxo normal de perfusão para uma artéria coronária agudamente ocluída (54), ou seja, dados experimentais destes animais não refletiram possíveis dados obtidos em humanos. Estudos como este impulsionaram, ao longo das últimas décadas, a utilização do porco como modelo de estudo de isquemia, especialmente devido às semelhanças anatômicas (53-55) e fisiológicas (56) com seres humanos.

Um ponto comum entre porcos e humanos é o fato de os pacientes elegíveis a terapias pró-angiogênicas serem aqueles, onde há áreas de 
Introdução

miocárdio hibernante (57). O miocárdio hibernante representa uma condição de disfunção ventricular reversível. Ou seja, em dada região afetada pela isquemia e composta por células hibernantes, se revascularizada, algumas células podem progressivamente reverter um estado de latência funcional tornando novamente esta área afetada um miocárdio viável e funcional (58). Em 2001 foi demonstrado que em porcos com alto grau de estenoses coronarianas e disfunção ventricular, áreas de musculatura hibernante podem ser encontradas (59).

Além disso, a razão entre tamanho do coração e peso corpóreo de um suíno de $30 \mathrm{~kg}$ é de 0,005 , exatamente igual à encontrada em seres humanos (60). Ademais, o coração de porcos é metabolicamente semelhante ao humano, tendo como principal substrato energético os ácidos graxos não esterificados, com os quais é gerada cerca de $80 \%$ da energia utilizada pelo miocárdio (61). Dadas as similaridades com humanos aqui apresentadas, o modelo de porcos é muito perspicaz para uso em estudos pré-clínicos em cardiologia. 
2.OBJETIVOS 

Objetivos

\subsection{Objetivo geral}

Testar a hipótese de que o transplante de células-tronco do tecido adiposo de porcos (pASCs) minimiza os efeitos deletérios pós-infarto sobre a perfusão e morfologia cardíacas em modelo de porcos infartados e humanizados por tratamento com maleato de enalapril e succinato de metoprolol.

\subsection{Objetivos específicos}

a) Avaliar se as pASCs se encontram no tecido cardíaco 30 dias após a injeção;

b) Avaliar a perfusão cardíaca nos diferentes grupos de porcos 30 dias após o tratamento com pASCs;

c) Avaliar o tamanho e composição do tecido cicatricial de VE nos diferentes grupos de porcos 30 dias após o tratamento com pASCs;

d) Avaliar a resposta imunológica contra o transplante de pASCs alogênicas nos diferentes grupos de porcos 30 dias após o tratamento. 

3.MATERIAIS E MÉTODOS 

Materiais e Métodos

Diferentes doses de pASC de um porco doador macho (portanto, células alogênicas), foram injetadas nas bordas da área de infarto do ventrículo esquerdo de porcos submetidos à indução de lesão pelo método endovascular, descrito em detalhes no apêndice A desta tese. Todos os animais dos grupos experimentais foram tratados durante o período de experimento com doses diárias de maleato de enalapril e succinato de metoprolol além das diferentes doses de pASCs. O tratamento teve como objetivo primário minimizar os efeitos deletérios causados pelo IM sob a condição mais próxima de um paciente candidato a receber esse tipo de tratamento. Para tanto o end-point primário deste estudo foi avaliar funcionalmente a perfusão miocárdica dos animais pós-tratamentos. Além disso, investigar a formação de novos vasos sanguíneos seguida da redução da área de infarto e a resposta inflamatória/imunológica contra as células-tronco alogênicas.

Todos os experimentos foram conduzidos de acordo com protocolo aprovado pela Comissão de Ética em pesquisa - CAPPesq (\#022/09). O cuidado animal foi cumprido com base na diretriz ARRIVAL (do inglês: Animals in Research: Reporting In Vivo Experiments) (62). Trinta e oito porcos fêmea (Sus scrofa domestica, linhagem MS60 EMBRAPA - peso, 15 a $20 \mathrm{~kg}$ ) foram mantidas em uma granja comercial para suínos (Granja RG, Suzano-SP, Brazil) com acesso livre à água e comida durante o período de protocolo. Para aclimatização os animais foram trazidos para a Divisão de Experimentação do Instituto do Coração - InCor, pelo menos 24 horas antes do início dos procedimentos. 
Os animais foram submetidos a jejum de água e comida por um período de 12-16 horas antes do início dos procedimentos. Estes animais foram então sedados com uma combinação de ketamina ( $8 \mathrm{mg} / \mathrm{kg}$, Vetbrands) e cloridrato de midazolam $(0,5 \mathrm{mg} / \mathrm{kg}$, Roche) por via intramuscular. Após 10 a 20 minutos, uma cânula foi introduzida em uma das veias superficiais da orelha pela qual a anestesia foi induzida com tiopental de sódio (12,5 mg / kg; Cristália). Em seguida, os animais foram submetidos à intubação orotraqueal (cânulas de 7$7,5 \mathrm{~mm}$ - Chilecom). A anestesia foi mantida com isoflurano $(1,5 \%-2,5 \%$, Baxter - em 100\% de ventilação de oxigênio) em equipamento ventilador compatível com uso deste tipo de anestésico (Origami Ergo System - Takaoka). Antes do procedimento, os porcos receberam uma injeção intramuscular profilática de 1,2 milhões de unidades de penicilina (Eurofarma). Após o procedimento, os animais foram tratados com dipirona sódica por via intramuscular (1000mg, 4 vezes, 2 doses diárias - Sanofi Aventis) para minimizar a dor.

Os animais que sobreviveram ao período completo do estudo (60 dias) foram submetidos à angioplastia coronária diagnóstica e ecocardiografia transtorácica, e, em seguida, foram sacrificados com uma overdose de cloreto de potássio (30-40 $\mathrm{mL}$ de solução de 19,1\%, Isofarma) administrada por via intravenosa e sob anestesia profunda de tiopental sódico.

\subsection{Desenho experimental}

Este estudo foi divido em três fases (Figura 1). Na fase I, 38 animais foram submetidos à angiografia basal seguida da indução do IM. A indução do infarto do miocárdio pode causar fibrilações ventriculares (FV) graves, 
Materiais e Métodos

principalmente no período de 30-45 minutos após a oclusão da artéria coronária. Somente os animais que não desenvolveram FV ou que tiveram o episódio revertido em menos de 30 minutos foram incluídos no protocolo. Vinte e quarto horas após a indução do IM todos os animais foram submetidos a tratamento contínuo com $10 \mathrm{mg}$ de maleto de enalapril e $25 \mathrm{mg}$ de succinato de metoprolol em dose diária e única. Cinco animais morreram durante a fase I devido a complicações pós-IM.

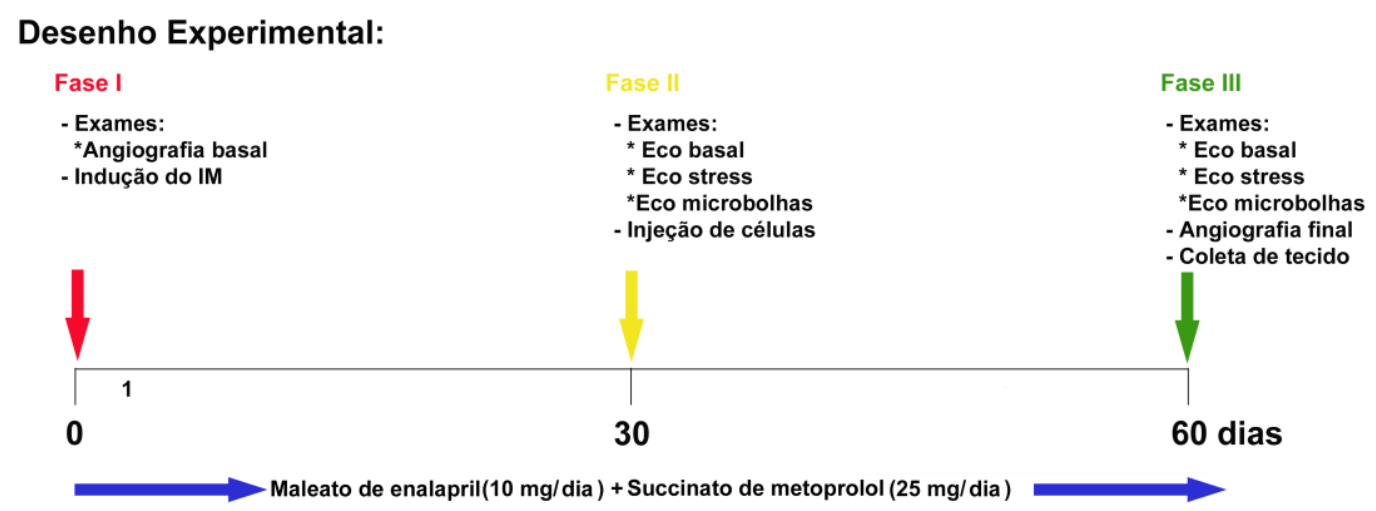

Figura 1: Desenho experimental do protocolo pASC/IM. IM: infarto do miocárdio; ECO: ecocardiografia transtorácica sob estresse farmacológico e análise de perfusão por contraste de microbolhas.

Na fase II, 30 dias após a indução de IM, um ecocardiograma basal, para avaliação morfológica e funcional, foi realizado em todos os animais para caracterizar o tipo de lesão obtida. Um exame mais complexo utilizando estresse farmacológico e contraste com microbolhas também foi realizado para obtenção da perfusão cardíaca dos animais antes dos tratamentos com células-tronco. Somente animais com lesão semelhante foram adicionados ao protocolo. Três animais morreram durante a realização do ecocardiograma devido a complicações do IM. Após este exame, os animais que passaram nos critérios de inclusão/exclusão (neste caso todos os que não morreram), foram 
Materiais e Método

randomizados nos 4 grupos experimentais a receber diferentes doses de pASC (sendo os grupos: PBS controle, 1, 2 ou 4 milhões de pASCs por quilograma de massa corpórea). Todos os 4 receberam também tratamento medicamentoso durante todo o protocolo conforme anteriormente explicado.

Um grupo extra de animais, não randomizado, foi incluído para o controle de viabilidade/mortalidade associada ao uso dos medicamentos. Neste grupo, os animais foram infartados e não receberam nenhum tipo de tratamento medicamentoso ou com células-tronco (6 animais). Destes $66 \%$ dos animais morrem no máximo 15 dias após indução do IM mostrando a fragilidade do modelo sem tratamento medicamentoso.

Já na fase III do estudo, 30 dias após a injeção de células, os animais sobreviventes foram submetidos novamente aos exames ecocardiográficos e também a uma angiografia final antes de serem mortos. Durante a fase III apenas um animal morreu devido a complicações do IM. Mais tarde, ao final da fase randomizada do estudo viu-se que este animal fazia parte do grupo de animais que receberam 1 milhão de $\mathrm{pASC} / \mathrm{Kg}$. Teratomas e teratocarcinomas não foram observados no coração dos porcos submetidos ao protocolo de injeção de células-tronco alogênicas. Todos os dados que serão apresentados a seguir foram obtidos dos animais que completaram o protocolo experimental

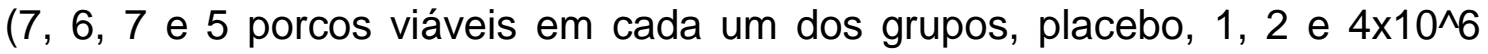
$\mathrm{pASC} / \mathrm{Kg}$ respectivamente). Todos os experimentos realizados foram analisados por pelo menos dois observadores "cegos" para os grupos experimentais em questão. 
Materiais e Métodos

\subsection{Extração, caracterização e geração do banco de pASCs}

Após anestesia e procedimentos de assepsia, o tecido adiposo subcutâneo abdominal de um porco macho adulto foi extraído. Deste, pASCs foram isoladas e caracterizadas e um banco de células foi gerado conforme previamente descrito por Dariolli e colaboradores (34). Em resumo, as pASCs foram isoladas a partir de 300 gramas de tecido adiposo através de digestão mecânica (tesoura e pinça) seguida de digestão enzimática (solução de $0,075 \%$ colagenase 1a). As pASCs foram cultivadas em DMEM-Low suplementado com 10\% SFB até passagem 4 quando foram congeladas em criotubos contendo 3.3 milhões de células em solução de SFB + 10\% DMSO. O número de células para cada injeção foi obtido a partir de descongelamento do número exato de criotubos necessário para cada animal dependendo de seu peso no dia da cirurgia para transplante das células. As células foram descongeladas e colocadas em seringas de insulina não mais que 30 minutos antes da injeção.

\subsection{Modelo de infarto do miocárdio de artéria fechada em porcos}

O modelo de indução de infarto baseado no uso de técnicas hemodinâmicas endovasculares para oclusão da ACX foi realizado como previamente descrito por Dariolli e colaboradores (63) e detalhado no Apêndice A desta tese. Resumidamente, depois de anestesiados os porcos foram submetidos a procedimentos de assepsia/antissepsia e então foi introduzida, através de um cateter, uma guia 0,014 até a porção distal de ACX. Pequenos pedaços de esponja de limpeza (próteses de poliuretano) foram levados até a porção proximal de ACX através da guia, com auxilio de um cateter balão. 
Materiais e Método

Estas próteses foram deixadas para ocluir a luz da coronária causando um trombo. Uma angiografia foi realizada 5 a 10 minutos após o posicionamento da última prótese implantada para confirmar o sucesso da oclusão.

\subsection{Procedimentos de injeção intramiocárdica de pASC}

Trinta dias após a indução do infarto, os animais foram submetidos a uma toracotomia lateral esquerda com abertura da cavidade torácica no quinto espaço intercostal. O pericárdio foi visualizado e excisado. Foi possível então observar as paredes posterior e lateral do VE e a partir desta visualização, um mapeamento elétrico da lesão foi realizado. Os resultados da visualização direta do VE, somados ao mapeamento elétrico da lesão e a uma ecocardiografia transtorácica básica, permitiram uma melhor definição da borda da lesão tanto na parede lateral como na parede posterior.

Tendo sido definidas as áreas para a injeção, 20 alíquotas $(0,2 \mathrm{~mL}$ de PBS com ou sem células) foram injetadas ao redor de toda a borda do infarto com o auxílio de seringas de insulina $\left(0.5 \mathrm{~mL}, 29 \mathrm{G}-\mathrm{BD}\right.$ Ultra-Fine $\left.{ }^{\mathrm{TM}}\right)$. As injeções foram realizadas por cirurgiões treinados e "cegos" para os grupos experimentais previamente randomizados. Após a injeção, as incisões foram suturadas e o ar da cavidade pleural foi removido. Informações adicionais sobre os procedimentos de injeção de células e mapeamento elétrico do VE estão descritas detalhadamente no Apêndice A desta tese.

\subsection{Ecocardiografia transtorácica}

\subsubsection{Ecocardiografia com perfusão miocárdica em tempo real}

A avaliação ecocardiográfica foi realizada com o ecocardiógrafo SONOS 5500 (Philips Medical Systems, Andover, MA), equipado com transdutor de 
Materiais e Métodos

banda larga de 4-2 MHz e com capacidade para a realização de imagens por meio de tecnologia denominada Energia Modulada (Power Modulation) para o estudo da perfusão miocárdica. Os animais foram submetidos, inicialmente, a um estudo ecocardiográfico basal, com medidas lineares das estruturas cardíacas e dos fluxos valvares obtidas de acordo com as recomendações da Sociedade Americana de Ecocardiografia (64). Para o estudo da perfusão miocárdica, o agente de contraste utilizado foi o DEFINITY® (Lantheus Medical Imaging, Inc. North Billerica, MA). Este foi administrado após diluição de 1,5mL de Definity ${ }^{\circledR}$ em $58,5 \mathrm{~mL}$ de soro fisiológico $0,9 \%$. A solução então foi administrada constantemente por via endovenosa periférica. A dose ideal de infusão do contraste foi ajustada de acordo com a obtenção visual de saturação adequada do contraste no miocárdio, caracterizada pela presença de sombra acústica ao nível da porção média do átrio esquerdo no plano apical de quatro câmaras.

Ajustes específicos do aparelho foram então realizados e incluíram índice mecânico baixo $(0,2)$ e frequência de repetição de pulsos de $25 \mathrm{~Hz}$. Todos os ajustes e a velocidade de infusão de contraste foram otimizados no estado basal e mantidos constantes para permitir comparação válida entre as imagens obtidas em repouso e sob estresse farmacológico. Um rápido pulso ultrassônico com utilização de índice mecânico elevado $(1,5)$, de quatro a cinco quadros (flash), foi manualmente disparado no pico de intensidade do contraste para destruir microbolhas dentro do miocárdio. Na sequência, foram analisadas as imagens com baixo índice mecânico $(0,2)$ por pelo menos 15 ciclos cardíacos consecutivos para permitir o repreenchimento miocárdico e, 
Materiais e Método

consequentemente, possibilitar os cálculos de velocidade das microbolhas na microcirculação e sua concentração máxima. O protocolo de estresse utilizado foi um protocolo bem estabelecido na prática clínica, sem associação de atropina, com administração endovenosa de dipiridamol de $0,56 \mathrm{mg} / \mathrm{kg}$ em quatro minutos. As imagens ecocardiográficas foram adquiridas em repouso e após injeção endovenosa do vasodilatador.

\subsubsection{Determinação quantitativa da perfusão miocárdica}

A determinação quantitativa da perfusão miocárdica foi realizada utilizando um software específico (Q-Lab 3.0 ou Q-Lab 6.0, Philips Medical Systems, Bothell, WA, USA). A intensidade acústica de sinal e a velocidade de repreenchimento da microcirculação pelas microbolhas foram quantificadas nos planos apicais de quatro, duas e três câmaras, tanto em repouso como durante o estresse pelo dipiridamol no final da sístole. Foram analisadas sequências de imagens digitais contendo um mínimo de 15 ciclos cardíacos, desde o flash ecocardiográfico até $015^{\circ}$ batimento. Inicialmente, era feito um alinhamento das imagens ao final da sístole, e, então, foram colocadas regiões de interesse transmurais nos diferentes territórios arteriais, com o cuidado de evitar as bordas endocárdicas e epicárdicas para que a intensidade do sinal fosse analisada de forma correta, não refletindo a intensidade acústica de regiões não pertencentes ao miocárdio, como exemplificado na Figura 2. 


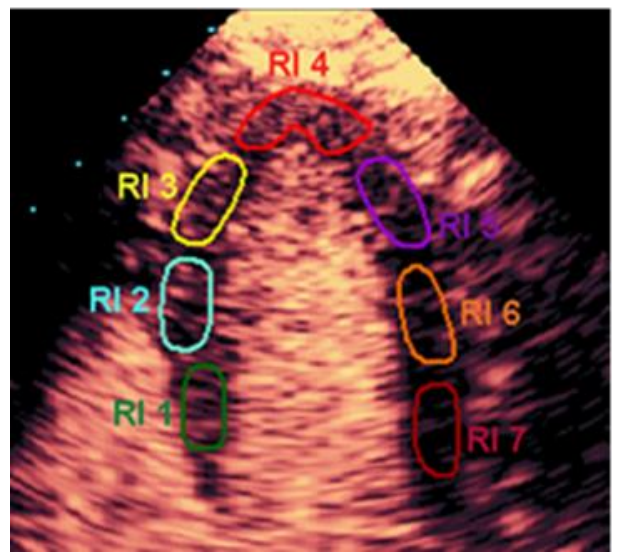

Figura 2: Regiões de interesse em imagem de Ecocardiografia com contraste. Imagem do plano apical de quatro câmaras, obtida pela ecocardiografia com perfusão miocárdica em tempo real, mostrando a colocação de regiões de interesse (RI) nos diferentes segmentos miocárdicos.

A intensidade de sinal a cada quadro após o flash era colocada em uma função exponencial descrita como: $y=A(1-e-\beta t)$, em que y é a intensidade acústica no tempo t, A é a intensidade acústica no platô e representa o volume sanguíneo miocárdico, e ß reflete a taxa de aumento da intensidade acústica e representa a velocidade de repreenchimento do miocárdio pelas microbolhas. Enquanto as variações no parâmetro B não são significativas, o parâmetro A sofre forte influência da concentração dos agentes de contraste, configurações do equipamento e propriedades acústicas dos tecidos (65).

Para compensar a heterogeneidade do feixe de ultrassom, assim como sombras acústicas do contraste, a intensidade acústica máxima corrigida do miocárdio $(A n)$ foi calculada pela divisão do platô de intensidade $(A)$ pela intensidade acústica máxima da cavidade ventricular esquerda adjacente (Ac cavidade), obtida no terceiro batimento pós flash. O fluxo sanguíneo miocárdico, então, foi obtido pelo produto Anxß. A razão entre o fluxo sanguíneo miocárdico durante a infusão de dipiridamol e o fluxo sanguíneo 
Materiais e Método

miocárdico no estado basal reflete a RFM (reserva Anxß). Além da RFM, foi determinada a reserva de velocidade de fluxo miocárdico (reserva ß), calculada como a razão entre o valor de $\beta$ durante a infusão de dipiridamol e o valor de $\beta$ no estado basal. Os valores médios dos índices de reserva para cada variável analisada ( $B$ e $A n x ß)$ foram obtidos por território arterial, a partir da soma do valor de cada segmento pertencente àquele determinado território dividido pelo número de segmentos analisados.

\subsection{Análises anatomopatológicas}

Após avaliação funcional terminal, os animais ainda sob anestesia foram mortos com overdose de cloreto de potássio $(\mathrm{KCl})$. Após a constatação da parada cardíaca, o coração foi retirado e então dissecado, para obtenção apenas do VE. Os VEs foram seccionados transversalmente, da base ao ápice, em secções de 5 mm (em média 8 secções - detalhes na Figura 5 do Apêndice A) e as secções foram submetidas a diferentes métodos de coloração e processamentos para análises.

\subsubsection{Avaliações Macroscópicas}

As secções 1 e 4-7 foram coradas em uma solução de 1\% cloreto 2,3,5trifenil tetrazólio (TTC) em solução tampão de fosfato de $\mathrm{pH} 7,4$. O procedimento foi realizado imediatamente após a retirada do coração. As secções transversais foram incubadas em $200 \mathrm{~mL}$ da solução de TTC, sob agitação e a $37^{\circ} \mathrm{C}$ por vinte minutos. Após a coloração os cortes foram incubados em solução tamponada de formaldeído $10 \%$, a temperatura ambiente por dez minutos. Os cortes foram lavados em água corrente e então fixados em solução tamponada de formaldeído 10\%. A área de infarto foi então 
Materiais e Métodos

quantificada conforme detalhado no artigo publicado por Dariolli $e$ colaboradores (63) e no Apêndice A. Com o objetivo de obter o índice de hipertrofia da parede de VE, a espessura da parede na lesão e na área remota foram medidas na secção média de VE (secção 4) em triplicatas. O índice de hipertrofia foi calculado por meio da razão entre a espessura da parede lesada e da parede remota. Todas as medidas macroscópicas foram obtidas a partir do software Image $J \Theta(66)$.

\subsubsection{Avaliações Microscópicas}

A secção 2 foi dividida em regiões: sadias, borda de infarto e infarto propriamente dito. Cada região foi congelada imediatamente em duplicatas, diretamente em nitrogênio liquido. A secção 3 foi dividida igualmente a secção 2 e as porções fixadas em paraformaldeído 4\%. Após 48 horas da fixação, os tecidos foram dispostos em cassetes plásticos do tipo processador/inclusor. Os cassetes foram processados em aparelho autotécnico com ciclo total de 12 horas para a desidratação, diafanização e parafinização do material. Os tecidos incluídos em parafina foram cortados em micrótomo ( $4 \mu \mathrm{m}$ de espessura) e dispostos em lâminas.

A coloração de Picrossirius Red foi utilizada para medir colágeno intersticial bem como para a análise de microscopia de luz polarizada utilizadas para estimar a maturação do colágeno do tecido cicatricial. Para a avaliação de colágeno intersticial as lâminas, depois de coradas, foram digitalizadas e analisadas por meio de um software específico (Leica Imaging Systems). Este software identifica e quantifica diferenças de tons previamente determinadas e fornecer um dado percentual da quantidade da cor selecionada. Vinte 
Materiais e Método

fotografias digitais no aumento de 20X do microscópio óptico foram tiradas de cada corte, estas foram escolhidas aleatoriamente sendo representante de todo o tecido cardíaco disposto na lâmina fotografada. Para correção dos erros de área em branco ou por erros de processamento, foram feitas medidas da área total de tecido em cada fotografia e estes valores foram utilizados para 0 cálculo final da diferença da área de colágeno encontrada em cada fotografia.

Por sua vez, a avaliação de maturação de colágeno por meio de imagens de luz polarizada foi realizada com auxilio de polarizador acoplado ao microscópio ligado a sistema de digitalização de imagem (Leica Imaging Systems). Quinze fotos randômicas da lesão foram registradas e analisadas no software ImageQuant - Leica, para medir a porcentagem de fibras vermelhas, amarelas e verdes que representam relativamente a porcentagem de fibras maduras (pouco flexíveis), intermediárias e imaturas (mais flexíveis), respectivamente. Para a análise das imagens o software foi ajustado para 0 parâmetro de cores $\mathrm{HSI}$, onde cada uma das cores a serem enxergadas foi estabelecida com base em uma lâmina de um animal controle infartado e não tratado (animal não randomizado). Para as aquisições de vermelho foram usados os seguintes parâmetros: H: 16, 0; S: 255,151 e I: 232, 12. Para as aquisições de amarelo: H: 34, 0; S: 210, 109; I: 253, 55. Para as aquisições de verde: $\mathrm{H}: 126,13 ; \mathrm{S}: 255,109$ e I: 99, 9 . A área total de tecido em cada imagem foi utilizada para normalizar a medida de porcentagem por área afetada.

A coloração usando Ácido Periódico de Schiff foi usada para quantificar o número de vasos nas três áreas de VE anteriormente descritas. Quinze imagens randômicas de 400X de magnificação foram registradas a partir de 
Materiais e Métodos

lâminas da região remota, da borda e IM. O número de vasos foi contado manualmente por dois operadores treinados e "cegos" para os grupos experimentais. $\mathrm{O}$ dado apresentado representa a relação entre o número de vasos por área de tecido avaliado.

As colorações com Hematoxilina e Eosina foram utilizadas para avaliar histologicamente o padrão das lesões e para avaliar se as células-tronco alogênicas injetadas geraram algum tipo de resposta imune celular de rejeição. As análises de rejeição foram feitas com base nas descrições prévias de Malliaras e colaboradores (67). Em resumo, vinte fotos randômicas com 200X de magnificação foram registradas de cada região de VE descritas anteriormente. As avaliações se basearam em observação de número, disposição e tipos celulares presentes em infiltrados inflamatórios encontrados nas fotos das três regiões de VE de cada animal, em cada um dos grupos experimentais. Para obtenção de padrão de análise foi utilizada a técnica de quantificação de rejeição estabelecida no ISHLT consensus (68), uma técnica consolidada para a avaliação de rejeição de órgãos transplantados. Todas as avaliações foram realizadas por dois observadores treinados e "cegos" para os grupos experimentais em questão.

\subsubsection{Imunohistoquímica}

Tanto para a avaliação e quantificação dos tipos de colágeno presentes na escara dos corações dos animais infartados dos diferentes grupos, quanto para a avaliação dos tipos de células inflamatórias observadas no VE, reações de imunohistoquímica foram realizadas conforme o protocolo abaixo. 
Materiais e Método

Após o processamento do tecido, conforme descrito no item anterior, lâminas com os cortes de tecidos foram obtidas. Primeiramente os cortes foram desparafinados. Logo após a desparafinização foi realizada a recuperação antigênica por meio da reação de citrato de sódio em alta temperatura para a exposição dos epítopos. Uma solução de 3\% de peróxido de hidrogênio (H2O2) foi utilizada por 10 minutos, para bloqueio da peroxidase endógena. Os cortes foram então bloqueados com solução $2 \%$ de BSA por uma hora a temperatura ambiente. Após lavagem, os cortes foram deixados incubando por 16 horas a $4^{\circ} \mathrm{C}$ com os anticorpos primários de interesse nas concentrações ideais para cada caso (detalhes na Tabela 1 ). No dia seguinte o material foi lavado e incubado por uma hora a temperatura ambiente com anticorpo secundário antiIgG conjugado com biotina. Após o período de incubação, os cortes foram incubados por 30 minutos com estreptavidina ligada a HRP, seguidos de coloração por cinco minutos com diaminobenzidina (DAB - Zymed). O material foi então contra corado com hematoxilina e montado com lamínula. A análise da porcentagem de área corada foi realizada no software Leica QWin 3 (Leica QWin Plus V 3.5.1 - Leica Microsystems) em 10-15 imagens com 200X de magnificação.

Tabela 1: Anticorpos utilizados para realização das reações de imunohistoquímica:

\begin{tabular}{ccccc}
\hline Anticorpo & Feito em & Concentração uso & marca & código \\
\hline Colágeno I & Rabbit & $5 \mu / \mathrm{mL}$ & Abcam & ab34710 \\
Colágeno III & Rabbit & $40 \mu l / \mathrm{mL}$ & Abcam & ab7778 \\
Anti-CD3 & Mouse & $5 \mu / \mathrm{mL}$ & Nows Biologicals & NBP1-28225 \\
Anti-CD45RA & Mouse & $5 \mu / \mathrm{mL}$ & Nows Biologicals & NB100-64997 \\
Anti-CD68 & Mouse & diferentes conc. & Abcam & ab49777 \\
Anti-CD68 & Mouse & diferentes conc. & Abcam & ab955 \\
Anti-CD68 & Mouse & diferentes conc. & Nowis Biologicals & NBP1-74570 \\
\hline
\end{tabular}


Materiais e Métodos

\subsection{Extração de DNA e PCR}

O DNA genômico foi extraído a partir de tecidos congelados da borda do infarto de todos os animais que terminaram o estudo, utilizando-se o protocolo de precipitação de DNA com isopropanol (69). Resumidamente, 0,5mg de tecido foram incubados no tampão de lise contendo: $100 \mathrm{mM}$ Tris $\mathrm{NaCl}, 5 \mathrm{mM}$ EDTA, $0,2 \%$ SDS, $200 \mathrm{mM} \mathrm{NaCl}$ e $20 \mu \mathrm{g} / \mu \mathrm{L}$ de Proteinase $\mathrm{K}$ a $56^{\circ} \mathrm{C}$ por 60 minutos sob agitação. Depois da lise, o isopropanol foi adicionado à mistura para precipitar o DNA extraído do tecido. Foi possível observar uma massa branca na coluna de solução. Os tubos então foram centrifugados a $14000 \times \mathrm{g}$ por 10 minutos para concentrar o DNA em um pellet. $\mathrm{O}$ isopropanol foi totalmente retirado, com cuidado para não perder o pellet de DNA, e então o pellet foi lavado com $1 \mathrm{~mL}$ e $70 \%$ etanol. O etanol foi retirado e os tubos com DNA mantidos a temperatura ambiente entre 5-10 minutos para total secagem e evaporação do etanol.

Para a realização da reação de PCR, 50ng de DNA extraído foram adicionados a um volume final de $10 \mu \mathrm{l}$ de reação contendo $0,4 \mu \mathrm{M}$ dos primers AMEL-F e AMEL-R (Tabela 2), 0,4mM de cada dNTP, 3mM MgCl2, 1unidade de Taq platinum-DNA-polymerase (Invitrogen) e 1x PCR-buffer. As seguintes condições de reação foram utilizadas: desnaturação por 3 minutos a $95^{\circ} \mathrm{C}$, seguida de 35 ciclos de desnaturação por 30 s a $95^{\circ} \mathrm{C}$, anelamento de primers por $30 \mathrm{~s}$ a $60^{\circ} \mathrm{C}$ e extensão de $45 \mathrm{~s}$ a $72^{\circ} \mathrm{C}$. Um passo final de extensão foi realizado por 5 minutos a $72^{\circ} \mathrm{C}$. O produto do PCR foi aplicado a um gel de $2 \%$ agarose para realização da eletroforese. $\mathrm{O}$ gel foi avaliado em transluminador 
Materiais e Método

ultravioleta (UV) e os produtos amplificados de XY 741pb e 562pb e XX somente uma banda de $741 \mathrm{pb}$ foram analisados.

\subsection{Extração de RNA e RT-PCR}

Para avaliar a expressão gênica do fator de crescimento vascular endotelial (do inglês, VEGF), o RNA total das amostras de tecido da borda e área remota ao infarto de VE foi extraído conforme instruções do protocolo de extração "single-step" baseado no uso do Trizol (Invitrogen, Carlsbad, CA). A transcrição reversa do RNA total obtido do tecido foi realizada utilizando o kit de síntese de cDNA SuperScript III (Invitrogen) segundo manual do fabricante e os PCRs foram realizados utilizando o protocolo descrito pelo fabricante para a Taq-polymerase platinum (Invitrogen). Os primers utilizados foram obtidos comercialmente e desenhados no software Primer3 ou foram usados a partir de publicações. Os dados relativos aos primers encontram-se na tabela 2.

Tabela 2: Primers para análise do cromossomo $\mathrm{Y}$ e para avaliação de expressão de VEGF:

\begin{tabular}{ccccccc} 
Gene & Senso $\mathbf{5}^{\prime}-\mathbf{3}^{\prime}$ & $\mathbf{p b}$ & Anti-senso $^{\prime} \mathbf{5}^{\prime} \mathbf{3}^{\prime}$ & $\mathbf{p b}$ & $\mathbf{T m}^{\circ} \mathbf{C}$ & Amplicon $(\mathbf{p b})$ \\
\hline \multirow{2}{*}{ AMEL } & CTTAATCAGCTCACTGTCTG & 20 & CTCAGTTAATCCTACTCTAG & 20 & 60 & $741 / 562$ \\
VEGF & TTGCTGCTCTACCTCCACC & 19 & CACAGGACGGCTTGAAGAT & 19 & 60 & 190 \\
$28 S$ & CTCAACGACCACTTCGTCAA & 20 & TCTGGGATGGAAACTGGAAG & 20 & 60 & 210 \\
\hline
\end{tabular}


Materiais e Métodos

\subsection{Estatística}

Os resultados foram expressos por média \pm erro padrão da média (EPM). Análises de variância de 1 ou 2 caminhos (ANOVA) seguidas de pós-teste do tipo Bonferroni post-hoc, ou testes $t$ Student não pareados foram utilizados para as comparações entre grupos, quando apropriado. Todas as análises estatísticas foram feitas usando o Software GraphPad Prism 5.0 (GraphPad Softwares Inc., CA, USA). Valores de $p<0.05$ foram considerados significativos. 

4.RESULTADOS 

Resultados

\section{1.pASCs alogênicas não foram encontradas no coração dos porcos} 30 dias após a injeção

Com o objetivo de tentar identificar a expressão gênica das células alogênicas injetadas no VE após a indução de IM, optou-se por construir um banco de células-tronco extraída da gordura de um porco macho e fazer a injeção das mesmas em fêmeas. Com essa estratégia seria possível utilizar técnicas de identificação através da expressão gênica ou hibridização por sonda, do cromossomo Y. Com base na diferença de comprimento dos cromossomos sexuais $\mathrm{X}$ e $\mathrm{Y}$, o gene amelogenina foi avaliado. Um PCR semiquantitativo foi realizado com objetivo de detectar vestígios de células de macho na área de borda de VE, baseado no DNA genômico. Apesar da capacidade deste método de identificar até $1 \%$ de DNA de macho em uma mistura com 99\% de DNA de fêmea (Figura 3A), nenhum vestígio de DNA proveniente das células de machos (doadas) foi encontrado nas amostras 30 dias após a injeção de células (Figura 3B). 
A)

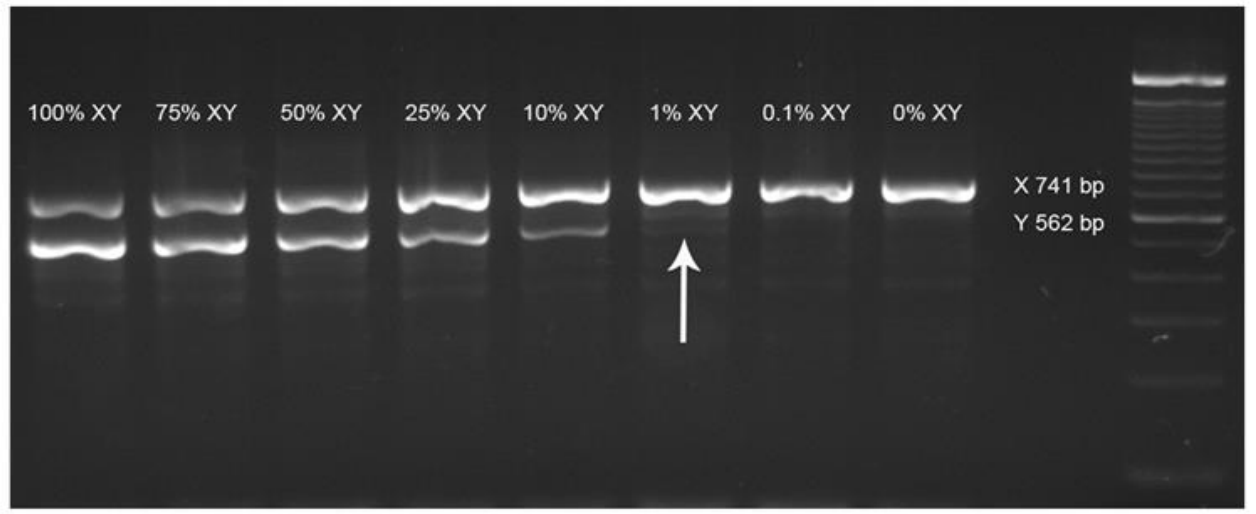

B)
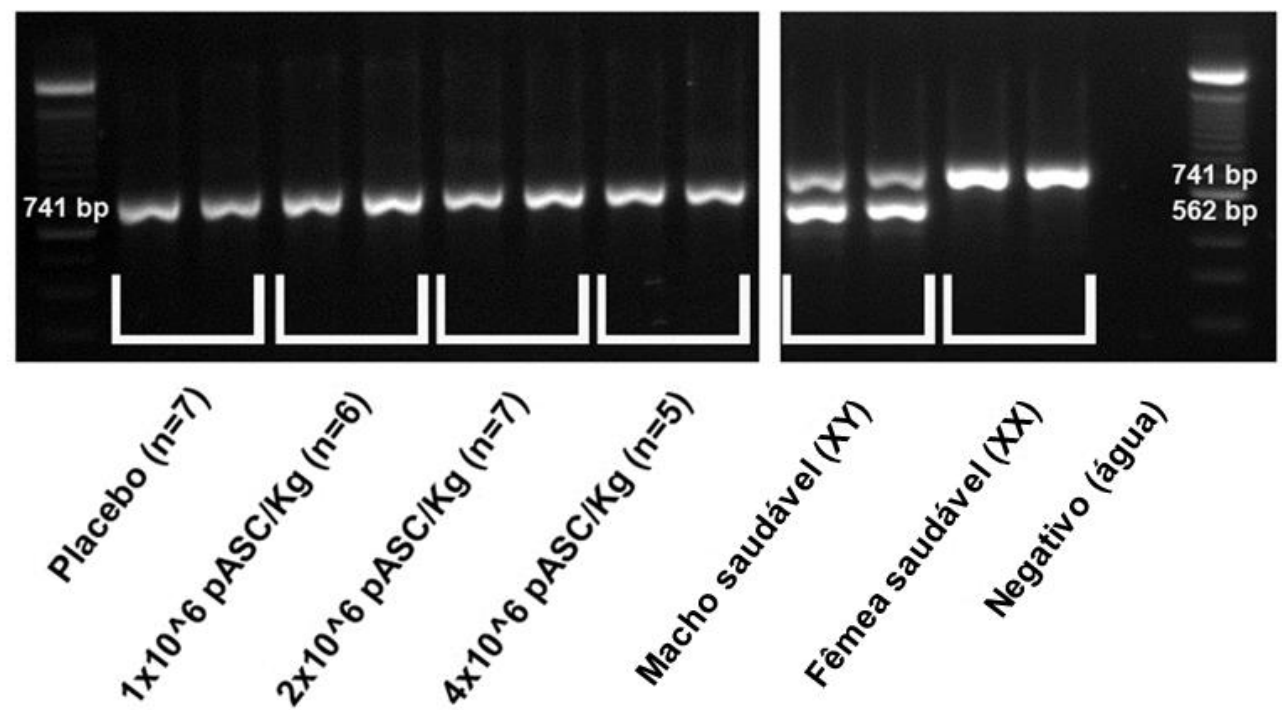

Figura 3: Identificação do DNA de células de machos no tecido cardíaco de fêmeas. A) Teste para identificação de DNA de macho em diferentes misturas de DNA de fêmea. Note que é possível identificar até $1 \%$ de material de macho misturado em DNA de fêmea. B) Não é possível identificar nenhum traço de DNA proveniente de células de macho nos tecido cardíacos retirados das fêmeas que receberam tratamento com pASC, 30 dias após as injeções. bp: base pairs (pares de base).

\subsection{Altas doses de pASCs alogênicas estimulam um aumento na perfusão miocárdica}

Predominantemente, os mecanismos de reparo cardíaco após terapia com células-tronco adultas parecem estar relacionados com o efeito parácrino de liberação de moléculas bioativas fortemente associadas aos processos de angio/vasculogênese. Apesar de as pASCs de machos não terem sido identificadas 30 dias após a injeção no tecido cardíaco de fêmeas e dos dados clássicos de função cardíaca como fração de encurtamento e fração de ejeção, 
Resultados

obtidos por ecocardiografia transtorácica, não apresentarem diferenças significativamente estatisticamente entre os grupos de tratamento, tanto em condição basal (Tabela 3) quanto após estresse farmacológico com dipiridamol (Tabela 4), os animais que receberam a injeção da maior dose de células (4 milhões de $\mathrm{pASC} / \mathrm{Kg}$ ) mostraram uma tendência em preservar a função cardíaca global (Figura 4). 
Tabela 3: Medidas lineares e derivações para acessar a função cardíaca de porcos via ecocardiografia transtorácica basal. As medidas pré-injeções foram realizadas quatro semanas após a indução de infarto e as medidas pré-eutanásia fora realizadas quatro semanas após a injeção de células-tronco. Dados são apresentados como média \pm erro padrão da média. $P>0,05$ :

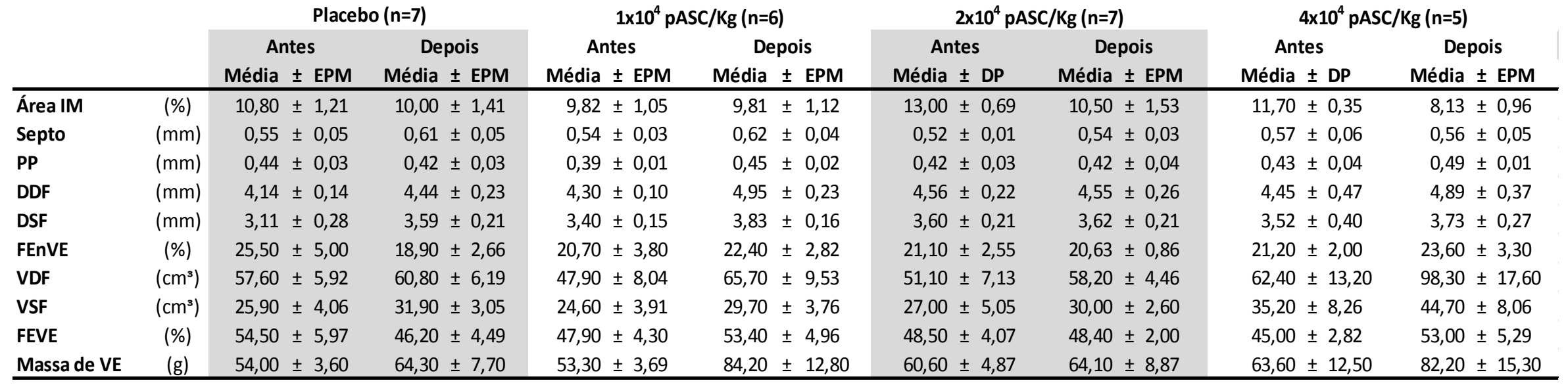

Abreviaturas: IM: infarto, Septo: septo interventricular, PP: parede posterior de VE, DDF: diâmetro diastólico final, DSF: diâmetro sistólico final, FEnVE: fração de encurtamento do VE, VDF: volume diastólico final, VSF: volume sistólico final, FEVE: fração de ejeção do VE, VE: ventrículo esquerdo, EPM: erro padrão médio. 
Resultados

Tabela 4: Medidas lineares e derivações para acessar a função cardíaca de porcos via ecocardiografia transtorácica sob estresse farmacológico. As medidas pré-injeções foram realizadas quatro semanas após a indução de infarto e as medidas pré-eutanásia fora realizadas quatro semanas após a injeção de células-tronco. Dados são apresentados como média \pm erro padrão da média. $P>0.05$.

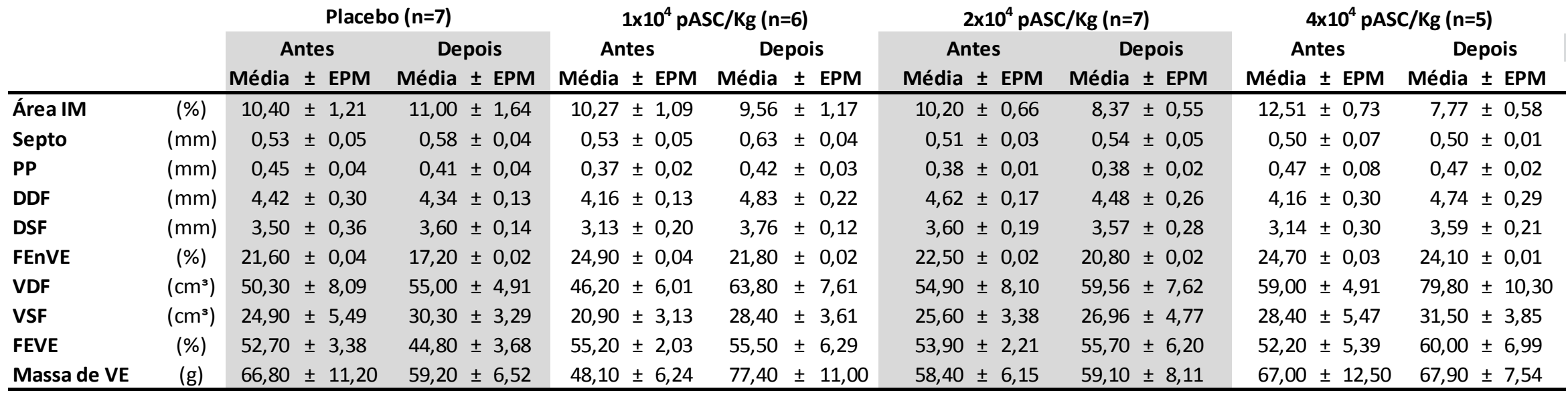

Abreviaturas: IM: infarto, Septo: septo interventricular, PP: parede posterior de VE, DDF: diâmetro diastólico final, DSF: diâmetro sistólico final, FEnVE: fração de encurtamento do VE, VDF: volume diastólico final, VSF: volume sistólico final, FEVE: fração de ejeção do VE, VE: ventrículo esquerdo, EPM: erro padrão médio. 
A)

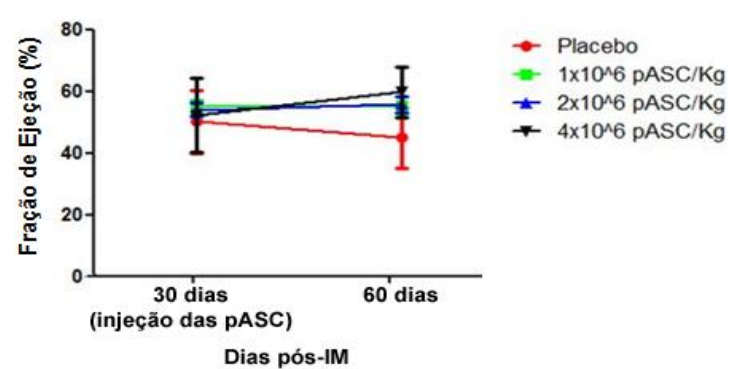

C)

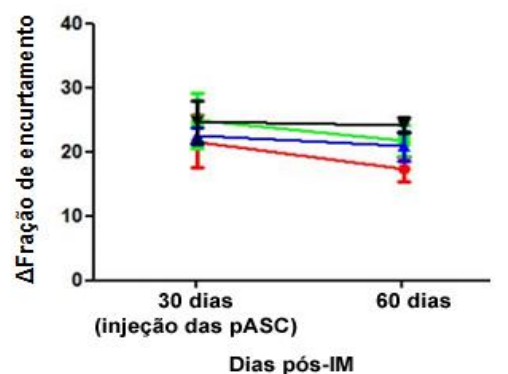

B)

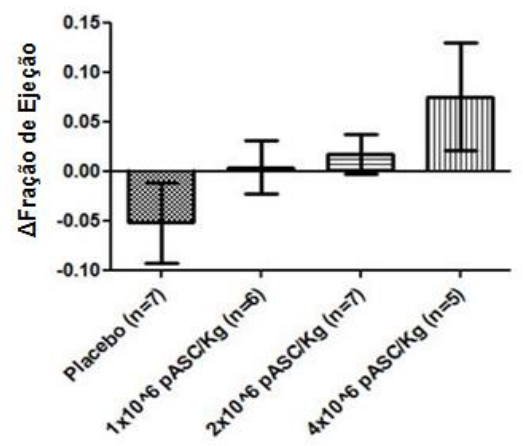

D)

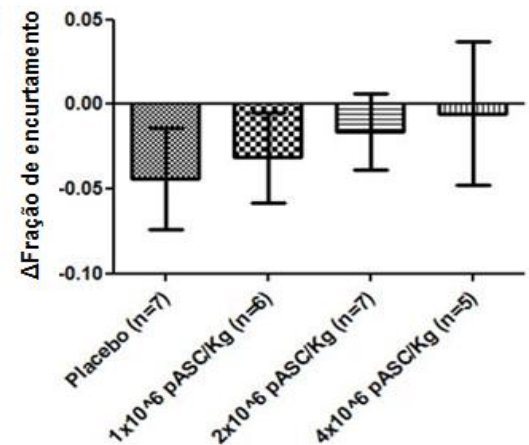

Figura 4: Função cardíaca ventricular esquerda medida através de ecocardiografia transtorácica. Estes parâmetros mostram uma tendência de melhora na função cardíaca do ventrículo esquerdo após a injeção de células-tronco no grupo $4(n=5)$ e uma ligeira tendência de manutenção da função nos grupos $2(n=6)$ e $3(n=7)$, enquanto que o grupo $1(n=7)$ mostra uma redução nos parâmetros funcionais avaliados. (A) Fração de ejeção média de cada grupo é mostrada 30 (injeção das células) e 60 dias após indução do infarto. (B) Comparação das mudanças absolutas da Fração de ejeção em cada grupo. Os $\Delta$ Fração de ejeção mostram uma clara tendência de melhora da fração de ejeção dos animais do grupo 4. (C) Fração de encurtamento média de cada grupo é mostrada 30 (injeção das células) e 60 dias após indução do infarto. (D) Comparação das mudanças absolutas da Fração de encurtamento em cada grupo. Os $\Delta$ Fração de encurtamento mostram uma tendência de redução da deterioração da capacidade de encurtamento do ventrículo esquerdo no sentido da maior dose de célulastronco injetada. Todos os dados são mostrados como média \pm erro padrão. $\mathrm{P}>0,05$ em todas as comparações.

Contudo, a perfusão miocárdica, medida através da ecocardiografia em tempo real com contraste de microbolhas, foi significativamente melhorada nos animais do grupo 4 (4 milhões de pASC/Kg). Neste grupo, as pASCs foram capazes de induzir o aumentar da perfusão miocárdica tanto na borda do infarto como na região remota da lesão, quando comparado ao grupo placebo (Figura 5A). Os grupos 2 e 3 (1 milhão de $\mathrm{pASC} / \mathrm{Kg}$ e 2 milhões de $\mathrm{pASC} / \mathrm{Kg}$ respectivamente) não apresentaram diferença estatisticamente significante quanto à perfusão miocárdica quando comparados com o grupo placebo 
Resultados

(Figura 5B). Interessantemente, todos os animais do grupo $4 \quad(n=5)$ demonstraram um aumento ou manutenção da perfusão em ambas as regiões avaliadas, após a injeção de células, enquanto que os outros grupos não demonstraram padrões bem definidos (Figura 5C e D).

Além disso, usando o contraste de microbolhas foi possível definir, por planimetria, a porcentagem de área não perfundida no ventrículo esquerdo, antes e após a injeção. No grupo 4, que recebeu a maior dose de células, observou-se uma redução significativa da área de tecido não perfundido 30 dias após a injeção de células (Figura 5E e F). Interessantemente, os porcos dos grupos 2 e 3 demonstraram uma tendência de redução das áreas não perfundidas (Figura 5E e F). Assim, somente altas doses de pASC foram capazes de melhorar a perfusão miocárdica de porcos infartados. 
Resultados

A)
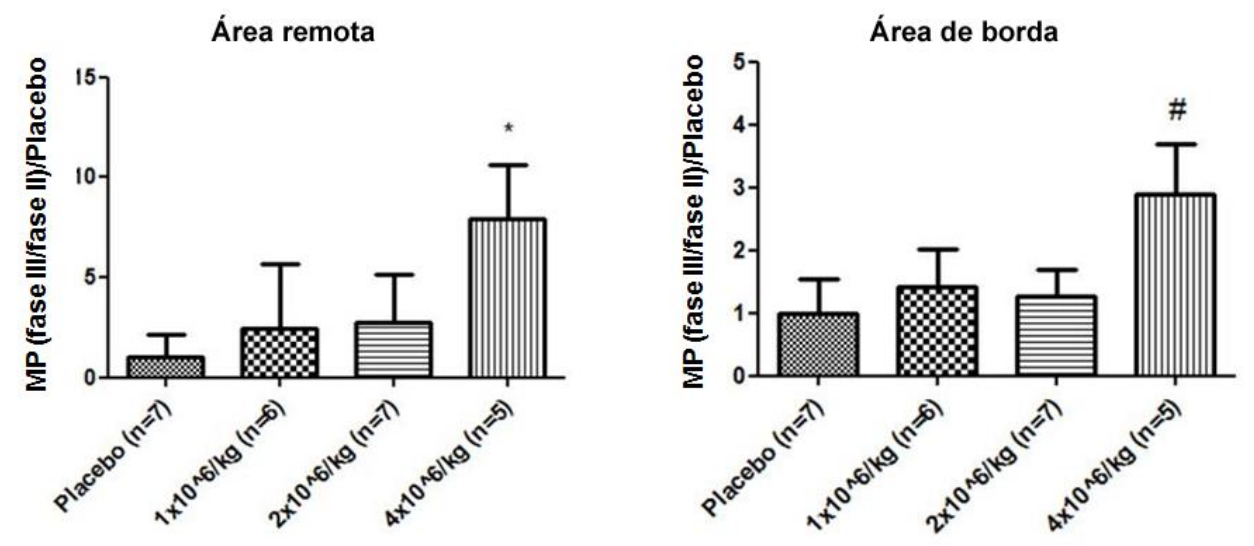

B)
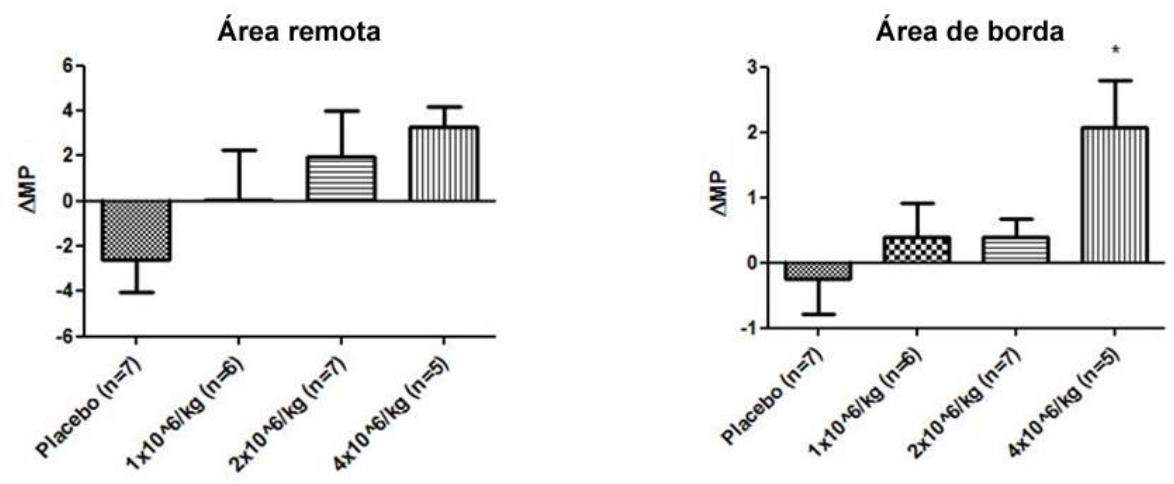

c)

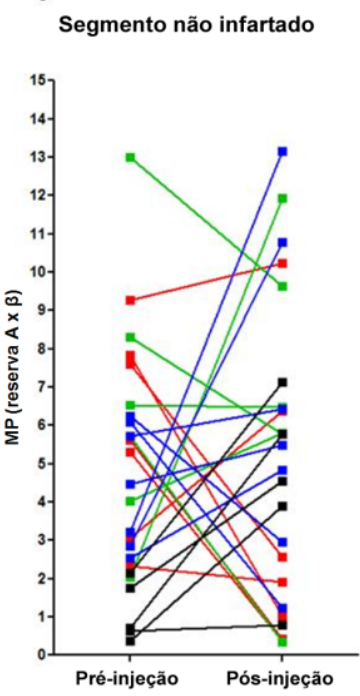

Segmento infartado

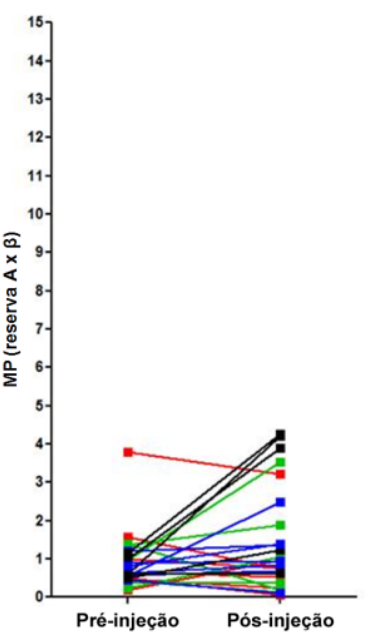

D) Segmento não infartado Segmento infartado
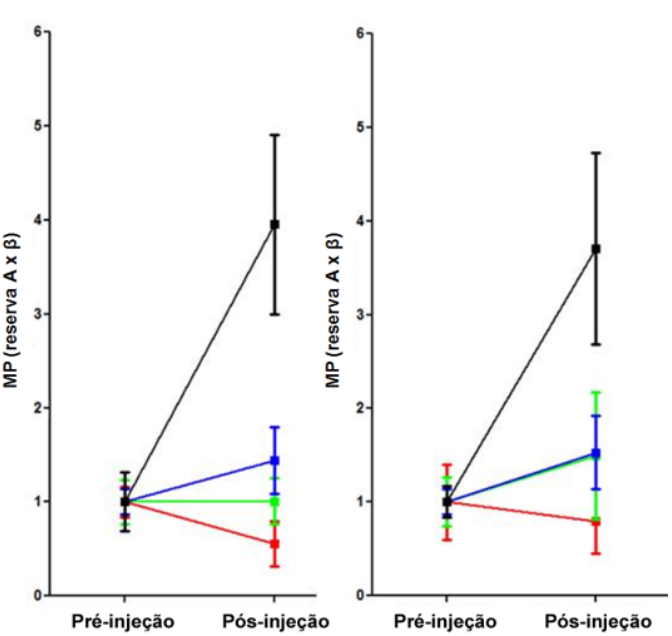
Resultados

E)

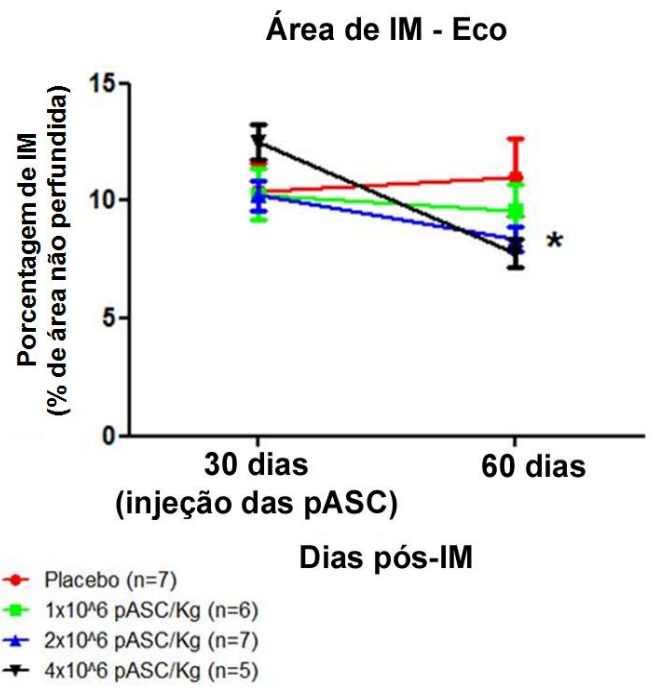

F)

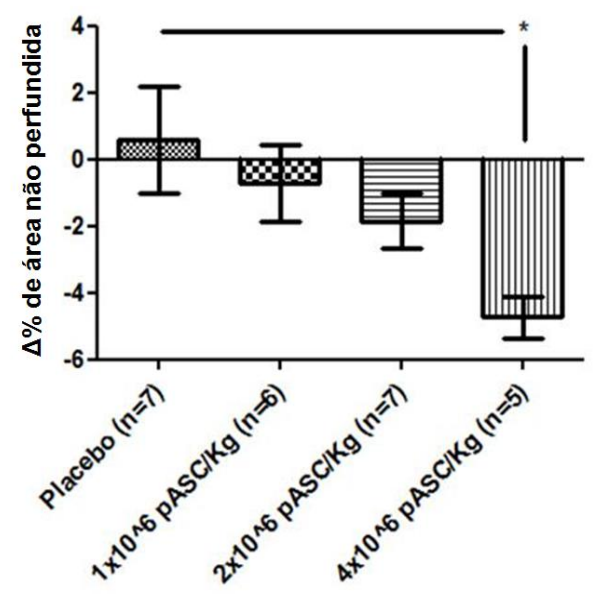

Figura 5: A perfusão miocárdica (MP) foi melhorada no grupo de animais que recebeu 4 milhões de $\mathrm{pASC} / \mathrm{Kg}$. A MP do ventrículo esquerdo calculada pelo método de ecocardiografia em tempo real usando microbolhas mostra que o maior dose de pASC usada é uma boa opção para aumentar e prevenir a deterioração da perfusão miocárdica tanto nas áreas remotas como na borda do infarto do miocárdio. (A) Para desenvolver as medidas de perfusão miocárdica por ecocardiografia os animais foram sedados. Imagens ecocardiográficas $2 \mathrm{D}$ em estado basal e usando microbolhas foram realizadas antes e após estresse farmacológico com dipiridamol. As imagens obtidas pela técnica de microbolhas foram usadas para calcular a MP de todos os animais antes e 30 dias após a injeção de pASC tanto na região remota como na borda dos infartos. A razão de MP foi calculada através da razão entre MP na fase III e MP na fase II. Todos os dados foram normalizados pelo grupo placebo. ${ }^{\star} \mathrm{P}<0.01$ para área remota e $\# \mathrm{P}<0.05$ para borda do infarto vs. Grupo placebo (ANOVA com pós-teste de Bonferroni). (B) $\triangle M P$ foram calculados com base na subtração dos valores de MP após a injeção de pASC e os valores obtidos antes da injeção para cada grupo. ${ }^{*} \mathrm{P}<0.03$ vs. grupo placebo (ANOVA com pós-teste de Bonferroni). Note que há uma tendência em prevenir a deterioração da MP nos outros grupos que receberam células. Dados apresentados em média \pm erro padrão. (C) MP propriamente foi mostrada. Cada traço representa a MP de um único animal antes e após a terapia celular. Note que a MP é menor nas áreas de infarto do que na área remota devido a composição fibrótica do tecido lesado. (D) Cada traço representa a MP média de cada grupo antes e após a terapia celular. Todos os dados foram normalizados pela media pré-injeção de cada um dos grupos. Note que a despeito da importante diferença dos níveis de perfusão entre as áreas avaliadas, o comportamento de MP é similar para cada grupo após o uso da terapia celular (E) Além disso, usando as imagens geradas pelas microbolhas foi possível fazer medidas de percentagem planimétricas das áreas não perfundidas do VE antes e após a terapia celular. Apesar de diferenças estatísticas entre os grupos não terem sido observadas, diferenças significativas antes e após a injeção de células foram observadas para o grupo 4, no qual, uma importante diminuição de área não perfundida foi observada. ${ }^{*} \mathrm{P}<0.001$ (Teste t de Student). (F) A redução significativa da área não perfundida pode ser melhor visualizada através do cálculo de $\Delta \%$ de área não perfundida entre o quando comparamos os grupo $4 \mathrm{e}$ placebo. ${ }^{*} \mathrm{P}<0.03$ (ANOVA com pós-teste de Bonferroni). 
Resultados

\subsection{Altas doses de pASC alogênicas estimulam o aumento no número de vasos na borda e áreas remotas ao infarto}

A perfusão miocárdica, a qual pode ser mensurada através de técnicas de medicina nuclear e ecocardiografia com contraste de microbolhas, em linhas gerais, está diretamente associada ao número de vasos funcionais disponíveis no músculo cardíaco. Para confirmar os dados de perfusão miocárdica do VE nos diferentes grupos de tratamento, o número total de vasos presentes no VE foi estimado através de coloração por PAS e contagem manual. As contagens foram realizadas por dois observadores cegos para os grupos experimentais e foram realizadas sobre as regiões remotas, de borda e cicatricial.

Assim como observado para o parâmetro de perfusão miocárdica, foi observado um aumento significativo no número de vasos na área remota e de borda do infarto do miocárdio nos porcos do grupo 4 (Figura 6A-C). O mesmo não foi observado na área cicatricial. Os porcos que receberam menos que 4 milhões de pASC/Kg não apresentaram aumento significativo do número de vasos no VE (Figura 6). Além disso, dados de expressão gênica mostraram que a expressão do fator de crescimento vascular endotelial (do inglês, VEGF) se encontra aumentada nos tecidos cardíacos dos animais que receberam a maior dose de células-tronco 30 dias após a injeção (Figura 6D e E) corroborando com os dados de perfusão e número de vasos observados. 
A)
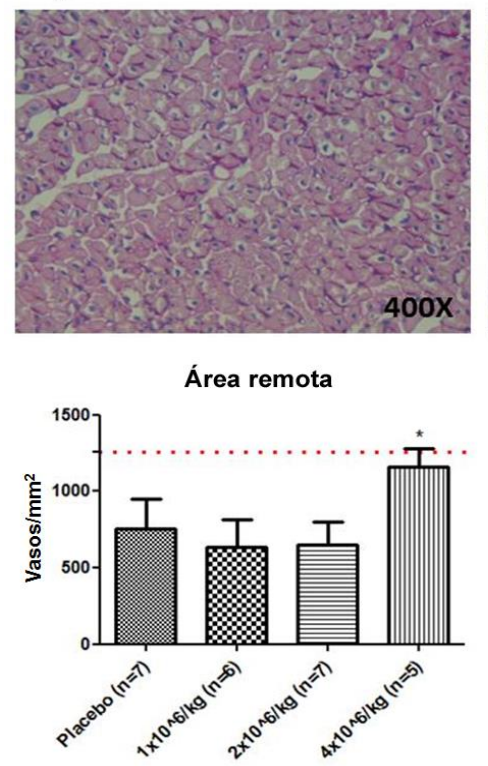

B)
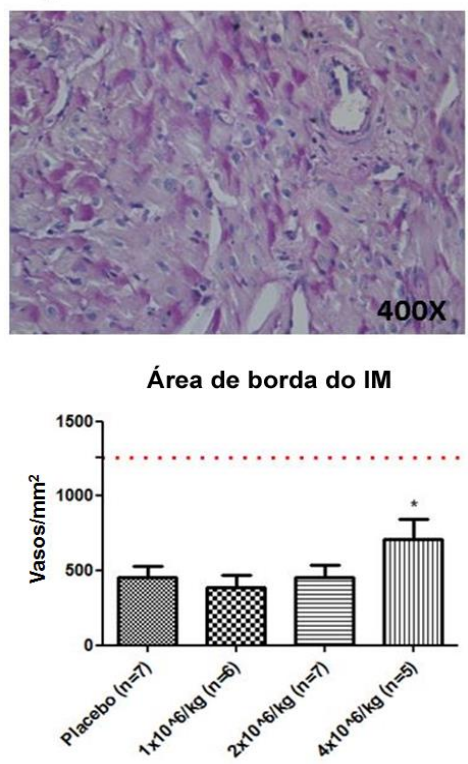

C)
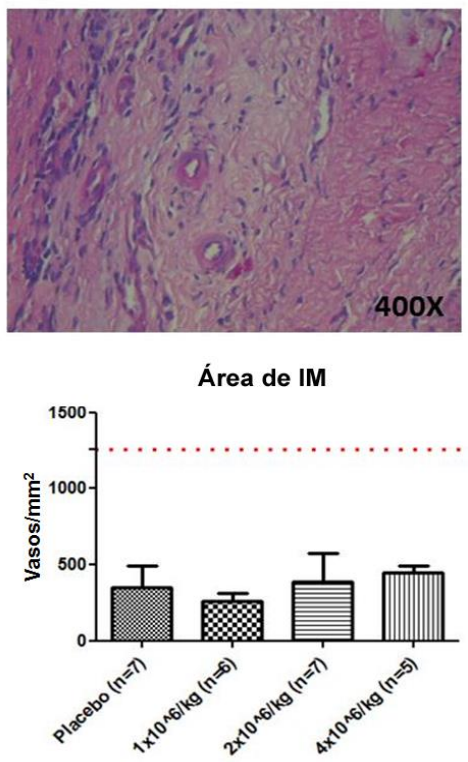

D)
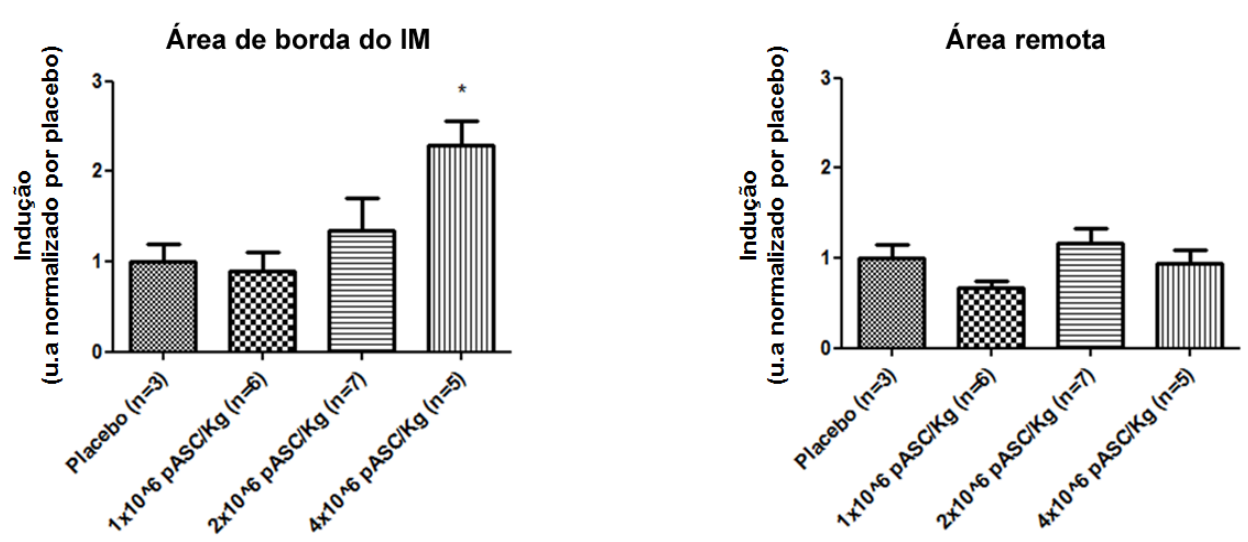

E)

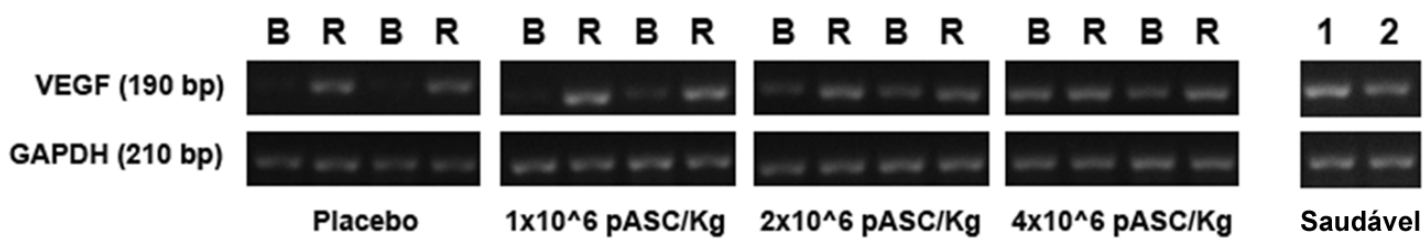

Figura 6: $O$ uso de 4 milhões de pASC alogênicas $/ \mathrm{Kg}$ implica em um aumento no número de vasos e a expressão genica de VEGF nas bordas e área remota ao infarto do miocárdio. Avaliação histológica dos corações de suínos infartados. (A à C) Coloração com ácido periódico de Schiff; as imagens são representativas das três áreas avaliadas por contagem manual do VE (remota, borda e infarto propriamente dito). A linha vermelha pontilhada representa o número médio de vasos contados no coração de porcos sadios. Os dados são apresentados como média \pm erro padrão médio da média. ${ }^{*} \mathrm{P}<0.0001$ comparado com todos os outros grupos (ANOVA com Pós-teste de Bonferroni). (D e E) Quantificação da expressão gênica de VEGF nas áreas remota (R) e de borda do infarto (B) e gel de agarose representativo das bandas obtidas por PCR ( $n=4$ animais por grupo). $O$ gene GAPDH foi usado como controle interno para normalizar a expressão de VEGF. Dois animais sadios foram utilizados como controle positivo de expressão. bp: base pairs (pares de base). 


\subsection{Altas doses de pASC alogênicas reduziram a área de lesão do VE}

De modo geral, uma obstrução de vasos coronarianos pode reduzir ou até cessar a perfusão miocárdica. Tal oclusão se não revertida rapidamente pode conduzir à isquemia do miocárdio seguida por necrose deste tecido. Além de ter sido demonstrada uma redução da área não perfundida do VE nos porcos tratados com o maior número de células-tronco (grupo 4), as avaliações anatomopatológicas realizadas em VE confirmaram uma redução significativa na área de lesão neste mesmo grupo de animais (Figura 7A e B).

Além disso, o remodelamento adverso de VE foi atenuado no grupo 4 como demonstrado pela diminuição do afinamento da parede lesionada (Figura 7C) e a redução da hipertrofia da parede septal (Figura 7D). Estes dados foram utilizados para calcular a razão de afinamento da parede, a qual apresentou uma diferença significativa entre o grupo 4 vs. os outros grupos experimentais testados (Figura 7E), reforçando a ideia de regulação do remodelamento adverso. 
Resultados

A)

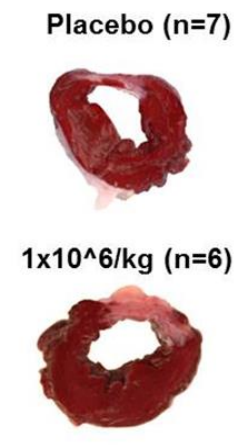

$2 \times 10^{\wedge} 6 / \mathrm{kg}(\mathrm{n}=7)$

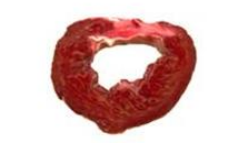

$4 \times 10^{\wedge} 6 / \mathrm{kg}(\mathrm{n}=5)$

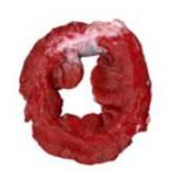

B)

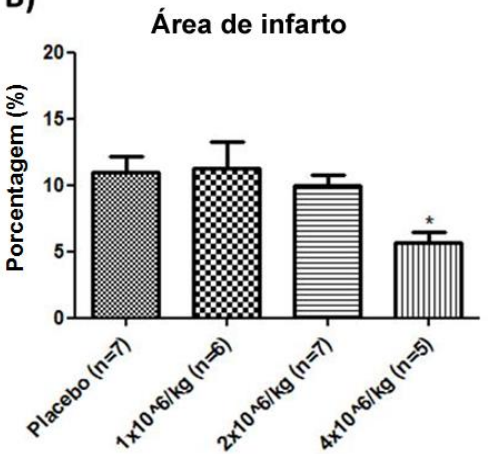

D)

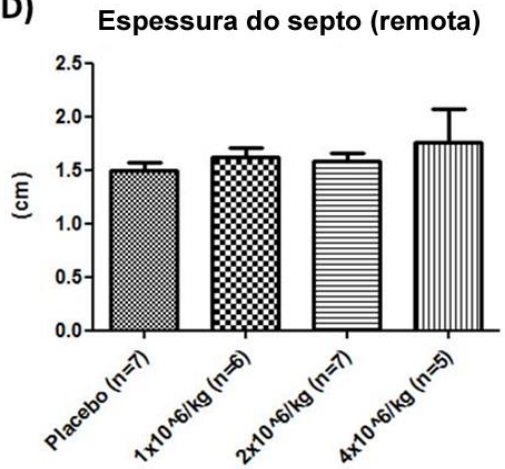

C)

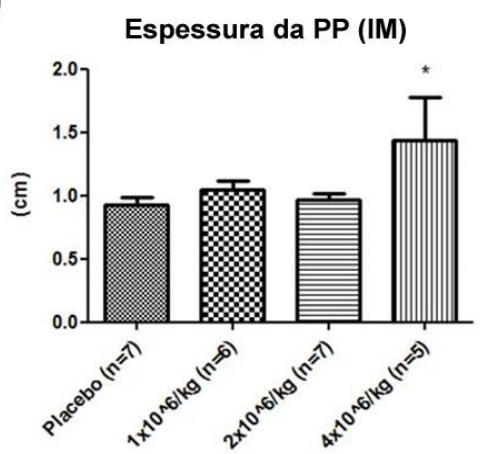

E)

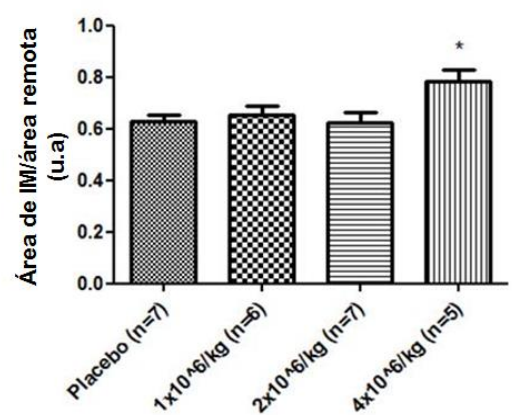

Figura 7: A dose de 4 milhões de $\mathrm{pASC} / \mathrm{Kg}$ é capaz de reduzir área lesada de VE $\mathbf{3 0}$ dias após tratamento. Após a eutanásia o VE de todos os porcos usados no estudo foram dissecados e cortados em fatias transversais de aproximadamente $5 \mathrm{~mm}$, da base até o ápice (7-8 fatias) e corados com TTC para avaliação da áreas de fibrose. (A) Fatias representativas cortadas ao nível dos músculos papilares após coloração com TTC. (B) A porcentagem de tecido infartado de VE foi calculada pela média da área planimétrica de todos os cortes de VE. O grupo 4 apresentou redução significativa da área de infarto quando comparado aos outros grupos experimentais ( ${ }^{*} \mathrm{P}<0,03$ - ANOVA com pós-teste de Bonferroni). (C e D) As espessuras das paredes posterior (IM) e septal (área remota) são mostradas, respectivamente. A dose de 4 milhões de $\mathrm{pASC} / \mathrm{Kg}$ foi capaz de impedir uma redução da espessura da parede posterior, que resultou em um remodelamento menos abrupto do VE ( ${ }^{*} P<0,05$ em comparação com placebo e 2 milhões de pASC/Kg - ANOVA com pós-teste de Bonferroni). O remodelamento menos abrupto pode ser melhor visualizado através (E) da razão de afinamento de parede calculada através das medidas de espessura da parede posterior e septal. Os animais do grupo 4 apresentaram melhor índice ( $\left.{ }^{*} P<0,01\right)$ em comparação com os grupos placebo e 2 milhões de pASC/Kg(ANOVA com pós-teste de Bonferroni). Os dados são apresentados como média \pm EPM. PP: parede posterior; IM: infarto do miocárdio.

Para que não houvesse dúvidas a respeito da redução da área de infarto e índice de afinamento da parede, e assim estes resultados pudessem ser meramente artefatos devido a alterações, por exemplo, na massa corpórea de um animal em comparação com outro, as análises apresentadas na Figura 8 foram realizadas. Nesta análise primeiramente a área de infarto obtida em percentagem foi dividida pela massa corpórea do animal (Figura 8A). Além 
Resultados

disso, para demonstrar que não houve crescimento diferencial dos animais dos

diferentes grupos, nem tão pouco hipertrofia de parede que pudesse justificar os dados obtidos pela razão de afinamento das paredes, a massa de VE foi dividida também pela massa corpórea do animal (Figura 8B). Estes dados dão suporte para os efeitos benéficos observados pelo tratamento de células testado no grupo 4.

A)

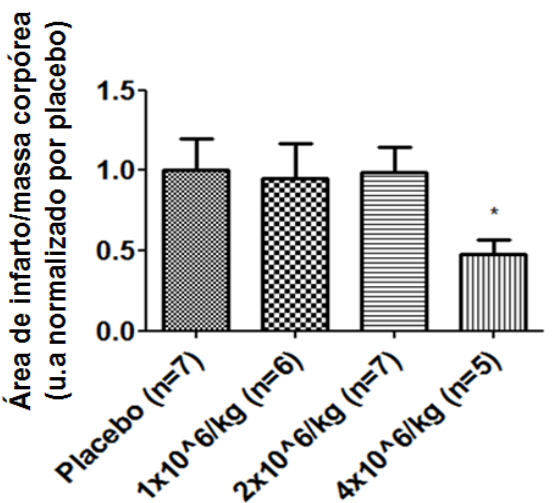

B)

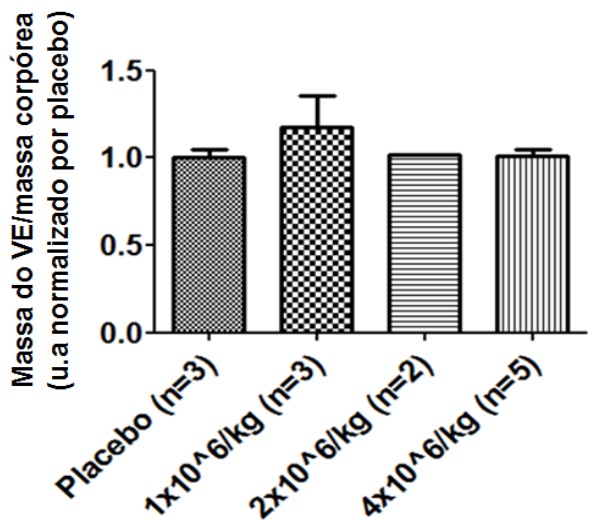

Figura 8: Parâmetros anatomopatológicos - Controles positivos para a redução da área de infarto e razão de afinamento das paredes de VE dos diferentes grupos tratados com pASC. (A) quantificação da área infartada de VE. Todos os animais tiveram a percentagem de área infartada indexada pelo peso corporal e então os dados foram normalizados pelo grupo placebo. Note a redução da área infartada nos animais do grupo 4 (53\% de redução) * $P<0,03$ em comparação com todos os outros grupos (ANOVA com pós-teste de Bonferroni). (B) Neste gráfico a massa de VE foi indexada pela massa corpórea de cada animal, e normalizado pelo grupo placebo, demonstrando que não houve alteração significativa entre a massa de VE e massa corpórea em nenhum dos grupos. Isso mostra que todos os animais foram submetidos ao mesmo grau alteração de massa corpórea independentemente do grupo a que pertenciam. Todos os dados são apresentados como médias \pm EPM.

Apesar da espessura da parede posterior ter sido sustentada e a razão de afinamento sido significativamente melhor nos animais do grupo 4, não foi observada diferença significativa na quantidade de colágeno intersticial medido nos cortes histológicos de coração, e comparados entre os grupos experimentais (Figura 9A). Visto que não foram observadas diferenças entre os grupos para a quantidade de colágeno intersticial, e tendo em vista que os até aqui todos os dados significativamente diferentes foram observados no grupo 
Resultados

4, foram avaliados então as porcentagens de colágeno I e III presentes na área cicatricial dos animais dos grupos placebo e grupo 4 (Figura 9B). Novamente, não foram observadas diferenças significativas na composição de colágeno entre estes dois grupos (Figura 9B). Além disso, as cicatrizes de todos os animais avaliados apresentaram cerca de $50 \%$ de colágeno tipo I e $50 \%$ de colágeno III (Figura 9B).

Tendo em vista que os dados de melhor remodelamento cardíaco adverso medido através de alterações no padrão de afinamento das paredes foram significativamente significativos, mas diferenças na composição das cicatrizes não foram observadas entre estes dois grupos, uma última análise foi realizada com objetivo de avaliar a maturação das fibras colágenas presentes nas cicatrizes de animais placebos vs. grupo 4. Para tanto, foram avaliadas imagens provenientes de microscopia óptica polarizada.

Interessantemente, os animais tratados com maior dose de pASC apresentaram um padrão de maturação de colágeno da área cicatricial completamente distinto dos animais do grupo placebo, sendo a lesão daqueles composta por fibras de colágeno menos maduras (padrão verde, Figura 9C). Juntos, esses dados reforçam a hipótese de que maiores doses de célulastronco mesenquimais são necessárias para promover benefícios no tratamento do infarto do miocárdio. 
A)

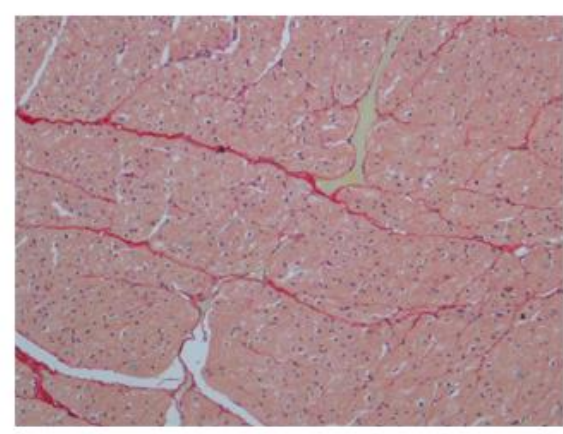

Área remota

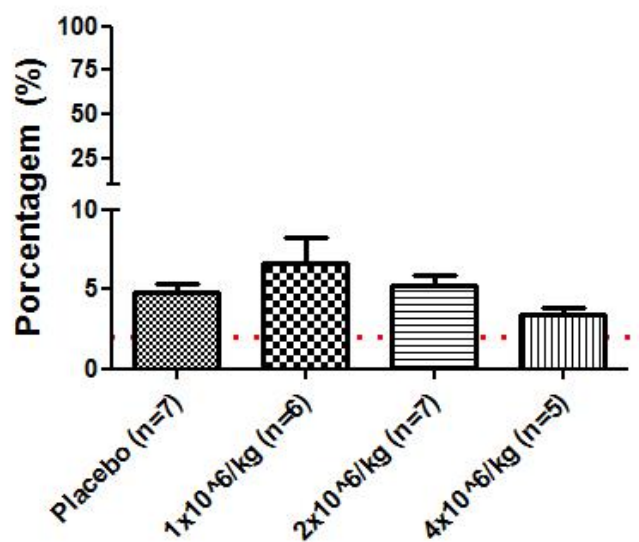

B)

\section{Colágeno tipo I}
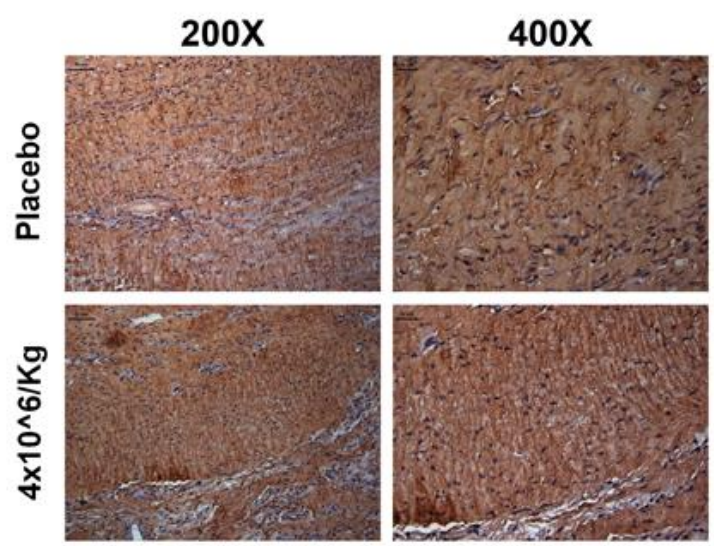

Colágeno tipo III
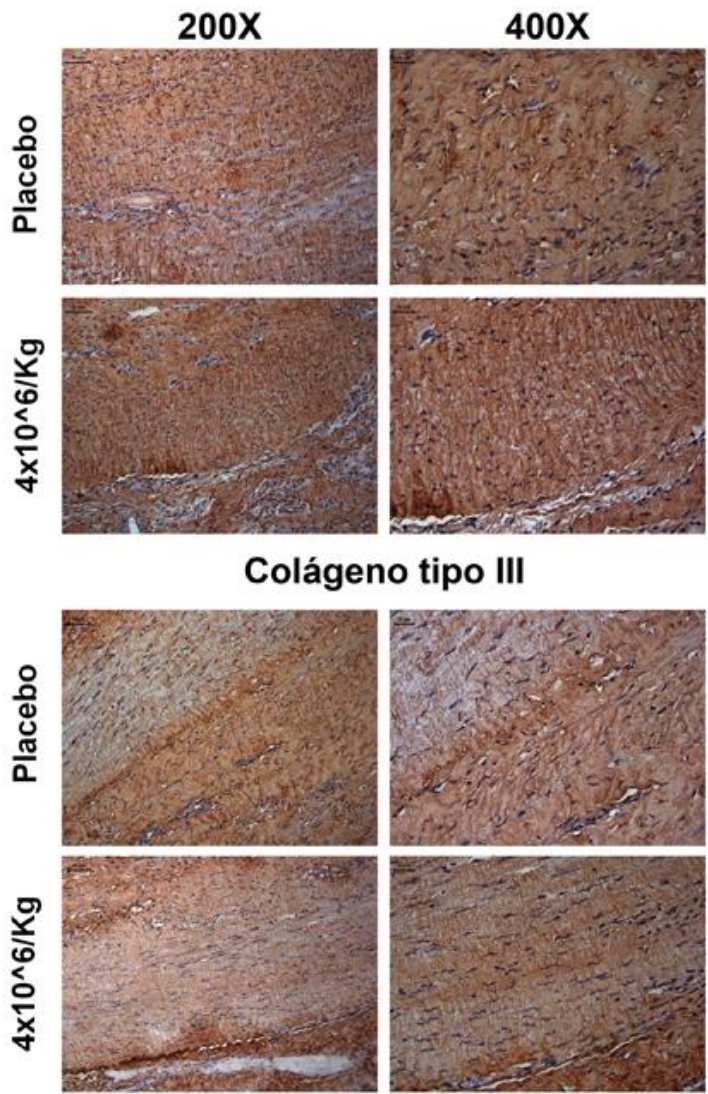

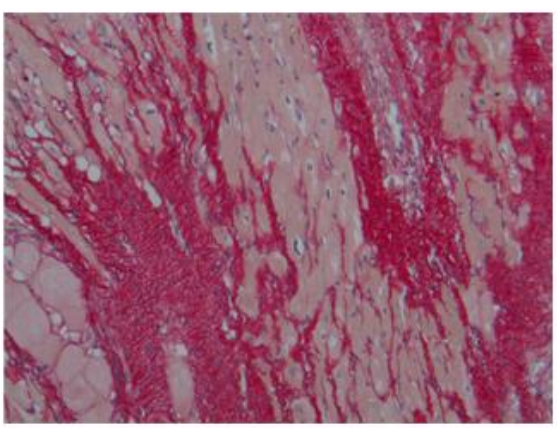

Área de infarto

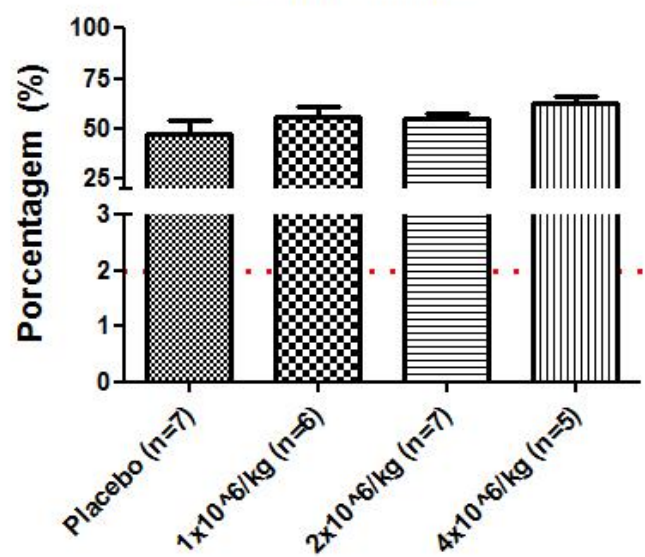

I

\section{$\square$ Colágeno I $\square$ Colágeno III}

II

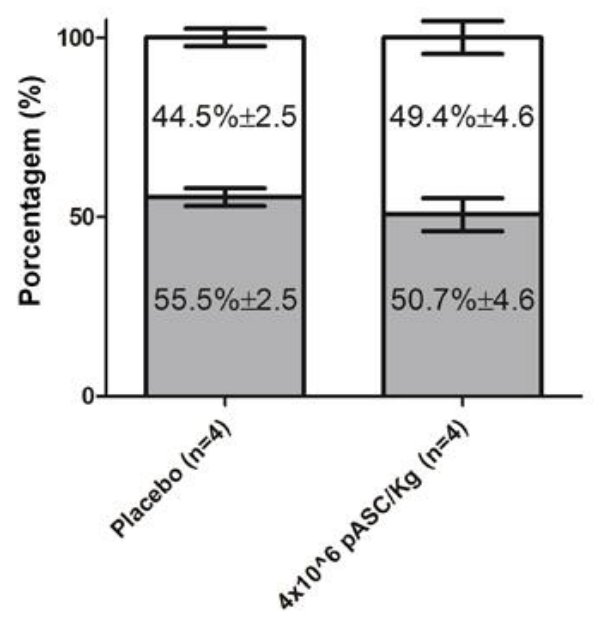


Resultados

C)
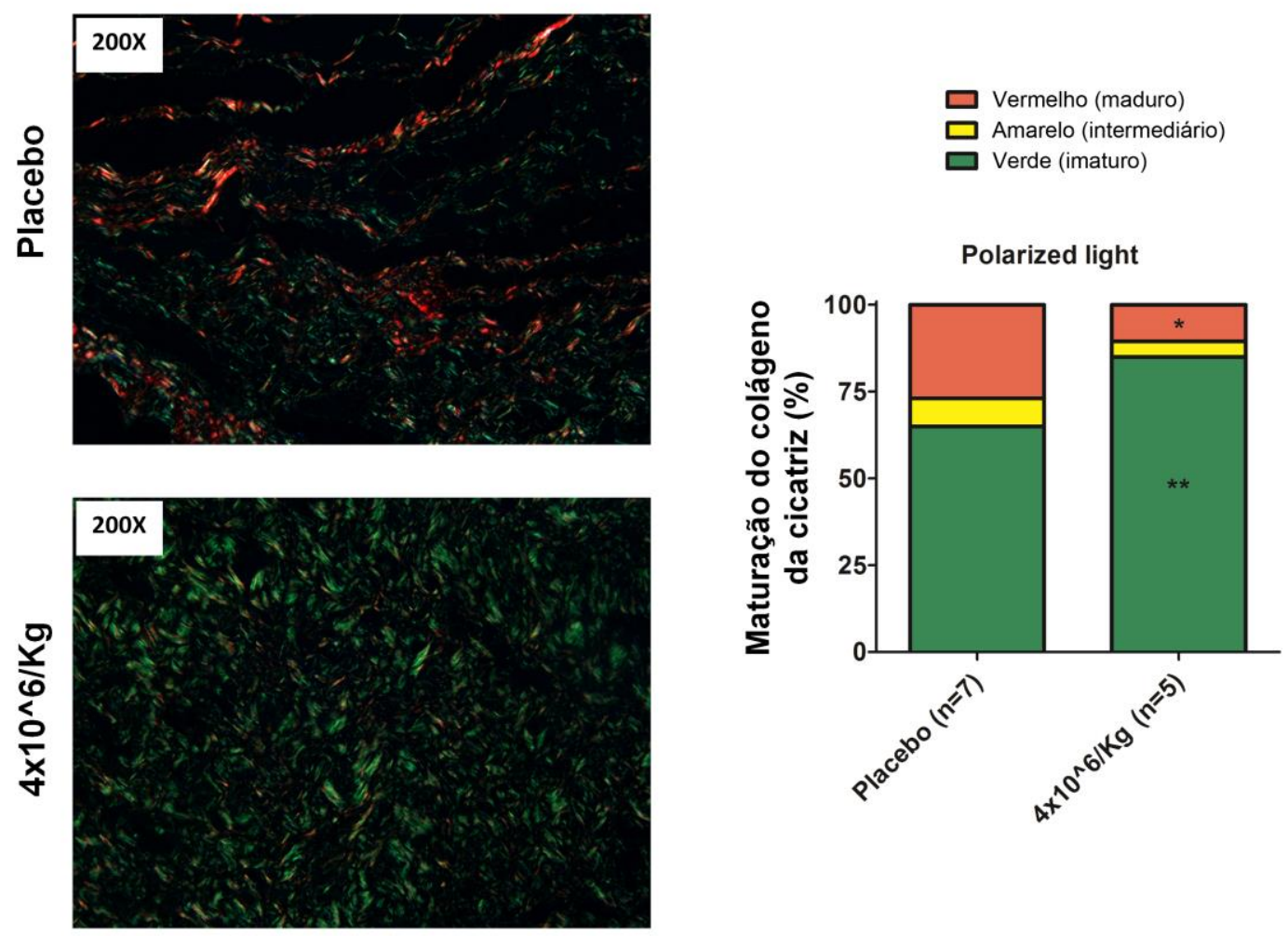

Figura 9: A maior dose de células alogênicas testada tem influência sobre a maturação do colágeno presente na área de cicatriz. Usando microscopia de luz tradicional, microscopia de luz polarizada e imunohistoquímica a composição e maturação da cicatriz foram qualificadas e quantificadas. (A) Imagens representativas de laminas histológicas coradas com Picrossirius-red e a quantificação da percentagem de colágeno intersticial presente no septo (I e II) e parede posterior (III e IV). Nenhuma diferença estatística foi observada entre os grupos estudados. (B) Porcentagem de colágeno por tipo de fibra. Imagens representativas de imunohistoquímica contra colágeno do tipo I e do tipo III usadas para quantificação. (BI) imagens representativas usadas na quantificação do colágeno I presente na área de cicatriz dos animais placebo vs. 4 milhões células/Kg. (BII) imagens representativas usadas na quantificação do colágeno III presente na área de cicatriz dos animais placebo vs. 4 milhões células $/ \mathrm{Kg}$. Note que não existe diferença significativa entre as quantidades de colágeno I e III entre os grupos comparados. (C) Quantificação de maturação de colágeno através de microscopia de luz polarizada. $(\mathrm{Cl})$ imagens representativas da cicatriz de animais placebo vs. 4 milhões células $/ \mathrm{Kg}$. (CII) Comparação entre a porcentagem de fibras de colágeno verdes, amarelas e vermelhas entre os animais placebo vs. 4 milhões células $/ \mathrm{Kg}$. Note que existe diferença significativa na maturação das fibras de colágeno entre os grupos comparados. Os animais do grupo 4 apresentam uma cicatriz menos madura e potencialmente mais elástica do que os placebo. Todos os dados são apresentados como média \pm EPM. 
Resultados

\subsection{Altas doses de pASCs alogênicas não provocaram um aumento da resposta inflamatória celular no coração}

Sabe-se que as injeções de células adultas alogênicas e xenogênicas podem provocar uma resposta inflamatória celular em órgãos hospedeiro destruindo as células do doador. Evidências têm demonstrado que as célulastronco mesenquimais adultas podem ser favorecidas em transplante, pois essas apresentam baixa imunogenicidade, mas esses tipos de dados ainda não estão bem esclarecidos. Por meio de avaliações patológicas de lâminas histológicas coradas com H\&E, a resposta de infiltrado inflamatório celular foi avaliada no VE de todos os porcos 30 dias após as injeções. Altas doses de pASC (2 e 4 milhões $/ \mathrm{Kg}$ ) não provocaram aumento na quantidade de células inflamatórias infiltradas em VE, todavia, no grupo 2 (1 milhão pASC/Kg) a quantidade de células inflamatórias observada foi aumentada (Figura 10A e B). Além disso, as células inflamatórias foram observadas somente nas bordas do IM e IM propriamente dito, sendo em sua maior quantidade no meio da lesão (Figura 10C e D e Tabela 5).

A resposta inflamatória também foi qualificada através da observação do tipo morfológico do infiltrado (irregular ou difusa). Infiltrados irregulares e difusos foram observados em ambas as áreas (borda e IM) e em todos os grupos. Não foram observadas diferenças estatísticas na frequência de infiltrados irregulares, mas foram observadas diferenças significativas para infiltrados difusos no grupo 2 quando comparado com os grupos 1 , 3 e 4 (Figura 10E e F). 
Resultados

A)

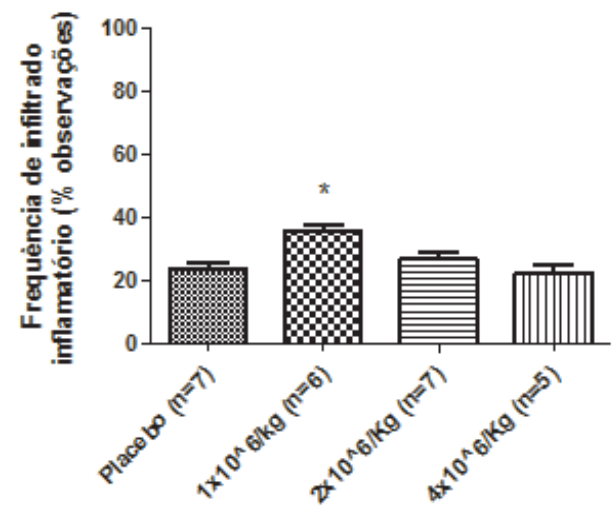

C)

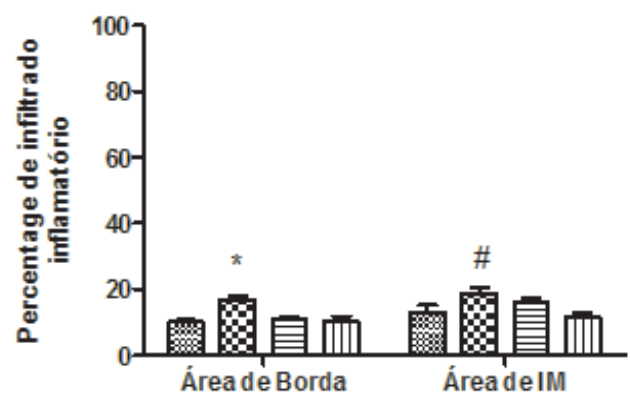

E)

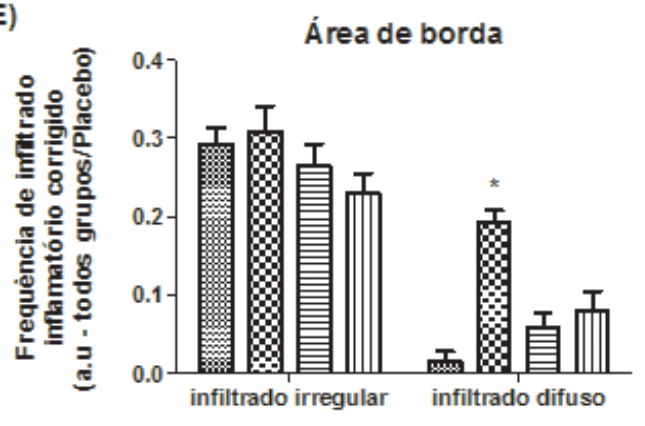

B)

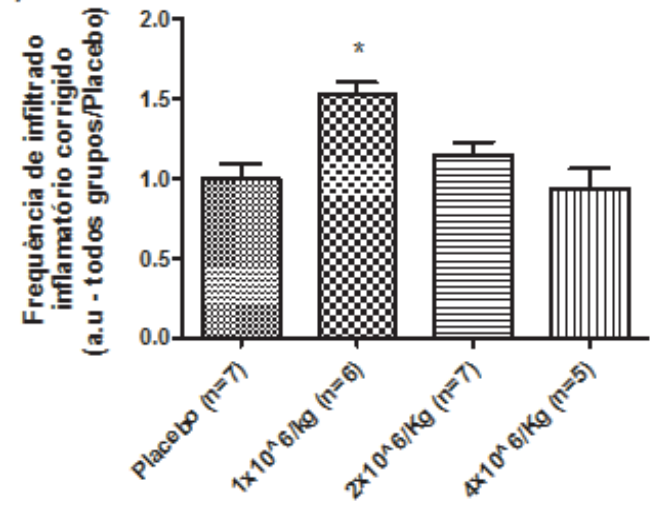

D)

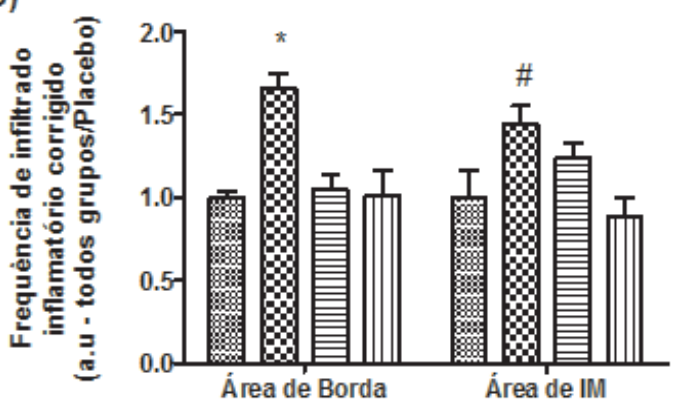

F)

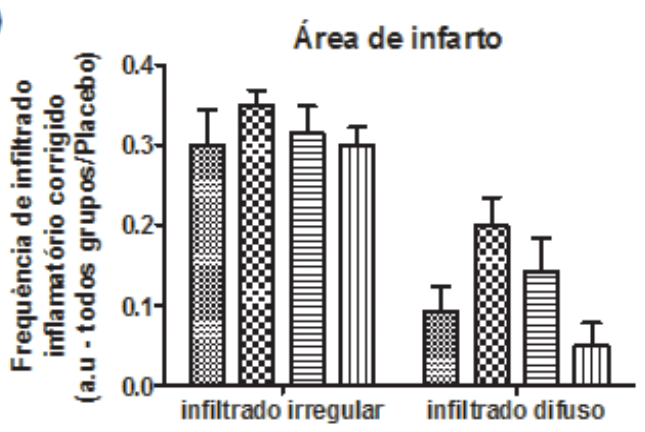

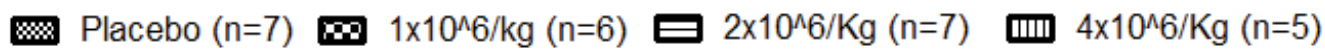

Figura 10: Altas doses de pASC alogênicas não provocam o aumento da infiltração de células inflamatórias no VE. A frequência, em porcentagem, de infiltrado inflamatório observado em lâminas histológicas coradas com H\&E foi avaliada 30 dias após a injeção de pASC nas 3 área de VE: remota, de borda e lesão. O infiltrado foi qualificado pela distribuição das células no tecido infiltrado como irregular ou difuso e normalização foram realizados pelo grupo placebo para esclarecer as frequências obtidas. (A) Frequência global de células inflamatórias observadas no VE total. Uma diferença significativa foi mostrada entre o grupo $1 \mathrm{e}$ os demais grupos. Estas observações foram sustentadas pelos outros gráficos representativos da frequência. * $P<0,005$ em comparação com placebo e 4 milhões de pASC/Kg (ANOVA com pós-teste de Bonferroni). (B) a frequência global de infiltração de células normalizada pelo grupo placebo. * $\mathrm{P}<0,001$ em comparação com placebo e 4 milhões de pASC/Kg (ANOVA com pós-teste de Bonferroni). (C) A frequência de células inflamatórias infiltradas pela área de VE. $\mathrm{Em}$ ambas as áreas, borda e $\mathrm{Ml}$, foram observadas contagens significativas de células no grupo 2 em comparação com outros grupos. ${ }^{*} \mathrm{P}<0,05$ (ANOVA com pós-teste de Bonferroni). (D) Frequência de infiltração de células por área de VE normalizada pelo grupo placebo. * $P$ $<0,01$ em comparação com placebo, 2 e 4 milhões de $\mathrm{pASC} / \mathrm{Kg}$ e \# $\mathrm{P}<0,05 \mathrm{em}$ comparação com placebo e 4 milhões de pASC/Kg. (E) Frequência de infiltrados irregulares e difusos na 
borda do IM normalizada pelo grupo placebo. Grupo 2 apresenta frequência significativa de células inflamatórias observadas na distribuição difusa em comparação com outros grupos. * $\mathrm{P}$ $<0,05$ (ANOVA com pós-teste de Bonferroni). (F) Frequência de infiltrados irregulares e difusos na área IM normalizada por placebo. Não foram observadas diferenças. Os dados são apresentados como média \pm erro padrão da média.

Tabela 5: Sistema de classificação para a rejeição das células alogênicas injetadas. Análise oito semanas após o infarto do miocárdio (4 semanas após injeção de pASC; - frequência de infiltrado inflamatório observado/observação total por área).

\begin{tabular}{|c|c|c|c|c|c|c|c|c|c|}
\hline & \multicolumn{3}{|c|}{ Área de infarto } & \multicolumn{3}{|c|}{ Área de borda } & \multicolumn{3}{|c|}{ Área remota } \\
\hline & Irregular & Difuso & $\begin{array}{c}\text { Dano de } \\
\text { miócito }\end{array}$ & Irregular & Difuso & $\begin{array}{l}\text { Danode } \\
\text { miócito }\end{array}$ & Irregular & Difuso & $\begin{array}{l}\text { Dano de } \\
\text { mócito }\end{array}$ \\
\hline Placebo & $42 / 140$ & $13 / 140$ & $0 / 140$ & $41 / 140$ & $2 / 140$ & $0 / 140$ & $0 / 140$ & $0 / 140$ & $0 / 140$ \\
\hline$(n=7)$ & $(7 / 7)$ & $(6 / 7)$ & $(0 / 7)$ & $(7 / 7)$ & $(1 / 7)$ & $(0 / 7)$ & $(0 / 7)$ & $(0 / 7)$ & $(0 / 7)$ \\
\hline $\begin{array}{l}1 \times 10^{\wedge} 6 \\
\mathrm{pASC} / \mathrm{Kg}\end{array}$ & $42 / 120$ & $24 / 120$ & $0 / 120$ & $37 / 120$ & $23 / 120^{*}$ & $0 / 120$ & $0 / 120$ & $0 / 120$ & $0 / 120$ \\
\hline$(n=6)$ & $(6 / 6)$ & $(6 / 6)$ & $(0 / 6)$ & $(6 / 6)$ & $(6 / 6)$ & $(0 / 6)$ & $(0 / 6)$ & $(0 / 6)$ & $(0 / 6)$ \\
\hline $\begin{array}{c}2 \times 10^{\wedge} 6 \\
\mathrm{pASC} / \mathrm{Kg} \\
(\mathrm{n}=6)\end{array}$ & $\begin{array}{r}44 / 140 \\
(7 / 7)\end{array}$ & $\begin{array}{c}20 / 140 \\
(5 / 7)\end{array}$ & $0 / 140$ & $37 / 140$ & $8 / 140$ & $0 / 140$ & $0 / 140$ & $0 / 140$ & $0 / 140$ \\
\hline $\begin{array}{c}4 \times 10^{\wedge} 6 \\
\mathrm{pASC} / \mathrm{Kg} \\
(n=5)\end{array}$ & $\begin{array}{r}30 / 100 \\
(5 / 5) \\
\end{array}$ & $\begin{array}{r}5 / 100 \\
(3 / 5) \\
\end{array}$ & $0 / 100$ & $23 / 100$ & $8 / 100$ & $0 / 100$ & $0 / 100$ & $0 / 100$ & $0 / 100$ \\
\hline
\end{tabular}

Além disso, as análises de imunohistoquímica das populações de linfócitos CD3 e CD45RA confirmaram que não houve diferença significativa de infiltrados entre os diferentes grupos de animais tratados com células-tronco em ambos, área total de VE (Figura $11 \mathrm{~A}$ e B) ou analisando as áreas isoladamente (remota, borda e IM - Figura 11C e D). 
Resultados

A)

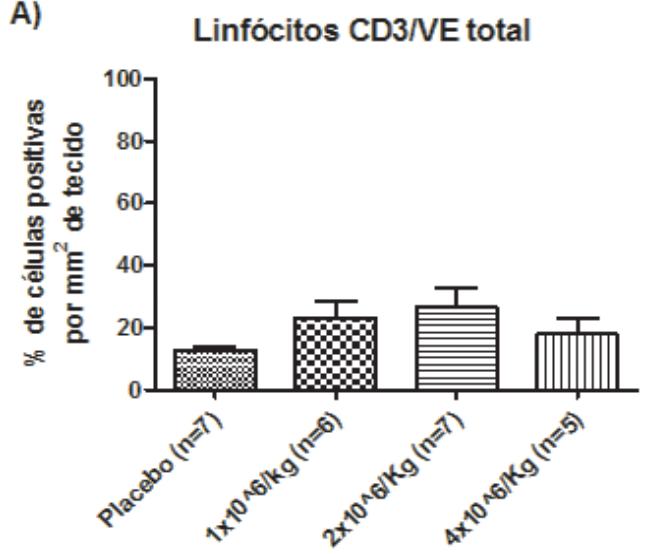

C)

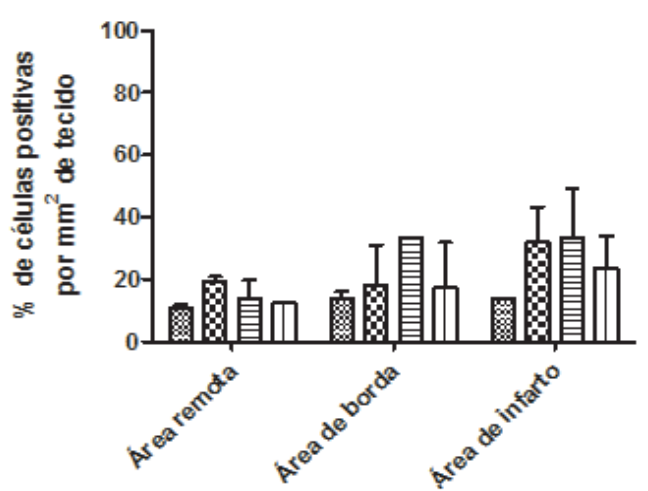

B) Linfócitos CD45RAIVE total

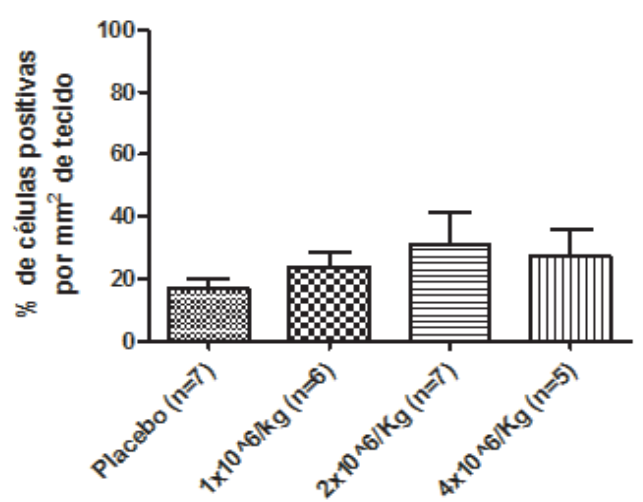

D)

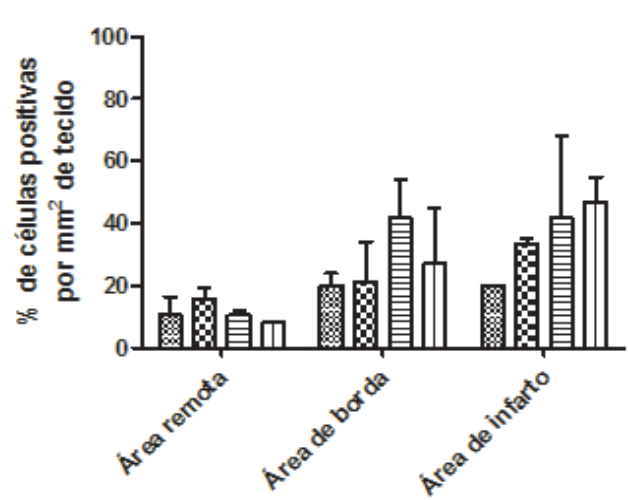

冈 Placebo (n=7) $\mathbf{m} 1 \times 10^{\wedge} 6 / \mathrm{kg}(\mathrm{n}=6)$ 曰 $2 \times 10^{\wedge} 6 / \mathrm{Kg}(\mathrm{n}=7)$ 皿 $4 \times 10^{\wedge} 6 / \mathrm{Kg}(\mathrm{n}=5)$

Figura 11: Análise dos tipos de linfócitos presentes no infiltrado inflamatório presente nas diferentes áreas de tecido cardíaco dos porcos tratados com pASC nas diferentes doses testadas. Avaliação de linfócitos CD3 e CD45RA. (A) Porcentagem de linfócitos CD3 positivos encontrados no VE. (B) Porcentagem de linfócitos CD45RA positivos encontrados no VE. (C) Porcentagem de linfócitos CD3 positivos encontrados por área de VE. (D) Porcentagem de linfócitos CD45RA positivos encontrados por área de VE. Não foram encontradas diferenças estatísticas entre os grupos experimentais testados. 



\section{DISCUSSÃO}



Discussão

Novos ensaios clínicos utilizando células-tronco continuam a ser propostos em cardiologia, a despeito da falta de informações mais detalhadas obtidas a partir de modelos animais de grande porte. Neste trabalho foi estabelecida a dose de células-tronco mesenquimais alogênicas derivadas do tecido adiposo mais eficaz e capaz de induzir melhora da perfusão miocárdica de suínos imunocompetentes, após 30 dias da oclusão permanente de ACX, e tratados diariamente com maleato de enalapril e succinato de metoprolol, e assim mimetizando nestes animais um quadro tipicamente observado na prática clínica. Estes dados demonstraram que o uso de 4 milhões de pASC alogênicas por quilograma de massa corpórea associado com a terapia medicamentosa não induziu a resposta inflamatória celular de rejeição e foi capaz de promover uma melhora da MP, bem como o aumento do número de vasos e uma redução da área de fibrose, atenuando o remodelamento adverso de VE e assim resultando na minimização dos efeitos deletérios do IM nestes animais.

Nas últimas décadas, a terapia celular tem sido testada como uma abordagem inovadora para o tratamento de doenças isquêmicas do coração, como o IM $(13,14,28)$. Embora um grande número de estudos tenha sido desenvolvido, questões importantes como a quantidade de células necessária para que haja efeitos de melhora do coração, e mesmo se o uso de célulastronco pode gerar efeitos aditivos a tratamentos bem estabelecidos, ainda permanecem obscuros. Dados anteriormente publicados por este laboratório demonstraram que apenas uma pequena quantidade de BM-MSC (13) e ASC (14) permanecem no coração de ratos após uma injeção intramiocárdica 
(aproximadamente $7 \%$ e $5 \%$ de células, respectivamente). No entanto, esses percentuais foram 3 a 5 vezes maiores quando as células foram associadas com biopolímeros, resultando em uma melhora da função cardíaca global $(13,14)$. Estes dados demonstram uma estreita relação entre a melhora funcional cardíaca e o número de células retido no VE pós-injeção.

Mesmo com a escassez de estudos de dose-resposta, diversos estudos têm mostrado o mesmo tipo de resultados positivos associados a grandes quantidades de células retidas (15,70-72). Poncelet et al. demonstraram em porcos que a injeção de 1 milhão de células/kg, 2 semanas após IM, foi capaz de aumentar significativamente a densidade capilar no miocárdio viável (70). Enquanto isso, os dados apresentados para nosso grupo 2 (de animais que receberam injeções de $1 \times 10^{\wedge} 6 \mathrm{pASC} / \mathrm{Kg}$ ) não apresentaram melhora significativa dos parâmetros avaliados, entre eles MP e número de vasos. Por outro lado, Quevedo e colaboradores obtiveram maior formação de vasos e uma melhoria do fluxo sanguíneo do miocárdio, em porcos, ao injetar 200 milhões de células 20 semanas após o IM (71). Nossos achados, avaliados pela ECMTR quantitativa e funcional, demonstraram claramente que o efeito da terapia celular sobre a perfusão miocárdica e a formação de vasos estavam diretamente relacionados com a dose de pASC $\left(4 \times 10^{6} \mathrm{cel} / \mathrm{kg}\right)$ injetadas. Estes dados são compatíveis com os dados apresentados por Quevedo et al., reforçando a importância de termos uma grande quantidade de células-tronco retidas no VE.

Avanços significativos têm sido obtidos em estudos pré-clínicos e clínicos usando células-tronco adultas para o tratamento de doenças cardíacas 
Discussão

$(14,15,41,73-76)$. No entanto, muitos estudos pré-clínicos demonstram que a melhoria da função cardíaca pós-tratamento celular está fracamente ligada a transdiferenciação destas células em cardiomiócitos ou células endoteliais $(13,14,77-79)$. Os mecanismos responsáveis pela melhora do coração parecem estar predominantemente ligados à ação parácrina destas células através da liberação de moléculas bioativas essenciais ao contexto do pósinfarto, especialmente no cenário vascular (13-15). Células-tronco adultas são capazes de regular seu perfil de expressão gênica e proteica a diferentes estímulos. Durante a isquemia cardíaca uma série de citocinas vasculares, tais como VEGF, pFGF, IGF-1, PDGF, angiopoietina são necessárias para ativar as vias de reparação vascular (80-83). Apesar de nossas pASCs não terem sido observadas no VE de porcos, 30 dias após a injeção, nossos achados mostraram que a expressão de VEGF aumentou no VE dos animais que receberam a dose mais elevada de células. A quantidade total de vasos também foi aumentada no grupo 4 quando em comparação com os outros grupos. Além disso, a dose mais elevada de células influenciou na melhora funcional do coração, medida através do aumento do fluxo sanguíneo do miocárdio em áreas remotas e de borda do infarto. Em conjunto, esses dados corroboram com a obtenção de efeitos secundários à ação parácrina de pASCs e reforçam a hipótese da angio/vasculogênese. Contudo, avaliações mais detalhadas devem ser realizadas para elucidar as dúvidas sobre o potencial de transdiferenciação de células-tronco adultas no coração.

A oclusão das artérias coronárias pode reduzir ou cessar a perfusão do tecido cardíaco causando isquemia miocárdica. Se o fluxo não for rapidamente 
Discussão

restabelecido, o período de isquemia pode ser seguido da necrose do tecido. Em quadros bem estabelecidos de insuficiência cardíaca, os benefícios terapêuticos da terapia com células-tronco adultas são limitados $(74,84)$. Para evitar a deterioração funcional do VE é essencial que o remodelamento cardíaco adverso seja inibido ou ao menos atenuado (84). Dados prévios publicados por este laboratório mostraram que ratos tratados com célulastronco mesenquimais de medula óssea ou tecido adiposo apresentam um aumento significativo no número de vasos sanguíneos no VE, além de uma atenuação do remodelamento ventricular através de alterações na área de tecido cicatricial (13-15). Em porcos tratados com BM-MSC a melhoria da perfusão e atenuação do remodelamento de VE também parecem estar associadas $(70,71)$.

No presente trabalho foi utilizado um modelo de infarto de artéria fechada em porcos tratados com fármacos clássicos, para assim, testar o efeito aditivo de diferentes doses de pASC sob a melhora da perfusão de VE. A ACX foi ocluída visando gerar uma lesão com repercussões funcionais controladas e relativamente baixas (63). Além da melhora da perfusão miocárdica, nossos dados mostraram que as áreas de lesão do VE foram diminuídas. As avaliações planimétricas realizadas através de imagens de ecocardiograma com microbolhas demonstraram que as áreas não perfundidas do VE, somente nos porcos do grupo $4\left(4 \times 10^{6} \mathrm{cel} / \mathrm{kg}\right)$, foram reduzidas significativamente após 30 dias do transplante de células.

Além da significativa redução das áreas de IM não-perfundidas, os porcos tratados com 4 milhões de células/Kg apresentaram uma área de infarto 
Discussão

significativamente menor e também uma menor redução da espessura da parede afetada pelo IM (parede posterior) quando comparado com os demais grupos. A progressão do IM está relacionada com a substituição de tecido necrótico por fibrose, que pode causar a desorganização da matriz extracelular (ECM) (85). Esta alteração morfológica afeta a função contrátil do VE, alterando a forma elíptica do coração para uma forma esférica, com reflexo sobre o índice de volume sistólico final (86). A prevenção do afinamento de paredes do miocárdio está associada à melhores prognósticos pós-IM $(87,88)$. Dai e colaboradores mostraram que o uso de injeções com solução mista de colágeno (95\% do col. I e $5 \%$ do col. III) diretamente no tecido cicatricial de ratos infartados foram capazes de engrossar a parede lesada, melhorando os índices de volume de ejeção do VE bem como a fração de ejeção. Deste modo, o abaulamento sistólico paradoxal do ventrículo foi prevenido (85).

O implante de uma matriz injetável de alginato absorvíveis (scaffolds) é outra abordagem acelular já testada com sucesso para evitar o afinamento excessivo da parede da cicatriz gerado pelo IM. Landa et al. mostraram num modelo de infarto em ratos que a injeção intra-cicatricial de polímeros de alginato foi capaz de aumentar a espessura da cicatriz, prevenindo o remodelamento adverso e com isso, a disfunção do VE, seja com administrações agudas (7 dias) ou tardias (60 dias) após indução do IM (89). Este tipo de abordagem utilizando matrizes de preenchimento também já foi testada em porcos, através do uso de injeções de alginato via cateter. Dois meses após a injeção de alginato na área de cicatriz, as funções sistólica e diastólica de VE foram melhoradas, bem como a espessura da cicatriz fibrosa, 
Discussão

a qual foi substituída por miofibroblastos e colágeno (90). Este tipo de dado reforça a necessidade de evitar que as paredes atingidas pelo infarto sofram alterações morfológicas excessivas após necrose tecidual.

Em ratos, as injeções de células-tronco mesenquimais derivadas da medula óssea ou do tecido adiposo realizadas nas bordas do IM são capazes de reduzir significativamente a área de IM, atenuar a redução da espessura de parede e alterar a composição do tecido fibroso que compõe a parede afetada de VE $(13,14)$. Apesar de nossos dados não apresentaram diferenças significativas nos valores de colágeno intersticial e também na composição de colágeno na cicatriz, entre os grupos experimentais testados, os animais do grupo 4 mostraram uma quantidade significativa de fibras de colágeno menos maduras (menos espessas e rígidas) compondo a cicatriz da lesão, quando comparados a animais do grupo placebo (grupo 1).

Em 1989, Whittaker e colaboradores propuseram um método inovador para analisar a cicatrização do tecido miocárdico pós-IM, para tanto utilizaram a associação da microscopia de campo claro e a microscopia de luz polarizada (do inglês, PLM), em que os tipos de colágeno poderiam ser medidos com base na cor das fibras de colágeno presente na cicatriz mostrada pelas imagens obtidas através da PLM (91). Alguns anos após, o mesmo grupo identificou que este método era capaz de medir a maturação e organização da matriz de colágeno, mas não os diferentes tipos de fibras de colágeno $(92,93)$. Nestes artigos os autores puderam correlacionar as fibras vermelhas, amarelas e verdes (as cores das fibras colágenas em ordem decrescente de espessura) com a maturação das fibras colágenas. 
Discussão

Considerando-se que nossos porcos injetados com 4 milhões de pASC/Kg não apresentaram diferenças na composição de colágeno da cicatriz (colágeno tipo I e III medidos por imunohistoquímica), foi realizada uma análise da maturação do colágeno na cicatriz dos animais do grupo placebo vs. grupo 4, através de lâminas histológicas coradas com picrossirius red e avaliadas por PLM. Esta análise mostrou que os animais do grupo 4 tiveram uma maturação diferenciada da cicatriz quando comparados com o grupo placebo, sendo a cicatriz daqueles menos madura, ou seja, com maiores quantidades de fibras colágenas finas/menos espessas/verdes.

Dados de proteômica ainda não publicados, deste laboratório, dão suporte às habilidades intrínsecas das ASCs em liberar moléculas bioativas, quando submetidas a diferentes estímulos de isquemia e estiramento, diretamente relacionadas com as vias de maturação de colágeno. A prolil-4hidroxilase $(\mathrm{P} 4 \mathrm{H})$ e seus inibidores, o HIF $(94,95)$ e proteínas de matriz tais como; periostina $(96,97)$, SPARC (98), Osteoglycin (99), entre outras, são proteínas relacionadas com a maturação do colágeno, foram observadas neste estudo e estão sendo estudadas em detalhes. Com base em nossos dados de proteômica e nossos achados em porcos, nos quais, há maior quantidade de fibras de colágeno imaturas (verde) e o menor afinamento de parede nos animais do grupo 4, nossa hipótese é de que as pASCs injetadas na borda do IM, quando em grande quantidade (maior probabilidade de retenção) estão afetando indiretamente a geração de um tecido cicatricial mais elástico, ou seja, menos rígido e portanto capaz de favorecer os movimentos de contração ritmada do coração. Em conjunto, esses dados reforçam a necessidade de 
Discussão

evitar o afinamento da parede dacicatriz para prevenir alterações mecânicas e físicas importantes na estrutura do VE e assim ajudar a reduzir a deterioração da função cardíaca global.

Apesar dos resultados positivos obtidos por nós, questões importantes sobre o uso deste tipo de terapia celular em humanos foram levantadas. Por exemplo, como realizar o isolamento desta grande quantidade de células, e superar as restrições logísticas e econômicas e, principalmente, como utilizar células-tronco autólogas visto que as comorbidades associadas ao histórico de pacientes influenciam diretamente na qualidade das células obtidas. Recentemente Frazier e colaboradores mostraram que o índice de massa corporal afeta a proliferação e a capacidade de diferenciação de hASCs (36). Além disso, Alt et al. e Fosset et al. demonstraram os efeitos negativos da idade para hASC (37) e para as células-tronco mesenquimais derivadas do líquido da membrana sinoviais (38), respectivamente.

Achados indicam que as MSCs derivadas de tecidos adultos apresentam baixa imunogenicidade in vivo em tratamentos alogênicos $(40-42,70,71)$ e são capazes de suprimir a proliferação de linfócitos in vitro $(41,42,44)$. Com base neste conhecimento de imunologia e a necessidade de desenvolver processos que evitem as limitações do uso de células de pacientes, o transplante de células alogênicas pode ter aplicabilidade na prática clínica. Para testar o uso de injeções alogênicas de ASC em porcos, nós previamente, desenvolvemos um "banco de células-tronco mesenquimais de porcos". O banco de pASC foi caracterizado e a viabilidade celular, morfologia, e características de crescimento, genéticas e de plasticidade não foram influenciados pelo 
Discussão

congelamento destas células a longo prazo (ao menos 1 ano) (34). Estes dados deram o suporte necessário para a utilização destas pASCs em uma estratégia alogênica.

Curiosamente, apesar da baixa imunogenicidade e da capacidade imunomoduladora das ASCs, nossos achados mostraram que a menor dose de pASC provocou um aumento da infiltração de linfócitos nas áreas de borda e IM. Altas doses de ASC de passagens baixas (P2-P4) não provocam proliferação de células T em ensaios de reação mista de linfócitos (do inglês, MLR) (43). As MSCs são capazes de suprimir a proliferação de linfócitos in vitro e in vivo de maneira dose-dependente (41). Ademais, Malliaras e colaboradores demonstraram que a injeção de células derivadas de cardiosferas alogênicas, no coração de ratos infartados e imunocompetentes, não gera resposta de rejeição tecidual ou sistêmica (67). Com base nas evidências positivas relacionadas aos benefícios da alta retenção de células em VE pós-injeção (13), e nos dados acima apresentados por diferentes grupos de pesquisa, consideramos que a resposta de rejeição observado no grupo $2\left(1 \times 10^{\wedge} 6 \mathrm{pASC} / \mathrm{Kg}\right)$ se deve a uma resposta de rejeição contra as pASCs, as quais, em baixa quantidade não devem ser capazes de inibir a proliferação de linfócitos T. Assim, a maior quantidade de células testada $\left(4 \times 10^{6} \mathrm{pASC} / \mathrm{Kg}\right)$ deve promover maior retenção de células no VE, de modo que assim elas sejam capazes de inibir a proliferação e infiltração de células inflamatórias no tecido cardíaco. Contudo, essas proposições ainda precisam ser melhor exploradas. 
O presente estudo apresenta algumas limitações técnicas. Em primeiro lugar, embora tenhamos realizado todo o protocolo terapêutico em um modelo de infarto homogêneo e reprodutível, a oclusão da artéria coronária circunflexa esquerda não promoveu um dano expressivo sobre a função do VE. Isso impediu que avaliações da fração de ejeção (FEVE) e encurtamento (FEnVE) do ventrículo esquerdo fossem considerados o endpoint primário deste estudo. Em segundo lugar, os porcos são animais quadrúpedes, portanto a anatomia e posicionamento do coração, no tórax destes animais, são distintas da observada em seres humanos, criando dificuldade técnica para a realização de imagens ecocardiográficas, especialmente em exames sem o uso de contraste por microbolhas.

Essa limitação restringiu-nos o uso de dados funcionais como volume, FEVE e FEnVE, apenas derivadas de medidas lineares, o que reduz a confiabilidade destas variáveis. Será importante em estudos futuros testar novos modelos de IM com maiores repercussões funcionais e métodos mais precisos para avaliar a função cardíaca como, por exemplo, a ecocardiografia transesofágica. Finalmente, o efeito dose-resposta de pASCs não foi completamente esclarecido. O número e o tempo que as células permanecem no VE dos porcos após as injeções precisam ser mais bem compreendidos em estudos futuros; com estas informações e com o aprimoramento de novas ferramentas, por exemplo, a associação às células a biopolímeros, talvez 0 número de células injetadas possa ser reduzido à medida que a retenção destas no VE pode aumentar. 
Discussão

Nas últimas décadas os tratamentos clínicos para doenças isquêmicas do coração têm melhorado significativamente, contudo, um número importante de pacientes ainda necessita de novas e eficientes abordagens para serem totalmente beneficiados. Neste estudo encontramos fortes evidências de que o número de ASC injetado no VE de porcos infartados é essencial para a melhoria da perfusão miocárdica. Nós também mostramos que a dose mais alta de pASCs alogênicas testada não induziu a um aumento na infiltração de células inflamatórias no VE. 

6. Conclusão 

Conclusão

\subsection{Conclusões Sumarizadas}

a) pASCs alogênicas injetadas não foram encontradas no coração dos porcos 30 dias após a injeção;

b) Altas doses de pASCs alogênicas estimulam um aumento na perfusão miocárdica;

c) Altas doses de pASCs alogênicas estimulam o aumento no número de vasos na borda e áreas remotas ao infarto;

d) O uso de altas doses de pASCs alogênicas reduziu a área cicatricial de VE;

e) O uso de altas doses de pASCs alogênicas influenciou na maturação do colágeno que compõe o tecido cicatricial;

f) Altas doses de pASCs alogênicas não provocaram um aumento da resposta inflamatória celular no coração. 
Conclusão

\subsection{Conclusão Final}

O conjunto de resultados apresentado sugere que a terapia com célulastronco adultas alogênicas além de segura, é eficaz e age sobre a melhora funcional do VE por meio da recuperação/prevenção da deterioração da perfusão global do ventrículo influenciando em outros parâmetros estruturais. Ademais, a principal contribuição deste trabalho se baseia no foco translacional visto que os dados apresentados foram obtidos em animais humanizados por tratamento medicamentoso. Deste modo, os dados obtidos comprovam não apenas uma prova de conceito do efeito do transplante celular puramente, mas o efeito aditivo deste ao tratamento medicamentoso clássico. Assim, podemos concluir que o tratamento com células-tronco adultas apresenta efeito aditivo a bem estabelecidos tratamentos para IM. 
7.ANEXOS 



\section{Anexos}

7.1. ANEXO A - Cópia do parecer de aprovação do Comitê de Ética para Análise de projetos de Pesquisa - CAPPesq.

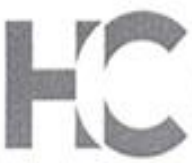

HOSPTHAL DAS CLingas

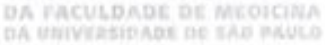

\section{APROVAÇÃO}

A Comissão de Ética para Análise de Projetos de Pesquisa CAppesq da Diretoria Clínica do Hospital das Clínicas e da Faculdade de Medicina da Universidade de São Paulo, em sessão de 04/02/2009. APROVOU O Protocolo de Pesquisa $n^{\circ}$ 0022/09, intitulado: "ESTUDO DO EFEITO dO IMPLANTE CARDÍACO DE FIBROBLASTOS GENETICAMENTE MODIFICADOS PARA EXPRESSAR VEGF EM CORAÇÃO DE SUÍNOS INFARTADOS - AVALIAÇÄO SOBRE A ANGIOGÊNESE E A FUNÇÃO CARDÍACA." apresentado pelo Departamento de COMISSÃO CIENTífICA DO INCOR.

Cabe ao pesquisador elaborar e apresentar à CAPPesq, os relatórios parciais e final sobre a pesquisa (Resolução do Conselho Nacional de Saúde n 196, de 10/10/1996, inciso IX.2, lefra "c").

Pesquisador (a) Responsável: Prof. Dr. José Eduardo Krieger Pesquisador (a) Executante: Rafael Dariolli

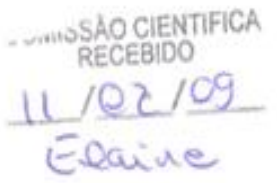

Prof. Dr. Eduardo Massad Presidente da Comissão de Ética para Análise de Projetos de Pesquisa

Comissåo de Ética para Análise de Projetos de Pesquisa do HCFMUSP e da FMUSP Diretoria Clinica do Hosptal das Clinicas da Faculdade de Medicina da Universidade de Sáo Paulo Rua Ovidio Pires de Campos. 225, $5^{\circ}$ andar - CEP 05403010 - Så Paulo - SP Fone: 01130696442 Fax 01130696492 e-mait: cappesq@incnet usp. br / secretariacappesq2@henet usp.br 
7.2. ANEXO B - Cópia do parecer de aprovação para adição de subprojeto no processo 0022/09, pelo Comitê de Ética para Análise de projetos de Pesquisa - CAPPesq.

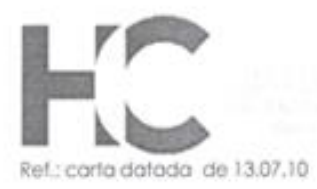

A

Comissão Científica

Incor

O Presidente da Comissão de Ética para Análise

de Projetos de Pesquisa - CAPPesa da Diretoria Clinica do Hospital das Clinicas e da Faculdade de Medicina da Universidade de São Paulo, em 08.09.10, tomou conhecimento que o Protocolo de Pesquisa $n^{\circ} 0022 / 09$, intitulado: "Estudo Do Efeito Do Implante Cardíaco De Fibroblastos Geneticamente Modificados Para Expressar VEGF Em Coração De Suínos Infartados - Avaliação Sobre A Angiogênese E A Funçāo Cardíaca.". contempla o sub-projeto intitulado "Estudo do efeito do implante alogênico de células-tronco mesenquimais derivadas do tecido adiposo em coraçāo de suínos infartados - Avaliação sobre a angiogênese e a função cardíaca", o qual será executado pelo aluno Rafael Dariolli. Bem como a prorrogação da data de término previsto de 08/2010 para 08/2014 e relatório parcial.

CAPPesq, 10 de Setembro de 2010

Prof. Dr. Eduardo Massad Presidente da Comissão

COMISSÃO CIENTIFICA RECEBIDO $\frac{14}{1009} 110$

Comissdo de Ética para Andilise de Projetes de Perquisa do HCFMUSP e da FMUSP oiretoria Clínica do Hospitat das Clinicas da Faculdade de Medicina da Universidade de sao Paulo kua Ovidio Pires de Campes. 225, $5^{\circ}$ andar - CEP 05430010 - Sjo Pavto - 28

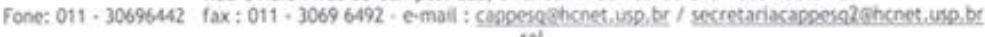




\section{REFERÊNCIAS BIBLIOGRÁFICAS}



Referências Bibliográficas

1. Go AS, Mozaffarian D, Roger VL, Benjamin EJ, Berry JD, Borden WB, et al. Heart disease and stroke statistics--2013 update: a report from the American Heart Association. Circulation. 2013; 127(1):e6-245.

2. Butler D. UN targets top killers. Nature. 2011; 477(7364):260-1.

3. Moran AE, Forouzanfar MH, Roth GA, Mensah GA, Ezzati M, Murray CJL, et al. Temporal trends in ischemic heart disease mortality in 21 world regions, 1980 to 2010: the Global Burden of Disease 2010 study. Circulation. 2014; 129(14):1483-92.

4. Schmidt MI, Duncan BB, Azevedo e Silva G, Menezes AM, Monteiro CA, Barreto $\mathrm{SM}$, et al. Chronic non-communicable diseases in Brazil: burden and current challenges. Lancet. 2011; 377(9781):1949-61.

5. Buja LM, Entman ML. Modes of myocardial cell injury and cell death in ischemic heart disease. Circulation. 1998; 98(14):1355-7.

6. Haunstetter A, Izumo S. Apoptosis: basic mechanisms and implications for cardiovascular disease. Circ Res. 1998; 82(11):1111-29.

7. Alberts B, Johnson A, Lewis J, Raff M, Roberts K, Walter P. Molecular Biology of the Cell. 4th ed. New York: Garland Science; 2002.

8. Fraga AM, Sukoyan M, Rajan P, Braga DP de AF, laconelli A, Franco JG, et al. Establishment of a Brazilian line of human embryonic stem cells in defined medium: implications for cell therapy in an ethnically diverse population. Cell Transplant. 2011; 20(3):431-40.

9. Alison MR, Poulsom R, Forbes S, Wright NA. An introduction to stem cells. $J$ Pathol. 2002; 197(4):419-23.

10. Brehm M, Zeus T, Strauer BE. Stem cells--clinical application and perspectives. Herz. 2002; 27(7):611-20.

11. Zipori D. Mesenchymal stem cells: harnessing cell plasticity to tissue and organ repair. Blood Cells Mol Dis. 2004; 33(3):211-5.

12. Zuk PA, Zhu M, Ashjian P, De Ugarte DA, Huang JI, Mizuno $\mathrm{H}$, et al. Human adipose tissue is a source of multipotent stem cells. Mol Biol Cell. 2002; 13(12):4279-95.

13. Nakamuta JS, Danoviz ME, Marques FLN, dos Santos L, Becker C, Gonçalves $\mathrm{G}$ a, et al. Cell therapy attenuates cardiac dysfunction post myocardial infarction: effect of timing, routes of injection and a fibrin scaffold. PLOS One. 2009; 4(6):e6005.

14. Danoviz ME, Nakamuta JS, Marques FLN, dos Santos L, Alvarenga EC, dos Santos A a, et al. Rat adipose tissue-derived stem cells transplantation attenuates cardiac dysfunction post infarction and biopolymers enhance cell retention. PLoS One. 2010; 5(8):e12077. 
15. Dos Santos L, Santos A a, Gonçalves G, Krieger JE, Tucci PJF. Bone marrow cell therapy prevents infarct expansion and improves border zone remodeling after coronary occlusion in rats. Int $J$ Cardiol. 2010; 145(1):34-9.

16. Dudas JR, Marra KG, Cooper GM, Penascino VM, Mooney MP, Jiang S, et al. The osteogenic potential of adipose-derived stem cells for the repair of rabbit calvarial defects. Ann Plast Surg. 2006; 56(5):543-8.

17. Farrell E, Both SK, Odörfer KI, Koevoet W, Kops N, O'Brien FJ, et al. In-vivo generation of bone via endochondral ossification by in-vitro chondrogenic priming of adult human and rat mesenchymal stem cells. BMC Musculoskelet Disord. 2011; $12: 31$.

18. Colter DC, Class R, DiGirolamo CM, Prockop DJ. Rapid expansion of recycling stem cells in cultures of plastic-adherent cells from human bone marrow. PNAS. 2000; 97(7):3213-8.

19. Kudo M, Wang Y, Wani MA, Xu M, Ayub A, Ashraf M. Implantation of bone marrow stem cells reduces the infarction and fibrosis in ischemic mouse heart. $J$ Mol Cell Cardiol. 2003; 35(9):1113-9.

20. Bassaneze V, Barauna VG, Lavini-Ramos C, Kalil J, Schettert IT, Miyakawa AA, et al. Shear stress induces nitric oxide-mediated vascular endothelial growth factor production in human adipose tissue mesenchymal stem cells. Stem Cells Dev. 2010; 19(3):371-8.

21. Danoviz ME, Bassaneze V, Nakamuta JS, dos Santos-Junior GR, Saint-Clair D, Bajgelman MC, et al. Adipose tissue-derived stem cells from humans and mice differ in proliferative capacity and genome stability in long-term cultures. Stem Cells Dev. 2011; 20(4):661-70.

22. Blande IS, Bassaneze V, Lavini-Ramos C, Fae KC, Kalil J, Miyakawa AA, et al. Adipose tissue mesenchymal stem cell expansion in animal serum-free medium supplemented with autologous human platelet lysate. Transfusion. 2009; 49(12):2680-5.

23. Fraser JK, Schreiber RE, Zuk PA, Hedrick MH. Adult stem cell therapy for the heart. Int J Biochem Cell Biol. 2004; 36(4):658-66.

24. Reyes M, Lund T, Lenvik T, Aguiar D, Koodie L, Verfaillie CM. Purification and ex vivo expansion of postnatal human marrow mesodermal progenitor cells. Blood. 2001; 98(9):2615-25.

25. Reyes M, Verfaillie CM. Characterization of multipotent adult progenitor cells, a subpopulation of mesenchymal stem cells. Ann N Y Acad Sci. 2001; 938:231-3; discussion 233-5.

26. Rickard DJ, Kassem M, Hefferan TE, Sarkar G, Spelsberg TC, Riggs BL. Isolation and characterization of osteoblast precursor cells from human bone marrow. J Bone Miner Res. 1996; 11(3):312-24. 
Referências Bibliográficas

27. Morel F, Szilvassy SJ, Travis M, Chen B, Galy A. Primitive hematopoietic cells in murine bone marrow express the CD34 antigen. Blood. 1996; 88(10):3774-84.

28. Orlic D, Kajstura J, Chimenti S, Jakoniuk I, Anderson SM, Li B, et al. Bone marrow cells regenerate infarcted myocardium. Nature. 2001; 410(6829):701-5.

29. Krampera M, Glennie S, Dyson J, Scott D, Laylor R, Simpson E, et al. Bone marrow mesenchymal stem cells inhibit the response of naive and memory antigen-specific T cells to their cognate peptide. Blood. 2003; 101(9):3722-9.

30. Murry CE, Soonpaa MH, Reinecke H, Nakajima H, Nakajima HO, Rubart M, et al. Haematopoietic stem cells do not transdifferentiate into cardiac myocytes in myocardial infarcts. Nature. 2004; 428(6983):664-8.

31. Anversa P, Sussman MA, Bolli R. Molecular genetic advances in cardiovascular medicine: focus on the myocyte. Circulation. 2004; 109(23):2832-8.

32. Zuk P a, Zhu M, Mizuno H, Huang J, Futrell JW, Katz a J, et al. Multilineage cells from human adipose tissue: implications for cell-based therapies. Tissue Eng. $2001 ; 7(2): 211-28$.

33. Tholpady SS, Katz AJ, Ogle RC. Mesenchymal stem cells from rat visceral fat exhibit multipotential differentiation in vitro. Anat Rec A Discov Mol Cell Evol Biol. 2003; 272(1):398-402.

34. Dariolli R, Bassaneze V, Nakamuta JS, Omae SV, Campos LCG, Krieger JE. Porcine Adipose Tissue-Derived Mesenchymal Stem Cells Retain Their Proliferative Characteristics, Senescence, Karyotype and Plasticity after LongTerm Cryopreservation. PLoS One. 2013; 8(7):e67939.

35. Lee RH, Kim B, Choi I, Kim H, Choi HS, Suh K, et al. Characterization and expression analysis of mesenchymal stem cells from human bone marrow and adipose tissue. Cell Physiol Biochem. 2004; 14(4-6):311-24.

36. Frazier TP, Gimble JM, Devay JW, Tucker H a, Chiu ES, Rowan BG. Body mass index affects proliferation and osteogenic differentiation of human subcutaneous adipose tissue-derived stem cells. BMC Cell Biol. 2013; 14(1):34.

37. Alt EU, Senst C, Murthy SN, Slakey DP, Dupin CL, Chaffin AE, et al. Aging alters tissue resident mesenchymal stem cell properties. Stem Cell Res. 2012; $8(2): 215-25$.

38. Fossett E, Khan WS, Longo UG, Smitham PJ. Effect of age and gender on cell proliferation and cell surface characterization of synovial fat pad derived mesenchymal stem cells. J Orthop Res. 2012; 30(7):1013-8.

39. Tse WT, Pendleton JD, Beyer WM, Egalka MC, Guinan EC. Suppression of allogeneic T-cell proliferation by human marrow stromal cells: implications in transplantation. Transplantation. 2003; 75(3):389-97.

40. Poh K-K, Sperry E, Young RG, Freyman T, Barringhaus KG, Thompson CA. Repeated direct endomyocardial transplantation of allogeneic mesenchymal 
stem cells: safety of a high dose, "off-the-shelf", cellular cardiomyoplasty strategy. Int J Cardiol. 2007; 117(3):360-4.

41. Bartholomew A, Sturgeon C, Siatskas M, Ferrer K, Mclntosh K, Patil S, et al. Mesenchymal stem cells suppress lymphocyte proliferation in vitro and prolong skin graft survival in vivo. Exp Hematol. 2002; 30(1):42-8.

42. Mclntosh KR, Lopez MJ, Borneman JN, Spencer ND, Anderson P a, Gimble JM. Immunogenicity of allogeneic adipose-derived stem cells in a rat spinal fusion model. Tissue Eng Part A. 2009; 15(9):2677-86.

43. Mclntosh K, Zvonic S, Garrett S, Mitchell JB, Floyd ZE, Hammill L, et al. The immunogenicity of human adipose-derived cells: temporal changes in vitro. Stem Cells. 2006; 24(5):1246-53.

44. Puissant B, Barreau C, Bourin P, Clavel C, Corre J, Bousquet C, et al. Immunomodulatory effect of human adipose tissue-derived adult stem cells: comparison with bone marrow mesenchymal stem cells. Br J Haematol. 2005; 129(1):118-29.

45. Di Nicola M, Carlo-Stella C, Magni M, Milanesi M, Longoni PD, Matteucci $P$, et al. Human bone marrow stromal cells suppress T-lymphocyte proliferation induced by cellular or nonspecific mitogenic stimuli. Blood. 2002; 99(10):383843.

46. Liu J, Lu XF, Wan L, Li YP, Li SF, Zeng LY, et al. Suppression of human peripheral blood lymphocyte proliferation by immortalized mesenchymal stem cells derived from bone marrow of Banna Minipig inbred-line. Transplant Proc. 2004; 36(10):3272-5.

47. Lee JE, Kim I, Kim M. Adipogenic differentiation of human adipose tissuederived stem cells obtained from cryopreserved adipose aspirates. Dermatol Surg. 2010; 36(7):1078-83.

48. Martinello T, Bronzini I, Maccatrozzo L, Mollo a, Sampaolesi M, Mascarello F, et al. Canine adipose-derived-mesenchymal stem cells do not lose stem features after a long-term cryopreservation. Res Vet Sci. 2011; 91(1):18-24.

49. Ock S-A, Rho G-J. Effect of dimethyl sulfoxide (DMSO) on cryopreservation of porcine mesenchymal stem cells (pMSCs). Cell Transplant. 2011; 20(8):1231-9.

50. Thirumala S, Gimble JM, Devireddy R V. Evaluation of methylcellulose and dimethyl sulfoxide as the cryoprotectants in a serum-free freezing media for cryopreservation of adipose-derived adult stem cells. Stem Cells Dev. 2010; 19(4):513-22.

51. Nauta AJ, Fibbe WE. Immunomodulatory properties of mesenchymal stromal cells. Blood. 2007; 110(10):3499-506.

52. Hughes GC, Post MJ, Simons M, Annex BH. Translational physiology: porcine models of human coronary artery disease: implications for preclinical trials of therapeutic angiogenesis. J Appl Physiol. 2003; 94(5):1689-701. 
Referências Bibliográficas

53. Maxwell MP, Hearse DJ, Yellon DM. Species variation in the coronary collateral circulation during regional myocardial ischaemia: a critical determinant of the rate of evolution and extent of myocardial infarction. Cardiovasc Res. 1987; 21(10):737-46.

54. Hearse DJ. Species variation in the coronary collateral circulation during regional myocardial ischaemia: a critical determinant of the rate of evolution and extent of myocardial infarction. Cardiovasc Res. 2000; 45(1):213-9.

55. Schaper W, Jageneau A, Xhonneux R. The development of collateral circulation in the pig and dog heart. Cardiologia. 1967; 51(6):321-35.

56. Swindle MM, Horneffer PJ, Gardner TJ, Gott VL, Hall TS, Stuart RS, et al. Anatomic and anesthetic considerations in experimental cardiopulmonary surgery in swine. Lab Anim Sci. 1986; 36(4):357-61.

57. Unger EF. Experimental evaluation of coronary collateral development. Cardiovasc Res. 2001; 49(3):497-506.

58. Depre C, Vatner SF. Mechanisms of cell survival in myocardial hibernation. Trends Cardiovasc Med. 2005; 15(3):101-10.

59. Hughes GC, Landolfo CK, Yin B, DeGrado TR, Coleman RE, Landolfo KP, et al. Is chronically dysfunctional yet viable myocardium distal to a severe coronary stenosis hypoperfused? Ann Thorac Surg. 2001; 72(1):163-8.

60. Hughes HC. Swine in cardiovascular research. Lab Anim Sci. 1986; 36(4):34850 .

61. Abdel-Aleem S, St Louis JD, Hughes GC, Lowe JE. Metabolic changes in the normal and hypoxic neonatal myocardium. Ann N Y Acad Sci. 1999; 874:25461.

62. Kilkenny C, Browne WJ, Cuthill IC, Emerson M, Altman DG. Improving bioscience research reporting: the ARRIVE guidelines for reporting animal research. PLoS Biol. 2010; 8(6):e1000412.

63. Dariolli R, Takimura CK, Campos C a, Lemos P a, Krieger JE. Development of a closed-artery catheter-based myocardial infarction in pigs using sponge and lidocaine hydrochloride infusion to prevent irreversible ventricular fibrillation. Physiol Rep. 2014; 2(8):1-11.

64. Lang RM, Bierig M, Devereux RB, Flachskampf F a, Foster E, Pellikka P a, et al. Recommendations for chamber quantification: a report from the American Society of Echocardiography's Guidelines and Standards Committee and the Chamber Quantification Writing Group, developed in conjunction with the European Association of Echocardiograph. J Am Soc Echocardiogr. 2005; 18(12):1440-63.

65. Jeetley P, Burden L, Greaves K, Senior R. Prognostic value of myocardial contrast echocardiography in patients presenting to hospital with acute chest pain and negative troponin. Am J Cardiol. 2007; 99(10):1369-73. 
66. Schneider CA, Rasband WS, Eliceiri KW. NIH Image to ImageJ: 25 years of image analysis. Nat Methods. 2012; 9(7):671-5.

67. Malliaras K, Li T-S, Luthringer D, Terrovitis J, Cheng K, Chakravarty T, et al. Safety and efficacy of allogeneic cell therapy in infarcted rats transplanted with mismatched cardiosphere-derived cells. Circulation. 2012; 125(1):100-12.

68. Stewart S, Winters GL, Fishbein MC, Tazelaar HD, Kobashigawa J, Abrams J, et al. Revision of the 1990 working formulation for the standardization of nomenclature in the diagnosis of heart rejection. J Heart Lung Transplant. 2005; 24(11):1710-20.

69. Langen M, Peters U, Körner U, Gissel C, Stanislawski D, Klein G. Semiquantitative detection of male pork tissue in meat and meat products by PCR. MESC. 2010; 86(3):821-4.

70. Poncelet AJ, Hiel A-L, Vercruysse J, Hermans D, Zech F, Gianello P. Intracardiac allogeneic mesenchymal stem cell transplantation elicits neoangiogenesis in a fully immunocompetent ischaemic swine model. Eur $J$ Cardiothorac Surg. 2010; 38(6):781-7.

71. Quevedo HC, Hatzistergos KE, Oskouei BN, Feigenbaum GS, Rodriguez JE, Valdes $D$, et al. Allogeneic mesenchymal stem cells restore cardiac function in chronic ischemic cardiomyopathy via trilineage differentiating capacity. PNAS. 2009; 106(33):14022-7.

72. Makkar RR, Smith RR, Cheng K, Malliaras K, Thomson LEJ, Berman D, et al. Intracoronary cardiosphere-derived cells for heart regeneration after myocardial infarction (CADUCEUS): a prospective, randomised phase 1 trial. Lancet. 2012; 379(9819):895-904.

73. Amado LC, Saliaris AP, Schuleri KH, St John M, Xie J-S, Cattaneo S, et al. Cardiac repair with intramyocardial injection of allogeneic mesenchymal stem cells after myocardial infarction. PNAS. 2005; 102(32):11474-9.

74. De Oliveira SA, Gowdak LHW, Buckberg G, Krieger JE. Cell biology, MRI and geometry: insight into a microscopic/macroscopic marriage. Eur J Cardiothorac Surg. 2006; 29 Suppl 1:S259-65.

75. Gowdak LHW, Schettert IT, Baptista E, Lopes NLG, Rochitte CE, Vieira MLC, et al. Intramyocardial injection of autologous bone marrow cells as an adjunctive therapy to incomplete myocardial revascularization--safety issues. Clinics. 2008; 63(2):207-14.

76. Gowdak LHW, Schettert IT, Rochitte CE, Lisboa LAF, Dallan LAO, César LAM, et al. Early increase in myocardial perfusion after stem cell therapy in patients undergoing incomplete coronary artery bypass surgery. J Cardiovasc Transl Res. 2011; 4(1):106-13.

77. Chen D, McKearin D. Gene circuitry controlling a stem cell niche. Curr Biol. 2005; 15(2):179-84. 
Referências Bibliográficas

78. Kinnaird T, Stabile E, Burnett MS, Lee CW, Barr S, Fuchs S, et al. Marrowderived stromal cells express genes encoding a broad spectrum of arteriogenic cytokines and promote in vitro and in vivo arteriogenesis through paracrine mechanisms. Circ Res. 2004; 94(5):678-85.

79. Wollert KC, Drexler H. Clinical applications of stem cells for the heart. Circ Res. 2005; 96(2):151-63.

80. Dobrucki LW, Tsutsumi Y, Kalinowski L, Dean J, Gavin M, Sen S, et al. Analysis of angiogenesis induced by local IGF-1 expression after myocardial infarction using microSPECT-CT imaging. J Mol Cell Cardiol. 2010; 48(6):1071-9.

81. Katayama Y, Takaji K, Shao Z-Q, Matsukawa M, Kunitomo R, Hagiwara S, et al. The value of angiogenic therapy with intramyocardial administration of basic fibroblast growth factor to treat severe coronary artery disease. Ann Thorac Cardiovasc Surg. 2010; 16(3):174-80.

82. Regieli JJ, Jukema JW, Nathoe HM, Zwinderman AH, Ng S, Grobbee DE, et al. Coronary collaterals improve prognosis in patients with ischemic heart disease. Int J Cardiol. 2009; 132(2):257-62.

83. Tao Z, Chen B, Tan X, Zhao Y, Wang L, Zhu T, et al. Coexpression of VEGF and angiopoietin-1 promotes angiogenesis and cardiomyocyte proliferation reduces apoptosis in porcine myocardial infarction (MI) heart. PNAS. 2011; 108(5):2064-9.

84. Mummery CL, Davis RP, Krieger JE. Challenges in using stem cells for cardiac repair. Sci Trans/ Med. 2010; 2(27):27ps17.

85. Dai W, Wold LE, Dow JS, Kloner RA. Thickening of the infarcted wall by collagen injection improves left ventricular function in rats: a novel approach to preserve cardiac function after myocardial infarction. J Am Coll Cardiol. 2005; 46(4):714-9.

86. White HD, Norris RM, Brown MA, Brandt PW, Whitlock RM, Wild CJ. Left ventricular end-systolic volume as the major determinant of survival after recovery from myocardial infarction. Circulation. 1987; 76(1):44-51.

87. Verma A, Meris A, Skali H, Ghali JK, Arnold JMO, Bourgoun M, et al. Prognostic implications of left ventricular mass and geometry following myocardial infarction: the VALIANT (VALsartan In Acute myocardial iNfarcTion) Echocardiographic Study. JACC Cardiovasc Imaging. 2008; 1(5):582-91.

88. Castelló Brescane R. The Prognostic Significance of Left Ventricular Geometry: Fantasy or Reality? Rev Española Cardiol. 2009; 62(3):235-8.

89. Landa N, Miller L, Feinberg MS, Holbova R, Shachar M, Freeman I, et al. Effect of injectable alginate implant on cardiac remodeling and function after recent and old infarcts in rat. Circulation. 2008; 117(11):1388-96. 
90. Leor J, Tuvia S, Guetta V, Manczur F, Castel D, Willenz U, et al. Intracoronary injection of in situ forming alginate hydrogel reverses left ventricular remodeling after myocardial infarction in Swine. J Am Coll Cardiol. 2009; 54(11):1014-23.

91. Whittaker $\mathrm{P}$, Boughner DR, Kloner RA. Analysis of healing after myocardial infarction using polarized light microscopy. Am J Pathol. 1989; 134(4):879-93.

92. Whittaker P, Kloner RA, Boughner DR, Pickering JG. Quantitative assessment of myocardial collagen with picrosirius red staining and circularly polarized light. Basic Res Cardiol. 1994; 89(5):397-410.

93. Rich L, Whittaker P. Collagen and Picrosirius Red Staining: A Polarized Light Assessment of Fibrillar Hue And Spatial Distribution. Braz J morphol Sci. 2005; 22(2):97-104.

94. Philipp S, Jürgensen JS, Fielitz J, Bernhardt WM, Weidemann A, Schiche A, et al. Stabilization of hypoxia inducible factor rather than modulation of collagen metabolism improves cardiac function after acute myocardial infarction in rats. Eur J Heart Fail. 2006; 8(4):347-54.

95. Fielitz J, Philipp S, Herda LR, Schuch E, Pilz B, Schubert C, et al. Inhibition of prolyl 4-hydroxylase prevents left ventricular remodelling in rats with thoracic aortic banding. Eur J Heart Fail. 2007; 9(4):336-42.

96. Norris RA, Damon B, Mironov V, Kasyanov V, Ramamurthi A, MorenoRodriguez $R$, et al. Periostin regulates collagen fibrillogenesis and the biomechanical properties of connective tissues. J Cell Biochem. 2007; 101(3):695-711.

97. Norris RA, Potts JD, Yost MJ, Junor L, Brooks T, Tan H, et al. Periostin promotes a fibroblastic lineage pathway in atrioventricular valve progenitor cells. Dev Dyn. 2009; 238(5):1052-63.

98. Schellings MWM, Vanhoutte D, Swinnen M, Cleutjens JP, Debets J, van Leeuwen REW, et al. Absence of SPARC results in increased cardiac rupture and dysfunction after acute myocardial infarction. J Exp Med. 2009; 206(1):11323.

99. Van Aelst LN, Voss S, Carai P, van Leeuwen R, Vanhoutte D, Sanders-van Wijk $\mathrm{S}$, et al. Osteoglycin Prevents Cardiac Dilatation and Dysfunction After Myocardial Infarction Through Infarct Collagen Strengthening. Circ Res. 2014; 116(3):425-36. 
APÊNDICES 



\section{Apêndice A}

Modelos de Infarto em Porcos 

Apêndice A

\section{Introdução}

\section{Modelos de infarto do miocárdio em porcos}

Os modelos animais adequados ao estudo das doenças cardiovasculares, especialmente os que mimetizam a estrutura e a função cardiovascular do homem, são de suma importância para compreender melhor os efeitos de novas estratégias para a reparação do miocárdio (1). Neste contexto, inúmeros modelos experimentais de infarto do miocárdio que podem ser gerados por diferentes técnicas têm sido propostos (2-10). Assim como os classicamente estabelecidos modelos em roedores $(11,12)$ alguns modelos de grande porte se baseiam em técnicas cirúrgicas, onde há a abertura do tórax para que haja a oclusão da artéria coronária (2-4). No entanto, em porcos, este tipo de modelo impõe uma série de complicações cirúrgicas capazes de aumentar significativamente a mortalidade, reduzindo a eficiência na geração do modelo. Para evitar esse tipo de complicação, consequente das técnicas extremamente invasivas, modelos mais recentes têm utilizados metodologias baseadas em técnicas percutâneas hemodinâmicas baseadas no uso de cateteres.

Grande parte dos modelos percutâneos utilizados atualmente se baseia em técnicas de indução de lesão miocárdica através de isquemia transitória (isquemia/reperfusão) (9,13-15), na qual o vaso sanguíneo é obstruído apenas por determinado tempo. No entanto, este tipo de modelo, além de não representar exatamente a fisiopatologia observada em seres humanos, também é um modelo que não favorece o estudo de estratégias, como as 
Apêndice A

terapias com células-tronco adultas. Nestas aplicações terapêuticas vislumbrase agir sobre a perfusão cardíaca e sobre a regeneração do músculo perdido. Quando a artéria coronária é recanalizada, o fluxo sanguíneo é reestabelecido nos tecidos antes com déficit de oxigênio e nutriente, de modo que toda a resposta fisiopatológica da doença é alterada. Além disso, a maioria dos modelos de infarto em grandes animais tem como alvo a oclusão da artéria coronária descendente anterior (DA) que comumente gera modelos com grande repercussão funcional (7) e com isso gerando casos de difícil reversão de quadro.

Nos últimos anos, visando mimetizar o tipo de obstrução coronária mais comumente observado em pacientes que chegam ao pronto socorro, novos modelos de oclusão total da artéria coronária, por via não cirúrgica, tem apresentado bons resultados $(5-8,10)$. Contudo, estes modelos, em sua maioria, se utilizam de materiais caros e/ou de difícil acesso e manipulação, tornando-os modelos de baixa reprodutibilidade $(5-8,10)$.

Com objetivo de melhorar a viabilidade e homogeneidade de modelos percutâneos, Reffelmann e colegas descreveram um modelo de infarto em porco, barato, de fácil manipulação e de alta reprodutibilidade, utilizando próteses de poliuretano confeccionadas a partir de esponjas de limpeza caseiras (16). Através de uso de técnicas percutâneas, com auxilio de cateteres, pequenos pedaços de esponja foram posicionados no terço distal da artéria coronária circunflexa esquerda $(\mathrm{ACX})$ de porcos. Este tipo de oclusão gerou uma lesão de baixa repercussão funcional, sobre a parede posterior do ventrículo esquerdo (VE) (16). A despeito de este modelo gerar uma lesão 
Apêndice A

pouco expressiva, os índices de mortalidade neste estudo foram superiores a $50 \%$ em 7 dias de seguimento, uma alta mortalidade associada essencialmente a episódios de arritmias seguidas de fibrilação ventricular irreversível (FVI), o que torna este um modelo de baixa aplicabilidade, ao menos conforme proposto pelos autores (16). 
Apêndice A

\section{Objetivo}

Desenvolver um modelo translacional de infarto do miocárdio de artéria fechada em porcos para uso em desenvolvimento de protocolos pré-clínicos de terapias alternativas como o uso de células-tronco.

\section{Objetivos específicos}

a) Desenvolver o modelo de infarto crônico por implante de ameróides constritores;

b) Desenvolver o modelo de infarto agudo por implante de prótese de poliuretano;

c) Caracterizar, pré-morte, os modelos de infarto do miocárdio;

d) Caracterizar histopatologicamente os modelos de infarto do miocárdio;

e) Desenvolver técnica de injeção diretamente no miocárdio baseadas no mapeamento elétrico epicárdico associado ao mapeamento ecocardiográfico da lesão. 
Apêndice $A$

\section{Materiais e Métodos}

Todos os experimentos foram conduzidos de acordo com protocolo aprovado pela Comissão de Ética em pesquisa - CAPPesq (protocolo número \#022/09). O cuidado animal foi cumprido com base na diretriz ARRIVAL (do inglês: Animals in Research: Reporting In Vivo Experiments) (17). Trinta e quatro porcos fêmea (Sus scrofa domestica, linhagem MS60 EMBRAPA - peso, 15 a $20 \mathrm{~kg}$ ) foram mantidas em uma Granja comercial para suínos (Granja RG, Suzano-SP, Brasil) com acesso livre à água e comida durante o período de protocolo. Para aclimatização os animais foram trazidos para a Divisão de Experimentação do Instituto do Coração - InCor, pelo menos 24 horas antes do início dos procedimentos.

Os animais foram submetidos a jejum de água e comida por um período de 12-16 horas antes do início dos procedimentos. Estes animais foram então sedados com uma combinação de ketamina ( $8 \mathrm{mg} / \mathrm{kg}$, Vetbrands) e cloridrato de midazolam (0,5 mg/kg, Roche) por via intramuscular. Após 10 a 20 minutos, uma cânula foi introduzida em uma das veias superficiais da orelha pela qual a anestesia foi induzida com tiopental de sódio (12,5 mg / kg; Cristália). Em seguida, os animais foram submetidos à entubação orotraqueal (cânulas de 7$7,5 \mathrm{~mm}$ - Chilecom). A anestesia foi mantida com isoflurano $(1,5 \%-2,5 \%$, Baxter - em 100\% de ventilação de oxigênio) em equipamento ventilador compatível com uso de anestésicos (Origami Ergo System - Takaoka). Antes do procedimento, os porcos receberam uma injeção intramuscular de 1,2 milhões de unidades de penicilina (Eurofarma) para evitar infecções. Após o procedimento, os animais foram tratados com dipirona sódica por via 
Apêndice A

intramuscular (1000mg, 4 vezes, 2 doses diárias - Sanofi Aventis) para minimizar a dor.

Os animais que sobreviveram ao período completo do estudo (30 dias) foram submetidos à angioplastia coronária diagnóstica e ecocardiografia transtorácica (que serão detalhados a frente), e, em seguida, foram sacrificados com uma overdose de cloreto de potássio (30-40 mL de solução de $19,1 \%$, Isofarma) administrada por via intravenosa e sob anestesia profunda de tiopental sódico.

\section{Desenho experimental}

Para que fosse possível o desenvolvimento do protocolo de terapia de células-tronco em porcos infartados (que será apresentado no capítulo 2 desta tese) foi necessário o estudo e desenvolvimento de um modelo de infarto adequado ao desenho experimental proposto. Do ponto de vista clínico, paciente que, por exemplo, apresentam angina pectoris são os menos beneficiados pelas praticas clinicas, cirúrgicas e intervencionistas atuais. Frequentemente nestes pacientes, a fração de ejeção não é um bom marcador para medição do acometimento cardíaco sofrido, visto que em sua maioria não há deterioração importante deste parâmetro, contudo estes pacientes são acometidos por um quadro crônico de isquemia do miocárdio.

Deste modo, inicialmente, o modelo de constrição por ameróides constritores (AMC) (18-20), descrito como capaz de mimetizar uma isquemia crônica foi testado em 7 animais dos quais 4 deles foram tratados com cloridrato de lidocaína como antiarrítmico, durante todo o procedimento e outros 3 animais que não foram tratados preventivamente contra arritmias. 
Apêndice A

Em um segundo momento, um modelo de infarto do miocárdio baseado no uso de cateteres foi desenvolvido. Este estudo também teve um grupo de animais não submetido a tratamento preventivo contra arritmias cardíacas (3 animais) e um grupo maior de animais (21 porcos) que foram submetidos ao tratamento com o cloridrato de lidocaína e então submetidos aos procedimentos de oclusão coronária via cateter que serão melhor detalhados algumas seções a diante.

\section{Procedimentos de cardioversão e uso de antiarrítmicos}

Para prevenir a ocorrência de episódios de arritmias ventriculares malignas durante a oclusão da artéria coronária, uma infusão intravenosa contínua de cloridrato de lidocaína (1 mg/kg/hora) (Cristália) ou cloridrato de amiodarona (1 a $1,5 \mathrm{mg} / \mathrm{kg} / \mathrm{hora}$ ) (Sanofi-Aventis), foi administrada previamente , e durante pelo menos 3 horas após o procedimento de indução do infarto do miocárdio. Nos casos onde episódios de arritmia ventricular ocorreram durante os procedimentos, bolus adicionais de cloridrato de lidocaína $(2,5$ a 12 mg / kg) ou o cloridrato de amiodarona $(1,0$ a $3 \mathrm{mg} / \mathrm{kg})$ foram administrados imediatamente, conforme necessário. Quando os métodos preventivos foram vencidos e houve constatação de fibrilação ventricular instalada e não revertida, desfibrilação elétrica foi realizada aplicando 200-300 J (Desfibrilador Codemaster XL - Hewlett Packard), com as pás do equipamento pressionadas contra a parede anterior do tórax. O uso do desfibrilador foi seguido pela realização de massagem cardíaca manual através da compressão cardíaca ritmada. A fibrilação foi considerada irreversível se o episódio excedeu 30 minutos sendo irreversível até esse período. 
Modelo de isquemia crônica por implante de ameróides constritores

Para a realização deste modelo de infarto crônico foram utilizados ameróides constritores de $1,75 \mathrm{~mm}$ de diâmetro luminal (Figura 1), o anel externo composto de titânio e o anel interno composto de caseína.

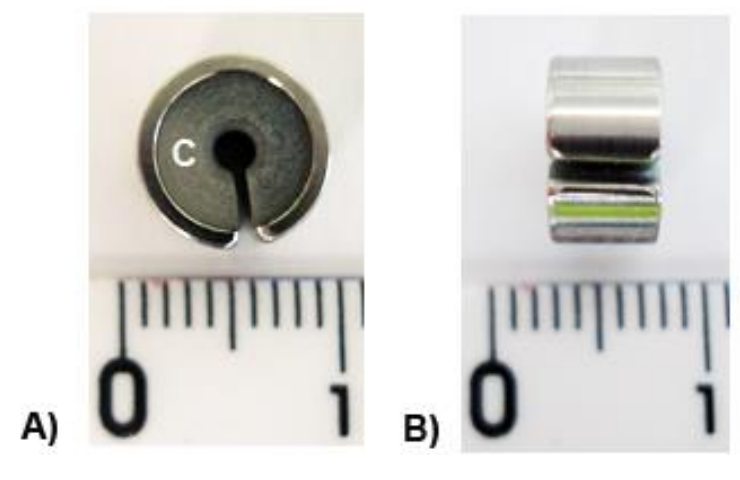

Figura 12: Ameróides constritores de titânio e caseína. A) Secção transversal, B) secção longitudinal. C: anel de caseína.

Os ameróides foram implantados cirurgicamente na região proximal de ACX. Os animais foram posicionados em decúbito lateral (Figura 2A), onde uma toracotomia lateral esquerda foi realizada (quarto espaço intercostal). A pele e músculos foram dissecados até a visualização do pericárdio (Figura 2B). Este foi cortado e amarrado para posterior sutura. O coração foi então levemente escorado com ajuda de uma compressa estéril para que sua porção posterior ficasse acessível. Próximo à base de inserção esquerda do átrio esquerdo, foi visualizada a porção proximal de ACX (Figura 2C). Com auxilio de tesouras delicadas, pinças delicadas e cotonetes a ACX foi dissecada até que uma área compatível com o tamanho do ameróides estivesse livre. A artéria foi isolada com fios de algodão 2.0 (Figura 2D). O ameróides foi posicionado sobre ACX (Figura 2E). O pericárdio foi suturado parcialmente para reduzir as aderências do ventrículo sobre as paredes internas do tórax. As camadas de músculos foram suturadas em planos e a pele foi suturada (Figura 
Apêndice A

2F). Trinta dias após a colocação do ameróides os animais foram submetidos à angiografia e sacrificados para avaliação da extensão da lesão através da coloração por cloreto de tetrazólio.
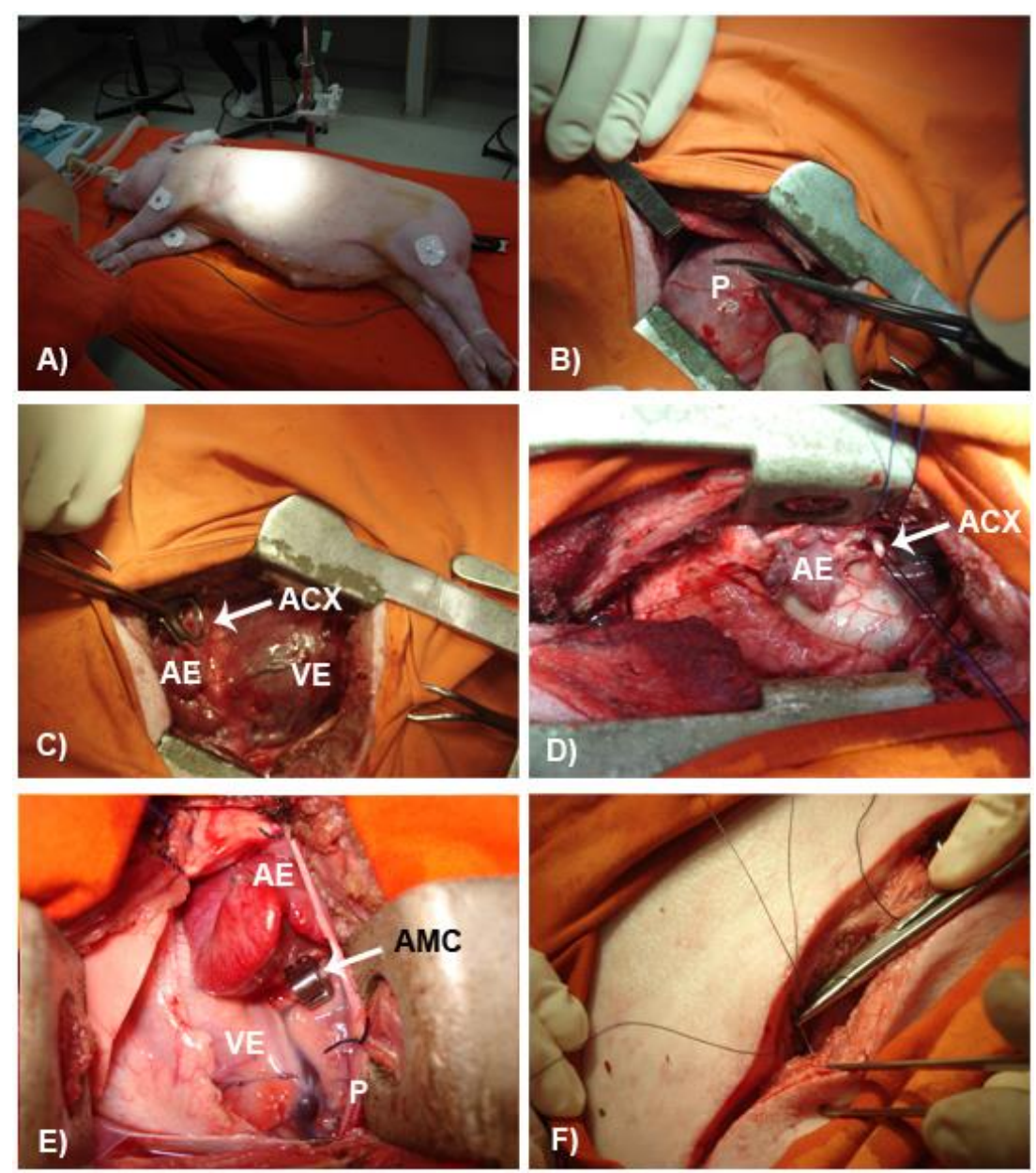

Figura 2: Modelo de infarto por implante de ameróides constritores. A) Decúbito lateral esquerdo. B) Incisão do pericárdio $(P)$. C) Ao ser levantado o átrio esquerdo (AE) foi possível observar a região proximal de ACX; VE: ventrículo esquerdo. D) ACX isolada com auxilio de fios de algodão. E) ameróides constritor (AMC) posicionado na porção proximal de ACX. F) Fechamento da incisão por planos. Note tamanho da incisão.

\section{Modelo percutâneo de isquemia seguido de necrose}

Para obtenção de acesso arterial, após procedimentos anestésicos, os animais foram posicionados em posição supina (Figura 3A), foi então realizada assepsia/antissepsia da região inguinal direita do membro inferior. A artéria femoral comum foi exposta por dissecção cirúrgica, então por visão direta foi 
Apêndice A

introduzida uma bainha vascular 6F (Thando Med - Figura 3B), seguida por administração de 10.000 UI de heparina.

A artéria coronária esquerda foi canulada seletivamente utilizando-se cateter guia 6F (Launcher ${ }^{\circledR}$ Coronary Guide Catheter - Medtronic - Figura 3B). Após a cateterização da coronária foi realizada injeção intra-coronária de contraste angiográfico e aquisição de angiografia basal. Em seguida, foi manipulada uma corda-guia 0.014 (Medtronic) até a porção distal de ACX, por qual uma prótese de poliuretano (esponja) foi guiada até a porção proximal de ACX, com auxílio de um cateter balão de "ponta cortada" (Sprinter® Legend RX Semicompliant Balloon Dilatation Catheter - Medtronic - Figura 3C). Na região de interesse esta prótese causou uma embolia ocluindo completamente a luz de ACX que foi confirmada por angiografia realizada pelo menos 5 minutos após colocação de cada prótese. Foram implantadas de 1 a 4 próteses por animal. Na figura 4 é possível observar um desenho esquemático do método desenvolvido.

Trinta dias após indução de infarto do miocárdio os animais foram submetidos a nova angiografia e também a ecocardiografia transtorácica. Posteriormente os animais, ainda sobre efeito anestésico, foram sacrificados e tiveram o coração processado para análises posteriores. 
Apêndice A

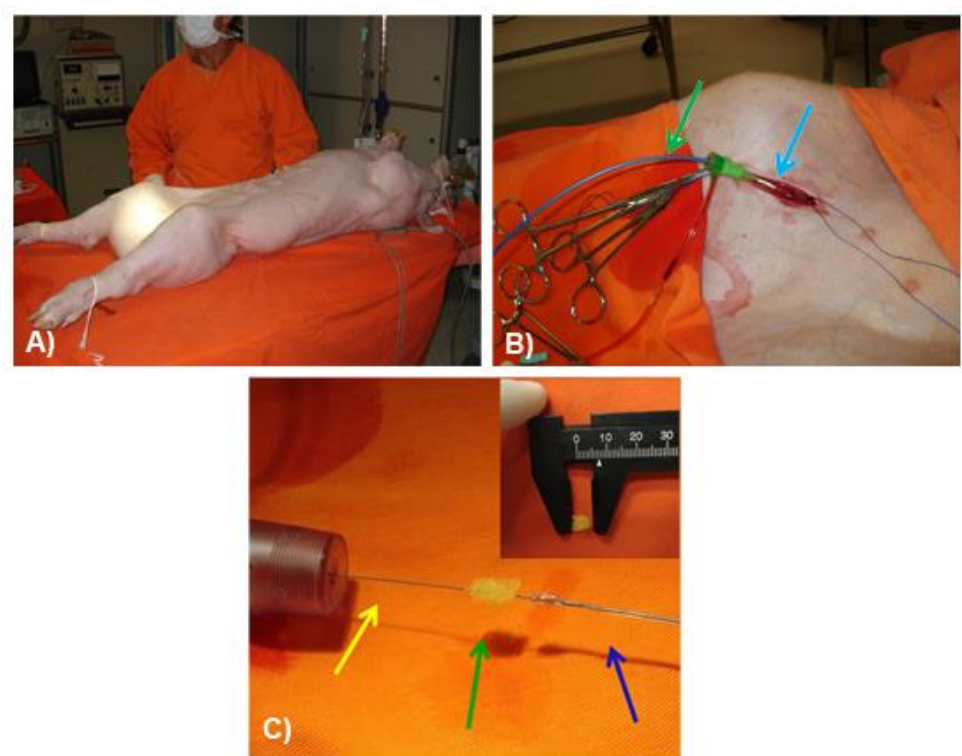

Figura 3: Acesso arterial para cauterização de ACX e posicionamento da prótese de poliuretano. A) Animal em posição supina. B) Acesso arterial realizado com sucesso pela artéria femoral; Seta verde: cateter terapêutico 6F; seta azul: introdutor $6 \mathrm{~F}$. C) No detalhe podemos observar uma prótese de poliuretano (aprox.. $7 \times 7 \times 7 \mathrm{~mm}$ ); seta amarela: fio-guia 0,014; seta verde: prótese já posicionada e pronta para ser introduzida; seta azul: cateter balão com ponta cortada.

\section{Preparo das Próteses de poliuretano}

Para o uso das próteses de poliuretano, uma esponja de limpeza nova foi esterilizada em óxido de etileno em procedimento padrão de esterilização de materiais cirúrgicos não autoclaváveis. A porção amarela (poliuretano) da esponja então foi cortada com tesoura cirúrgica esterilizada em pequenos pedaços com volume aproximado de $7 \times 7 \times 7 \mathrm{~mm}$. As próteses foram posicionadas no cateter guia 0.014 somente no ato da introdução pelo cateter 6F para posicionamento na porção proximal de ACX (Figura 3C). 
A)

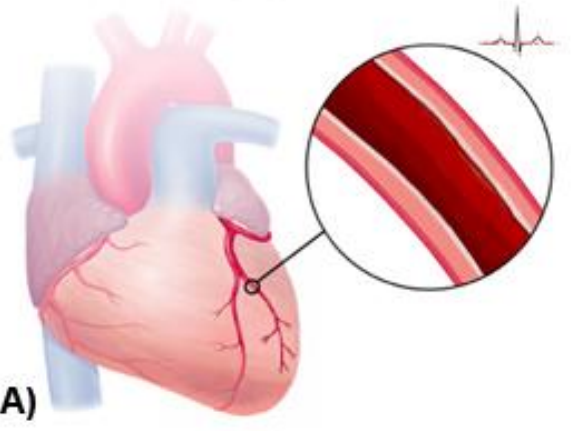

C)

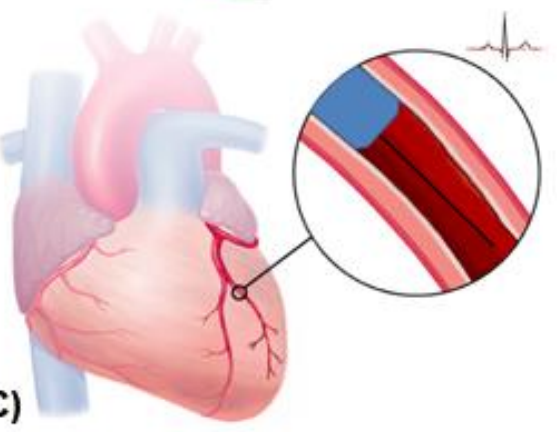

B)
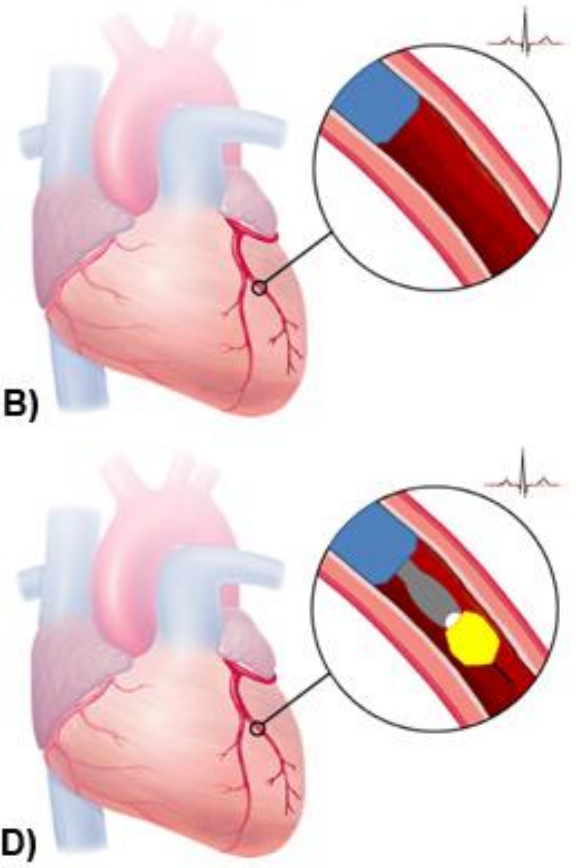

D)

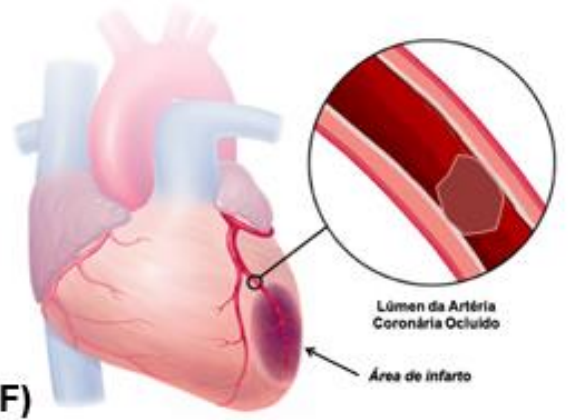

Figura 4: Desenho esquemático do protocolo de indução de infarto. A) coronária alvo com fluxo normal. B) posicionamento do cateter terapêutico. C) o fio-guia é levado até a porção mais distal da artéria alvo. D) Através do fio-guia, com auxilio de um cateter balão de ponta cortado, a prótese de poliuretano é levada até a região de interesse. E) 5 a 10 minutos após colocação da prótese ocorre a formação de um trombo fixo que obstrui completamente a luz coronária. F) Com o passar dos dias uma lesão necrótica será observada na região que era banhada pela coronária ocluída (imagem base modificada de http://scrapetv.com/News/laruelocal/wp-content/uploads/2011/05/coronary-arterydisease.jpg).

\section{Testes bioquímicos: Marcadores de necrose}

As medidas de concentrações de troponina $\mathrm{T}$ por metodologia ultrassensível e CK-MB circulantes foram realizadas pelo laboratório de análises clínicas de Medicina Diagnóstica do grupo Fleury. As medidas foram realizadas de acordo com as recomendações do fabricante dos Kits comerciais (Roche). As medidas foram feitas no soro dos porcos, os quais foram 
Apêndice A

submetidos a uma coleta seriada de até 24 horas após a oclusão (intervalos de 1 hora por coleta).

\section{Angiografia}

As angiografias das artérias coronárias foram realizadas visando avaliar a coronária de interesse. Para tanto foi utilizado contraste radiológico iodado injetado diretamente no seio coronariano via cateter 6F. As imagens foram adquiridas em escopia (BV Pulsera - Philips). Já com as imagens, o diâmetro das coronárias foi medido baseado no diâmetro máximo de cada segmento, através do sistema Philips de Imagem Cardíaca Digital (DCl; Philips, Eindhoven, Netherlands) para que fosse possível estimar a homogeneidade das coronárias dos diferentes animais. Para a calibração do aparelho foi usada a ponta de um cateter. Este procedimento foi realizado por um profissional especializado. Foram realizadas imagens em duas projeções contra-laterais, sendo uma delas $60^{\circ}$ anterior obliqua esquerda e a outra $30^{\circ}$ anterior obliqua direita para determinar a geração de circulação colateral intra e/ou intercoronária.

\section{Eletrocardiograma}

Durante todo 0 procedimento os animais foram mantidos sob monitoramento de frequência cardíaca, saturação e pressão arterial média $(P A M=P A D+1 / 3(P A S-P A D) ;$ onde PAM é a pressão arterial média; PAD a pressão arterial diastólica e PAS a pressão arterial sistólica) através de um monitor portal de 12 derivações (DX 2020 - DIXTAL). Os animais foram posicionados em posição supina e monitorizados desde a indução anestésica 
Apêndice A

até no mínimo 3 horas após a oclusão de ACX. Os dados referentes a estas variáveis foram anotados a cada cinco minutos.

\section{Ecocardiografia transtorácica básica e de perfusão}

Os animais foram submetidos a estudo ecocardiográfico em ecocardiógrafo disponível comercialmente (SONOS 5500 - Philips Medical Systems). Foram realizadas medidas lineares das estruturas cardíacas e fluxos valvares e em seguida um estudo com contraste miocárdico, para análise de perfusão em tempo-real (ECMTR). Foi usando contraste comercial (DEFINITY® (Lantheus Medical Imaging, Inc. North Billerica, MA) em condição basal e posteriormente sob estresse farmacológico por administração endovenosa de dipiridamol de $0,56 \mathrm{mg} / \mathrm{kg}$ em quatro minutos. Estes exames foram realizados após um mês da indução do infarto. As medidas lineares das estruturas cardíacas e fluxos valvares foram avaliadas no próprio equipamento utilizado para a aquisição das imagens. As medidas de fluxo miocárdico foram realizadas no software de análises Q-lab (Phillips) conforme descrito por Porter em 2011 (21). Todas as medidas foram obtidas de acordo com as normas da Sociedade Americana de Ecocardiografia (22). Essas medidas foram realizadas com o objetivo de quantificar o desempenho cardiovascular nesses animais e avaliar a estrutura perfundida do ventrículo esquerdo 30 dias após a oclusão de ACX. 
Apêndice A

\section{Avaliações Macroscópicas}

\section{Processamento do Ventrículo Esquerdo}

Após avaliação funcional terminal, os animais ainda sob anestesia foram sacrificados com overdose de cloreto de potássio $(\mathrm{KCl})$. Após a constatação da parada cardíaca o coração foi retirado e então dissecado, para obtenção apenas do Ventrículo Esquerdo (VE). Os VEs foram seccionados transversalmente, da base ao ápice, em secções de $5 \mathrm{~mm}$ (em média 7 secções - Figura 5).

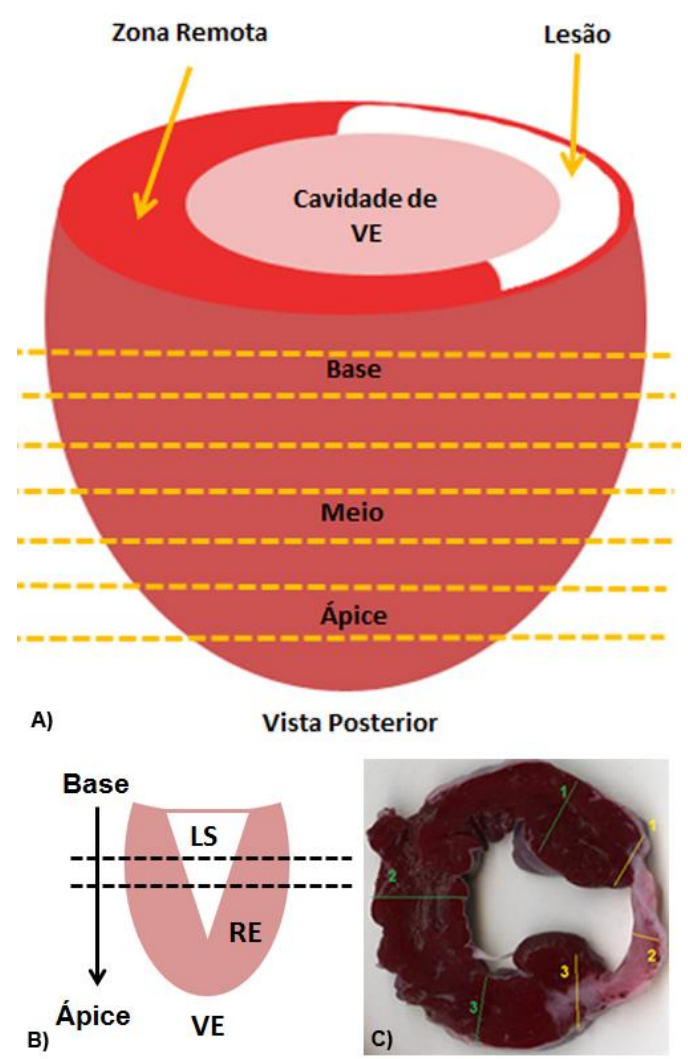

Figura 5: Processamento de VE após constatação de óbito. A) Esquema de corte de VE adotado B) e formato da lesão, cerca de 7 fragmentos foram gerados da base ao ápice. C) fatia de VE esquerdo representativa. 
Coloração com Cloreto de 2,3,5 Trifenil Tetrazólio (TTC)

Uma solução de 1\% TTC em solução tampão de fosfato de $\mathrm{pH} 7,4$ foi utilizada. O procedimento foi realizado imediatamente após a retirada do coração. As secções transversais foram incubadas em $200 \mathrm{~mL}$ da solução de TTC, sob agitação e a $37^{\circ} \mathrm{C}$ por vinte minutos. Após a coloração os cortes foram incubados em solução tamponada de formaldeído 10\%, a temperatura ambiente por dez minutos. Os cortes foram lavados em água corrente e então fixados em solução tamponada de formaldeído 10\%.

\section{Quantificação macroscópica da área de infarto do miocárdio}

Após terem sido submetidos à coloração com TTC os cortes de VE foram dispostos lado a lado com todos os cortes reconstruindo o coração com visões tanto do ápice para a base como da base para o ápice. As pranchas foram fotografadas numa resolução de 300 dpi (Scanner GE) e então as imagens foram usadas para realização das medidas macroscópicas para a caracterização da lesão.

Para medida da área de necrose todas as fatias de VE foram medidas em ambas as orientações (ápice-base e base-ápice - Figura 6). O resultado foi expresso pela média de todas as fatias em ambas as orientações. 
Apêndice A

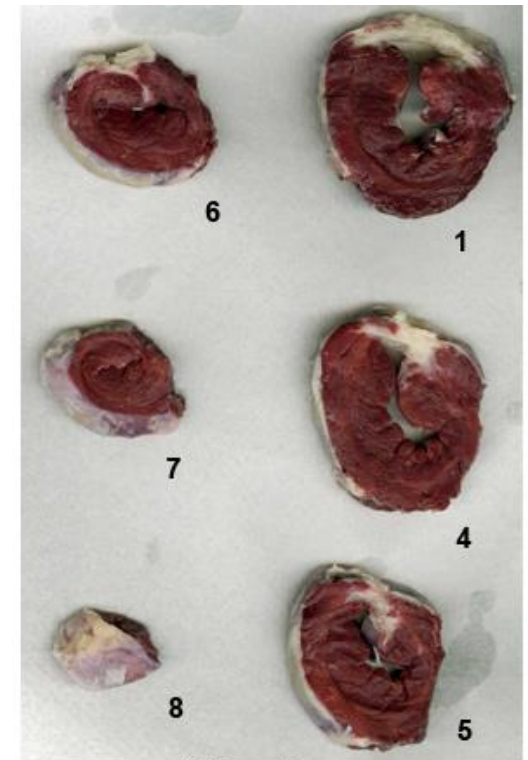

A)

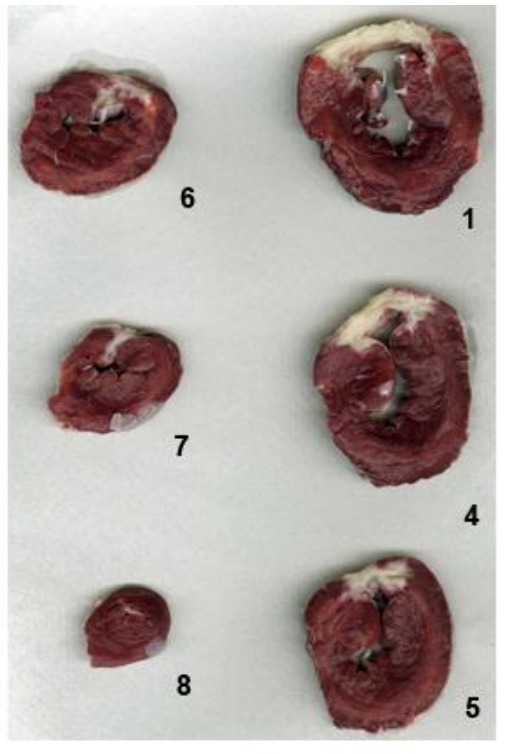

B) Base - Ápice

Figura 6: Pranchas com cortes de VE nas duas orientações. A) vista do ápice para a base. B) vista da base para o ápice, note que as fatias 2 e 3 foram utilizadas para congelamento de tecido e histologia respectivamente.

Ainda utilizando todas as fatias de VE em ambas as orientações, a espessura do septo (área remota ao infarto) e parede posterior (infarto propriamente dito) foram medidas através da média de três distancias diametralmente opostas tanto na área de lesão como na parede septal remota (Figura 7). Com essas medidas um índice relativo de hipertrofia (medida da parede posterior dividido pela medida do septo) foi calculado. Todas as medidas realizadas sobre as imagens das fatias de VE foram realizadas no software de análises Image $J(23)$. 

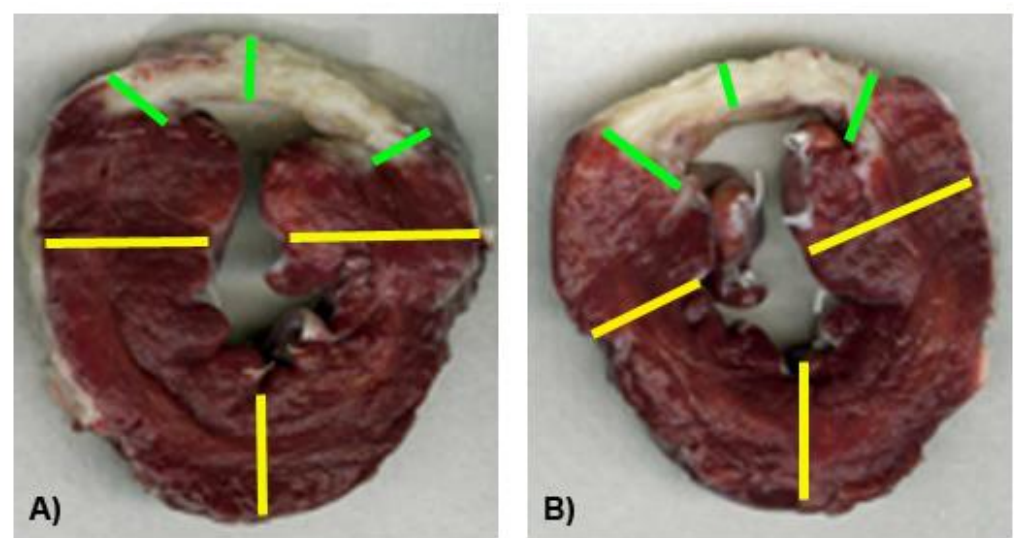

Figura 7: Medidas de espessura de paredes de VE. A) vista do ápice para a base. B) vista da base para o ápice, medidas em verde representam a parede posterior, área de lesão e medidas em amarelo a parede septal, remota a lesão.

\section{Avaliações microscópicas}

\section{Processamento do ventrículo esquerdo}

Após avaliação funcional, os animais ainda sob anestesia foram sacrificados com overdose de cloreto de potássio $(\mathrm{KCl})$. Após a constatação da parada cardíaca o coração foi retirado e então dissecado, para obtenção apenas do Ventrículo Esquerdo (VE). Os VE foi seccionados transversalmente, da base ao ápice, em secções de $5 \mathrm{~mm}$ (em média 7 secções - Figura 5). A secção 2 foi dividida em regiões: sadias, borda de infarto e infarto propriamente dito. Cada região foi congelada imediatamente em duplicatas, diretamente em nitrogênio liquido, para análises futuras. A secção 3 foi dividida igualmente a secção 2 e as porções fixadas em paraformaldeído 4\%. Após 48 horas da fixação, os tecidos foram dispostos em cassetes plásticos do tipo processador/inclusor. Os cassetes foram processados em aparelho autotécnico com ciclo total de 12 horas para a desidratação, diafanização e parafinização do material. Os tecidos incluídos em parafina foram cortados em micrótomo 
Apêndice A

( $4 \mu \mathrm{m}$ de espessura) e dispostos em lâminas. O restante das fatias de VE foi submetido à coloração com TTC como descrito anteriormente.

\section{Quantificação de Colágeno intersticial}

As lâminas correspondentes à zona remota e a área de infarto propriamente ditas, geradas a partir do corte dos tecidos ( $4 \mu \mathrm{m}$ de espessura), foram submetidas à coloração de Picrossirius Red. Depois de coradas as laminas foram observadas em microscópio ligado a sistema de digitalização de imagem (Leica Imaging Systems) e as imagens digitalizadas dos corações foram analisadas com uso de um software (ImageQuant - Leica). Este software é capaz de identificar e quantificar através da diferença de tons nas cores que são a ele indicadas e a partir daí fornecer um dado percentual da quantidade de determinada cor na imagem. Vinte fotografias digitais na aumento de 200X do microscópio óptico foram tiradas de cada corte, estas foram realizadas aleatoriamente sendo uma amostragem representativa de todo o tecido cardíaco disposto na lamina fotografada. Para correção dos erros de área em branco ou por erros de processamento, foram feitas medidas da área total de tecido em cada fotografia e estes valores foram usados para o cálculo final da área de colágeno encontrada em cada fotografia.

\section{Procedimentos cirúrgicos para injeção epicárdica}

Toracotomia lateral esquerda

Quatro semanas após a indução do infarto do miocárdio, os animais foram anestesiados, monitorados e ventilados mecanicamente conforme descritos no item "Preparo dos animais para procedimentos invasivos". Os 
Apêndice A

animais foram então submetidos aos procedimentos de antissepsia/assepsia. Um calço confeccionado com campo cirúrgico dobrado foi colocado sob o tórax direito dos animais para que houvesse uma elevação do coração, facilitando o acesso às regiões mais apicais do órgão. Em seguida, os porcos foram submetidos à toracotomia no lado esquerdo do peito, na altura do quarto espaço intercostal. Primeiramente a pele foi seccionada com auxílio de bisturi convencional, em seguida um bisturi elétrico (cauterizante) foi usado para cauterizar os pequenos vasos. Todas as interfases musculares daí em diante foram seccionadas usando o bisturi elétrico para evitar sangramento excessivo. As camadas de músculos seccionadas foram rebatidas lateralmente para posteriores suturas. Ao serem visualizadas, tanto a veia como a artéria mamária esquerda foram isoladas e ocluídas com fio de algodão 2-0, para evitar sangramentos. Ao ser visualizado, o pericárdio foi pinçado delicadamente e aberto com auxílio de tesoura fina. $O$ nervo frênico foi preservado e o pericárdio foi amarrado para posterior fechamento. Com auxilio de uma pinça do tipo Collin o átrio esquerdo foi elevado e foi possível observar a região de ACX onde a prótese de poliuretano foi deixada.

Após abertura completa de todas as estruturas que se encontravam em nível superior ao coração foi possível observar na minoria dos casos a área de lesão bem delimitada, no entanto, nos demais casos esse limite foi impossível de ser estabelecido a olho nu. Para isso foi desenvolvida uma técnica de medida elétrica diretamente na parede epicárdica descrita no item a seguir.

\section{Mapeamento Elétrico Epicárdico do Ventrículo esquerdo}


Apêndice A

Para que fosse possível obter injeções atingindo sempre a borda do infarto do miocárdio, foi necessário desenvolver um método que associado ao ecocardiograma fosse capaz de nos dar um mapa mais fiel da anatomia da área de lesão, já que está não foi bastante clara na maior parte dos animais observados. Para tanto desenvolvemos um mapeamento elétrico baseado no sinal do eletrocardiograma.

O eletrodo superior esquerdo foi desconectado do animal sob monitoramento elétrico com eletrocardiógrafo de 5 eletrodos e então ligado na extremidade de uma caneta bisturi desligada do sistema de cauterização (Figura 8A). Ao ser ligado na extremidade desta caneta, a mesma, tornou-se um eletrodo livre e manipulável. A ponta metálica da caneta bisturi foi então dobrada formando uma base não pontiaguda (Figura $8 \mathrm{~A}$ ). $\mathrm{O}$ ganho do eletrocardiógrafo foi então reduzido para N/4, reduzindo assim o sinal gerado e transmitido na tela (Figura 8B). A ponta metálica da caneta foi então encostada na parede de interesse do ventrículo esquerdo, fechando o circuito e gerando uma onda elétrica visualizável na tela do monitor eletrocardiográfico (Figura 8B e C).

Nas regiões remotas a lesão, foi possível observar um complexo elétrico de tamanho grande e com perfil mais próximo do esperado. À medida que o eletrodo foi sendo encaminhado para a região de lesão o sinal elétrico reduziu e o complexo formado pelo monitor de eletrocardiograma foi diminuindo até que no meio da lesão propriamente dita o sinal desapareceu completamente indicando ausência de corrente elétrica. Deste modo foi possível encontrar a zona de transição entre a área lesada e a zona remota, a qual foi denominada de borda do infarto e na qual injeções de PBS foram injetadas. 

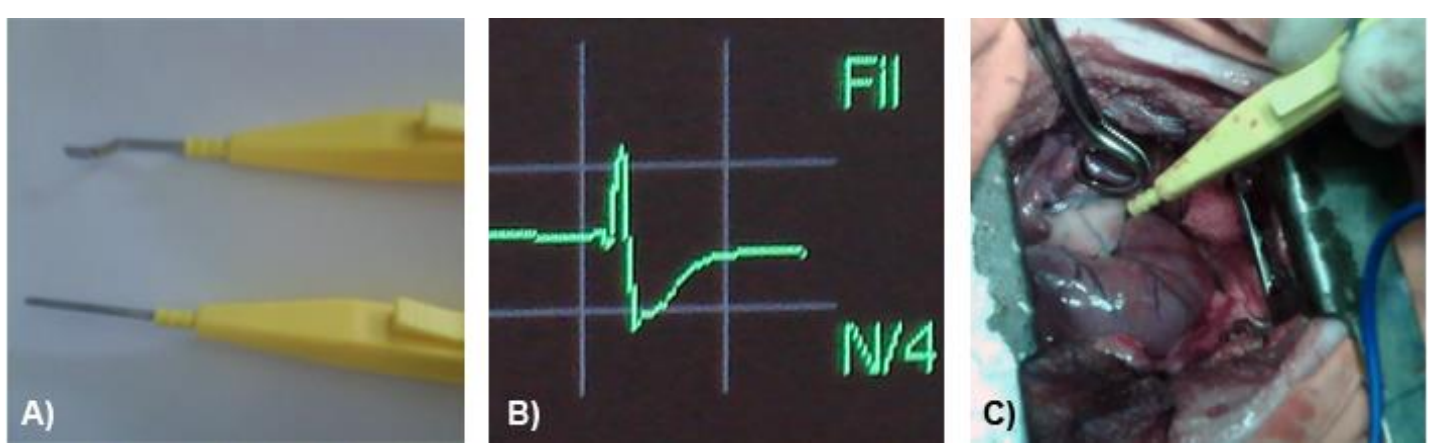

Figura 8: Mapeamento elétrico epicárdico. A) canetas bisturi, note ponta metálica em conformação arredondada (caneta superior) para não perfurar o coração vs. Ponta normal (caneta inferior). B) ganho de ECG em N/4. C) Caneta bisturi modificada ligada ao ECG em contato com a borda do infarto via parede epicárdica.

\section{Injeção de solução de fosfato (PBS) diretamente no miocárdio}

Após a visualização das paredes lateral e posterior, do ventrículo esquerdo, com o auxílio de uma seringa de tuberculina, foram injetados em pleno miocárdio, na região de borda do infarto, vinte alíquotas de $0,20 \mathrm{~mL}$ de solução de PBS (Figura 9A), cobrindo toda a extensão da lesão. Após a injeção, a incisão foi fechada por planos e o ar do espaço pleural removido com auxilio de um dreno (Figura 9B-D), o qual foi retirado ao final do fechamento da pele.

Todos as animais receberam curativos locais bem como tratamento com antibióticos e analgésicos como descrito no item "Preparo dos animais para procedimentos invasivos". 
Apêndice $A$
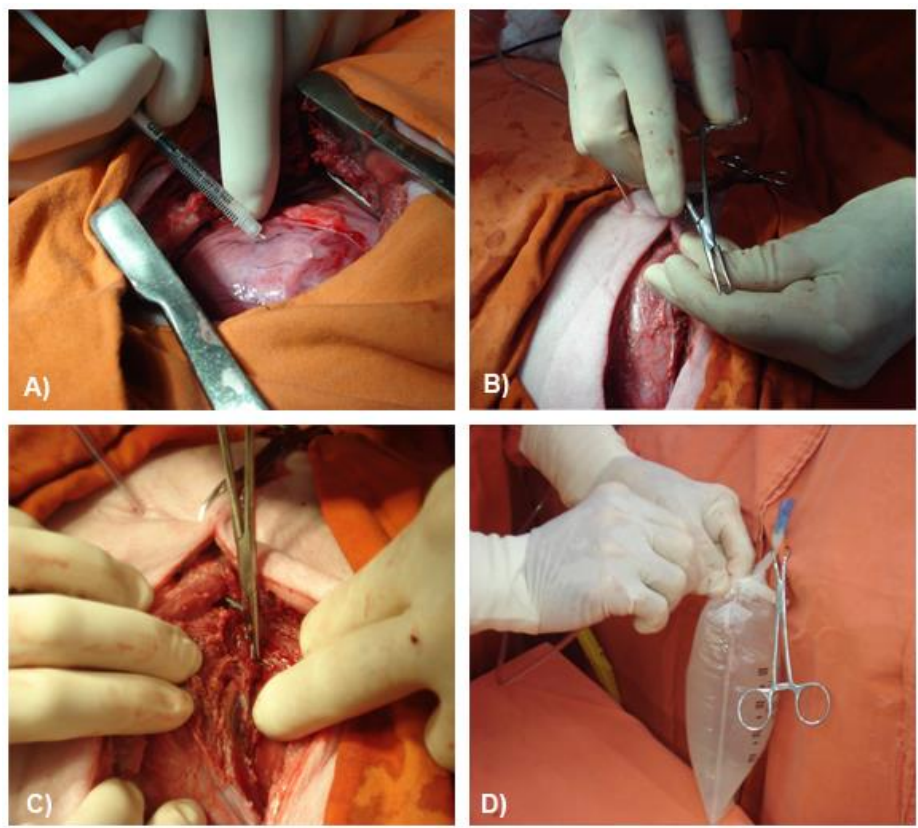

Figura 9: Injeção na borda do infarto. A) as injeções foram feitas em ângulo para evitar que a agulha perfurasse a parede de VE atingindo a cavidade. B a D) Colocação de dreno para retirada do ar da cavidade, em $\mathrm{B}$ podemos observar que o tubo para dreno foi transpassado através da pele do animal, em C podemos observar a colocação do tubo do dreno no interior da cavidade pleural e em $D$ a colocação do tubo no interior de um recipiente de soro que foi posicionado abaixo do nível do tórax do animal.

\section{Estatística}

Os resultados foram expressos por média \pm erro padrão da média (EPM). Testes $\mathrm{t}$ de Student não pareados foram utilizados para comparar grupos. Todas as análises estatísticas foram feitas usando o Software GraphPad Prism 5.0 (GraphPad Softwares Inc.,CA, USA). Valores de $p<0.05$ foram considerados significativos. 
Apêndice A

\section{Resultados}

Modelo de isquemia crônica por uso de ameróides constritores (AMC)

Para a realização do modelo de $A M C$ os porcos foram submetidos aos preparos anestésicos e de assepsia/antissepsia. Os animais tiveram o coração cirurgicamente exposto através da toracotomia lateral e os AMCs foram posicionados na porção proximal de ACX (Figura 10).
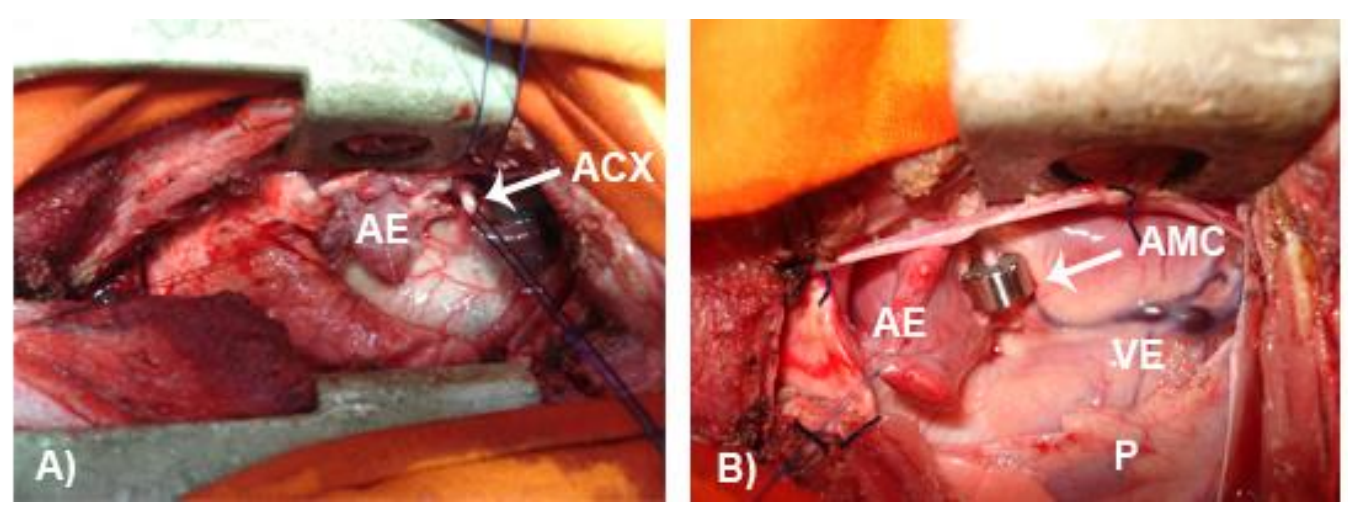

Figura 10: Colocação do ameróides constritor (AMC) em ACX. A) ACX sendo isolada com auxílio de fios de algodão após dissecção abaixo do átrio esquerdo ( $A E)$. B) AMC colocado na porção proximal de ACX. Note que a artéria continua entumecida sugerindo fluxo sanguíneo constante até o momento da colocação.

Em um primeiro experimento onde métodos antiarrítmicos farmacológicos não foram utilizados, $100 \%$ dos porcos submetidos à cirurgia de implante dos AMCs morreram durante as primeiras 24 horas pós-procedimento $(n=3)$. Destes $66,7 \%$ (2 animais) morreram ainda durante o procedimento tendo ACX completamente ocluída e 33,3\% (1 animal) morreram cerca de 3 horas após o implante do AMC (Tabela 1). Todos os animais morreram após episódios irreversíveis de fibrilação ventricular. 
Apêndice A

Tabela 1: Mortalidade dos porcos submetidos ao implante de AMC

\begin{tabular}{cccc}
\hline Período & Morte (\%) & Taxa de FV (\%) & Morte pós FVI (\%) \\
\hline \multirow{4}{*}{ Sem uso do Cloridrato de lidocaína $(n=3)$} \\
Procedimento & $66,7(n=2)$ & $66,7(n=2)$ & $66,7(n=2)$ \\
Até 24 horas & $33,3(n=1)$ & $33,3(n=1)$ & $33,3(n=1)$ \\
& \multicolumn{4}{c}{ Uso do Cloridrato de lidocaína $(n=4)$} \\
Procedimento & $25,0(n=1)$ & $25,0(n=1)$ & $25,0(n=1)$ \\
Até 24 horas & $25,0(n=1)$ & $X$ & $X$ \\
\hline
\end{tabular}

Abreviações: FV: fibrilação ventricular; FVI: fibrilação ventricular irreversível.

Com objetivo de minimizar a incidência de fibrilação ventricular um novo grupo de porcos, tratados com cloridrato de lidocaína, foi submetido ao procedimento cirúrgico de implante de AMCs. A mortalidade deste grupo foi reduzida para $50 \%$, ou seja, 2 animais (Tabela 1). Destes apenas um deles teve morte precedida por FV. O outro animal morreu nas 24 horas posteriores à cirurgia de implante de AMC por falência da função cardíaca global. Neste animal foi detectada oclusão total do lúmen de $\mathrm{ACX}$, mas o animal foi encontrado morto na baia, portanto não foi possível identificar se houve FV.

Os animais que sobreviveram ao procedimento de implante de AMC foram submetidos à angiografia diagnóstica para avaliação da condição de ACX 30 dias após a cirurgia de implante dos mesmos (Figura 11). Dos 2 animais sobreviventes ( $50 \%$ vivos) um dos animais apresentou uma obstrução completa da luz de ACX, abaixo do AMC (Figura 11 A e B), enquanto que 0 outro animal apresentou fluxo insuficiente na luz de ACX (Figura 11C e D), de modo que, após o sacrifício, a avaliação patológica macroscópica revelou um coração com perfil de lesão miocárdica com cicatriz fibrosa (Figura 12A) e um outro coração sem lesão macroscópica aparente (Figura 12B) respectivamente. 
Apêndice A
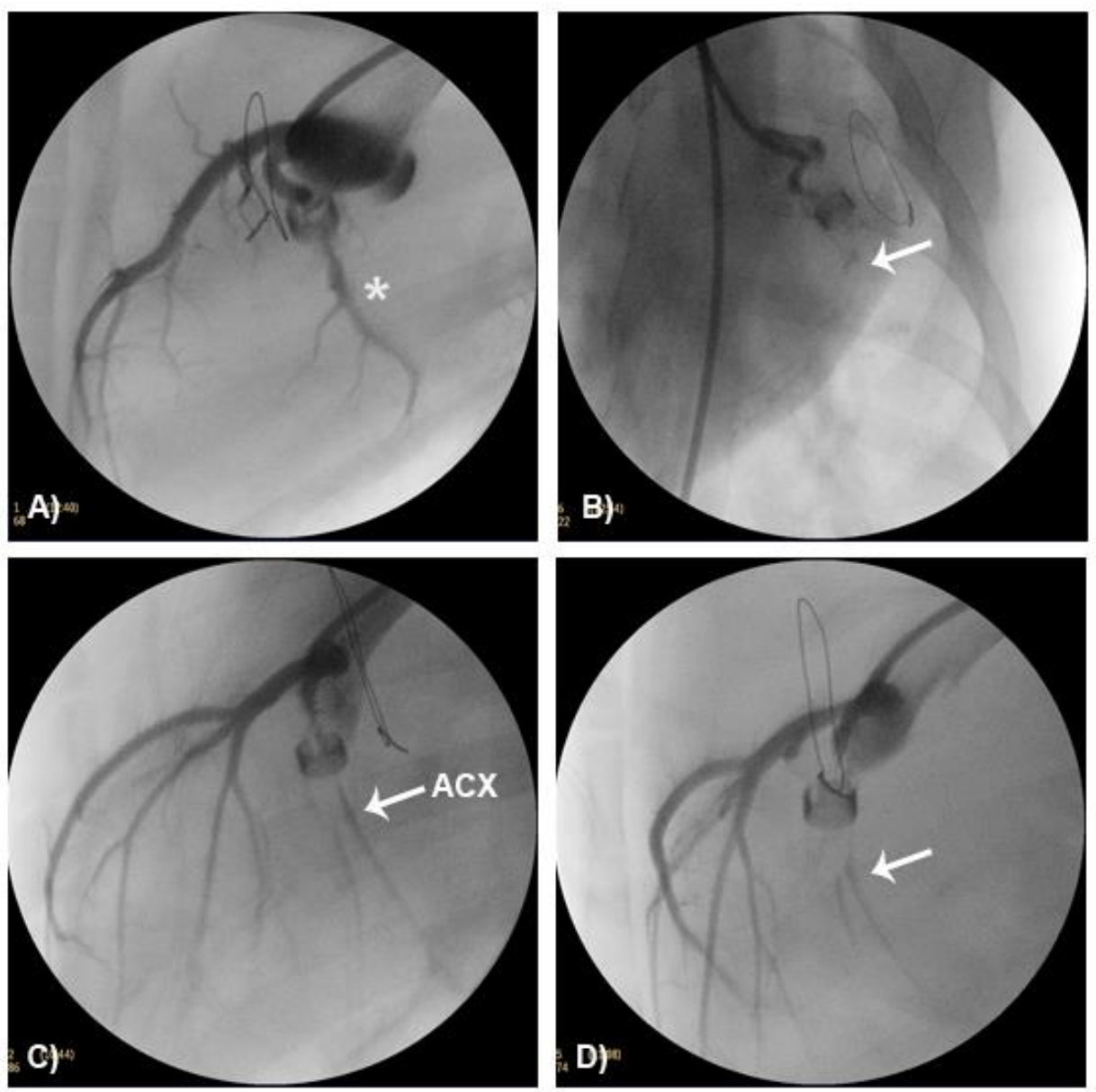

Figura 11: Angiografia confirmatória 30 dias após colocação de AMC. A) Neste animal na imagem a $60^{\circ}$ anterior obliqua esquerda pode-se observar fluxo em artéria aparentemente ACX. * ramo importante de ACX. B) Ao mudarmos para um plano de $30^{\circ}$ anterior obliquo direito pudemos confirmar que na verdade ACX não apresenta fluxo verdadeiro (seta). C e D) É possível observar em ambos os planos que ACX deste animal apresenta um fluxo baixo de sangue. Note que no segundo animal (C e D) existe uma dominância aparente da coronária descendente anterior, a qual apresenta muitos ramos, ao contrário do que é observado para 0 primeiro animal - estas diferenças não foram quantificadas.

Este modelo não se mostrou homogêneo e tão pouco de fácil reprodutibilidade, além de envolver uma série de procedimentos cirúrgicos deliciados exatamente sobre a área onde posteriormente haverá uma reoperação para a injeção de células-tronco, ou seja, a re-operação pode tornase um evento ainda mais arriscado e de alta mortalidade. 
Apêndice A

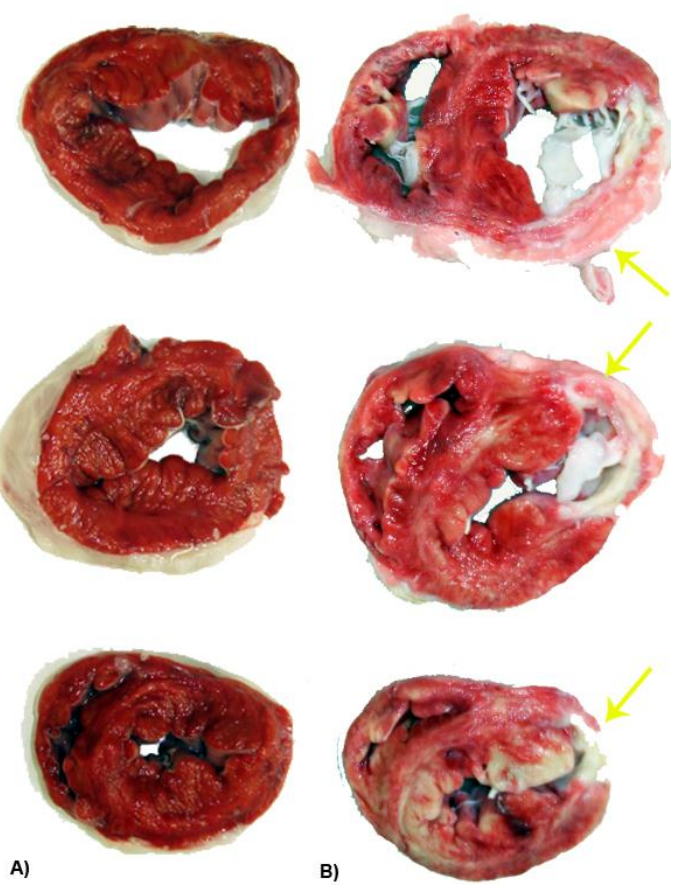

Figura 12: Avaliação macroscópica do coração dos animais submetidos ao implante de AMC. A) Cortes seriados dos ventrículos do animal 1, corados com cloreto de tetrazólio, no qual é possível observar que não há áreas de necrose na parede posterior/lateral do ventrículo esquerdo. B) cortes seriados dos ventrículos do animal 2, onde pode-se observar uma área de necrose bem demarcada que se estende da base ao ápice do ventrículo esquerdo (setas amarelas).

\section{Modelo percutâneo de isquemia seguido de necrose}

Em um segundo momento uma nova abordagem, agora intervencionista, foi testada. Usando procedimentos hemodinâmicos, muito menos invasivos do que os procedimentos cirúrgicos usados na colocação dos ameróides constritores, um embolo endovascular foi gerado no interior da região proximal de ACX a partir da colocação de uma prótese de poliuretano (esponja de limpeza) na qual um coágulo se formou obstruindo completa e permanentemente a luz de ACX. Inicialmente uma angiografia basal foi realizada para servir de guia para o posicionamento da prótese de poliuretano em ACX (Figura 13A). Através de um cateter guia 6F uma prótese foi carregada através de uma corda guia 0,014 até a porção distal de ACX (Figura 13B) e então com auxílio de um cateter-balão, com a ponta cortada, as 
Apêndice A

próteses foram posicionadas na porção proximal de ACX (Figura 13C). Após 510 minutos do posicionamento da prótese uma nova angiografia foi adquirida confirmando a obstrução completa do lúmen de ACX (Figura 13D). Trinta dias após a indução de infarto do miocárdio, os animais foram sacrificados e o coração processado para análises anatomopatológicas. Com esse modelo a mortalidade final foi reduzida e a homogeneidade e reprodutibilidade atingidas (Tabela 2).
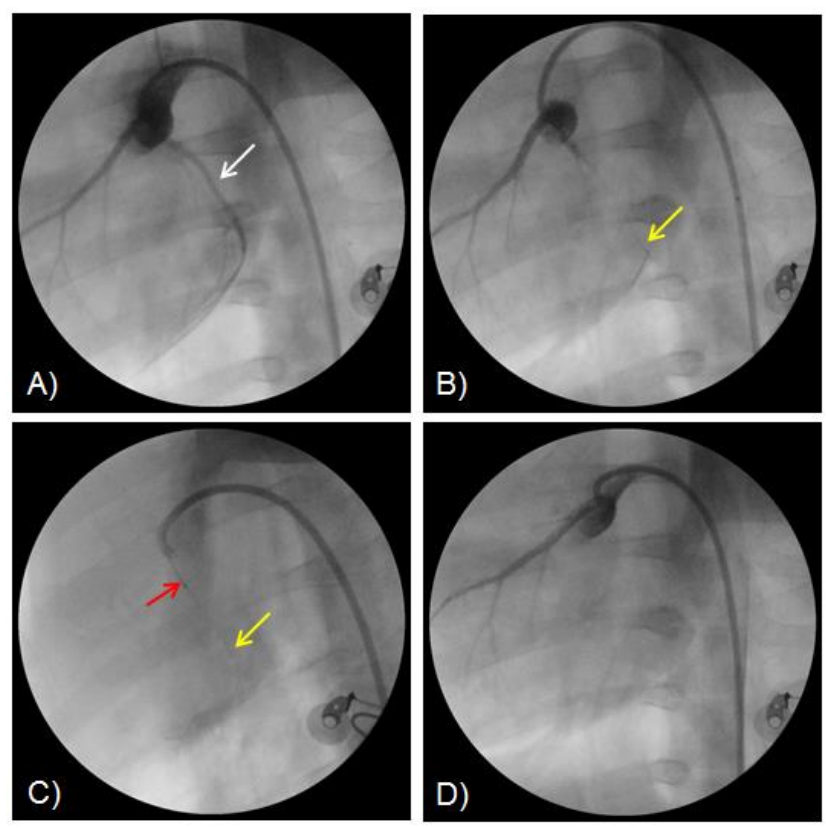

Figura 13: Modelo de infarto agudo do miocárdio sem intervenção cirúrgica Angiografia confirmatória da oclusão total e permanente da ACX. Uma prótese de poliuretano foi colocada na porção proximal da artéria coronária circunflexa esquerda ( $A C X)$. A) A seta branca indica a ACX antes da oclusão da mesma. B) A seta amarela indica a corda-guia pela qual a prótese foi introduzida na ACX. C) A seta vermelha indica a ponta do cateter balão usado para empurrar a prótese até a porção proximal da ACX. D) Angiografia 5 à 10 minutos após oclusão total e permanente da ACX, atentar ao detalhe da falta de fluxo na ACX ( $n=21)$.

Esse modelo de infarto foi descrito pela primeira vez por Reffelmann e colaboradores em 2004 (16) apresentando elevada mortalidade. Neste estudo foram realizadas oclusões distais de ACX. Estas foram descritas pelos autores como necessárias visto que as tentativas de oclusão da artéria coronária 
Apêndice A

descendente anterior (DA) acarretaram em mortalidade muito elevada.

Observamos alta mortalidade também em nosso laboratório usando o modelo de oclusão de DA (3 animais), por isso, também foi feita a opção de oclusão de ACX, no entanto, para que a área de lesão fosse maior que a obtida por Reffelmann, as oclusões foram feitas na região proximal de ACX.

Tabela 2: Mortalidade dos porcos submetidos ao procedimento intervencionista

\begin{tabular}{lccc}
\hline Período & Morte (\%) & Taxa de FV (\%) & Morte pós FVI (\%) \\
\hline \multicolumn{4}{c}{ Sem uso do Cloridrato de lidocaína $(n=3)$} \\
Procedimento & $66,6(n=2)$ & $66,7(n=2)$ & $66,7(n=2)$ \\
Até 24 horas & $33,3(n=1)$ & $33,3(n=1)$ & $33,3(n=1)$ \\
Até 30 dias & $X(n=0)$ & $X(n=0)$ & $X(n=0)$ \\
& \multicolumn{4}{c}{ Uso do Cloridrato de lidocaína $(n=21)$} \\
Procedimento & $23,8(n=5)$ & $28,6(n=1)$ & $19,0(n=4)^{*}$ \\
Até 24 horas & $X(n=0)$ & $X(n=0)$ & $X(n=0)$ \\
Até 30 dias & $4,8(n=1)$ & $4,8(n=1)$ & $4,8(n=1)^{* *}$ \\
\hline
\end{tabular}

Abreviações: FV: fibrilação ventricular; FVI: fibrilação ventricular irreversível. * ou $57,0 \%$ dos 7 porcos que tiveram FV, ${ }^{* *}$ ou $14,0 \%$ dos 7 porcos que tiveram FV. 
Apêndice A

\section{O uso do antiarrítmico cloridrato de lidocaína}

Ao iniciarem-se os testes com os diferentes modelos adotados, seja AMC ou o modelo intervencionista, um problema recorrente observado foi a elevada mortalidade devido as arritmias ventriculares seguidas de fibrilação ventricular irreversível, o que também foi observado por Reffelmann e cols (16). Para reduzir esse problema foi adotado o uso, profilático e de manutenção, de solução de $2 \%$ cloridrato de lidocaína como antiarrítmico. Este foi administrado por via venosa juntamente com o soro fisiológico aos animais durante todo 0 protocolo desde antes de as obstruções serem realizadas e em bolus quando os quadros de arritmia foram sustentados por mais que 5 ciclos consecutivos de batimento. Com isso foi possível reduzir o índice de fibrilações e por consequência a mortalidade em ambos os modelos testados (AMC e oclusão endovascular - Tabelas 1 e 2 , respectivamente).

Devido ao elevado número de publicações que se utilizam de amiodarona como antiarrítmico, nossos primeiros testes foram realizados utilizando essa droga, no entanto, dados da literatura demonstram que o uso de infusão endovenosa desta droga tem efeito em porcos apenas 60 minutos após o início da infusão (4), de modo que seu uso endovenoso foi incompatível com o desenho do protocolo de indução de infarto (momento crítico dos quadros de taquicardia concentra-se nos 35-45 minutos após oclusão). Além disso, as tentativas de uso desta droga em bolus durante episódios de taquicardia ventricular converteram esse estado imediatamente para fibrilação ventricular e por isso esse medicamento foi excluído do protocolo. 
Apêndice A

A viabilidade do procedimento foi determinada principalmente pela manutenção do quadro de estabilidade dos animais após a obstrução de ACX. Após ter sido adicionado ao protocolo o antiarrítmico cloridrato de lidocaína, a mortalidade ainda assim observada foi relacionada principalmente a problemas técnicos como obstrução excessivamente proximal de ACX ocasionando fechamento completo do seio coronário (2 animais) e embolia gasosa coronária ocasionada por má manipulação dos cateteres (2 animais). Um único animal morreu devido a um edema pulmonar agudo nas primeiras 24 horas após a oclusão e outro animal morreu devido a uma lesão de grande extensão a qual ocasionou arritmia seguida de fibrilação ventricular irreversível, constatada por filmagem de monitoração da baia onde o animal se encontrava, (5-30 dias após indução do infarto; Tabela 3).

Tabela 3: Mortalidade por causa

\begin{tabular}{ccc}
\hline Causa da Morte & Absoluto (n) & Relativo (\%) \\
\hline Mortalidade total (\%) & 6 & 28,6 \\
\hline EPA & 1 & 4,8 \\
EGC $^{*}$ & 2 & 9,5 \\
OTSC $^{*}$ & 2 & 9,5 \\
Complicações Tardias* $^{*}$ & 1 & 4,8 \\
\hline
\end{tabular}

Abreviações: EPA: embolia pulmonar aguda; EGC: embolia gasosa coronária; OTSC: obstrução total do seio coronário; n: número; *: complicação seguida de fibrilação.

Comparativamente ao trabalho publicado por Reffelmann e cols (16) nossos dados demonstram uma redução importante na porcentagem de morte total do protocolo de indução (28,6\% vs. $52 \%$ ), além disso, nossos dados de mortalidade são apresentados após um segmento de 30 dias após a oclusão de ACX enquanto que no trabalho publicado o segmento é de apenas 7 dias. 
Apêndice A

Outros grupos de animais foram submetidos ao protocolo de indução de infarto por oclusão endovascular de ACX para uso no protocolo de terapia celular o qual será apresentado no capítulo 2 desta tese. Nestes novos grupos as taxas de mortalidade foram mantidas ou até reduzidas ainda mais em alguns blocos de animais visto que não houve mais casos de fechamento completo do seio coronário e nem embolia gasosa coronária, demonstrando o aprimoramento da técnica pelos operadores.

\section{Incidência de fibrilação ventricular (FV) e o uso de cloridrato de lidocaína}

Durante o desenvolvimento do modelo de oclusão de ACX por via percutânea foi observado, em média trinta e cinco minutos após a oclusão da coronária, um período crítico para ocorrência de arritmias (taquicardia ventricular), podendo ser precedido por fibrilações ventriculares (33\% dos animais - Figura 14A). Nos casos onde arritmias ventriculares foram observadas e superaram 5 batimentos consecutivos, além da dose de $1 \mathrm{mg} / \mathrm{kg} / \mathrm{hora}$ de cloridrato de lidocaína suplementada no soro, doses de 4 a 6 $\mathrm{mL}$ em bolus venoso foram administradas nesses animais. Nos animais onde as arritmias não foram controladas e as fibrilações ventriculares ocorreram, o cardioversor desfibrilador foi utilizado. Doses de adrenalina também foram administradas por via endovenosa quando da grande queda de frequência cardíaca. A despeito de todos os procedimentos de cardioversão e medicamentosos utilizados, a reversão do quadro de fibrilação ventricular foi pouco eficiente $(71 \%$ dos animais que fibrilaram, não reverteram, ou seja, $23,8 \%$ de um total de 21 animais - Figura 14B e Tabelas 1 e 2). 
Apêndice A

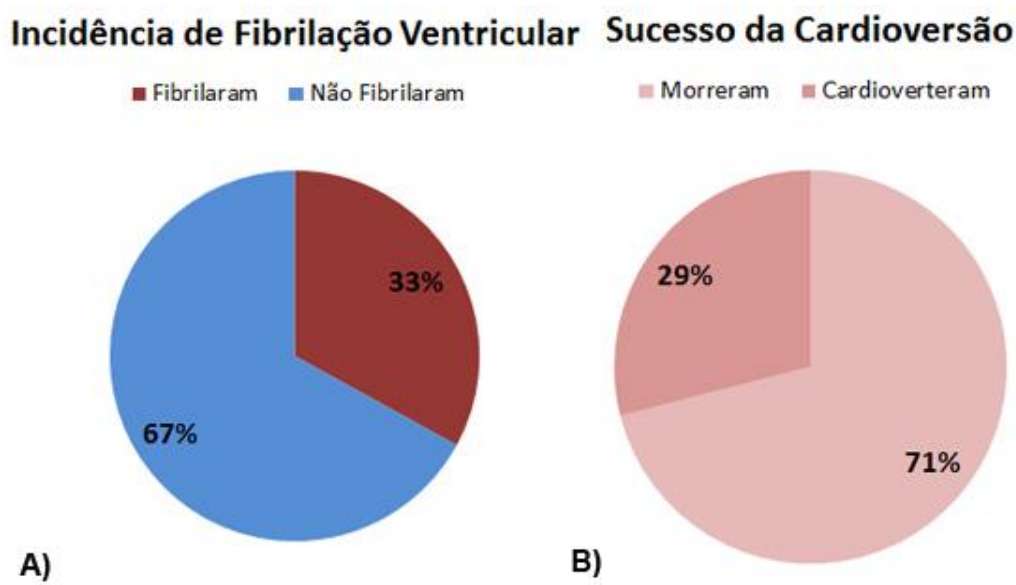

Figura 14: Fibrilação ventricular no modelo de oclusão de ACX. A) com o uso do cloridrato de lidocaína houve uma redução significativa na incidência de fibrilação ventricular após 30 minutos da oclusão de $\operatorname{ACX}(\mathrm{n}=21)$. B) Evitar a fibrilação é essencial para o sucesso do protocolo de indução visto que a índice de reversão é muito baixo (ver também mortalidade total em tabela $2-n=7$ )

\section{Tempo de procedimento}

Para o desenvolvimento deste grupo de animais o tempo médio de procedimento para indução de infarto do miocárdio foi de cinquenta e quatro minutos, desde a intubação orotraqueal até o fechamento da incisão na pele. Em média foram necessários vinte e três minutos até a introdução da primeira prótese na região proximal de ACX e trinta minutos após o inicio da oclusão para realizar a retirada dos cateteres e a sutura da pele. Após fechamento da incisão os animais foram mantidos ainda sob ventilação mecânica até recuperação espontânea da respiração, o que em alguns casos levou até duas horas após a sutura da pele.

A manutenção dos animais no respirador mecânico até completa recuperação espontânea da respiração bem como dos sinais de consciência foram pontos diferenciais para que 0 animal apresentasse uma recuperação pós-procedimento, mais rápida e sem complicações tardias. As tentativas forçadas de desmame dos animais em geral conduziram os animais a quadros 
Apêndice A

de estresse com episódios de taquicardia ventricular e FV não sendo uma prática aconselhada.

\section{Número de próteses de poliuretano implantadas}

Para completa obstrução do lúmen de ACX foram implantadas de 1 a 4 próteses de poliuretano por animal. O número de próteses implantadas variou de caso para caso. Através de uma angiografia realizada após 5 minutos da colocação da primeira prótese, foi avaliada a necessidade de adição de nova prótese. Nos casos onde após 5 minutos foi observado fluxo sanguíneo, mesmo que residual, uma nova prótese foi adicionada, até que a obstrução de ACX fosse completa (Figura 15). Dos 21 animais submetidos a oclusão por próteses de poliuretano somente 2 animais tiveram 0 luz de ACX completamente ocluída com apenas uma prótese, duas próteses foram suficientes para ocluir a coronária da maioria dos animais (13 porcos), quatro animais precisaram de 3 próteses e apenas dois animais precisaram de 4 prótese para obtenção da completa obstrução de ACX (Figura 15D). 
Apêndice A
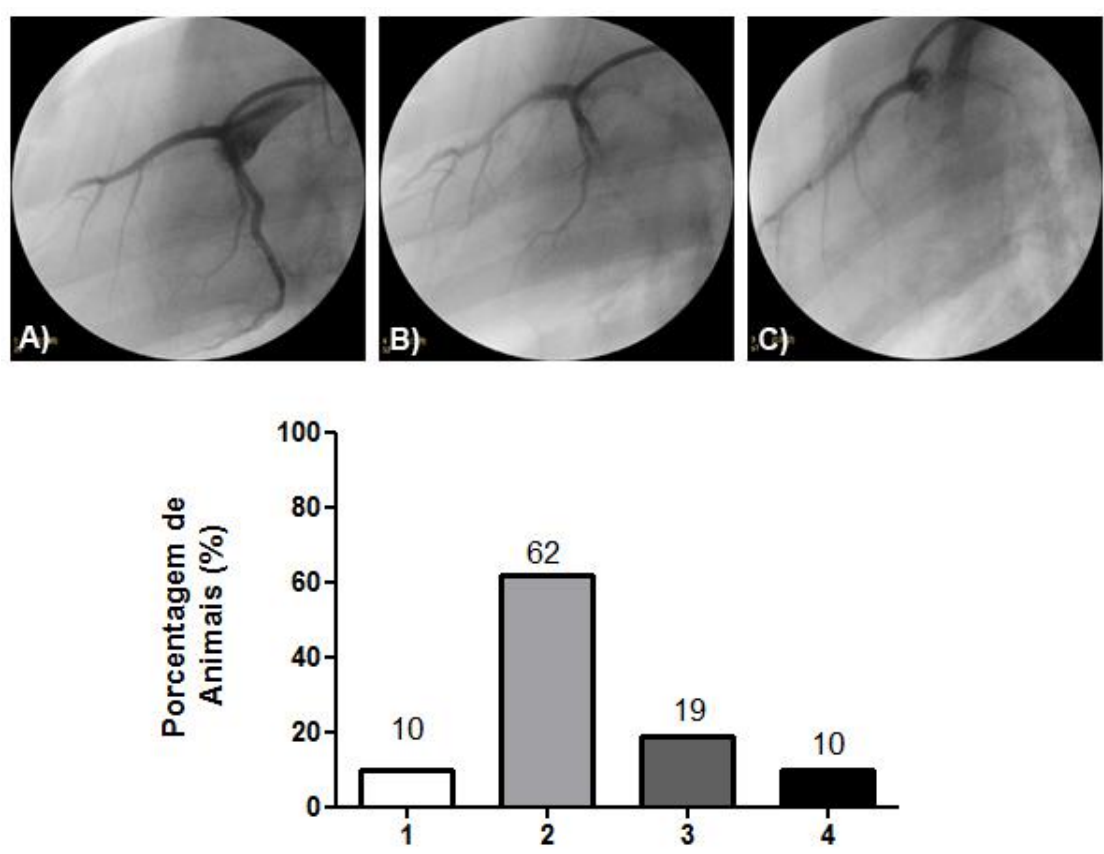

D)

$\mathrm{N}^{\circ}$ de Próteses Implantadas

Figura 15: Número de próteses implantadas para ocluir $100 \%$ do fluxo de ACX. A) Angiografia representativa da coronária ACX antes da obstrução. B) Nesta angiografia pode-se observar que há fluxo residual em ACX. C) após adição do número necessário de próteses a oclusão de ACX é completa $(n=21)$.

\section{Avaliação da homogeneidade e reprodutibilidade do modelo percutâneo de indução de IM em porcos}

Após ter sido demonstrada a superioridade do modelo de infarto por indução percutânea sobre o modelo de AMC e serem estabelecidas as condições ideais para a realização do primeiro, em porcos, este animais foram seguidos por 30 dias após a oclusão e a lesão gerada pela oclusão de ACX foi caracterizada detalhadamente com objetivo de avaliar sua homogeneidade e reprodutibilidade.

\section{Marcador precoce de isquemia - Distúrbios de condução elétrica}

O primeiro indício de que o modelo percutâneo de infarto desenvolvido foi eficiente em ocluir a artéria alvo pode ser visualizado através do eletrocardiograma (ECG), Sabidamente desnivelamentos do segmento ST do 
Apêndice A

ECG podem ser associados com alguns tipos de infartos do miocárdio (2426). No protocolo aqui demonstrado, todos os animais apresentaram distúrbio de condução elétrica sendo possível observar desnivelamento do segmento ST pelo ECG, em diferentes derivações, após a oclusão total de ACX (Figura 16A e B). O tempo para que fosse possível observar esse tipo de alteração no perfil do ECG variou conforme observado na Figura 16C.

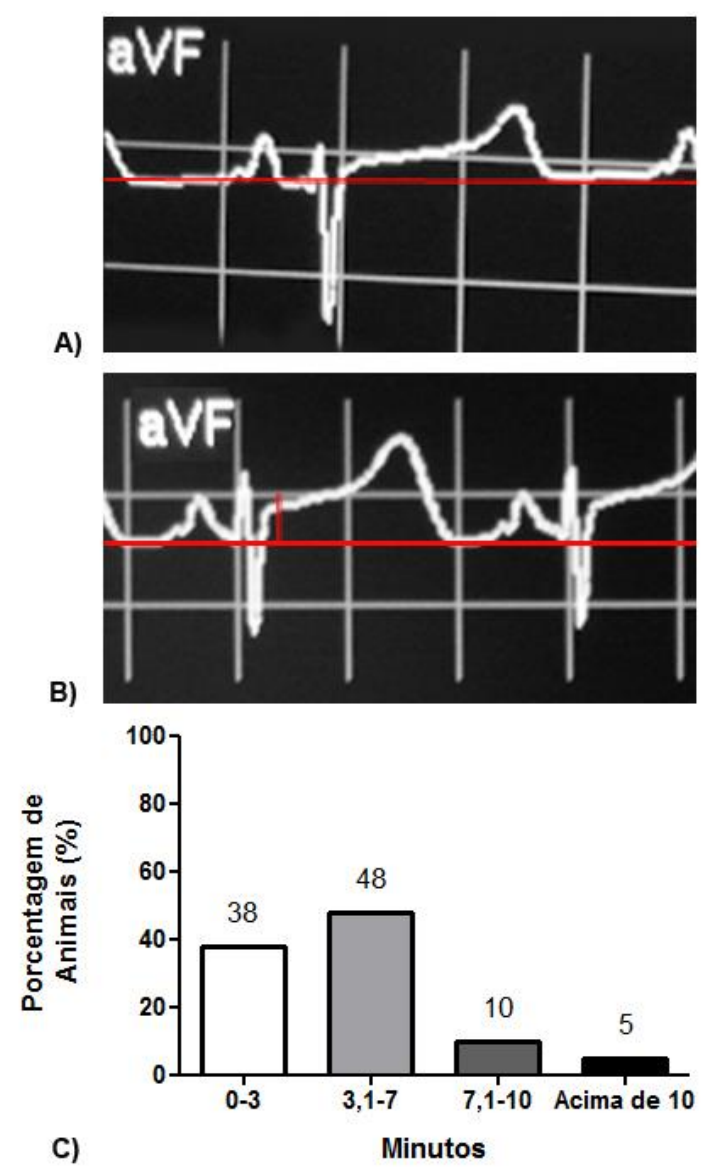

Figura 16: Distúrbio de condução elétrica - Um marcador precoce de lesão decorrente de isquemia. A) Eletrocardiograma representativo de traçado normal para porcos. B) Eletrocardiograma representativo de traçado alterado precocemente após oclusão de ACX, este desnivelamento tende a aumentar ficando muito evidente com a passar do tempo. C) Quantificação do tempo para obtenção do desnivelamento de ST, notar que esse marcador se apresenta precocemente tendo a maior parte dos animais apresentado tal alteração entre 1 e 5 minutos após oclusão de $\mathrm{ACX}(\mathrm{n}=21)$.

Parâmetros fisiológicos (Frequência cardíaca, saturação de Oxigênio e pressão arterial média) 
Apêndice A

Durante todo o procedimento os animais foram mantidos sob monitoramento de frequência cardíaca, saturação e medida direta de pressão. Não foram observadas alterações significativas na frequência cardíaca e nem na saturação média $\mathrm{O}_{2}$ (intubação orotraqueal) durante todo o período avaliado (Figura 17A-D). Por outro lado, diferenças significativas foram observadas na pressão arterial média (Figura 17E e F). Após oclusão total de ACX a pressão sanguínea média de todos os animais caiu em média $18 \mathrm{mmHg}$.

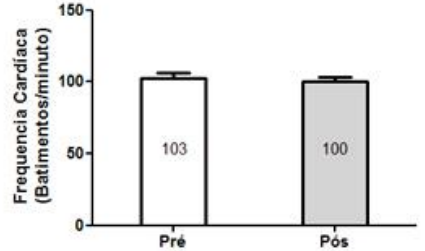

A)

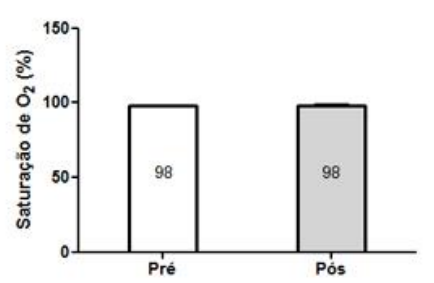

C)

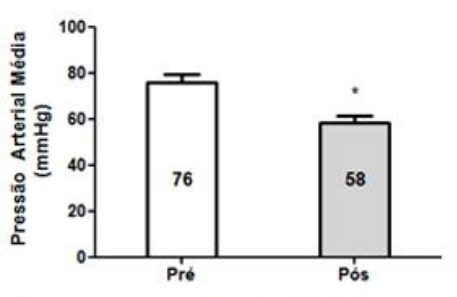

E)
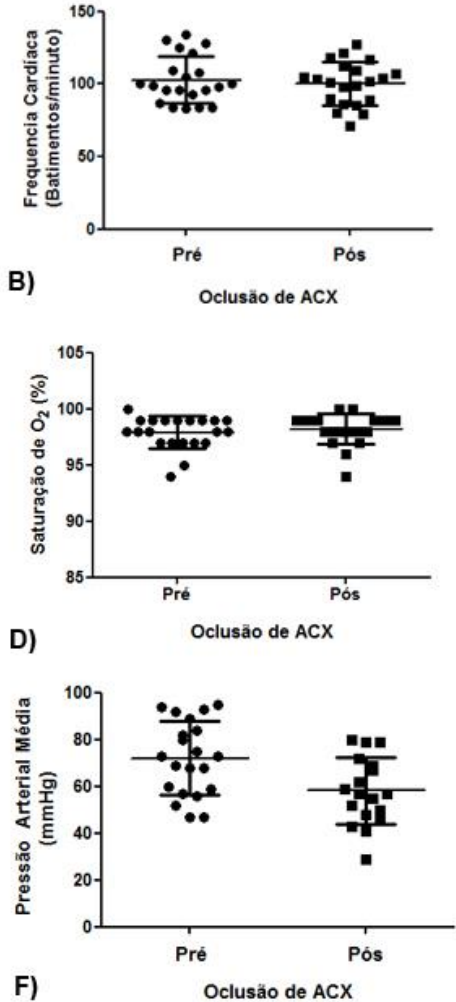

Figura 17: Monitoramento durante procedimento de indução de infarto do miocárdio. A) Não houve diferenças na frequência cardíaca média dos animais antes e após a oclusão de ACX. B) Observar a distribuição de frequência do animais. C e D) Não houve diferenças na saturação média de oxigênio dos animais antes e após a oclusão de ACX. E e F) Observou-se uma redução significativa da pressão sanguínea média dos animais após a oclusão de ACX; $p<0,05 ; n=21$.

\section{Marcadores bioquímicos de necrose - Confirmação do infarto do miocárdio}


Apêndice A

Para avaliar se a obstrução de ACX através do implante de prótese de poliuretano foi eficiente em gerar um modelo de infarto do miocárdio foram usados exames clínicos bioquímicos clássicos como padrão para diagnóstico de infarto. Estes testes são capazes de detectar proteínas no soro do sangue dos porcos oriundas do extravasamento destas quando da morte celular por necrose, caracterizando o infarto.

Foi identificado um aumento progressivo das concentrações de Troponina T e CKMB circulantes, atingindo os níveis diagnósticos (27) após a obstrução de ACX. Os níveis de referência para diagnóstico de infarto do miocárdio foram alcançados em média 3 horas após a oclusão para o teste de troponina $T$ ultrassensível (limite de $0,1 \mathrm{ng} / \mathrm{mL}$ ) e em média 6 horas para CKMB (limite de 5 $\mathrm{ng} / \mathrm{mL}$ ), ambos se mantendo elevados até o final da dosagem (Figura 18). Estes resultados demonstram que o modelo acima discutido foi capaz de gerar uma lesão por necrose acarretando na falência de parte da musculatura cardíaca devido à morte celular, como esperado. 
Apêndice A
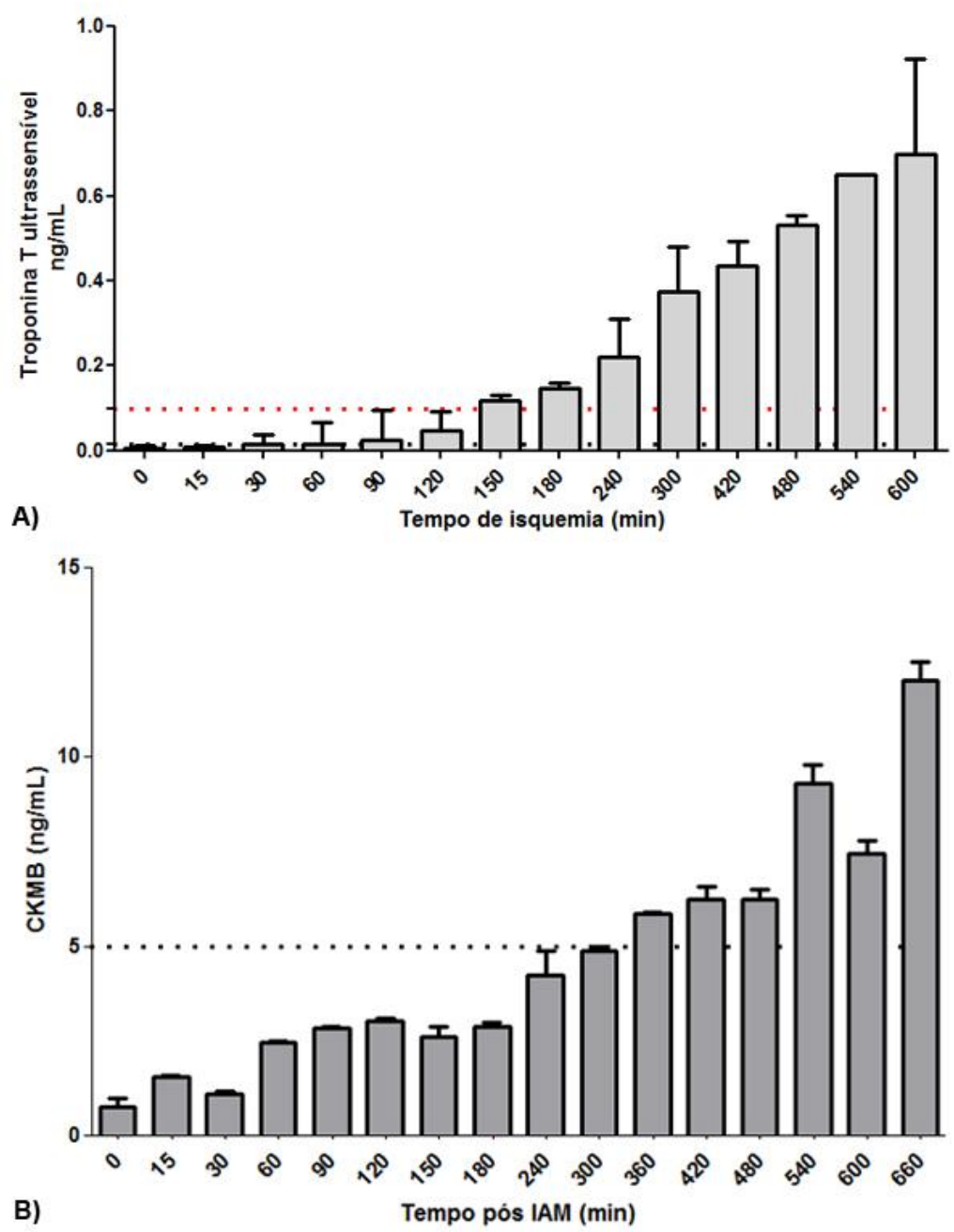

Figura 18: Diagnostico bioquímico de infarto do miocárdio. A) Medida seriada de Troponina T circulante por método ultrassensível. Observa-se que a partir de 3 horas da oclusão é possível detectar níveis que diagnosticam infarto do miocárdio (limite teste 0,014 $\mathrm{ng} / \mathrm{mL}$, limite inferior para infarto acima de $0,1 \mathrm{ng} / \mathrm{mL}-\mathrm{N}=4$ ). B) Medida seriada de CK-MB circulante (limite teste e limite inferior para infarto acima de $5 \mathrm{ng} / \mathrm{mL}-\mathrm{N}=2$ ). A partir de 6 horas da oclusão é possível detectar níveis que diagnosticam infarto do miocárdio.

\section{Função cardíaca prejudicada - Ecocardiografia transtorácica}

Trinta dias após a indução do infarto pelo protocolo endovascular, através do ecocardiograma transtorácico de estresse com dipiridamol, foram feitas avaliações de morfologia função e perfusão do coração dos animais (Tabela 4 e 5). 
Apêndice A

Tabela 4: Dados de morfologia e função por ecocardiograma transtorácico

\begin{tabular}{lllllll} 
& & \multicolumn{9}{c}{ Sadios $(\mathbf{n}=7)$} & \multicolumn{2}{c}{ IM $(\mathbf{n}=15)$} \\
& & Média & \pm DP & Média & \pm DP & \\
\hline Área afetada & $(\%)$ & $x$ & $\pm x$ & 10.87 & \pm 2.73 & \\
Septo & $(\mathrm{cm})$ & 0.41 & \pm 0.02 & 0.53 & \pm 0.08 & $*$ \\
Parede Posterior & $(\mathrm{cm})$ & 0.44 & \pm 0.02 & 0.39 & \pm 0.07 & \\
DDIF & $(\mathrm{cm})$ & 3.33 & \pm 0.21 & 4.38 & \pm 0.32 & $\S$ \\
DSIF & $(\mathrm{cm})$ & 2.01 & \pm 0.17 & 3.50 & \pm 0.39 & $\S$ \\
FECVE & $(\%)$ & 39.55 & \pm 6.09 & 19.95 & \pm 7.43 & $\ddagger$ \\
VDF & $\left(\mathrm{cm}^{3}\right)$ & 45.41 & \pm 7.02 & 87.44 & \pm 14.44 & $\ddagger$ \\
VSF & $\left(\mathrm{cm}^{3}\right)$ & 13.00 & \pm 2.80 & 51.92 & \pm 13.13 & $\ddagger$ \\
FEVE & $(\%)$ & 70.97 & \pm 7.29 & 40.37 & \pm 13.00 & $\dagger$ \\
Massa de VE & $(\mathrm{g})$ & 30.89 & \pm 3.73 & 54.41 & \pm 8.42 & $\ddagger$ \\
\hline
\end{tabular}

Abreviações: DDIF: diâmetro diastólico interno final; DSIF: diâmetro sistólico interno final; FECVE: Fração de encurtamento de VE; VDF: Volume diastólico final; VSF: volume sistólico final; FEVE: fração de ejeção de VE; VE: ventrículo esquerdo, DP: desvio padrão, IM: infarto do miocárdio. ${ }^{*} \mathrm{P}<0.05 ; \mathrm{P}<<0.005 ; \mathrm{P} P<0.0002$, §P $<0.0001$; Student's $\mathrm{t}$-test IM vs. animais sadios.

Foi observada a motilidade do ventrículo esquerdo por segmentos. Todos os animais infartados apresentaram lesão na parede posterior: segmento inferior, ínfero-lateral e lateral, sendo possível observar hipocinesia ou mesmo acinesia destes segmentos.

Quando da avaliação dos parâmetros morfológicos dos quais foram gerados dados funcionais, observou-se uma fração de encurtamento do VE baixa $(19,95 \%$ após estresse, Tabela 4). Este parâmetro demonstrou o encurtamento prejudicado de VE compatível com a lesão da parede posterior e a repercussão desta sobre a capacidade contrátil do VE. O dano causado ao VE também ficou evidente ao se avaliar a fração de ejeção de VE, observou-se que a lesão comprometeu importantemente a função cardíaca do órgão (Fração de ejeção de VE; IM 40,37\% VS. 70,97\% controle sadio - Tabela 4). Interessantemente, todos os animais avaliados apresentaram insuficiência mitral variando de moderada até importante (Figura 19A). Devido à lesão 
Apêndice A

gerada acometer a parede posterior de VE, há uma retração da musculatura papilar nessa região (Figura 19B). Retraído, o músculo papilar traciona as cordoalhas tendínosas gerando uma força sobre a cúspide posterior e causado o mau fechamento da mesma.
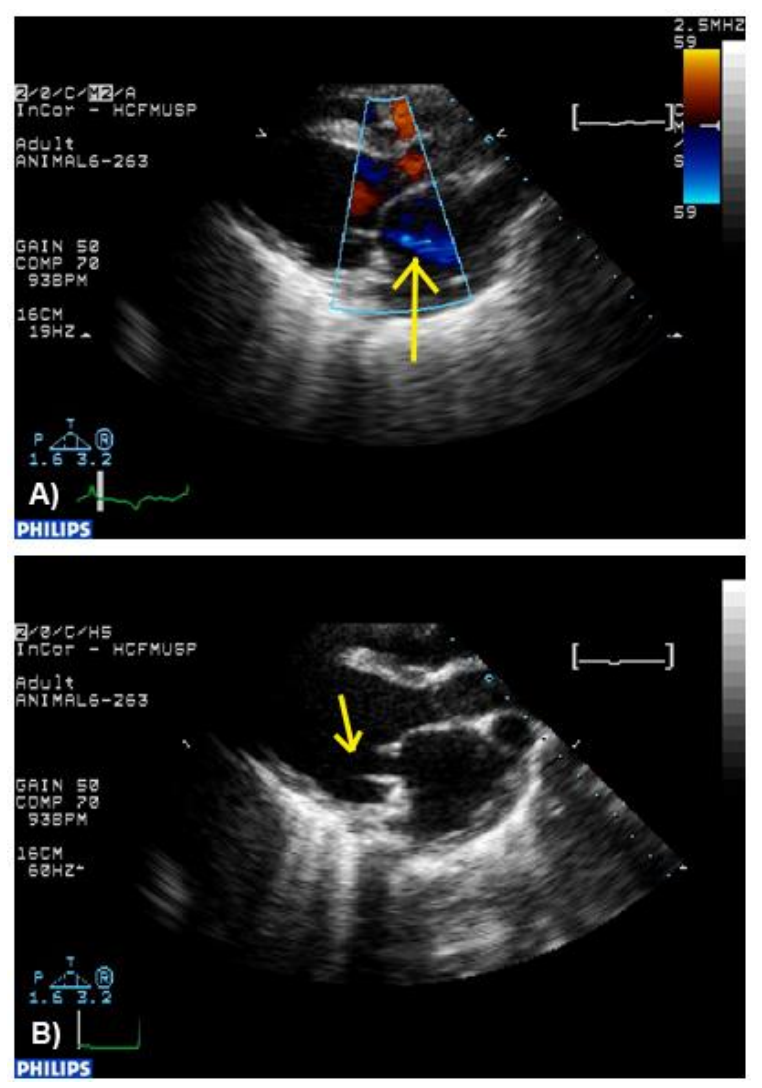

Figura 19: Insuficiência Mitral em porcos infartados. A) Imagem representativa de ecocardiografia de fluxo em cores, eixo paraesternal-longo, note jato de retorno de fluxo que vem de VE para a cavidade do atraio esquerdo quando da válvula mitral coaptada (seta amarela). B) Imagem representativa de ecocardiografia bi-dimensional, eixo paraesternallongo, note retração da cúspide posterior da válvula mitral (seta amarela).

Além disso, com auxilio de um contraste de microbolhas foi possível observar uma redução drástica no volume de sangue miocárdico da região infartada (Reserva A - Tabela 5), bem como na velocidade do fluxo sanguíneo (Reserva $\beta$ ) da mesma região (Figura 20). Estes dados foram traduzidos em fluxo sanguíneo miocárdico (FSM - Reserva A x Reserva $\beta$ - Tabela 5) o qual é afetado drasticamente na região da parede posterior (lesão). 


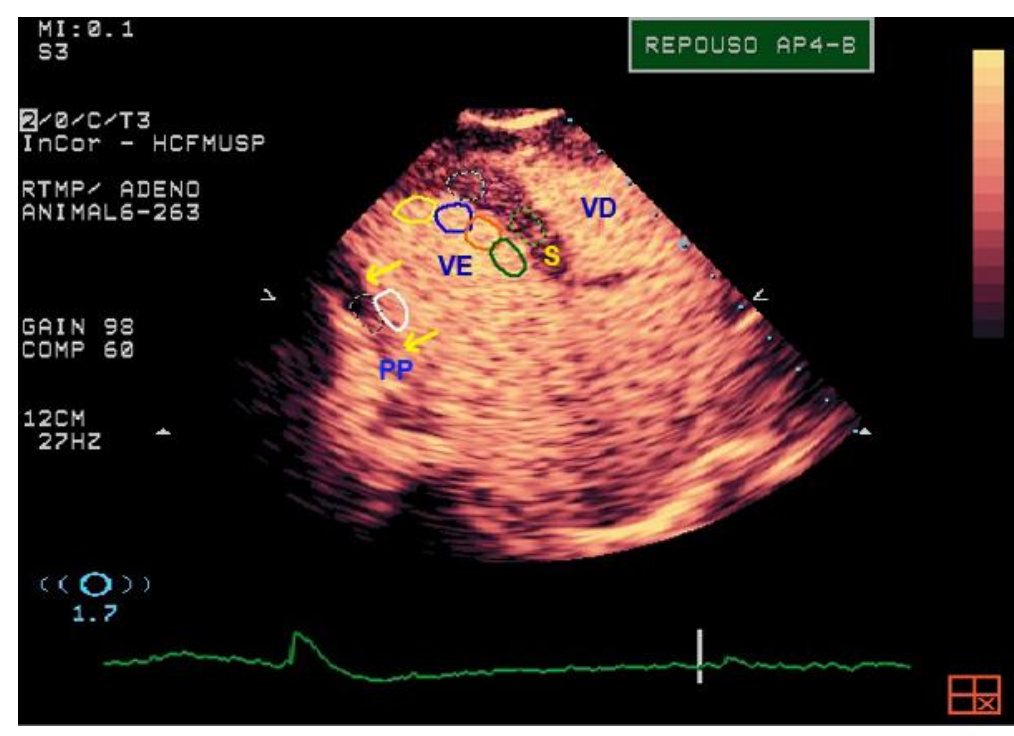

Figura 20: Ecocardiografia com contraste. Note que é possível ver uma diferença bastante marcante entre a espessura da parede posterior (PP - área de lesão) vs. Septo interventricular (S). As áreas demarcadas com figuras pontilhadas representam as áreas onde foi medido o fluxo sanguíneo miocárdico, já as figuras continuas, representam as área de cavidade medidas para fazer a correção da densidade do contraste entre a cavidade e a parede miocárdica. Note que na parede posterior há uma quantidade infinitamente menor de contraste quando comparada ao septo interventricular.

Tabela 5: Fluxo sanguíneo miocárdico (FSM)

\begin{tabular}{ccccccccc} 
& & \multicolumn{3}{c}{ Área remota } & \multicolumn{3}{c}{ Área de Infarto } \\
Variável & \multirow{2}{*}{ Unidade } & média & \pm & Desvio & média & \pm & desvio \\
\hline Reserva $A$ & & 2,13 & \pm & 0,51 & 0,75 & \pm & 0,23 \\
\multirow{2}{*}{ Reserva $\boldsymbol{\beta}$} & & 2,17 & \pm & 0,61 & 0,73 & \pm & 0,20 \\
\hline FSM & $(\mathrm{A} \times \beta)$ & 4,86 & \pm & 2,45 & 0,58 & \pm & 0,28 \\
\hline
\end{tabular}

Resumidamente todos os dados obtidos pela ecocardiografia transtorácica corroboram para a eficiência na geração do IM através do modelo de indução endovascular.

\section{Avaliações histopatológicas}

Área de necrose e hipertrofia - Avaliações macroscópicas 
Apêndice A

Após sacrifício o coração dos animais foi retirado, dissecado para obtenção do ventrículo esquerdo. O ventrículo foi fatiado do ápice até a base (aprox. 7 fatias de $5 \mathrm{~mm}$ cada) e as fatias submetidas a coloração de TTC para avaliar a viabilidade do músculo, bem como a área de necrose. Após coloração foi possível observar um padrão de lesão semelhante em todos os animais. A lesão se estendeu da base do coração até o ápice em forma de um triangulo invertido (Figura 21 A e B) atingindo a parede posterior nos segmentos inferior e ínfero-lateral (Figura 21B). Em média 10,95\% do ventrículo esquerdo foram atingidos pela lesão (Figura 21C). Além disso, os valores de área de lesão obtidos por análise macroscópica demonstraram alta correlação com as medidas de área baseadas em ultrassom, realizadas por ecocardiografia (Figura 21 D). Este dado tem grande relevância do ponto e vista que é possível, utilizando de uma técnica não invasiva, estimar a área de infarto dos animais infartados por este protocolo antes que esses façam parte de protocolos experimentais, uniformizando os futuros resultados obtidos a partir desse modelo.

Ainda avaliando a área de infarto obtida pela obstrução de ACX pelo modelo percutâneo de oclusão dados de medida de colágeno intersticial foram obtidos, outro parâmetro amplamente utilizado para demonstrar a ocorrência de hipertrofia de VE $(28,29)$. Na área acometida pela lesão, mais de $50 \%$ de colágeno foi observado no interstício das fibras. Já na porção remota a lesão cerca de $5 \%$ de colágeno foi observado no interstício do músculo cardíaco (Figura $21 \mathrm{E}-\mathrm{G}$ ) enquanto que em animais saudáveis esses valor não superou $2 \%$ em toda a extensão do ventrículo esquerdo. 

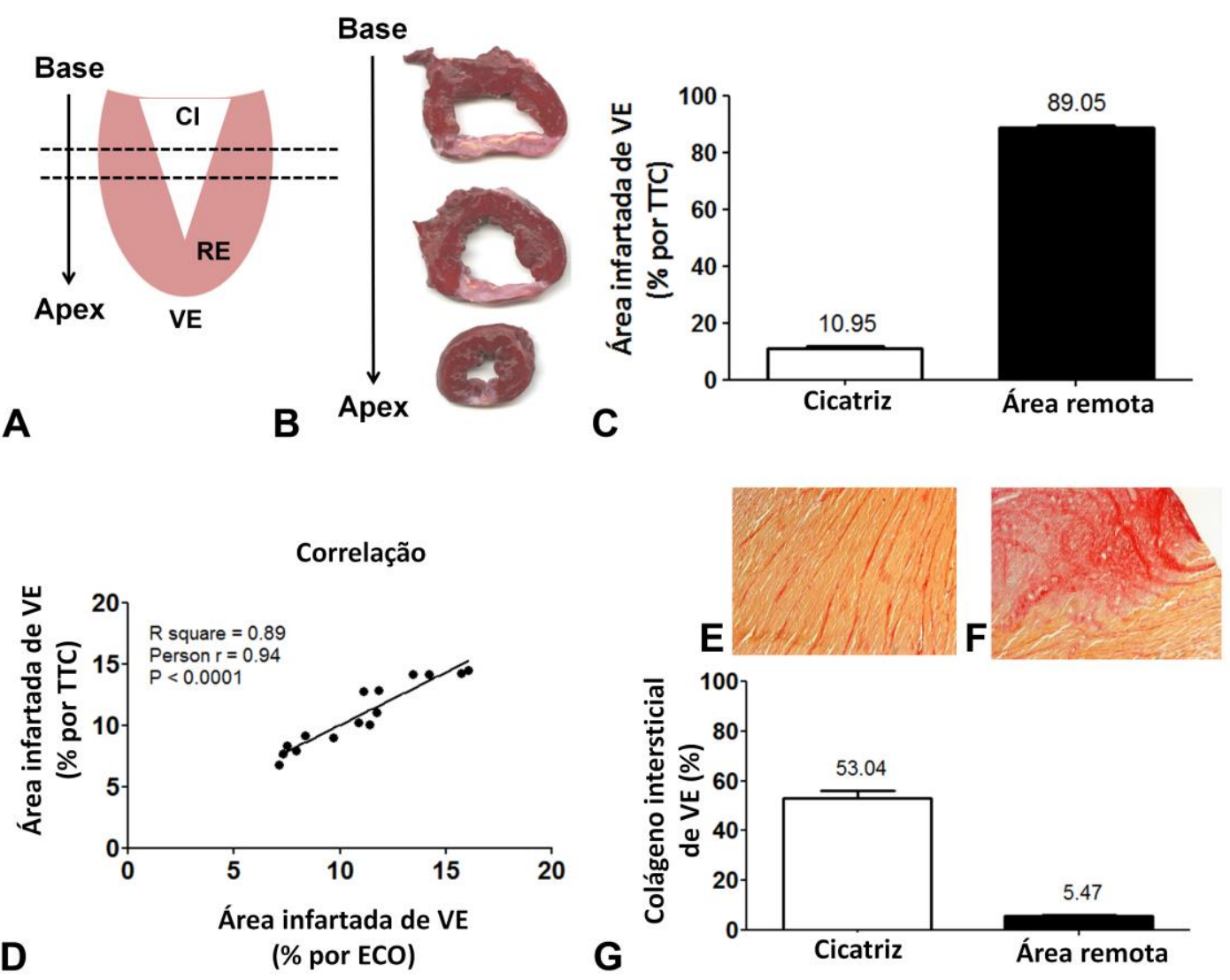

Figura 21: Padrão macroscópico da lesão no VE de porco infartados por oclusão endovascular de ACX. A) Desenho esquemático representando morfologia da lesão na parede posterior. B) Corte seriado de VE da base ao ápice. Note que lesão se estende por quase o VE. C) Quantificação da área de infarto dos animais submetidos ao protocolo $(n=15)$. D) Análise de correlação entre as medidas de área de infarto realizadas por histopatologia e Ecocardiografia transtorácica. E e F) Figuras representativas do tecido remoto e da cicatriz respectivamente corados com picrossirius red. G) Quantificação da porcentagem de colágeno intersticial presente na área remota e cicatriz de VE dos animais infartados pelo métodos endovascular (valor médio da porcentagem de cológeno intersticial em animais sadios e de $2 \%$ em toda a extensão de VE; $P<0,001)$.

Nestas lâminas observou-se ainda uma clara alteração no tamanho das células ainda viáveis na área de lesão, sendo que estas apresentaram cerca de 5-10 vezes maior volume do que as células na região remota a lesão (200X magnificação para ambas as fotos - Figura 22). Visto que o aumentou de colágeno no interstício das fibras cardíacas é parte do processo de remodelamento cardíaco pós-infarto (30), estes dados corroboram com a ideia de que o modelo percutâneo de infarto padronizado cursa com morte por 
Apêndice A

necrose seguida de uma cascata de eventos que culminam no remodelamento cardíaco como observado por outros grupos de pesquisa em outros modelos de infarto $(28,29)$.
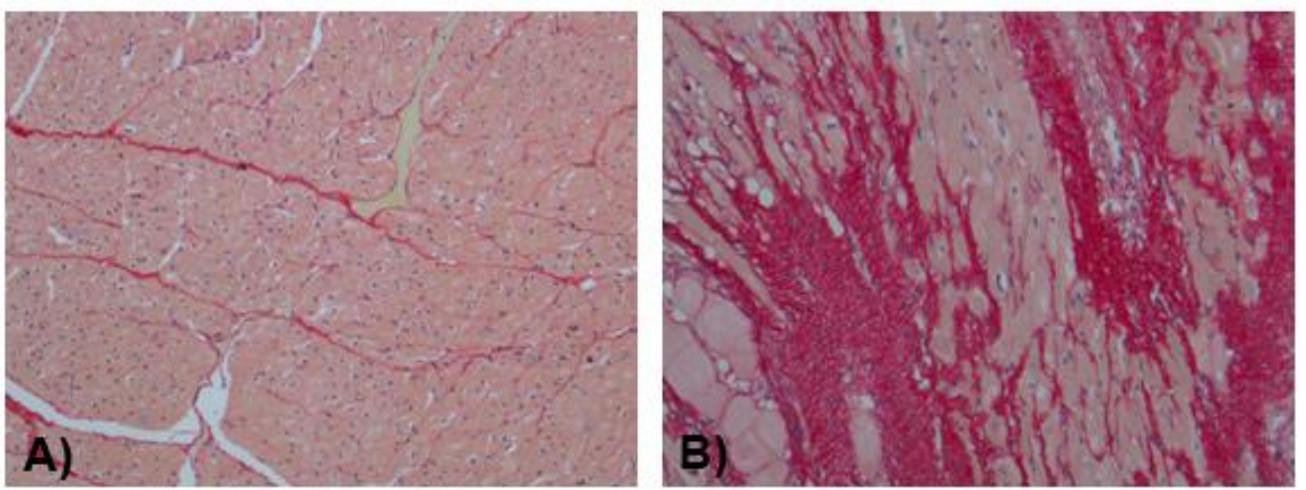

Figura 22: Cortes histológicos de coração corados com picrossirius red - Evidencia de aumento no colágeno intersticial. A) Figura representativa de área remota o infarto. Note fibras colágenas (rosa escuro) evidenciadas no interstícios das fibras musculares e a organização do tecido cardíaco. B) Corte de área de lesão. Note aumento exacerbado na quantidade de fibras de colágeno no interstício muscular e também infiltradas nas regiões que anteriormente foram ocupadas por cardiomiócitos sadios (dados parcial reproduzido na Figura $9 A$, página 45 desta tese).

Lâminas histológicas da área remota, zona de borda e infarto propriamente dito, foram coradas com hematoxilina e eosina, e como esperado, foi possível observar o padrão clássico de desorganização das fibras musculares, bem como a substituição do tecido muscular por tecido fibroso, nas regiões de transição entre borda e IM (Figura 23). 
Apêndice A
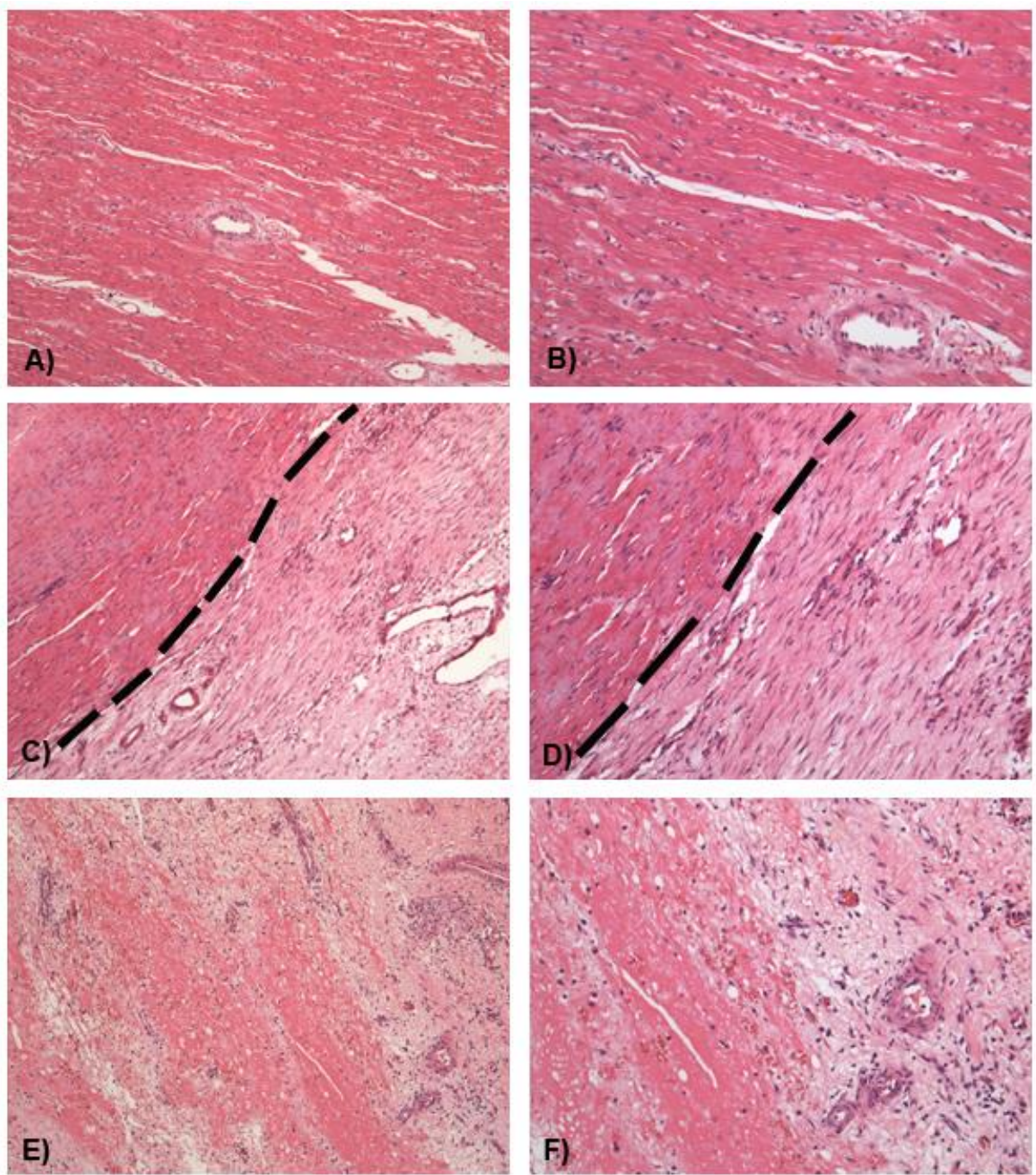

Figura 23: Cortes histológicos do coração 30 dias pós-infarto. A e B) Corte longitudinal de tecido cardíaco da área remota ao infarto (septo interventricular). Note a organização normal das fibras musculares. C e D) Corte longitudinal de tecido cardíaco da borda do infarto. Note que na linha tracejada há uma clara diferença de organização e composição do tecido. E e F) Corte longitudinal de tecido cardíaco da área de infarto (parede posterior). Note a completa desorganização das fibras musculares. Todos os cortes foram corados com H\&E (A, C E com 100X magnificação e B, D e F com 200X magnificação); $n=15$.

\section{Padronização das técnicas de cirurgia e injeção de células-tronco diretamente no miocárdio (via intramiocárdica)}

Neste item segue uma sequencia de resultados expostos de forma descritiva demonstrando os percalços e soluções encontradas para a obtenção de um procedimento cirúrgico adequado de injeção de células-tronco no coração. 
Apêndice A

\section{Acesso a lesão}

Para o futuro uso do modelo de infarto nos protocolos de terapia com células-tronco, após toda a caracterização e confirmação da homogeneidade e reprodutibilidade do modelo, foi necessário o estudo da anatomia do infarto do miocárdio gerado no coração dos porcos, in vivo, bem como a aplicabilidade dos procedimentos cirúrgicos suportáveis por esses animais e também procedimentos pós-operatórios. Para tanto, alguns animais foram submetidos aos procedimentos cirúrgicos completamente estéreis (compatíveis com procedimentos cirúrgicos aplicados em humanos) e receberam injeções de solução tampão de fosfato (PBS).

Para que fosse possível atingir a área de lesão, que se encontrava nos segmentos lateral, inferior e ínfero-lateral do ventrículo esquerdo, como detectado no exame de ecocardiograma, foi realizada uma toracotomia lateral esquerda na altura do quarto espaço intercostal (Figura 24A). Como porcos são animais quadrupedes, a posição anatômica do coração deste animal é levemente alterada quando comparada com o coração de bípedes como os humanos. Esta diferença anatômica implica numa torção leve para o lado direito do corpo dos animais, fazendo com que o órgão fique mais distante da abertura por toracotomia lateral, quando estes estão em decúbito lateral direito. Para facilitar tal procedimento os animais tiveram o tórax, do lado direito (em contato com a mesa cirúrgica), elevado com o auxilio de um "calço" confeccionado com um campo cirúrgico. Deste modo, todo o tórax foi elevado, elevando também o coração, expondo assim quase toda a extensão da lesão 
Apêndice A

(principalmente paredes lateral, posterior, e ínfero-lateral) sem que fossem necessárias manobras excessivas do órgão.

Durante a dissecção dos músculos na parede lateral esquerda foi necessário o cuidado de ocluir a veia e artéria mamaria esquerdas para evitar extravasamento exacerbado de sangue (Figura 24B). Outro cuidado importante foi tomado quando do final da dissecção para que não houvesse lesões do átrio esquerdo. Na maioria dos casos foi possível observar um aumento no volume do átrio esquerdo dos animais através do Eco transtorácico, sendo esse apêndice tensionado contra a parede torácica, o que elevou o risco de acidentes durante a abertura os músculos intercostais. Nos primeiros casos, tal contato com o átrio, acarretou em acidentes onde houve perfuração do mesmo e sangramento excessivo, sendo necessária rápida intervenção para evitar a morte prematura do animal.

Ao final da dissecção muscular e passados os pontos críticos da abertura do tórax, foi possível observar o pericárdio. Este então foi seccionado (Figura 24C e D), sendo preservado o nervo frênico, e amarrado para posterior fechamento. 
Apêndice A
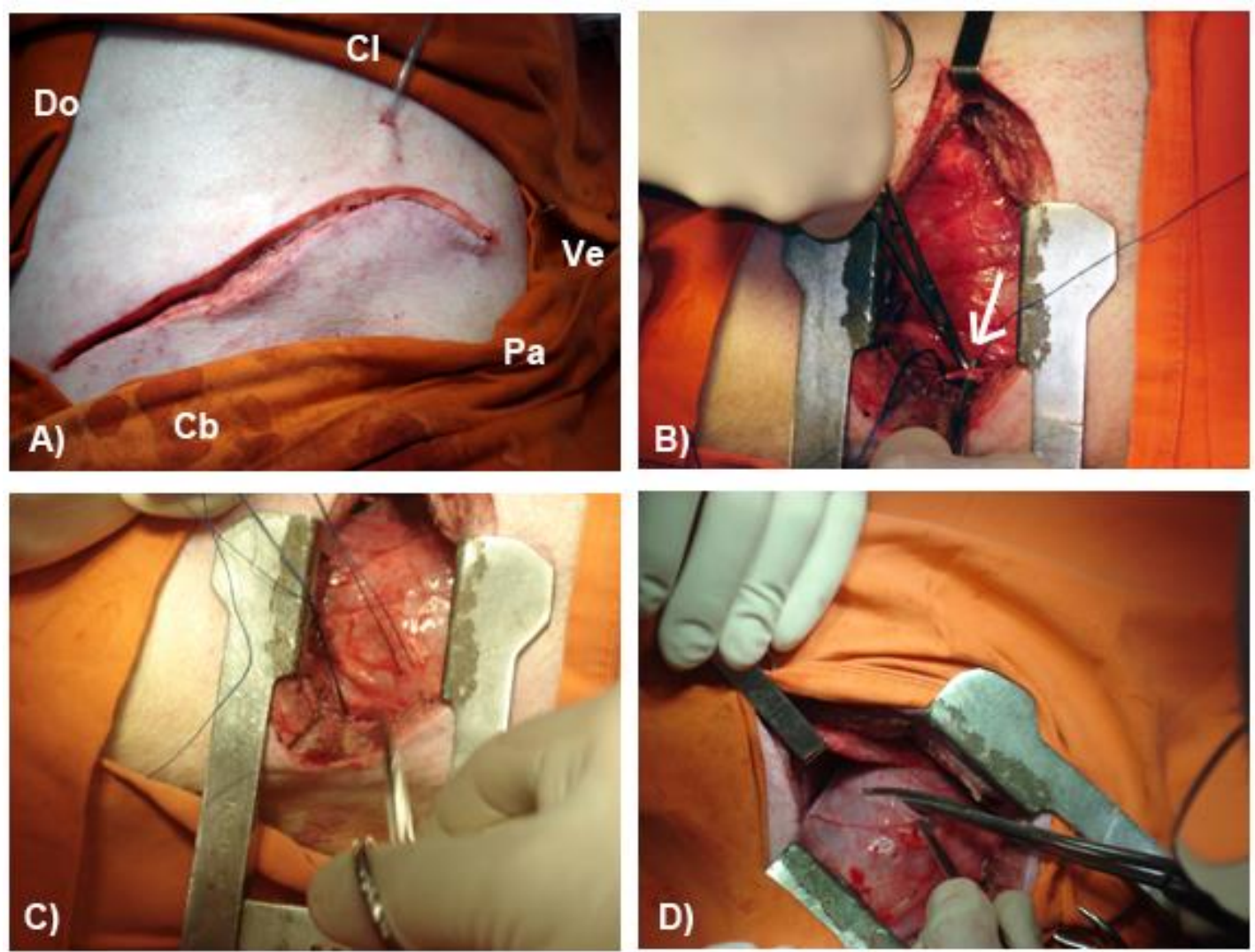

Figura 24: Cuidados para abertura e exposição do coração. A) Tamanho e local da incisão para acesso ao coração. Cb; cabeça; Cl: cauda; Ve: ventre; Do: dorso; Pa: pata anterior. B) note artéria mamária apontada pela seta. C) Com auxílio de fios de algodão o pericárdio é seguro, D) para então ser cortado e amarado para posterior sutura ao final do procedimento de injeção.

A lesão causada pela oclusão de ACX não foi observada, a olho nu, de forma tão clara e delineada como era o esperado para todos os animais (Figura 25). 

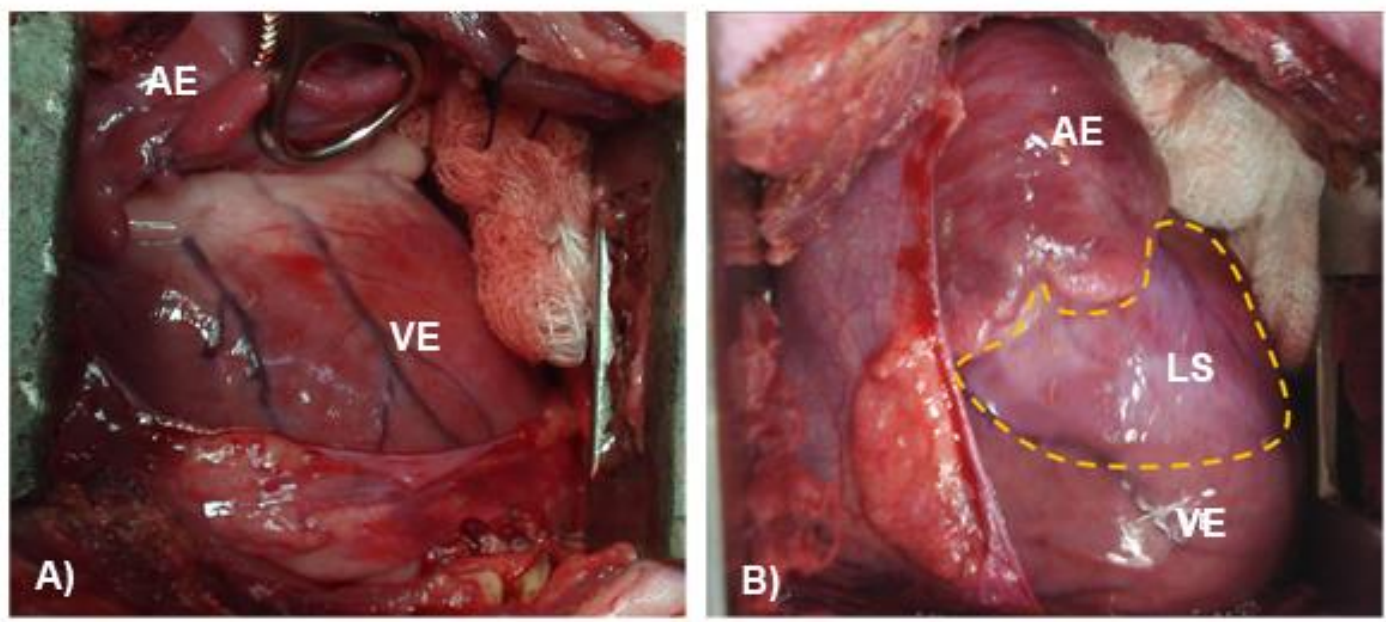

Figura 25: Não há um padrão de visualização da lesão em todos os porcos. A) coração de um animal onde a lesão não é visualizada a olho nu. B) coração de um animal que apresenta uma lesão bem demarcada e visualizável a olho nu. Ambos os corações apresentam lesões de tamanho semelhante (aprox. 10\%).

Assim, o mapeamento de contratilidade dos segmentos do coração feito com o ecocardiograma foi muito importante para guiar as injeções para a borda do infarto do miocárdio (Figura 26). Contudo, para melhorar o índice de acerto das injeções, uma nova técnica que pudesse colaborar para a localização, no ato cirúrgico, das bordas do infarto foi desenvolvida.

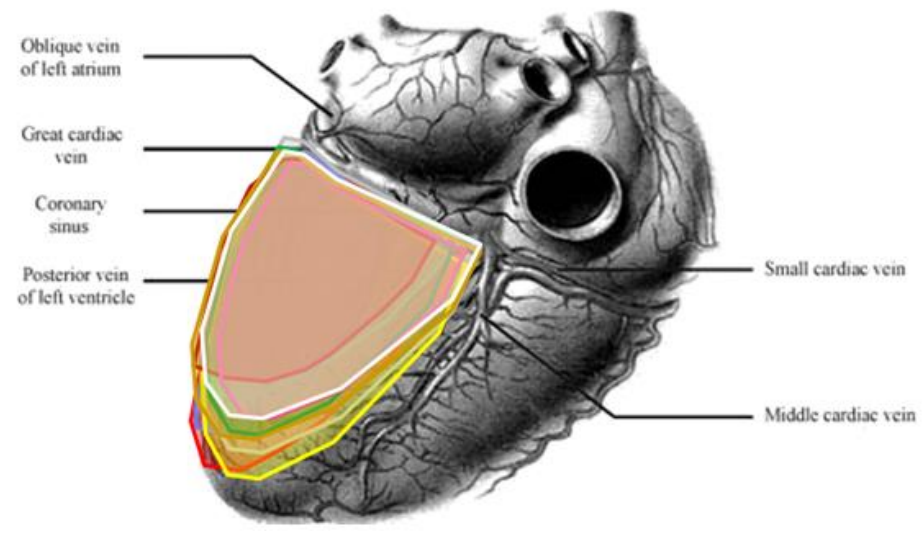

Figura 26: Área de infarto visualizada pelo Ecocardiograma. Figura representativa da extensão e localização da lesão em alguns corações. Este mapa foi desenvolvido a partir da observação da morfologia e capacidade contrátil do ventrículo esquerdo visto em diferentes planos no ecocardiograma.

\section{Mapeamento elétrico epicárdico da lesão}


Apêndice A

Baseado na condução de impulso elétrico pelo coração e utilizando-se do sistema de eletrocardiograma um mapeamento elétrico epicárdico foi realizado. Nas regiões aonde o impulso elétrico chegava de forma adequada foi possível observar um complexo elétrico de alta intensidade e com morfologia mais aproximada da esperada (Figura 27A). À medida que o eletrodo foi posicionado em direção à área de lesão propriamente dita uma diminuição importante do sinal de eletrocardiograma foi observado (Figura 27B), sendo considerada essa a região de transição da lesão, até que um complexo muito pequeno foi observado no centro da lesão (Figura 27C). Desta forma, foi possível, juntamente com o mapeamento feito pelo ecocardiograma, mapear a área de lesão e obter uma referência mais direta para a borda do infarto onde as injeções de PBS foram feitas.

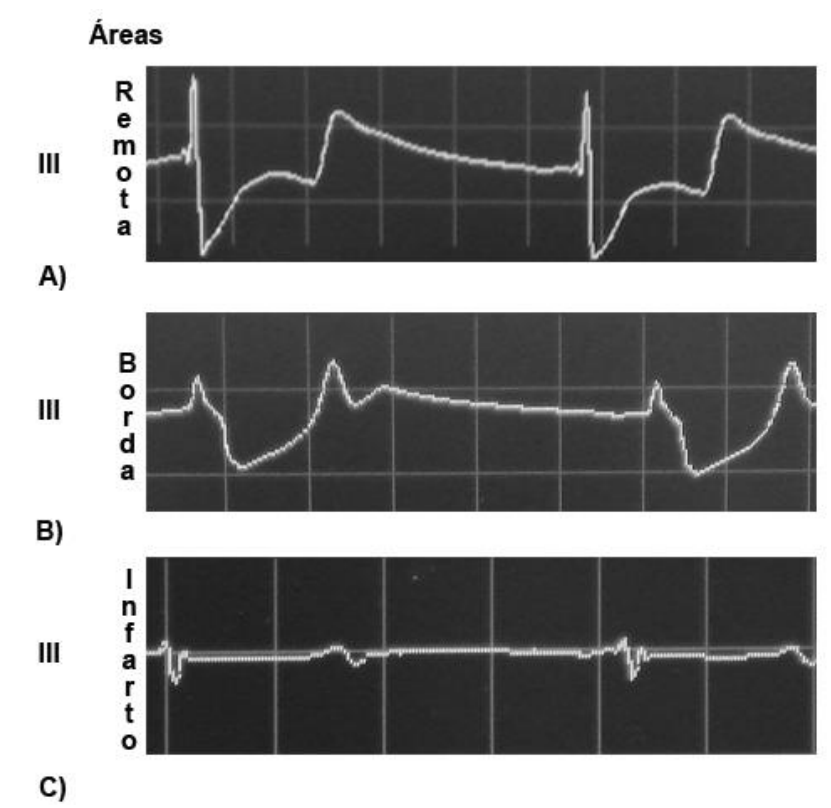

Figura 27: Mapeamento elétrico da parede epicárdica - guia para as injeções. A) eletrodo sobre tecido da zona remota ao infarto. Note que a formação de complexos de alta amplitude e que eles se repetem em períodos compatíveis com o de uma área normal, porém com perfil de zona com repercussão de lesão. B) eletrodo sobre borda do infarto. Note diminuição importante na amplitude do complexo, eles também começam a ser visualizados em tempos maiores de distancia entre um e outro. C) Eletrodo colocado sobre tecido fibroso. Note que o complexo 
Apêndice A

praticamente desaparece, quase não há transmissão de sinal elétrica nesta região, os pequenos complexos formados tornam-se mais distantes. Atentar para as diferenças de escala.

\section{Cuidados pós-operatórios, manutenção da saturação e temperatura corpórea}

Durante as injeções alguns animais apresentaram sensibilidade exacerbada ao contato das agulhas com ventrículo esquerdo. Nestes casos, quadros de taquicardia com extra-sístoles bem demarcadas e com episódios longos e consistentes foram observados. Nestes animais a insistência em injetar a solução de PBS antes que a taquicardia fosse cessada acarretou em fibrilação ventricular e procedimentos de cardioversão foram necessários (uso de medicamentos bem como desfibrilador cardíaco).

Após o termino das injeções, o campo cirúrgico foi averiguado e limpo para que não fossem deixados instrumentos e nem outros materiais usados durante o procedimento no interior da cavidade (ex: gazes e compressas). $O$ pericárdio foi parcialmente fechado com o objetivo de reduzir aderências entre o coração e o pulmão bem como ao gradeado costal evitando assim comprometimento funcional do órgão por adesão do mesmo. Os músculos foram suturados por planos. Ao final da sutura um curativo foi feito sobre a pele para manter o local isolado do contato com bactérias.

O pós-operatório se mostrou um ponto preponderante para o sucesso do protocolo de injeção. Ao final do procedimento de sutura da pele, o anestésico inalatório foi retirado para que o animal recuperasse a consciência. Juntamente com a retirada do anestésico foi administrado um coquetel de antibióticos e analgésicos. Este procedimento foi repetido por até 4 dias após o procedimento cirúrgico. Os animais foram desmamados do respirador mecânico somente ao 
Apêndice A

recuperarem completamente a consciência e com isso sua capacidade respiratória autônoma. Nos primeiros casos onde a respiração autônoma foi forçada com o desligamento do respirador artificial, os resultados de recuperação e sobrevida foram inferiores visto que alguns animais demonstraram uma capacidade autônoma súbita seguida de uma queda importante de saturação, a qual levou estes a complicações e em alguns casos a morte.

Durante a recuperação já após obtenção da autonomia respiratória outro ponto importante para o sucesso de protocolo foi a manutenção da temperatura corpórea dos animais. 
Apêndice A

\section{Discussão}

Neste apêndice, foram fornecidas evidências detalhadas de que um material barato e facilmente disponível pode ser utilizado para produzir um modelo robusto e homogêneo de IM de artéria fechada através de técnicas endovasculares em porcos, quando associados com o uso de cloridrato de lidocaína. Embora limitados pela elevada taxa de mortalidade, os dados primeiramente descrito por Reffelmann et al. (16), foram neste trabalho, reproduzidos e melhorados com sucesso, sendo alcançada uma baixa mortalidade em um modelo homogêneo de IM em porcos.

Ainda hoje, uma ampla gama de estudos tem empregado o uso de modelos cirúrgicos de IM em animais de grande porte, onde o peito do animal deve ser aberto para realização da oclusão coronária $(2,3,20)$. Contudo, estes modelos impõem dificuldades agudas e pós-operatórias intrínsecas $(31,32)$ devido à sua natureza invasiva. Estas acabam por resultar em altas taxas de mortalidade e custos elevados, ou ainda podem afetar negativamente a homogeneidade da lesão gerada entre os diferentes animais, como demonstrado em nosso modelo de constrição ameróides. Além disso, Munz e colegas também mostraram $67 \%$ de mortalidade em um modelo cirúrgico de oclusão de ACX em suínos (32), enquanto que o mesmo parâmetro foi inferior a 30\% em nosso modelo percutâneo de indução de infarto.

Alguns modelos percutâneos de isquemia/reperfusão utilizando cateteresbalão para ocluir temporariamente a luz do vaso, bem como, microesferas de gel de agarose (6), e esponja de polímero bioabsorvível revestido de apatita 
Apêndice A

(33) já foram descritos anteriormente. Diferentemente destes modelos de isquemia/reperfusão, alguns modelos não cirúrgicos dede artéria fechada têm sido propostos. O uso de microembolos do tipo Embospheres $(7,10)$, implante de boninas denominadas "coils" (5) ou mesmo o uso de esponjas (16) entre outros materiais tem sido testado com o objetivo de gerar uma oclusão permanente das artérias coronarianas. Modelos de IM de artéria fechada manter um status crônico de baixo fluxo sanguíneo na área lesada e, portanto, são modelos mais adequados para realização de estudos que objetivam explorar processos associados à neo-angio/vasculogênese, a qual se acredita estar fundamentalmente ligada à prevenção da deterioração cardíaca pós-IM $(11,12,34)$.

Esponjas de uso doméstico são produtos de baixo custo e prontamente disponíveis, assim como de fácil esterilização e manipulação durante os procedimentos de oclusão percutânea de artérias coronárias. No primeiro relato descrevendo o uso de esponjas de limpeza para o desenvolvimento de um modelo de IM, os dados apresentados mostram uma obstrução do terço distal de ACX, área que acarreta na oclusão apenas da região apical do VE, contudo, apesar de realizarem uma oclusão baixa, os autores apresentaram dados de altas taxas de mortalidade (52\%) e em curto período de seguimento (em 7 dias) (16).

Nossos dados, diferentemente dos de Reffelmann, demonstram um sucesso de viabilidade inquestionavelmente superior (viabilidade de 71,4\%) após 30 dias de seguimento e a partir de uma oclusão proximal (que causa uma lesão significativamente maior em extensão). Nos dados reportados por 
Apêndice A

Reffelmann e colaboradores as elevadas perdas foram associadas principalmente a episódios de arritmia (16). Da mesma forma, em nossas primeiras tentativas de ocluir ACX todos os animais apresentaram episódios importantes de arritmias seguidas, frequentemente, de fibrilação ventricular irreversível.

Com o objetivo de diminuir a mortalidade por arritmia aguda relacionada com a oclusão coronária, nós testamos primeiramente em nossos porcos o uso de amiodarona intravenosa. Esta droga foi escolhida por ser o antiarrítmico mais comumente usado na prática clínica/hemodinâmica, contudo os resultados de contenção das arritmias apresentaram pouco sucesso. Estes dados foram consistentes com dados anteriormente publicados mostrando que a amiodarona intravenosa pode não surtir efeito imediatamente após o início da infusão em suínos (4). Por conta dos resultados negativos obtidos o próximo passo foi testar outro tipo de antiarrítmico. O cloridrato de lidocaína, previamente utilizado com sucesso contra a fibrilação ventricular em suínos tanto em casos agudos como crônicos de arritmia.

Baseado nas experiências com a amiodarona e nos relatos da literatura acerca da resposta crônica ao uso dos antiarrítmicos em porcos $(4,35)$, o protocolo experimental usando o cloridrato de lidocaína foi cuidadosamente planejado para incluir a infusão contínua desta droga antes, durante e após a oclusão da ACX para assim minimizar as arritmias (principalmente 35-45 min após a oclusão), evitando as fibrilações ventriculares. Além disso, ao observarmos episódios prolongados de arritmias, injeções em bolus de lidocaína foram realizadas controlando a maior parte dos casos. É importante 
Apêndice $A$

salientar que a utilização da lidocaína não afetou a reprodutibilidade da lesão do miocárdio induzida por oclusão da artéria ACX.

De um modo geral a literatura tem demonstrado que o uso de antiarrítmicos só tem eficiência em modelos animais se e quando utilizado desde o inicio dos processos que possam vir a estimular a incidência de FV (35). Neste sentido, procedimentos que evitem a incidência de FV devem ser muito bem estudados e padronizados antes que se inicie um protocolo como o de indução de infarto aqui proposto, pois assim como nossos dados, a literatura demonstra pouco sucesso na reversão de FV em animais como o porco $(4,16)$.

Além de barato e eficiente este modelo mostrou padrões bem marcados e facilmente mensuráveis durante o procedimento de indução de IM. Marcadores precoces capazes de direcionar o experimentador são essenciais para que perdas sejam minimizadas. Em nosso estudo o monitoramento do ECG permitiu que o padrão/homogeneidade das lesões geradas fosse observado até 10 minutos após a obstrução de ACX. Outro marcador interessante observado precocemente e classicamente estudado em humanos foi a pressão sanguínea dos animais antes e após a obstrução.

Em humanos é observado um padrão de redução de pressão sanguínea associado à oclusão coronária. Este evento é observado com maior preponderância em mulheres e é um mecanismo de defesa do sistema cardiovascular contra os efeitos da oclusão coronária (36). Interessantemente nossos infartos foram induzidos em fêmeas e estas tendem a um comportamento cardiovascular semelhante ao observado mais pronunciadamente na população humana feminina, reforçando ainda mais a 
Apêndice A

similaridade deste modelo animal com o organismo humano. Os porcos submetidos ao infarto por oclusão permanente de ACX também apresentam elevação nos níveis séricos de Troponina T e CKMB poucas horas após a confirmação da obstrução. Ademais, os padrões histopatológicos dos corações, 30 dias após a indução do IM, reforçaram a homogeneidade do modelo em questão.

O modelo de oclusão endovascular de ACX aqui apresentado resultou em áreas de lesão da ordem de $9-12 \%$ de tecido cicatricial além de mostrar redução significativa de parâmetros funcionais medidos por ecocardiografia (fração de encurtamento, $20 \%$ vs. $40 \%$ e fração de ejeção, $40 \%$ vs. $71 \%$ em relação a suínos saudáveis) ainda que estes resultados sejam menos expressivos do que os relatado para modelos de oclusão da DA, os quais se associam com alterações, geralmente graves, da função cardíaca $(7,37)$. Considerando que os meios eficazes para substituir cardiomiócitos perdidos pós-IM ainda não estão totalmente estabelecidos, modelos que pretendam auxiliar nesse tipo de estudos não devem apresentar alterações funcionais muito aberrantes, visto que, por exemplo, o uso de células-tronco, até onde se conhece não pretende substituir o tecido perdido, mas sim agir sobre a formação de novos vasos e manutenção e preservação das funções não perdidas sendo impossível obter esse tipo de fim em corações que apresentem insuficiência cardíaca evidente $(11,12,34)$.

A despeito da qualidade do modelo obtido através da obstrução de ACX, a lesão gerada nestes animais atingiu, em linhas gerais, a parede posterior do ventrículo esquerdo. Do ponto de vista fisiopatológico este não seria um 
Apêndice $A$

problema importante, contudo ao almejar o uso do modelo de IM para o teste terapêuticos com injeções de células e outros materiais, este é um tipo de lesão que pode causar problemas técnicos durante a cirurgia.

Para que a parede posterior de VE possa ser manipulada adequadamente através de uma toracotomia (abertura menos invasiva e de melhor recuperação pós-cirúrgica) o coração precisa ser muito manipulado. É bem conhecido também que as lesões causadas pela oclusão de artérias coronárias vão variar em extensão e profundidade de tecido atingida (podendo ou não ser transmurais) dependentemente de uma série de fatores intrínsecos ao indivíduo, como a viabilidade da circulação colateral, capacidade de resposta imunológica e mesmo área total atingida pela falta de oxigênio e a repercussão que esses fatores terão sobre a morte celular $(38,39)$. Deste modo, controlar exatamente esses padrões durante a indução de infarto é muito difícil.

Sendo assim, associado ao mapeamento ecocardiográfico clássico que se baseia na análise subjetiva da contratilidade segmentar do miocárdio, o uso do mapeamento epicárdico se fez muito informativo para identificação da área de lesão e a transição da mesma favorecendo maior acerto das injeções nas áreas de interesse. Diferentes técnicas para mapear o coração têm sido descritas para as mais diversas práticas (40-43). Baseado em diferentes propostas de mapeamento e visando única e exclusivamente favorecer as práticas de injeção de células-tronco na área de borda de infarto, o protocolo de mapeamento epicárdico com auxilio do ECG foi desenhado e utilizado neste estudo. 
Apêndice A

Um último ponto de suma importância a ser considerado ao se usar modelos suínos de infarto do miocárdio, em especial o modelo aqui proposto, é o cuidado pós-operatório principalmente ligado a manutenção da temperatura corpórea dos animais. Porcos apresentam temperatura corpórea média superior à encontrada em humanos $\left(38.8^{\circ} \mathrm{C}\right.$ - (44)). Sendo assim mantê-los nessa temperatura horas após os procedimentos cirúrgicos se fez essencial para que esses animais pudessem recuperar satisfatoriamente suas funções vitais como andar, se alimentar, etc. Visto que os procedimentos anestésicos reduzem a temperatura corpórea até pelo menos $5^{\circ} \mathrm{C}$ levando estes animais a uma quebra brusca de temperatura e, por conseguinte à hipotermia, cuidar da manutenção de temperatura fez a diferença para o aumento da viabilidade do modelo.

É importante ressaltar que atualmente faltam à medicina, meios eficazes para substituir adequadamente (por tecido contrátil) o grande número de cardiomiócitos que são perdidos após o infarto do miocárdio. Deste modo, modelos animais que se prestem a ser pontes de conexão entre os estudos pré-clínicos e os futuros ensaios com pacientes não devem apresentar fisiopatologias como a insuficiência cardíaca, onde o coração já está totalmente debilitado e por isso certamente não se apresentará como um órgão passível de benefícios. Em contraste a estes casos, as abordagens mais atualmente estudadas baseadas no uso de terapias com células geneticamente modificadas ou células-tronco, nos últimos 10 anos têm fornecido evidências de que a inflamação local, deposição de colágeno e a morte celular podem ser 
Apêndice A

orientadas e podem ter relevância clínica a condições isquêmicas humanas bastante específicas.

\section{Conclusões sumarizadas}

a) $\quad$ modelo de infarto induzido por oclusão endovascular de ACX foi superior em homogeneidade e viabilidade comparado ao modelo de oclusão por ameróides constritores;

b) $\quad$ uso de solução de $2 \%$ cloridrato de lidocaína, por via endovenosa (1mg/kg/hora), como antiarrítmico é indispensável para manutenção da viabilidade do modelo;

c) $\mathrm{O}$ modelo de infarto induzido por oclusão endovascular de ACX apresenta padrões:

i) diagnósticos precoces compatíveis com um infarto do miocárdio com elevação de ST;

ii) diagnósticos bioquímicos utilizados na clínica (dosagem de Troponina T e CK-MB) positivo horas após a oclusão;

iii) macro e microscópicos que corroboram à lesão gerada;

iv) funcionais e de perfusão miocárdica, medidos pela ecocardiografia transtorácica, compatíveis com a lesão gerada;

d) Os procedimentos cirúrgicos, padronizados e detalhadamente descritos, são essenciais para que haja sobrevida sem maior comprometimento do coração dos animais após as injeções;

e) Para que haja homogeneidade nas injeções é necessário que as técnicas de mapeamento epicárdico, sejam associadas ao mapa da lesão gerado pela ecocardiografia transtorácica. 
Apêndice A

\section{Conclusão final}

Ao todo, nós fornecemos evidências de um modelo robusto, homogêneo e viável de infarto do miocárdio por artéria fechada desenvolvido através de técnicas percutâneas de oclusão da ACX em porcos. O uso de prótese de poliuretano é capaz de ocluir permanentemente a artéria alvo gerando a lesão esperada e o uso de cloridrato de lidocaína antes, durante e após os procedimentos de oclusão previne altos índices de mortalidade pós-indução de IM gerando um modelo de baixo custo e baixa taxa de mortalidade em porcos. 
Apêndice A

\section{Referências Bibliográficas}

1. Mummery CL, Davis RP, Krieger JE. Challenges in using stem cells for cardiac repair. Sci Transl Med. 2010; 2(27):27ps17.

2. Cheng $\mathrm{Y}$, Yang $\mathrm{Y}$, Zhang H, Li X, Kang S, Qian H, et al. No-reflow disrupts the expression and distribution of connexin 43 in a swine model. Microvasc Res. 2011; 82(3):404-9.

3. Weiss SM, Saint DA. The persistent sodium current blocker riluzole is antiarrhythmic and anti-ischaemic in a pig model of acute myocardial infarction. PLoS One. 2010; 5(11):e14103.

4. Tsagalou EP, Anastasiou-Nana MI, Charitos CE, Siafakas CX, Drakos SG, Ntalianis $A$, et al. Time course of fibrillation and defibrillation thresholds after an intravenous bolus of amiodarone--an experimental study. Resuscitation. 2004; 61(1):83-9.

5. Dib N, Diethrich EB, Campbell A, Gahremanpour A, McGarry M, Opie SR. A percutaneous swine model of myocardial infarction. J Pharmacol Toxicol Methods. 2006; 53(3):256-63.

6. Eldar M, Ohad D, Bor A, Varda-Bloom N, Swanson DK, Battler A. A closed-chest pig model of sustained ventricular tachycardia. Pacing Clin Electrophysiol. 1994; 17(10):1603-9.

7. Carlsson M, Wilson M, Martin AJ, Saeed M. Myocardial microinfarction after coronary microembolization in swine: MR imaging characterization. Radiology. 2009; 250(3):703-13.

8. Suzuki Y, Oyane A, lkeno F, Lyons JK, Yeung AC. Development of animal model for calcified chronic total occlusion. Catheter Cardiovasc Interv. 2009; 74(3):468-75.

9. Suzuki Y, Lyons JK, Yeung AC, Ikeno F. In vivo porcine model of reperfused myocardial infarction: in situ double staining to measure precise infarct area/area at risk. Catheter Cardiovasc Interv. 2008; 71(1):100-7.

10. Varga-Szemes A, Kiss P, Brott BC, Wang D, Simor T, Elgavish G a. Embozene $^{\mathrm{TM}}$ microspheres induced nonreperfused myocardial infarction in an experimental swine model. Catheter Cardiovasc Interv. 2013; 81(4):689-97.

11. Nakamuta JS, Danoviz ME, Marques FLN, dos Santos L, Becker C, Gonçalves $\mathrm{G}$ a, et al. Cell therapy attenuates cardiac dysfunction post myocardial infarction: effect of timing, routes of injection and a fibrin scaffold. PLOS One. 2009; 4(6):e6005

12. Danoviz ME, Nakamuta JS, Marques FLN, dos Santos L, Alvarenga EC, dos Santos A a, et al. Rat adipose tissue-derived stem cells transplantation 
attenuates cardiac dysfunction post infarction and biopolymers enhance cell retention. PLoS One. 2010; 5(8):e12077.

13. Buszman PP, Wojakowski W, Milewski K, Dębiński M, Pająk J, Aboodi MS, et al. Controlled reperfusion with intravenous bivalirudin and intracoronary abciximab combination therapy in the porcine myocardial infarction model. Thromb Res. 2012; 130(2):265-72.

14. Mazo M, Hernández S, Gavira JJ, Abizanda G, Araña M, López-Martínez T, et al. Treatment of reperfused ischemia with adipose-derived stem cells in a preclinical Swine model of myocardial infarction. Cell Transplant. 2012; 21(12):2723-33.

15. Duran JM, Taghavi S, Berretta RM, Makarewich CA, Sharp lii T, Starosta T, et al. A characterization and targeting of the infarct border zone in a Swine model of myocardial infarction. Clin Trans/ Sci. 2012; 5(5):416-21.

16. Reffelmann T, Sensebat O, Birnbaum Y, Stroemer E, Hanrath P, Uretsky BF, et al. A novel minimal-invasive model of chronic myocardial infarction in swine. Coron Artery Dis. 2004; 15(1):7-12.

17. Kilkenny C, Browne WJ, Cuthill IC, Emerson M, Altman DG. Improving bioscience research reporting: the ARRIVE guidelines for reporting animal research. PLoS Biol. 2010; 8(6):e1000412.

18. Chen SL, Zhu CC, Liu YQ, Tang LJ, Yi L, Yu BJ, et al. Mesenchymal stem cells genetically modified with the angiopoietin-1 gene enhanced arteriogenesis in a porcine model of chronic myocardial ischaemia. J Int Med Res. 2009; 37(1):6878.

19. Miyagawa S, Saito A, Sakaguchi T, Yoshikawa Y, Yamauchi T, Imanishi Y, et al. Impaired myocardium regeneration with skeletal cell sheets--a preclinical trial for tissue-engineered regeneration therapy. Transplantation. 2010; 90(4):364-72.

20. Tuzun E, Oliveira E, Narin C, Khalil H, Jimenez-Quevedo P, Perin E, et al. Correlation of ischemic area and coronary flow with ameroid size in a porcine model. J Surg Res. 2010; 164(1):38-42.

21. Porter TR, Xie F. Myocardial perfusion imaging with contrast ultrasound. JACC Cardiovasc Imaging. 2010; 3(2):176-87.

22. Lang RM, Bierig M, Devereux RB, Flachskampf F a, Foster E, Pellikka P a, et al. Recommendations for chamber quantification: a report from the American Society of Echocardiography's Guidelines and Standards Committee and the Chamber Quantification Writing Group, developed in conjunction with the European Association of Echocardiograph. J Am Soc Echocardiogr. 2005; 18(12):1440-63.

23. Schneider CA, Rasband WS, Eliceiri KW. NIH Image to ImageJ: 25 years of image analysis. Nat Methods. 2012; 9(7):671-5. 
Apêndice A

24. Lyngbæk S, Marott JL, Møller D V, Christiansen M, Iversen KK, Clemmensen PM, et al. Usefulness of Soluble Urokinase Plasminogen Activator Receptor to Predict Repeat Myocardial Infarction and Mortality in Patients with ST-Segment Elevation Myocardial Infarction Undergoing Primary Percutaneous Intervention. Am J Cardiol. 2012; 110(12):1756-63.

25. Porela P, Kytö V, Nikus K, Eskola M, Airaksinen KEJ. PR depression is useful in the differential diagnosis of myopericarditis and ST elevation myocardial infarction. Ann Noninvasive Electrocardiol. 2012; 17(2):141-5.

26. Smith SW, Dodd KW, Henry TD, Dvorak DM, Pearce LA. Diagnosis of STElevation Myocardial Infarction in the Presence of Left Bundle Branch Block With the ST-Elevation to S-Wave Ratio in a Modified Sgarbossa Rule. Ann Emerg Med. 2012; 60(6):766-76.

27. Morrow DA, Cannon CP, Jesse RL, Newby LK, Ravkilde J, Storrow AB, et al. National Academy of Clinical Biochemistry Laboratory Medicine Practice Guidelines: Clinical characteristics and utilization of biochemical markers in acute coronary syndromes. Circulation. 2007; 115(13):e356-75.

28. Lu J, Yao YY, Dai MQ, Ma SG, Zhang FS, Cao L, et al. Erythropoietin attenuates cardiac dysfunction by increasing myocardial angiogenesis and inhibiting interstitial fibrosis in diabetic rats. Cardiovasc Diabetol. 2012; 11(1):105.

29. Seeland U, Selejan S, Engelhardt S, Müller P, Lohse MJ, Böhm M. Interstitial remodeling in beta1-adrenergic receptor transgenic mice. Basic Res Cardiol. 2007; 102(2):183-93.

30. Alberts B, Johnson A, Lewis J, Raff M, Roberts K, Walter P. Molecular Biology of the Cell. 4th ed. New York: Garland Science; 2002.

31. Lukács E, Magyari B, Tóth L, Petrási Z, Repa I, Koller A, et al. Overview of large animal myocardial infarction models (review). Acta Physiol Hung. 2012; 99(4):365-81.

32. Munz MR, Faria M a, Monteiro JR, Aguas AP, Amorim MJ. Surgical porcine myocardial infarction model through permanent coronary occlusion. Comp Med. $2011 ; 61(5): 445-52$.

33. Suzuki Y, Oyane A, Ikeno F, Lyons JK, Yeung AC. Development of animal model for calcified chronic total occlusion. Catheter Cardiovasc Interv. 2009; 74(3):468-75.

34. Gonçalves G a, Vassallo PF, dos Santos L, Schettert IT, Nakamuta JS, Becker $\mathrm{C}$, et al. Intramyocardial transplantation of fibroblasts expressing vascular endothelial growth factor attenuates cardiac dysfunction. Gene Ther. 2010; 17(3):305-14.

35. Reynolds JC, Rittenberger JC, Menegazzi JJ. Drug administration in animal studies of cardiac arrest does not reflect human clinical experience. Resuscitation. 2007; 74(1):13-26. 
36. Airaksinen KE, Ikäheimo MJ, Linnaluoto $M$, Tahvanainen KU, Huikuri H V. Gender difference in autonomic and hemodynamic reactions to abrupt coronary occlusion. J Am Coll Cardiol. 1998; 31(2):301-6.

37. McCall FC, Telukuntla KS, Karantalis V, Suncion VY, Heldman AW, Mushtaq M, et al. Myocardial infarction and intramyocardial injection models in swine. Nat Protoc. 2012; 7(8):1479-96.

38. Buja LM, Entman ML. Modes of myocardial cell injury and cell death in ischemic heart disease. Circulation. 1998; 98(14):1355-7.

39. Haunstetter A, Izumo S. Apoptosis: basic mechanisms and implications for cardiovascular disease. Circ Res. 1998; 82(11):1111-29.

40. Anderson KP, Walker R, Ershler PR, Fuller M, Dustman T, Menlove R, et al. Determination of local myocardial electrical activation for activation sequence mapping. A statistical approach. Circ Res. 1991; 69(4):898-917.

41. Cuculich PS, Zhang J, Wang Y, Desouza K a, Vijayakumar R, Woodard PK, et al. The electrophysiological cardiac ventricular substrate in patients after myocardial infarction: noninvasive characterization with electrocardiographic imaging. J Am Coll Cardiol. 2011; 58(18):1893-902.

42. Ghanem RN, Jia P, Ramanathan C, Ryu K, Markowitz A, Rudy Y. Noninvasive electrocardiographic imaging (ECGI): comparison to intraoperative mapping in patients. Heart Rhythm. 2005; 2(4):339-54.

43. Von Bary C, Mazzitelli D, Voss B, Kübler F, Schmeller M-L, Ndrepepa G, et al. Evaluation of epicardial microwave lesions in the pig model using an electroanatomic mapping system. J Interv Card Electrophysiol. 2008; 22(1):511.

44. Ingram DL, Legge KF. Variations in deep body temperature in the young unrestrained pig over the 24 hour period. J Physiol. 1970; 210(4):989-98. 


\section{Apêndice B}

Geração de piPSCs e CM-piPSCs 

Apêndice $B$

\section{Introdução}

\section{Terapia celular: conceitos de proteção e regeneração cardíaca}

Centenas de publicações têm sido veiculadas na literatura demostrando os benefícios do uso de células-tronco adultas no contexto das doenças isquêmicas do coração (por exemplo, MSCs e ASCs), contudo não existem dados satisfatórios que demonstram seu potencial sobre a regeneração cardíaca, ou seja, a substituição do tecido perdido pós-infarto (1-5).

\section{Proteção cardíaca}

A despeito da infinidade de estudos pré-clínicos, que se utilizam de células-tronco adultas de diferentes fontes, apresentarem melhora na função ventricular pós-infarto, evidências substanciais sugerem que esta melhora está fracamente vinculada a mecanismos de transdiferenciação destas célulastronco e, portanto da substituição tecidual (1,5-8). Os mecanismos responsáveis por essa melhora funcional, predominantes parecem estar ligados à ação parácrina das células-tronco adultas, através da qual há liberação de moléculas bioativas importantes no contexto do reparo cardíaco pós-infarto $(5,1,2)$. Estas moléculas agem primordialmente sobre a melhora da perfusão cardíaca (9-12), proteção contra morte celular (13), influência sobre a produção de matriz extracelular e formação da cicatriz pós-lesão $(14,15)$ e finalmente sobre a melhora global da geometria e função cardíacas agindo efetivamente de modo protetor, mas não regenerativo $(3,7,8)$.

\section{Regeneração cardíaca}


Apêndice B

Tendo em vista os resultados pré-clínicos favoráveis, mas restritos a proteção do miocárdio, obtidos com o uso de células-tronco adultas, o grande desafio de estabelecer estratégias capazes de substituir/regenerar os cardiomiócitos evitando assim que um número crescente de pacientes atinja graus importantes de insuficiência cardíaca continua sem uma resposta satisfatória.

Objetivando a substituição do tecido fibroso por cardiomiócitos funcionais alguns grupos de pesquisa tem proposto, como novas fontes de células de maior plasticidade, o uso de células de origem fetal, como as obtidas da placenta ou cordão umbilical (16). Outros tipos celulares recentemente estudados como potenciais alvos para a regeneração são as denominadas cardiosferas $(17,18)$ e também as células c-Kit positivas (19) as quais podem ser obtidas diretamente do tecido cardíaco. Contudo, os resultados até aqui demonstrados ainda são pouco efetivos.

A fim de obter a regeneração cardíaca tão almejada as células-tronco embrionárias têm sido exploradas por alguns grupos de pesquisadores, a despeito de todas as questões éticas, políticas e técnicas que envolvem esse assunto $(20,21)$. Recentemente Chong e colaboradores demonstraram significativa regeneração do VE de macacos após terem injetado cardiomiócitos diferenciados, in vitro, a partir de células embrionárias humanas. Contudo, questões eletrofisiológicas ainda continuam a permear negativamente os resultados obtidos (22). Apesar dos resultados positivos obtidos por Chong et al. em modelo de macacos, além de outros dados previamente obtidos em diferentes modelos animais pelo mesmo grupo de pesquisadores (22-25), o 
Apêndice $B$

uso das células embrionárias continua a gerar discussões, de modo que novas fontes de células precisam ser obtidas.

Em 2006 o laboratório do Prof. Yamanaka publicou um protocolo propondo transformar células obtidas de tecidos adultos, ou seja, completamente diferenciadas, em células com características embrionárias e sem os entraves éticos e políticos até então enfrentados com as ESCs (26). Baseado na expressão forçada de 4 fatores de transcrição a se saber, Oct4, Sox-2, KLF-4 e c-Myc, fibroblastos retirados da pele de roedores foram transformados em células pluripotentes muito semelhantes as células embrionárias originais (26). Esta se tornou a mundialmente conhecida fórmula para obtenção das células pluripotentes induzidas (do inglês, iPSCs). Após a descoberta desta fórmula, protocolos diversos têm sido propostos para que estas células pluripotentes sejam diferenciadas nos mais diferentes tipos celulares adultos e progenitores dentre eles os cardiomiócitos (27).

Em 2012 Lian e colaboradores propuseram um protocolo de diferenciação baseado na modulação das vias de Wnt usando pequenas moléculas $(28,29)$. Este protocolo e mais recentemente variações dele propostas por Burridge et al. (30) tem se mostrado significativamente eficientes a todos os outros anteriormente propostos, sendo este a base a ser seguida para o sucesso da diferenciação de cardiomiócitos. Se apropriando destes dois conhecimentos recentemente publicados, nosso grupo de estudo em célulastronco vem se apropriando das habilidades de: [1] reprogramar células humanas e [2] aprimorar protocolos de diferenciação de iPSCs em cardiomiócitos, com os objetivos de obter novas fontes de células capazes de agir ativamente sobre a regeneração cardíaca. 
Apêndice B

\section{Objetivo}

Desenvolver plataformas de reprogramação de células adultas de porcos em células pluripotentes induzidas bem com protocolos de diferenciação destas piPSCs em cardiomiócitos funcionais capazes de realizar regeneração cardíacas.

\section{Objetivos específicos}

a) Desenvolver plataforma de reprogramação de pASC em células pluripotentes induzidas de porcos (piPSCs);

b) Desenvolver protocolos de diferenciação de piPSCs em cardiomiócitos (in vitro); 
Apêndice $B$

\section{Materiais e Métodos}

Isolamento, expansão, congelamento e caracterização fenotípica de pASCs

Células-tronco mesenquimais derivadas do tecido adiposo de porcos (pASCs) foram extraídas de porcos da linhagem MS60 EMBRAPA conforme descrito em Dariolli et al. 2011 (31). Resumidamente, os animais foram anestesiados e após assepsia/antissepsia o tecido adiposo da região abdominal foi extraído cirurgicamente. O tecido adiposo foi digerido mecanicamente e posteriormente submetido à digestão enzimática $(0,1 \%$ colagenase tipo $1 \mathrm{a})$, a $37^{\circ} \mathrm{C}$ por 45 minutos sob agitação. A solução foi centrifugada (1500 rpm, 10 minutos, $4^{\circ} \mathrm{C}$ ) e o pellet foi ressuspendido em DMEM-Low suplementado com $10 \%$ de SFB e $1 \% \mathrm{P} / \mathrm{S}$. As células foram mantidas em estufas sob atmosfera úmida contendo $5 \%$ de $\mathrm{CO} 2$ a $37^{\circ} \mathrm{C}$. Células entre passagens 3-5 foram utilizadas para a reprogramação.

\section{Obtenção de iPSCs porcinas: reprogramação celular}

As células-tronco mesenquimais derivadas do tecido adiposo abdominal de porcos foram obtidas conforme acima descrito. Para a reprogramação foi utilizado o protocolo previamente descrito por Somers e colaboradores (32), com modificações. Resumidamente, $10^{\wedge} 5$ células, de um único porco macho foram plaqueadas em uma P35 mm pré-tratada com GelTrex (LifeTechnologies). Vinte e quatro horas após o plaqueamento das pASC estas foram submetidas à transdução viral em volume mínimo de meio de cultura de cultivo padrão (600 $\mu$ L de DMEM-Low 10\% SFB). Ao meio de cultura usado foi adicionado o vírus polisistrônico e excisável STEMCA (Millipore) expressando 
Apêndice B

os 4 fatores de transcrição gênica descritos por Yamanaka e colaboradores (Oct-4, Sox-2, KLF-4 e c-Myc). Após 6-8hs da transdução, o volume de meio mínimo foi aumentado para um volume final de $2 \mathrm{~mL}$. Após $24 \mathrm{~h}$ da transdução (D1), o meio padrão foi substituído por meio E6FN (meio E6 (Life) $+10 \mathrm{ng} / \mathrm{mL}$ de $\beta F G F$ humano (Life) + 0,5mM de Butirato de sódio - NaB (Sigma). Nos dias 3, 5, 7 e 9 o meio foi trocado por E6FN novo. A partir do dia 11 até o 25 o meio foi então trocado diariamente. pelo meio E8N (E8 (Life) $+0.25 \mathrm{mM}$ de $\mathrm{NaB}$ (Sigma)). Após o dia 25 da reprogramação induzida por vírus, colônias foram visualizadas e coletadas manualmente.

As colônias coletadas foram plaqueadas em placas pré-plaqueadas com pASCs mitomicinizadas e cultivadas em meio E8 pelas primeiras 3-5 passagens. A partir dai foram então cultivas em placas pré-tratadas com GelTrex e no meio de cultura caseiro nomeado de "PORCAS" composto por: KO-DMEM (LifeTechnologies), 20\% KOSR (LifeTechnologies), 1X aminoácidos não essenciais (NEAA - LifeTechnologies), 1X GlutaMax (LifeTechnologies), 0,1M $\beta$-mercaptoetanol (Sigma), $1 \mu \mathrm{L} / \mathrm{mL}$ de Fator inibitório de Leucemia (do inglês, LIF) a $10 \mathrm{ug}$ (LifeTechnologies) e $10-20 \mathrm{ng} / \mathrm{mL}$ de $\beta F G F$ humano (LifeTechnologies). As células foram passadas em pequenas colônias usando VERSENE (LifeTechnologies). Somente nos dias de passagem as células foram plaqueadas com o meio PORCAS suplementado com 5 uM de inibidor de ROCK (Y-27632, Sigma).

\section{Caracterização das iPSCs de porcos}

Coloração com fosfatase alcalina 
Apêndice $B$

A coloração de fosfatase alcalina foi realizada conforme instrução do fabricante do Kit utilizado (“Leukocyte Alkaline Phosphatase Kit” - Sigma). Resumidamente as células mantidas em colônias entre 10 e 100 células aproximadamente, foram fixadas e em seguida submetidas à coloração. Células rosadas foram consideradas positivas para pluripotência, ou seja, iPSCs verdadeiras, e suas colônias foram mantidas para os próximos passos da caracterização e utilização das células.

Expressão gênica e proteica de marcadores de pluripotência em piPSCs

Para a análise de expressão gênica dos marcadores de pluripotência das piPSCs, o RNA total foi extraído de diferentes colônias através das instruções do protocolo de extração "single-step" baseado no uso do Trizol fornecido pelo fabricante (Invitrogen, Carlsbad, CA). A transcrição reversa do RNA total obtido das células foi realizada utilizando o kit de síntese de cDNA SuperScript III (Invitrogen) segundo manual do fabricante e as Reação em cadeia da polimerase (PCR) foram realizadas utilizando o protocolo descrito pelo fabricante para a Taq-polymerase platinum (Invitrogen). Os primers utilizados foram obtidos comercialmente e desenhados no software Primer3 ou foram usados a partir de publicações. Os dados relativos aos primers encontram-se na tabela 1. 
Tabela 1: Primers para caracterização de pluripotência de piPSCs.

\begin{tabular}{|c|c|c|c|c|c|}
\hline Gene & Forward 5'-3' / Reverse 5'-3' & pb & $\mathrm{Tm}^{\circ} \mathrm{C}$ & Amplicom (pb) & Fonte \\
\hline ОСТ4 & $\begin{array}{c}\text { CAAACTGAGGTGCCTGCCCTTC } \\
\text { АTTGAACTTCACCTСССТCСАACС }\end{array}$ & $\begin{array}{l}22 \\
25\end{array}$ & 60 & 189 & Wu et al \\
\hline sox2 & $\begin{array}{l}\text { GTTCCATGGGCTCAGTGGTCAAG } \\
\text { AAGCGTACCGGGTIITCTCCATAC }\end{array}$ & $\begin{array}{l}23 \\
25\end{array}$ & 60 & 347 & Wu et al \\
\hline NANOG & $\begin{array}{c}\text { AGCCCCAGCTCCAGTTCAGC } \\
\text { AATGATCGTCACATATCTTCAGGCTGTA }\end{array}$ & $\begin{array}{l}21 \\
28\end{array}$ & 60 & 181 & Wu et al \\
\hline Dmnt3- $\beta$ & $\begin{array}{l}\text { CTACCTCACCATCGACCTCACAG } \\
\text { CAGGAGAAACCCTTGATCTITCCC }\end{array}$ & $\begin{array}{l}23 \\
24\end{array}$ & 60 & 280 & Wu et al \\
\hline DPPA5 & $\begin{array}{l}\text { CGGGGTCAGGTTGGTTAAGA } \\
\text { ACTGGAGCATCCACTTGGTC }\end{array}$ & $\begin{array}{l}20 \\
20\end{array}$ & 60 & 289 & Wu et al \\
\hline pTERT & $\begin{array}{l}\text { AAGACGCTGTTTGCTGTGC } \\
\text { CCGCCACGCCCTGTGGATGT }\end{array}$ & $\begin{array}{l}19 \\
20\end{array}$ & 60 & 99 & Cheng et al \\
\hline LIFR & $\begin{array}{l}\text { CCCAAATAATGTTGAGGTTCTG } \\
\text { GTITCGGGTCTGCATCAG }\end{array}$ & $\begin{array}{l}22 \\
20 \\
\end{array}$ & 60 & 118 & Cheng et al \\
\hline
\end{tabular}

pb: Pares de base; $\mathrm{Tm}^{\circ} \mathrm{C}$ : temperatura média de anelamento.

A expressão proteica de Oct-4, Sox-2 e SSEA4 foram obtidas através de protocolo de Imunofluorescência. Resumidamente, as células foram plaqueadas, em placas de 24 poços pré-tratadas com GelTrex, em colônias de 10-100 células e 24 horas após o plaqueamento foram fixadas por 10 minutos na temperatura ambiente, em uma solução de 4\% PFA. As placas foram então lavadas com solução de PBS e permeabilizadas (solução permeabilização) por 10 minutos a temperatura ambiente. Após a permeabilização as placas foram lavadas e submetidas a bloqueio em solução 1\% BSA por 1 hora. Os anticorpos primários foram diluídos na solução de bloqueio conforme indicado na tabela 2 e incubados por aproximadamente 16 horas a $4^{\circ} \mathrm{C}$ em câmara úmida. Após incubação do anticorpo primário, as placas foram novamente lavadas com PBS e o anticorpo secundário, diluído em solução de bloqueio, foi adicionado e incubado no escuro por 1 hora. Ao final da incubação as placas foram incubadas com 2-(4-Amidinophenyl)-1 H-indole-6-carboxamidina (DAPI) por 15-20 minutos e examinadas no microscópio de fluorescência. 
Apêndice $B$

Tabela 2: Anticorpos e diluições para caracterização das piPSCs.

\begin{tabular}{ccccc} 
Anticorpo & Feito em & Concentração uso & marca & código \\
\hline Oct-4 & Rabbit & $1: 400$ & Cellsignaling & $\# 2840 S$ \\
SOX-2 & Rabbit & $1: 400$ & Cellsignaling & $\# 3579 S$ \\
SSEA4 & Mouse & $1: 500$ & Cellsignaling & $\# 4755 S$ \\
NANOG & Rabbit & $1: 800$ & Cellsignaling & $\# 4903 S$ \\
TRA-1-60 & Mouse & $1: 100$ & Cellsignaling & $\# 4746 S$ \\
TRA-1-81 & Mouse & $1: 100$ & Cellsignaling & $\# 4745 S$ \\
\hline
\end{tabular}

Desenvolvimento e caracterização de corpos embrióides

As piPSCs foram plaqueadas em baixa confluência para que as colônias pudessem atingir uma tamanho ideal para a formação do corpo embrióide. Foi considerado tamanho ideal quando as colônias ocupavam quase que a totalidade do campo de visão na objetiva de 10X do microscópio (EVOS XL. Life Tchnologies). As células foram então passadas com dispase (1mg/mL) por 10 minutos. Neste processo, as colônias se soltam da placa permanecendo integras. Estas colônias foram então ressuspendidas em meio PORCAS suplementado com 10uM iROCK e plaqueadas em placas de $60 \mathrm{~mm}$ não aderentes. Vinte quatro horas após o plaqueamento observou-se a formação de corpos embrióides (do inglês, embryoid bodies - EBs). Todo o meio de cultura mais os EBs foram transferidos da placa para um tubo de $15 \mathrm{~mL}$, com auxilio de uma micro-pipeta de $1 \mathrm{~mL}$ e ponteira de $1 \mathrm{~mL}$ com "boca larga" para não danificar os EBs. Após 15-20 minutos, todos os EBs estavam sedimentados no fundo do tubo, então o meio de cultura PORCAS foi retirado e substituído cuidadosamente por meio IMDM (Life) suplementado com 20\% SFB. Os EBs foram cuidadosamente ressuspendidos com auxilio de micropipeta de $1 \mathrm{~mL}$ e ponteira de $1 \mathrm{~mL}$ com "boca larga" e novamente transferidos para uma placa não aderente. Estes EBs foram mantidos por 4 dias em placas 
Apêndice B

não aderentes e então transferidos para placas aderentes em meio IMDM 20\% SFB suplementado com 5uM de iROCK. O meio IMDM 20\% SFB foi trocado a cada 48 horas por 20 dias. Os EBs aderiram às placas e células com diferentes padrões morfológicos migraram dos EBs para a placa. Vinte dias após plaqueamento em placas aderentes, as células aderidas foram submetidas a extração de RNA total por Trizol e caracterizadas para os primers da tabela 3.

Tabela 3: Primers para caracterização dos EBs de piPSCs.

\begin{tabular}{|c|c|c|c|c|c|}
\hline Gene & Forward 5'-3' / Reverse 5'-3' & pb & $\mathrm{Tm}^{\circ} \mathrm{C}$ & Amplicom (pb) & Fonte \\
\hline NeuroD & $\begin{array}{l}\text { GACTTGCGTTCAGGCAAAAGC } \\
\text { GGGCGACTGGTAAGAGTAGG }\end{array}$ & $\begin{array}{l}21 \\
20\end{array}$ & 60 & 207 & Wu et al \\
\hline ENOLASE & $\begin{array}{l}\text { TCTGTGACTGAATCTATCCAGG } \\
\text { CTITGGGTTACGGAACTTGCG }\end{array}$ & $\begin{array}{l}22 \\
21\end{array}$ & 60 & 252 & Wu et al \\
\hline AFP & $\begin{array}{l}\text { TGCCTCCGCCATTCTCTGATG } \\
\text { CTGGACCCTCTTCTGCAAAGC }\end{array}$ & $\begin{array}{l}21 \\
21\end{array}$ & 60 & 228 & Wu et al \\
\hline
\end{tabular}

pb: Pares de base; $\operatorname{Tm}^{\circ} \mathrm{C}$ : temperatura média de anelamento.

\section{Análise de Cariótipo}

Para a realização do cariótipo as piPSCs foram plaqueadas em P35 mm para atingirem confluência de $70-80 \%$ em 24 horas. Então as células foram incubadas com $10 \mu \mathrm{g} / \mathrm{mL}$ de Colchicina (colcemid - Gibco) por 90 minutos em incubadora $\left(5 \% \mathrm{CO}_{2}, 37^{\circ} \mathrm{C}\right)$. Após esse período as células foram tripsinizadas e centrifugadas a 1500 RPM por 5 minutos até obtenção de pellet. O pellet então foi incubado por 5 minutos em solução hipotônica $(0,1 \mathrm{M} \mathrm{KCl})$ por 20 minutos a $37^{\circ} \mathrm{C}$. As células foram então fixadas com solução de metanol/acido acético glacial (3:1). Após fixadas as células foram gotejadas em laminas histológicas de vidro e foram deixadas secando por 3 dias a temperatura ambiente para obtenção de bandeamento padrão do tipo G. As laminas foram coradas com 
Apêndice $B$

Giemsa conforme indicado pelo fabricante do kit de coloração (KaryoMAX® Giemsa, Gibco). As metáfases foram localizadas nas lâminas e registradas com auxílio de microscópio Leica HC (Leica). As imagens foram capturadas por câmera digital Leica DC250 acoplada ai microscópio e analisadas no software Leica CW4000 Karyo (Leica).

\section{Protocolos de diferenciação cardíaca para iPSCs (CM-IPSCs)}

Cardiomiócitos maduros foram obtidos a partir de iPSCs de porcos humanas (controle positivo) através de modificações do protocolo previamente publicado por Lian e colaboradores $(28,29)$. Resumidamente, as iPSCs foram cultivadas em placas de $35 \mathrm{~mm}$ previamente tratadas com GelTrex (Life Technologies) em meio PORCAS (porcos) até atingirem $80-90 \%$ de confluência, quando foram soltas da placa pela ação de tripsina (Tryple, Life Technologies). As células foram então plaqueadas na proporção de

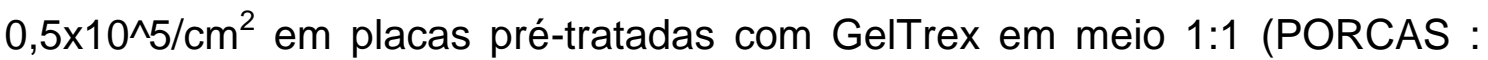
mTeSR - Stemcell Technologies). Os poços foram submetidos à troca de meio diária até atingir $80-90 \%$ de confluência e então se deu início ao protocolo de diferenciação usando pequenas moléculas. Cada clone foi submetido a pelo menos 2 protocolos diferentes de diferenciação, um deles padronizados no LGCM (homemade - HM) e o outro baseado em meio de diferenciação comercial (PSC Cardiomyocyte Differentiation Kit - Life Technologies). Como controle positivo de eficiência dos protocolos de diferenciação foram utilizadas células da linhagem embrionária humana BR-1, previamente estabelecida pelo grupo da Professora Lygia da Veiga Pereira (33) e células pluripotentes 
Apêndice $B$

induzidas geradas no Laboratório de Genética e Cardiologia Molecular pelo aluno de doutorado Diogo Biagi.

Protocolo Homemade - HM: As células atingiram 80-90\% de confluência após 3-4 dias do plaqueamento. A partir daí os poços foram submetidos a tratamento com meio de diferenciação A (RPMI + B27- insulina + 3,6 ou 9 uM de GSK-3 inhibitor CHIR 99021 (Millipore)) por 24 horas (D0). Após 24h os poços foram lavados $2 \mathrm{X}$ com RB- e então submetidos a tratamento com meio $\mathrm{B}$ (RB- + 10ng/mL de BMP-4 (R\&D)) por 24h (D1). Após 24h o meio B foi retirado e o meio C (RB- + 7,5 uM do inibidor de Wnt, IWP-4 (Cayman Chemical)) foi adicionado aos poços (D2). Após 48hs os poços foram lavados 2X com RPMl + B27 (Life) $(\mathrm{RB}+)$ e então submetidos a tratamento com meio $\mathrm{D}(\mathrm{RB}++5,0 \mathrm{uM}$ de IWP-4) (D4). Após 24h o meio $D$ foi retirado e RB+ foi adicionado nos poços (D5). Trocas diárias de RB+ foram realizadas até o D7 e a partir daí trocas a cada $48 \mathrm{hs}$ até os poços atingirem o dia desejado.

Protocolo Comercial: Conforme estabelecido pelo fabricante (LifeTechnologies), as células atingiram $80-90 \%$, a partir daí os poços foram submetidos ao tratamento com meio de diferenciação A por 48 horas (D0). Após $48 \mathrm{~h}$ o meio $A$ foi substituído pelo meio B (D2). Após mais $48 \mathrm{~h}$ o meio B foi então substituído pelo meio de manutenção (D4) o qual foi trocado a cada 48hs. Em ambos os protocolos foi possível observar células contráteis a partir do dia 7 (D7). Em células humanas houve um aumento exponencial das células contráteis com o passar dos dias. Já as células de porco demonstraram algumas características especiais frente aos protocolos de diferenciação, as quais serão apresentadas e discutidas nas próximas seções deste apêndice. 
Apêndice $B$

\section{Caracterização preliminar dos cardiomiócitos obtidos a partir para iPSCs de porcos (CM-piPSCs)}

Morfológica funcional

A análise da geração eficiente de cardiomiócitos verdadeiros a partir dos protocolos de diferenciação acima descritos se basearam primeiramente na observação morfológica das células pluripotentes no tempo, até a obtenção de células contráteis visualmente qualificáveis. Vídeos foram gravados com auxilio de câmera fotográfica convencional e microscópio com tela. Os vídeos fora editados usando software de edição semiprofissional e de livre uso, disponível na internet. Os vídeos gerados são meramente qualitativos não pretendendo ser julgados por sua qualidade para uso quantitativo em primeira instancia.

Expressão gênica de marcadores nas diferentes fases de diferenciação das piPSCs

Para a análise de expressão gênica dos marcadores das diferentes fases da diferenciação das piPSCs em cardiomiócitos, o RNA total foi extraído de diferentes colônias através das instruções do protocolo de extração "singlestep" baseado no uso do Trizol fornecido pelo fabricante (Invitrogen, Carlsbad, CA). A transcrição reversa do RNA total obtido das células foi realizada utilizando o kit de síntese de cDNA SuperScript III (Invitrogen) segundo manual do fabricante e as Reação em cadeia da polimerase (PCR) foram realizadas utilizando o protocolo descrito pelo fabricante para a Taq-polymerase platinum (Invitrogen). Os primers utilizados foram obtidos comercialmente e desenhados 
Apêndice $B$

no software Primer3 ou foram usados a partir de publicações. Os dados relativos aos primers encontram-se na tabela 4.

Tabela 4: Primers para caracterização da mesoderme na diferenciação de CMpiPSCs.

\begin{tabular}{|c|c|c|c|c|c|c|}
\hline Gene & Forward 5'-3' / Reverse 5'-3' & $\mathrm{pb}$ & $\mathrm{Tm}^{\circ} \mathrm{C}$ & Amplicom (pb) & Fase & Fonte \\
\hline Brackyury $T$ & $\begin{array}{l}\text { GAGTGGACCACCTACTGAGC } \\
\text { АCATCCTCCTGCCGTCTTG }\end{array}$ & $\begin{array}{l}20 \\
20\end{array}$ & 60 & 168 & mesoderme & Primer-blast NCBI \\
\hline MIX-L1 & $\begin{array}{l}\text { GCTTCCCGAGTCTAGGATCC } \\
\text { TGGGAGCTAGGGTCTGAGAT }\end{array}$ & $\begin{array}{l}20 \\
20\end{array}$ & 59 & 228 & mesoderme & Primer3 \\
\hline Msx-1 & $\begin{array}{l}\text { CCACTCGGTGTCAAAGTGGA } \\
\text { GTACTGCTTCTGGCGGAACT }\end{array}$ & $\begin{array}{l}20 \\
20\end{array}$ & 60 & 558 & mesoderme & Primer-blast NCBI \\
\hline GATA-4 & $\begin{array}{c}\text { CGGCCTCTACCACAAGATGA } \\
\text { GGGCTTCCGTITCTGGTTा }\end{array}$ & $\begin{array}{l}20 \\
20\end{array}$ & 59 & 224 & progenitor Card. & Primer3 \\
\hline GAPDH & $\begin{array}{l}\text { CTCAACGACCACTTCGTCAA } \\
\text { TCTGGGATGGAAACTGGAAG }\end{array}$ & $\begin{array}{l}20 \\
20\end{array}$ & 60 & 210 & controle constitutivo & West et al. \\
\hline
\end{tabular}


Apêndice $B$

\section{Resultados}

\section{piPSCs geradas a partir de pASC apresentam expressão de fosfatase alcalina}

piPSCs foram geradas a partir da reprogramação de pASC usando o sistema de expressão lentiviral dos 4 fatores de reprogramação descrito por Takahashi e colegas (26). pASCs de um porco macho foram usadas e geraram diversas colônias ao longo dos 25 dias de reprogramação. Praticamente todas as colônias geradas entre os dias 4 e 20 desapareceram completamente. Sete colônias com morfologia esperada ao final dos 25 dias foram coletadas manualmente e devidamente plaqueadas separadamente em placas que haviam sido recobertas previamente com pASCs mitomicinizadas. As células obtidas apresentavam morfologia semelhante à observada para células embrionárias de diversos organismos, sendo que estas de tamanho bem pequeno, entre 10-100 vezes menores, do que as células que as deram origem (Figura $1 \mathrm{~A}$ e B). A presença de núcleo volumoso e com centrômeros bem evidentes, denotando o estado proliferativo ativo, também foi observada, além de um citoplasma pouco evidente e da formação clássica de colônias (Figura 1 B e C).

Destas sete colônias coletadas e cultivadas 5 delas apresentaram forte expressão de fosfatase alcalina nas primeiras passagens (Figura 1 D-F). Outras duas colônias apresentaram expressão reduzida e foram congeladas e armazenadas em nitrogênio liquido. As cinco outras foram submetidas às caracterizações que serão apresentadas a seguir. 

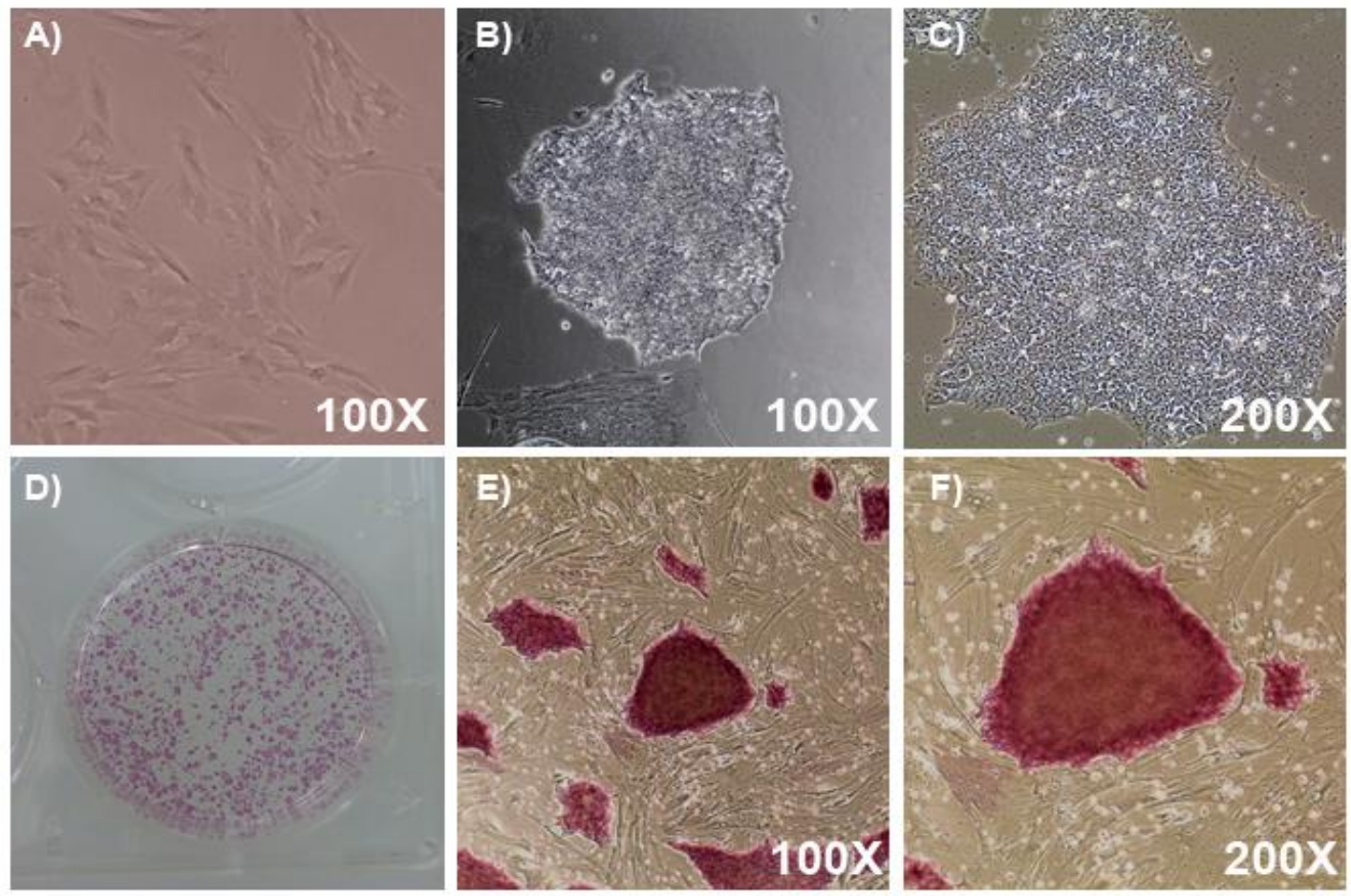

Figura 1: Células tronco mesenquimais derivadas do tecido adiposo de porcos reprogramadas. A) pASCs pré-reprogramação em P4. B e C) Colônias de piPSCs derivada de pASC em P8 cultivada em GelTrex. Note em C a relação de tamanho do núcleo celular e do citoplasma, bem como os centrômeros evidentes. D) Vista geral de placa de piPSC em P4 ainda cultivadas em pASCs mitomicinizadas. Coloração rosada denota a expressão de fosfatase alcalina nas colônias. E e F) colônias com atividade elevada de fosfatase alcalina em detalhes (clone 617).

\section{piPSCs geradas a partir de pASC apresentam expressão genica e proteica de marcadores de pluripotência}

Células-tronco pluripotentes, dentre outros parâmetros, são caracterizadas por apresentarem a expressão gênica de determinados fatores de transcrição e proteínas específicos deste tipo celular. Aqui um set de primers foi utilizado para demonstrar que as colônias anteriormente selecionadas por morfologia e expressão de fosfatase alcalina também apresentavam a expressão de alguns marcadores de pluripotência (Figura 2). Os clones apresentaram a expressão de todos os marcadores testados, contudo a expressão foi variável de um clone para outro como é esperado em reprogramações virais (Figura 2). 
Apêndice B

A)

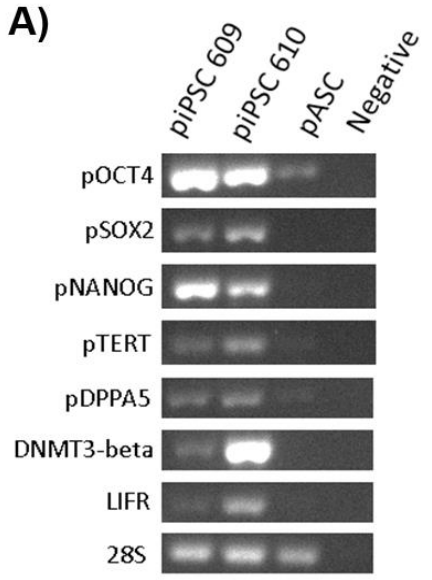

B)

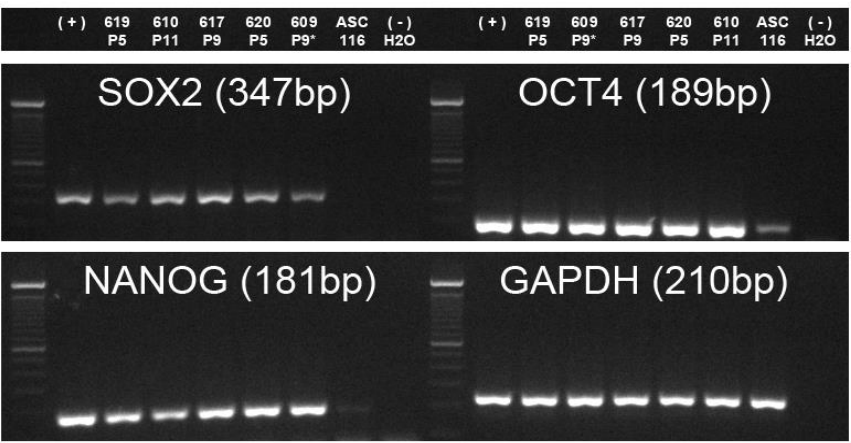

Figura 2: pASCs apresentam expressão de diversos marcadores relacionados à pluripotência. A) Clones 609 e 610 apresentando quadro completo de marcadores utilizados para caracterização dos clones de piPSCs. Note que existe diferença de expressão de alguns fatores entre os clones. B) Quadro simplificado de caracterização de pluripotência utilizado para averiguar regularmente os níveis de expressão dos principais marcadores de pluripotência nos clones estudados. Note que as células PASC que deram origem as piPSCs, são células mesenquimais adultas e por isso apresentam níveis de pluripotência claramente constatadas pela expressão basal de Oct-4 nestas células.

Além da análise de expressão gênica, os clones de piPSC foram submetidos a avaliação da expressão proteica através de imunofluorescência e demonstraram a expressão de marcadores como Oct-4, Sox-2 e SSEA4 (Figura 3). Anticorpos contra NANOG, TRA-1-60 e TRA-1-81 também foram testados, no entanto, estes anticorpos não foram produzidos contra proteínas de porco e sim humanas e não haviam sido testados em porcos até então. Nossos testes falharam em identificar essas proteínas (dados não mostrados) utilizando esses anticorpos. Contudo somandos os dados de expressão gênica e proteica aqui apresentados os 5 clones foram considerados iPSCs verdadeiras, ou seja, células pluripotentes induzidas. 
Apêndice $B$

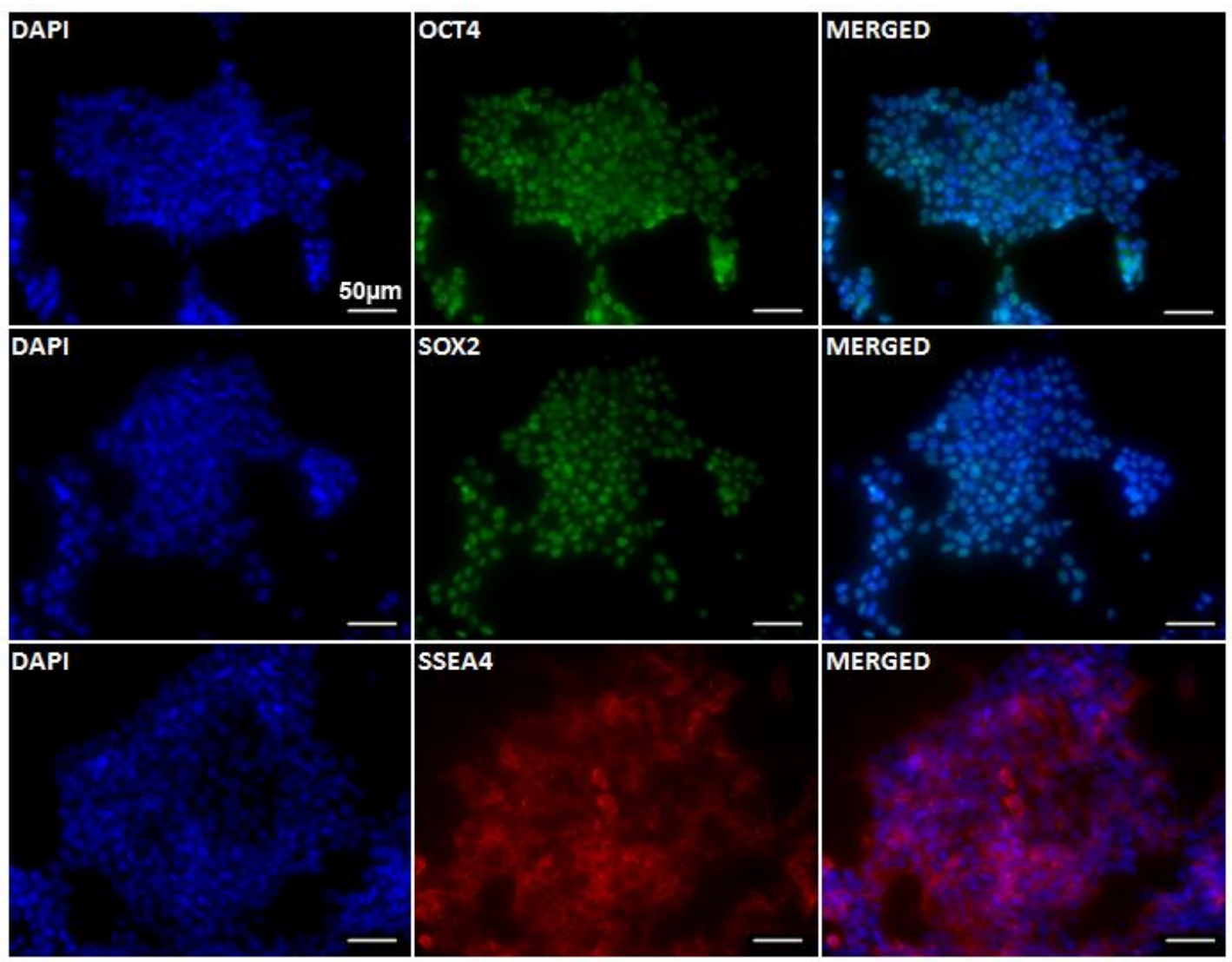

Figura 3: piPSCs apresentam a expressão proteica de marcadores de pluripotência. Imunofluorescências representativas da expressão de Oct-4, Sox-2 e SSEA4 no clone 610. Note que Oct-4 e Sox-2 são totalmente correlatos com a marcação de núcleo evidenciada por DAPI, como se espera. Já SSEA4 tem expressão distribuída. 
Apêndice $B$

piPSCs geradas a partir de pASC são capazes de gerar corpos embriódes aptos a expressar marcadores dos três folhetos germinativos

Outro teste aplicável às células pluripotentes é o de capacidade de diferenciação nos 3 folhetos germinativos (endo, meso e ectoderme). Este teste pode ser feito ao menos de duas maneiras diferentes sendo elas os ensaios de diferenciação por geração de corpos embrióides (in vitro) e o teste de formação de teratomas (in vivo). Ambos os testes foram realizados com as piPSCs, contudo o segundo sem sucesso devido a problemas técnicos do método e até aqui não solucionados. Já o teste de formação de corpos embrióides se mostrou aplicável (Figura 4). Todos os clones testados foram capazes de gerar corpos embrióides. Após 4 dias da formação e cultivos dos EBs em solução, estes foram plaqueados em condições para favorecer a aderência no plástico. Após vinte dias de cultivo em aderência (24 dias após a formação dos EBs) células de diferentes morfologias foram observadas na placa e a expressão gênica de NeuroD (ecto), ENOLASE (meso) e AFP (endoderme) foram identificadas por PCR (Figura 4 D). Um EB gerado a partir do clone 620 foi mantido com sucesso em cultivo em suspensão por até 50 dias. Este EB cresceu e apresentou morfologia saudável e adequado durante todo o período (Figura $4 \mathrm{E}$ ). 
Apêndice B

A)
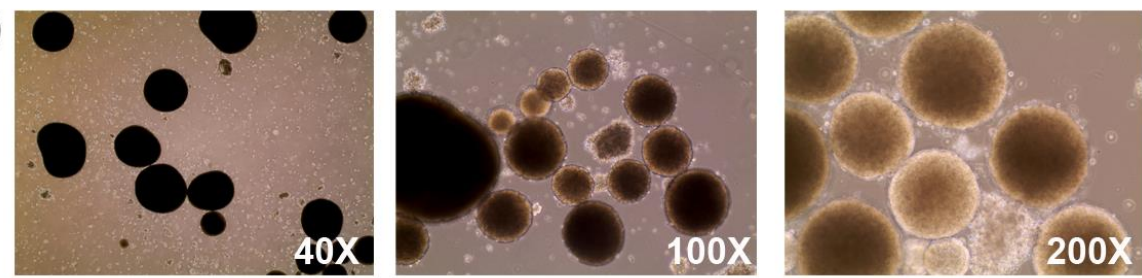

B)
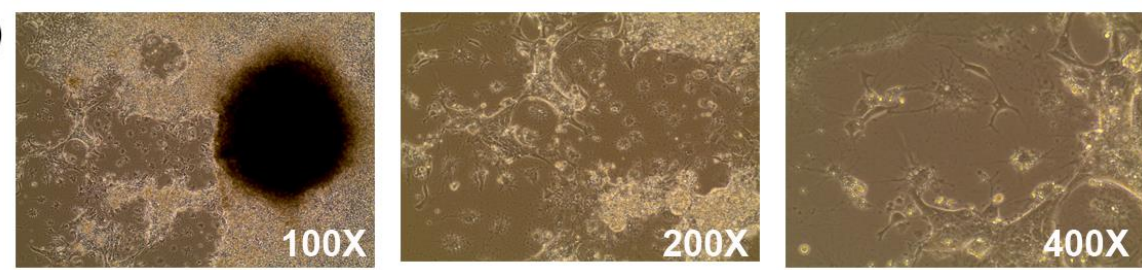

C)
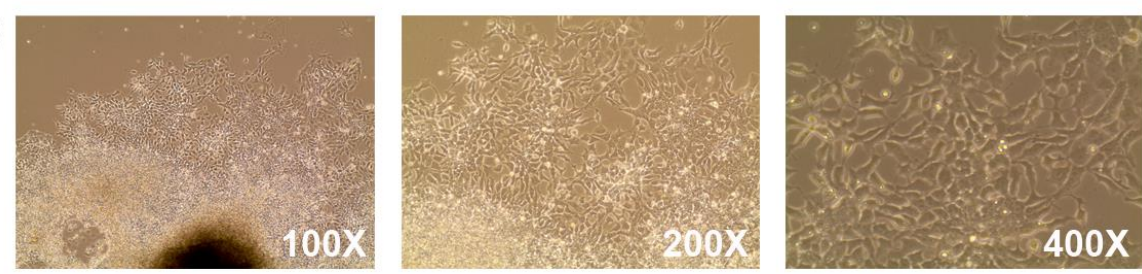

D)

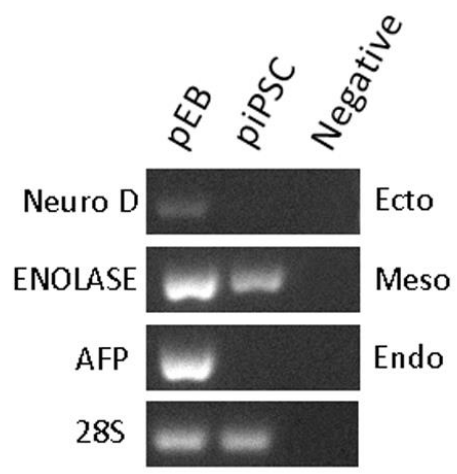

E)

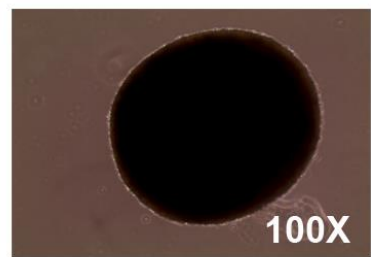

Figura 4: piPSCs geram corpos embrióides capazes de se diferenciar em células das 3 linhagens germinaivas. A) Fotos representativas dos EBs em cultivo não aderidos ( 1 a 4 dias após sua formação). B e C) Fotos representativas de EBs cultivados aderidos após 4 dias de cultivo em suspensão. Note que em B é possível observar a presença de algumas células com morfologia similar a encontrada para células do sistema nervoso, já em $\mathrm{C}$ uma série de células similares a células endoteliais de porcos podem ser observadas. D) Imagem representativa de RT-PCR para os marcadores de ecto, meso e endoderme respectivamente representadas pela expressão de NeuroD, ENOLASE e AFP. Note que piPSCs derivadas de pASC apresentam certo nível de expressão de ENOLASE. E) Foto representativa de EB cultivado em suspensão por mais de 40 dias. Note o tamanho relativo deste EB em relação aos EBs presentes na foto do item A 100X de magnificação.

\section{piPSCs geradas a partir de pASC não apresentam alterações cromossômicas nas primeiras passagens - Análise de cariótipo}

Além do perfil de pluripotência as piPSCs foram submetidas à análise de cariótipo para descartar possíveis alterações cromossômicas que fizessem destas células aberrações, impossibilitando seu uso em estudos futuros. 
Apêndice B

Nenhum tipo de aberração cromossômica como deleções, inserções ou translocações foi observada em nenhum dos clones estudados até a passagem 16 (Figura 5).

C
I
o
n
e
6
1
7

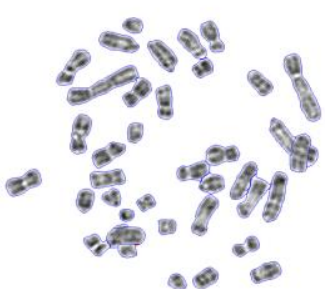

C
I
o
n
e
6
1
9

C
I
o
n
e
6
2
0

C
I
o
n
e
6
1
0

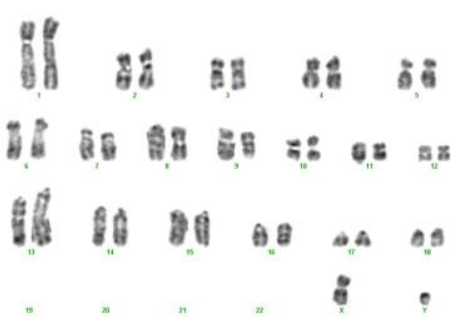

î 18 it a

If

*

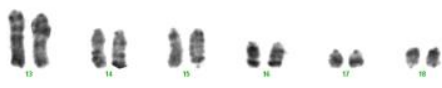

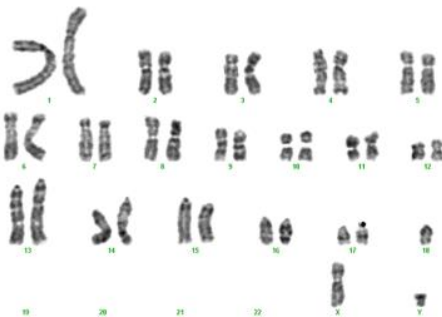

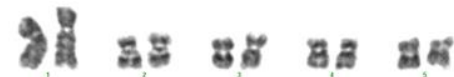

ปิน

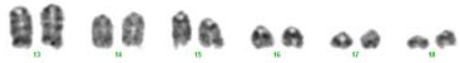

औ

Figura 5: piPSCs apresenta cariótipo normal nas primeiras passagens após reprogramação. Figura representativa da análise de cariótipos de 4 diferentes clones de piPSCs em passagem 16. Note que não há alterações grosseiras como deleções, translocações ou inserções cromossômicas nos cariótipos apresentados. Entre 5 e 10 metáfases foram avaliadas por clone e os mesmos resultados foram obtidos. 
Apêndice $B$

piPSCs não respondem satisfatoriamente aos protocolos de diferenciação de cardiomiócitos previamente estabelecidos para células humanas

Após a caracterização das piPSCs estas células foram então submetidas a tentativas de protocolos de diferenciação baseados nos protocolos previamente descritos e testados neste laboratório para iPSCs e células embrionárias humanas. Inicialmente o protocolo baseado no uso de pequenas moléculas capazes de modular a via de Wnt, previamente publicado por Lian e colegas foi testado (28). Variações deste protocolo tem sido validadas com frequência neste laboratório tanto para células embrionárias humanas como iPSCs e foram realizados como controle positivo dos métodos. Alguns resultados de diferenciação das células humanas podem ser observados nos vídeos depositados nos links da tabela 5 :

Tabela 5: Links para vídeos de diferenciações usando protocolo HM em hESCs e hiPSCs.

\begin{tabular}{|c|c|}
\hline Célula/matriz/meio & Link \\
\hline ESC humana (BR-1) em meio HM & $\underline{\text { https://www.youtube.com/watch?v=wdP6ePkR7Q8 }}$ \\
\hline Tay 6 em GelTrex (HM) & $\underline{\text { https://www.youtube.com/watch?v=USZIHIQDjCM }}$ \\
\hline Tay 6 em Fibronectina (HM) & https://www.youtube.com/watch?v=bsrUNkAhcTo \\
\hline
\end{tabular}

Contudo, a aplicação dos protocolos humanos em piPSCs 24 horas após a troca do meio de cultivo para o meio de diferenciação $A(R P M I+B 27$ sem insulina+inibidor de GSK3- $\beta$ ) fizeram com que as células de porcos morressem completamente (Figura 6). Deste modo, variações do meio de cultura usado para humanos foram testadas para tentar evitar a morte prematura das células de porcos. Para tanto os meios base DMEM+10\% SFB e RPMI+10\% SFB foram comparados com RPMI+B27 - insulina (Figura 6). Claramente as piPSCs responderam melhor nas condições onde $10 \%$ de soro fetal bovino foi utilizado 
Apêndice $B$

(Figura 6). Já o meio padrão para diferenciação, a base de RPMI suplementado com B27 foi insuficiente para manter as células pluripotentes de porco vivas mais que 24 horas (Figura 6).
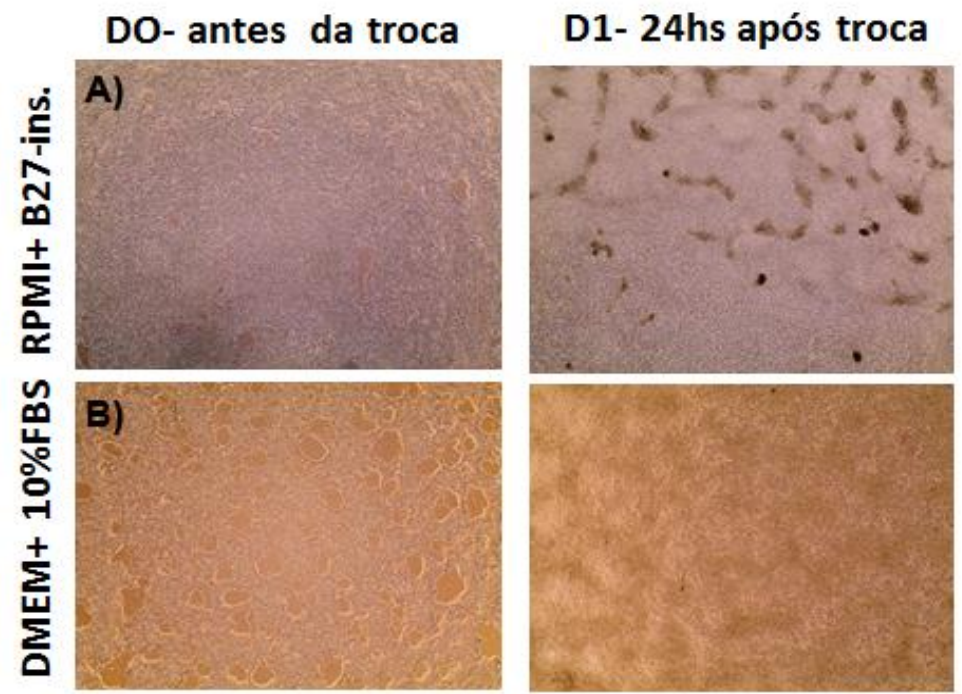

D2- 48hs após troca
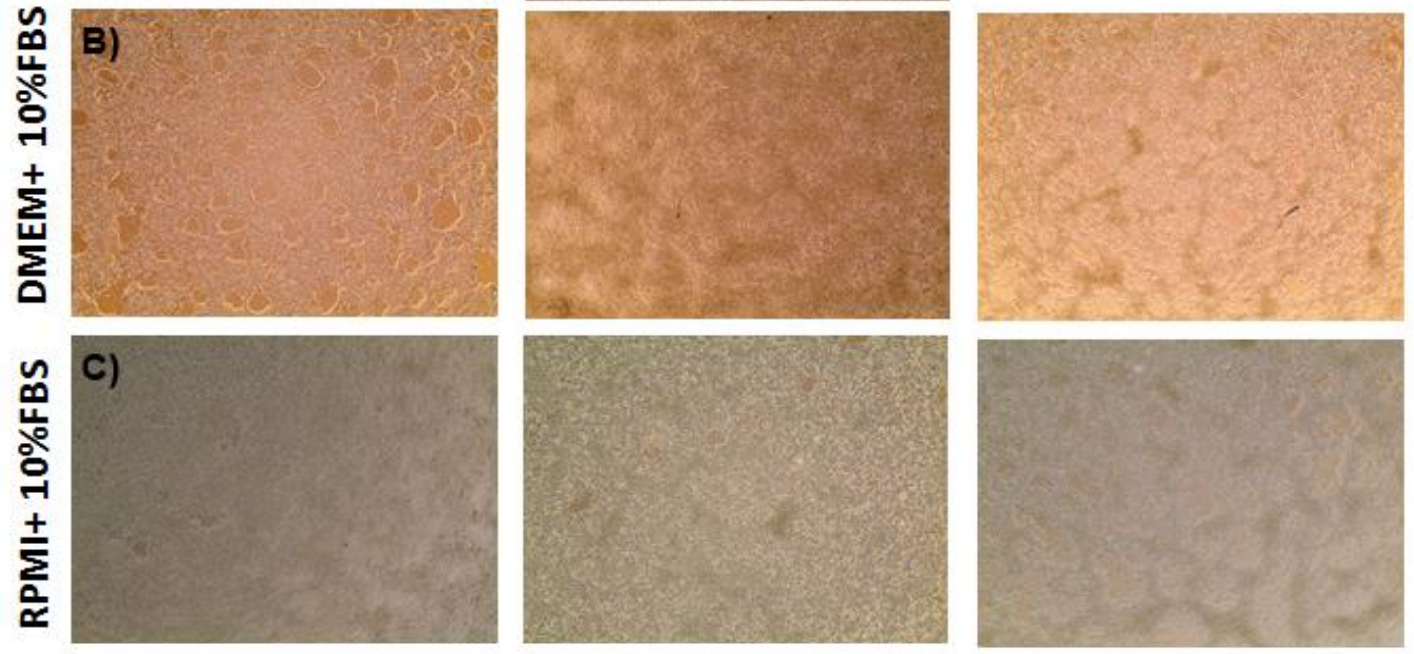

\section{$40 X$}

Figura 6: piPSCs não suportam meio de cultura para indução de diferenciação mesodérmica. A) piPSCs submetidas ao meio de diferenciação padrão no protocolo de diferenciação de cardiomiócitos com pequenas moléculas. Note que após 24 horas da troca do meio (D1) praticamente já não existem mais células vivas e aderidas na placa. B) piPSCs submetidas a meio DMEM suplementado com soro fetal bovino a $10 \%$ e adição da droga inibidora de GSK3- $\beta$. Note que as células sobrevivem e continuam crescendo (D1 e D2 já não há mais espaços vazios na placa. C) piPSCs submetidas a meio RPMI suplementado com $10 \%$ SFB. Note que assim como no meio da figura B, ao ser inserido o SFB no meio as células passam a suportar a condição de inibição de GSK3- $\beta$ sugerindo fortemente que o problema não sem encontra nesta inibição mas sim no meio de cultura padrão para diferenciação humana. 
Apêndice B

piPSCs dão origem a cardiomiócitos funcionais a despeito da baixa eficiência do protocolo até aqui estabelecido

A despeito de as piPSCs não terem sobrevivido ao meio RPMI+B27insulina, no meio $\mathrm{RPMI}+10 \% \mathrm{SFB}$, as células se mantiveram vivas por muito mais tempo e com isso foi possível obter, em um único experimento, uma região mínima onde as células pluripotentes induzidas de porcos geraram cardiomiócitos funcionais (Figura 7), os quais foram qualificados por apresentarem capacidade contrátil, registrada no vídeo depositado no link a seguir: https://www.youtube.com/watch?v=070fk_3jBSk.

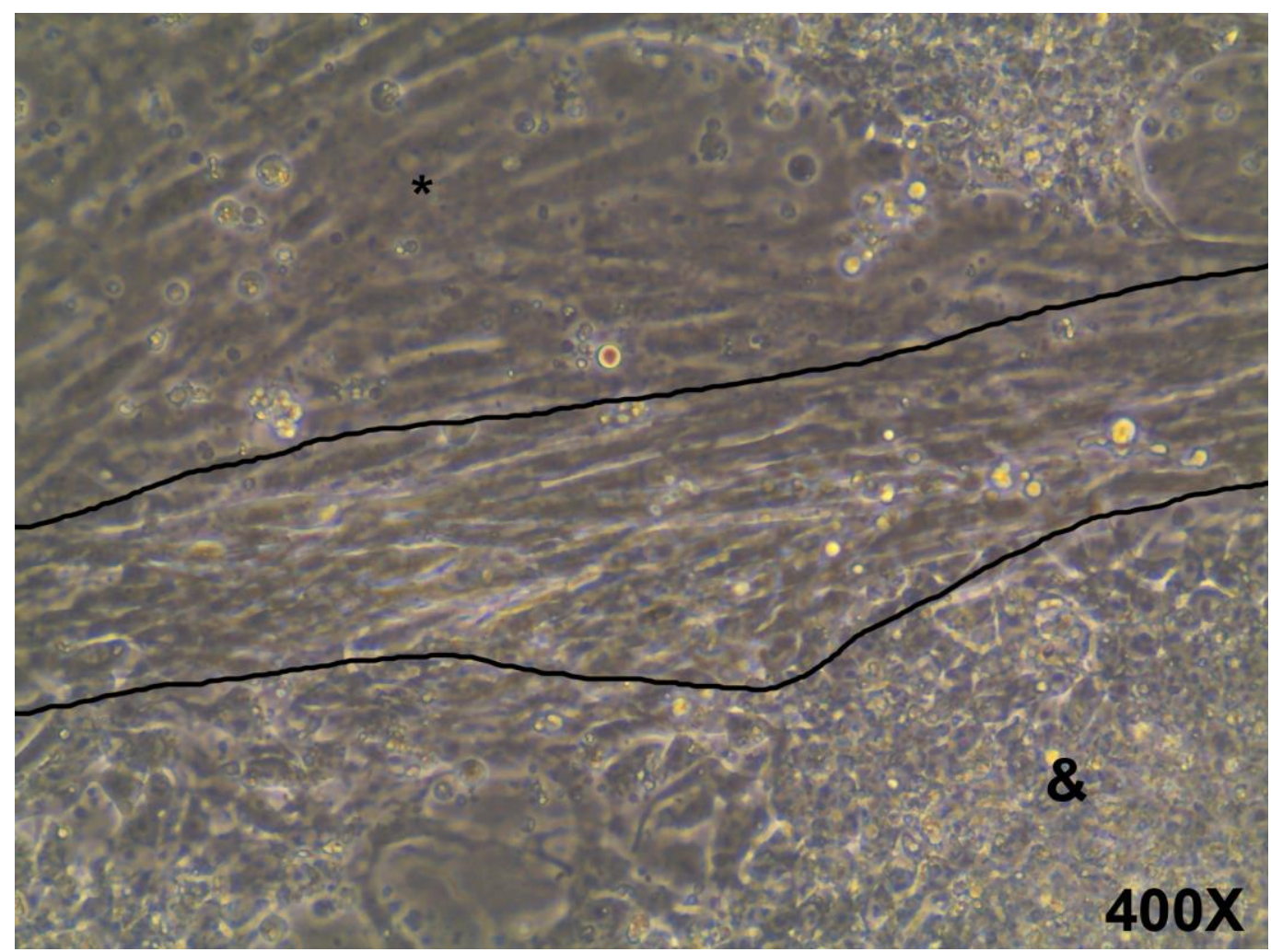

Figura 7: piPSCs são capazes de se diferenciar em cardiomiócitos funcionais. A figura representativa acima demonstra a exata região do poço da placa de 12 poços onde um pequeno grupo de células se diferenciou em cardiomiócitos funcionais. Estas são as células entre as linhas contínuas pretas. Note que existe uma série de outras células que se diferenciaram em algum tipo celular parecido morfologicamente com fibroblastos $\left(^{*}\right)$ bem como algumas células que ainda mantiveram o perfil clássico de células pluripotentes (\&). Mais detalhes da diferenciação podem ser visualizados no vídeo. 
Apêndice $B$

\section{piPSCs respondem agudamente à indução mesodérmica mas não sustentam os níveis de expressão}

Tendo em vista que as piPSCs foram capazes de gerar cardiomiócitos funcionais e responderam positivamente aos novos meios de cultura testados, mas levando em consideração que o SFB é um potente indutor de diferenciações aleatórias devido a grande variedade de fatores de crescimento e citocinas nele presentes (um dos motivos pelos quais o teste de diferenciação de EBs é feito usando $20 \%$ de SFB), novas combinações de meios visando reduzir as concentrações de SFB foram testadas e a viabilidade celular observada. Em um primeiro conjunto de experimentos as piPSCs foram submetidas a diferenciação em variações do meio base RPMI+B27 acrescido de CHIR, um inibidor de GSK3- $\beta$ largamente utilizado para a indução de diferenciação mesodérmica: RPMI + 10\% SFB; RPMI + 1X B27(-) + 2X NEAA + 2.5\% SFB; Adv. DMEM/F12 + 1X L-Glutamina e 50\% of RPMI + 1X B27(-) + $50 \%$ Ad. D/F12 + 1X L-Glutamina. O uso dos aditivos com aminoácidos não essenciais (NEAA), L-Glutamina e mesmo o uso do meio comercial Advanced DMEM/F12 mais rico que os demais meios de base, surtiram efeitos benéficos sobre a viabilidade das células, sem que para isso fosse necessário o uso de concentrações tão elevadas de SFB (Figura 8). Tendo o meio RPMI + 1X B27() $+2 \mathrm{X}$ NEAA $+2.5 \%$ SFB respondido muito bem com relação a manutenção de viabilidade das piPSCs quando comparado ao meio RPMI $+10 \%$ SFB, aquele foi escolhido como potencial meio para os próximos passos da diferenciação. 
Apêndice $B$

A)

Cl. 617 P34
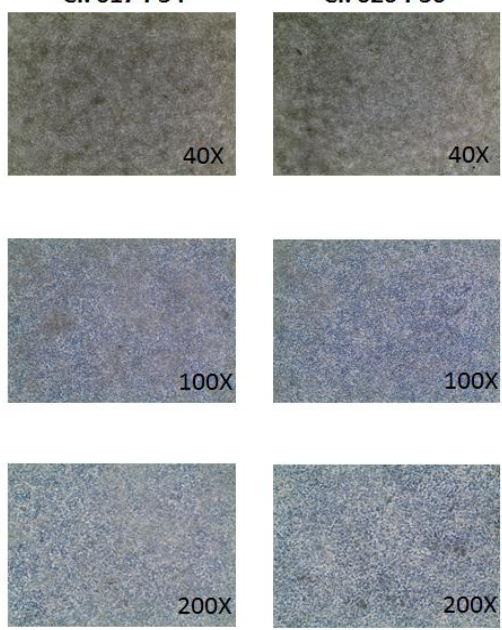

RPMI + 10\% FBS

C)

Cl. 617 P34
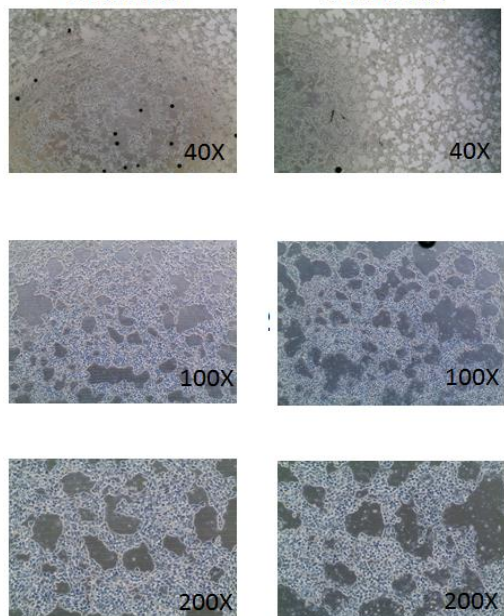

Adv. D/F12 + 1X L-Glutamine
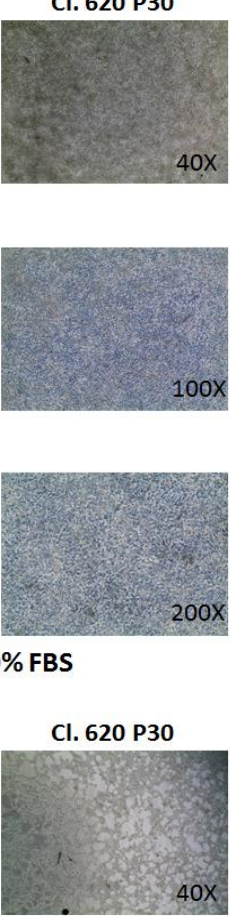

B)

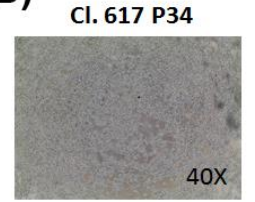

Cl. 620 P30
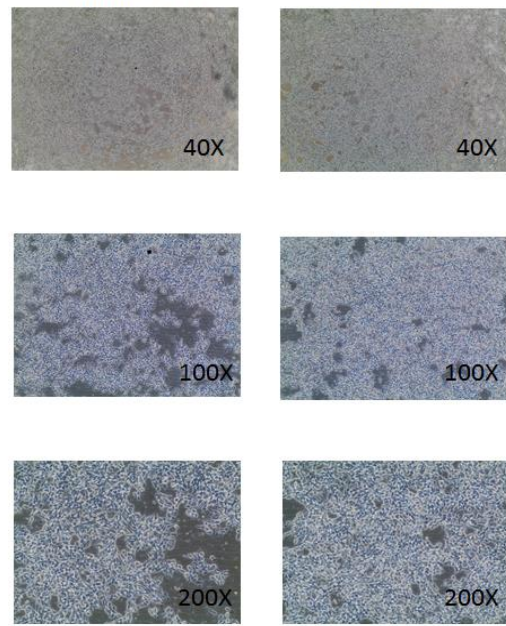

RPMI + 1X B27(-) + 2X NEAA + 2.5\% FBS

D)

Cl. 617 P34

Cl. 620 P30
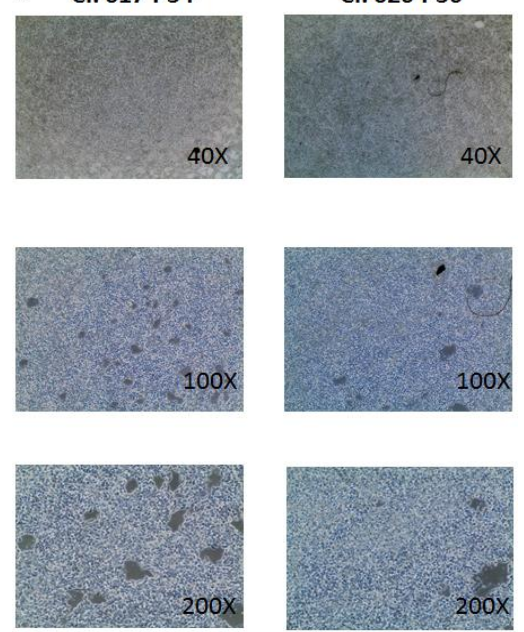

$50 \%$ of RPMI + 1 X B27(-) + $50 \%$ Ad. D/F12 + 1X L-Glut

Figura 8: piPSCs respondem bem a mudança de meio de cultura com menores concentrações de SFB quando em associação com outros elementos essenciais. A) meio de cultura padrão onde houve a diferenciação de piPSCs em cardiomiócitos funcionais. Note que as células apresentam ótima viabilidade nesse meio. B) Meio de cultura padrão para diferenciação humana acrescido de aminoácidos não essenciais e baixa concentração de SFB. Note que a viabilidade e piPSCs se assemelha a encontrada no meio apresentado em A. C) Meio Advanced DMEM/F12 acrescido de L-Glutamina. Neste caso o meio foi testado por prometer ser um meio mais rico que o RPMI sem um meio funcional para uso de baixíssimas concentrações de SFB (da ordem de 1\%), contudo para as piPSCs esse meio ainda não se fez suficiente. D) Mistura de 1:1 dos meios $B$ e $C$. A viabilidade celular foi preservada na figura apresentada, mas a reprodutibilidade do dado não aceitável.

Além da viabilidade celular, foram avaliados nas piPSCs o nível de expressão do marcador mesodérmico Brachyury $(T)$, após as primeiras horas do inicio da diferenciação. Uma curva de dose de CHIR foi testada. A partir dela foi definida a dose de $12 \mathrm{uM}$ de CHIR como sendo a dose ótima, na qual 
Apêndice $B$

não houve aumento na mortalidade celular e houve bom nível de expressão de

Brachyury 24 horas após inicio da diferenciação (Figura 9). O teste de expressão de Brachyury para os demais meios demonstrou que algo relacionado ao meio Advanced DMEM/F12 bloqueia expressão de $\mathrm{T}$, sendo que as células nesse meio não apresentaram expressão deste gene após 24 horas de protocolo (dado não mostrado).
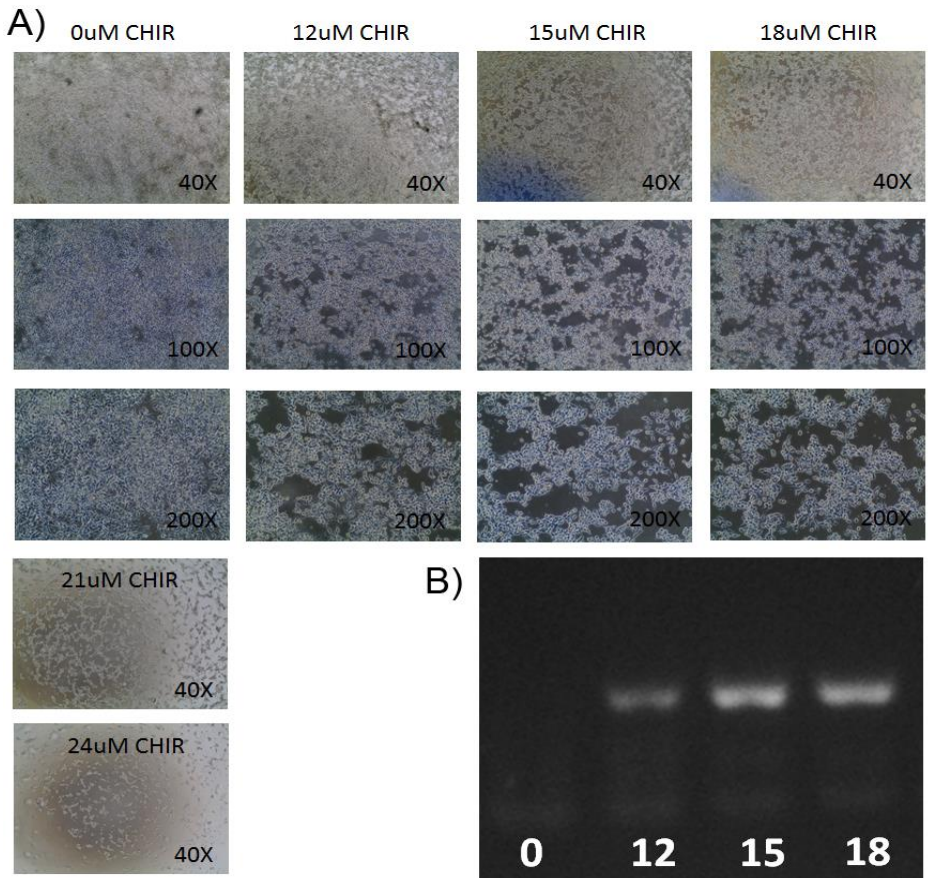

B)

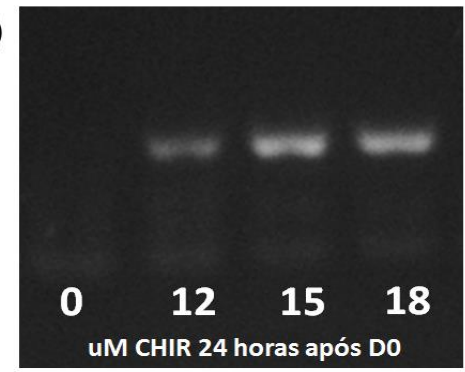

Figura 9: Curva dose resposta para o uso de CHIR em piPSCs. Estas células responderam com aumento expressivo da morte à medida que a dose de droga foi aumentada após 24 horas do início do tratamento. A) Imagens representativas do clone 617 em diferentes magnificações para as diferentes doses de CHIR testadas. Note que a dose de 12 uM causa morte celular e esta aumenta conforme a dose de CHIR é aumentada. Doses acima de 18 uM causam morte elevada das piPSCs. As doses de 15 e $18 \mathrm{uM}$ apresentam-se com níveis similares de mortalidade visualizada qualitativamente através da microscopia de luz. B) Gel de agarose representativo demonstrando a expressão genica de Brachyury, 24 horas após o início do tratamento com o inibidor de GSK3- $\beta$. Note que as doses de 15 e 18 uM apresentam uma expressão relativa superior a observada em 12 uM. Contudo, os níveis de morte celular também são superiores.

Apesar de as piPSCs responderem bem a troca de meio para o RPMI+B27- + NEAA + SFB, ao acompanhar a expressão de Brachyury no tempo observou-se que a expressão desse marcador não se sustentou além 
Apêndice $B$

das 24 horas iniciais, além do que um aumento da mortalidade das células foi observada após este período inicial no novo meio (Figura 10). A expressão sustentada de Brachyury seguida da expressão de outros genes de mesoderme como MIX-L1 e Msx-1 são prerrogativas para a eficiente diferenciação de células pluripotentes humanas em cardiomiócitos, mas vistos os dados até aqui apresentados, esta não se mostrou similar para as piPSCs nas condições propostas.

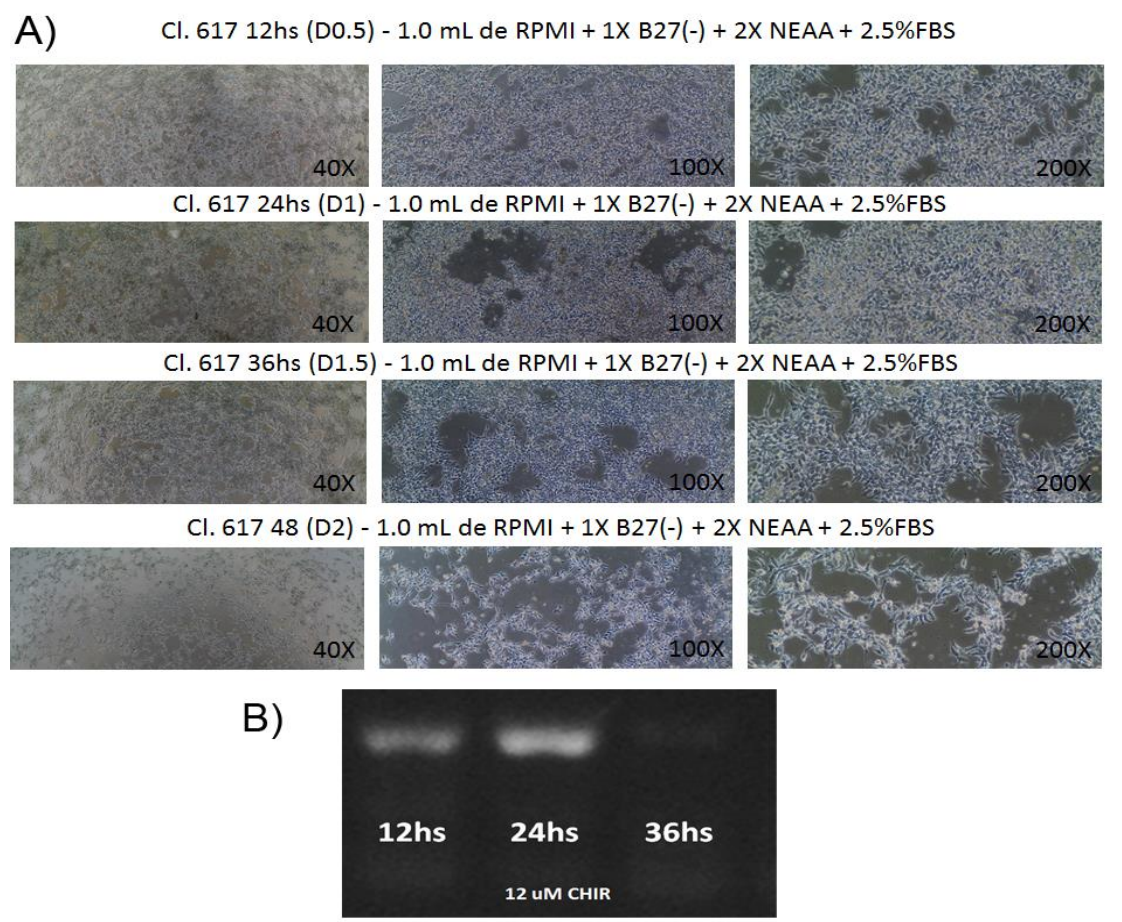

Figura 10: piPSCs perdem a expressão de T após 24 horas da inibição de GSK3- $\beta$. A) Imagens representativas do clone 617. Note que a medidas que as horas passaram houve aumento da morte celular seguido de B) uma redução da expressão genica de Brachyury. Tal alteração potencialmente se relaciona com a baixa eficiência obtida na diferenciação, ou seja apenas uma parcela pequena das células que sobrevive a fase inicial do tratamento são propriamente aptas a responderem ao restante dos estímulos para diferenciação em cardiomiócitos funcionais.

Tendo esse resultado sido obtido no meio de cultura modificado, a pergunta imediata seria se isso é diferente no meio com $10 \%$ SFB, visto que neste, cardiomiócitos funcionais foram obtidos, mesmo que com baixa 
Apêndice $B$

eficiência. Tentando responder a essa questão um novo experimento exatamente igual ao que gerou os cardiomiócitos funcionais foi realizado, contudo, células foram coletadas a cada 24 horas por 2 dias. Como era de se esperar, no D0 não houve expressão de Brachyury. Vinte e quatro horas após a inibição de GSK3- $\beta$ a expressão de Brachyury foi idêntica a encontrada no experimento anterior para o meio de cultura modificado. Além de Brachyury a expressão de MIX-L1 também foi observada. No entanto, 48 horas após o inicio do protocolo nenhuma expressão de Brachyury nem de MIX-L1 foram visualizadas. Interessantemente, algumas células com perfil morfológico de células nervosas foi visualizado e, portanto a expressão de NeuroD foi testada e mostrou que especialmente em um dos clones testados havia uma leve expressão deste gene (Figura 11). 


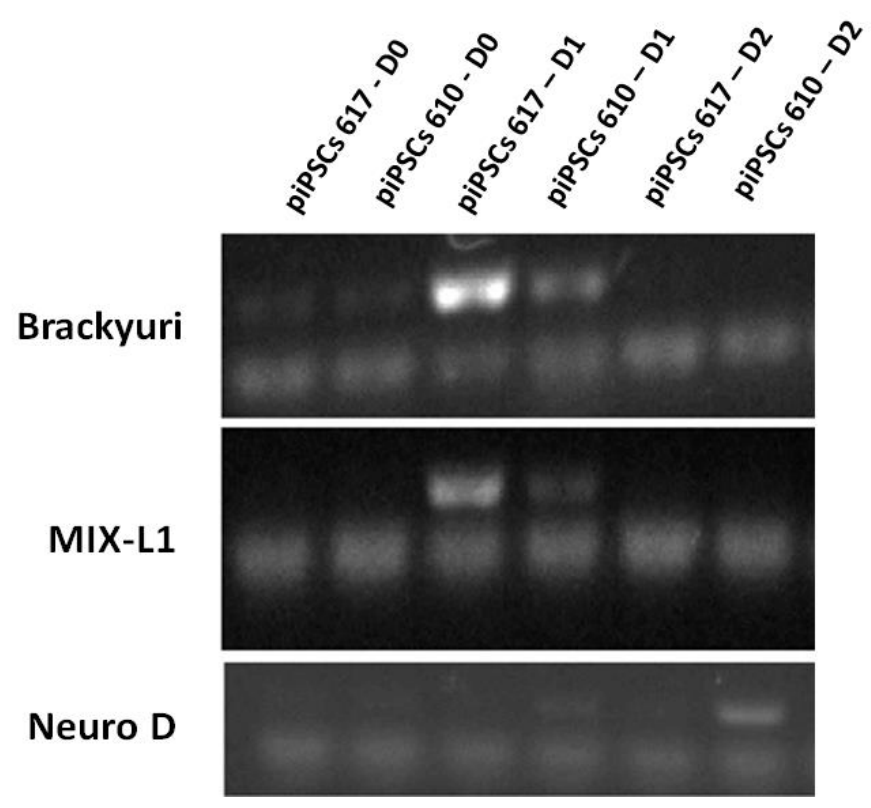

Figura 11: piPSCs perdem a expressão de T e MIX-L1 após 24 horas da inibição de GSK3$\beta$ mesmo em meio RPMI+10\% SFB. Note que a medidas que as horas passam há desaparecimento da expressão dos genes de Brachyury e MIX-L1. Além disso, especialmente no clone 610 nota-se uma baixa expressão do gene NeuroD. Tal expressão potencialmente evidencia que a diferenciação não é especifica com esse meio e se relaciona com a baixa eficiência obtida diferenciação.

\section{piPSCs não respondem ao meio de diferenciação comercialmente disponível}

Recentemente um meio de diferenciação de cardiomiócitos para células pluripotentes foi lançado no mercado. Com o objetivo de testar a eficiência e estabilidade deste meio comercial, tanto células embrionárias e iPSCs humanas como as piPSCs foram submetidas a este protocolo. Mais uma vez as piPSCs não responderam adequadamente ao protocolo de diferenciação. 0 meio comercial também causou morte exacerbada da população de piPSCs após 24-48hs do inicio do protocolo, inviabilizando que o mesmo fosse continuado além das primeiras 48hs. Já em células humanas, seja embrionárias (BR-1) ou iPSCs, os resultados foram tão bons ou mesmo melhores que os obtidos nos protocolos caseiros. Os dados qualitativos do 
Apêndice $B$

protocolo em células humanas podem ser visualizados nos vídeos depositados nos links da tabela 6.

Tabela 6: Links para vídeos de diferenciações usando protocolo comercial em hESCs e hiPSCs.

\begin{tabular}{|c|c|}
\hline Célula/matriz/meio & Link \\
\hline ESC humana (BR-1) em meio Comercial - 1 & https://www.youtube.com/watch?v=Zuqv2FAM9AM \\
\hline ESC humana (BR-1) em meio Comercial - 2 & $\underline{\text { https://www.youtube.com/watch?v=EJQz905FDLY }}$ \\
\hline Clone T6 em meio comercial & $\underline{\text { https://www.youtube.com/watch?v=deF8jiyT0Fk }}$ \\
\hline
\end{tabular}

\section{Discussão}

Os dados apresentados neste apêndice demonstram que assim como para células humanas, através de um sistema viral polisistrônico de expressão dos genes Oct-4, Sox-2, KLF-4 e c-Myc, fomos capazes de reprogramar permanentemente células-tronco adultas derivadas do tecido adiposo de porcos em células pluripotentes induzidas. As piPSCs geradas apresentaram os principais marcadores moleculares relacionados a pluripotência e já classicamente estabelecidos para a caracterização de iPSCs em outras espécies. Estas células também foram capazes, através de diferenciação em corpos embrióides, de gerar células dos três folhetos embrionários. Além disso, não apresentaram alterações cromossômicas e ainda foram induzidas a se diferenciar em cardiomiócitos funcionais capazes de se contrair com ritmo.

Tendo em vista que as abordagens classicamente empregadas no tratamento do IM não são capazes de gerar novas células musculares contráteis e que até o momento as novas terapias propostas não foram 
Apêndice B

eficazes para este mesmo fim, ou seja, não há regeneração do musculo afetado, a busca por novas fontes de células e novas abordagens capazes de reestabelecer a grande massa de tecido cardíaco perdida em um episódio de IM continua. Atualmente, com o advento das células pluripotentes induzidas (iPSCs) (26) uma nova avenida de conhecimentos se abriu e, com esta, diferentes abordagens celulares passaram a ser exploradas.

As células pluripotentes induzidas a partir de células somáticas adultas foram pela primeira vez apresentadas por Takahashi e Yamanaka no ano de 2006 (26) e renderam a este o prêmio Nobel de Fisiologia ou Medicina de 2012. Neste trabalho, células de fibroblastos adultos de murinos foram reprogramados através da expressão de 4 fatores de transcrição, hoje corriqueiramente conhecidos, Oct-4, Sox-2, KLF-4 e c-Myc, os quais, foram expressos através de vetores retrovirais. Quase que simultaneamente em 2007 os grupos de Yamanaka e James A. Thomson publicaram a então reprogramação dos fibroblastos humanos $(34,35)$. Após estas publicações uma série de outros organismos e tipos celulares passou a ser testada, dentre eles o porco.

Quase que simultaneamente em 2009, 3 grupos independentes geraram com sucesso iPSCs de porcos usando fibroblastos e sistemas virais (36-39). Assim como nos trabalhos anteriormente citados, nossas piPSCs geradas através do sistema viral polisistrônico STEMCA, previamente descrito por Somers e colaboradores para reprogramação de células humanas (32), foram positivas para marcação com fosfatase alcalina além de apresentarem uma série de marcadores de pluripotência, como Oct-4, NANOG, TERT, DPPA5 
Apêndice $B$

entre outros e o marcador de superfície SEEA4. Nestes trabalhos, a pluripotência das iPSCs geradas foi testada através de protocolos de formação de teratoma $(37,38)$ e geração e diferenciação de corpos embrióides (36-38). Nossas piPSCs geradas a partir de ASCs foram capazes de gerar corpos embrióides que foram mantidos em suspensão por até 50 dias. Eles também apresentaram crescimento normal e morfologia saudável. Os corpos embrióides da piPSCs foram ainda capazes de gerar células das três linhagens germinativas quando cultivados aderidos à placa e com SFB. No entanto, os testes para formação de teratoma foram mal sucedidos. Os camundongos nude injetados morreram poucos dias após a injeção subcutânea das piPSCs, por conta de uma infecção. Devido à incompatibilidade de tempo entre o problema obtido e a confecção desta tese, este experimento ainda não foi repetido, contudo todos os dados de caracterização de pluripotência e os obtidos para os corpos embrióides somados dão suporte à plasticidade das piPSCs geradas a partir de pASCs.

As piPSCs obtidas através da reprogramação com STEMCA vírus não apresentaram aberrações cromossômicas. Os 5 clones gerados foram avaliados em diferentes passagens, e, até a passagem 16, nenhuma aberração cromossômica grosseira foi observada. Contudo, uma série de trabalhos recentes tem demonstrado que os processos de reprogramação celular podem causar defeitos genéticos, os quais podem limitar o uso das iPSCs em aplicações clínicas (40-45). Mayshar e colaboradores demonstraram através de uma meta-análise que existem diversas aberrações resultantes da adaptação das células reprogramadas em cultivo, outra série importante está 
Apêndice $B$

relacionada a condições das células somáticas que as deram origem. Além disso, eles também observaram aneuploidias bem evidentes nas primeiras passagens de hiPSCs denotando considerável pressão seletiva durante 0 processo de reprogramação (43). Steichen e colegas demonstraram que diferentes métodos de reprogramação exercem influência sobre o número de polimorfismos de um único nucleotídeo em hiPSCs (45).

Além das aberrações cromossômicas e polimorfismos outro tipo importante de alteração de perfil que tem despertado interesse está relacionado aos padrões epigenéticos das iPSCs bem como das células somáticas que as dão origem (46-51). Bar-Nur e colegas demonstraram que hiPSCs geradas a partir de células beta da ilhota pancreática apresentam, quando comparadas a ESCs e iPSCs de outras origens, capacidade superior de se diferenciar em células produtoras de insulina (46). Polo e colegas mostraram que iPSCs de camundongos geradas a partir de fibroblastos, células hematopoiéticas e células miogênicas apresentam padrões transcricionais e epigenéticos muito distintos entre si, principalmente nas primeiras passagens, e estes influenciam diretamente nas habilidades destas em se diferenciarem (50).

Além disso, Lister e colaboradores, através de uma análise de metilação de DNA do genoma completo de 5 linhagens de iPSCs, demonstraram que estas apresentam significativa variabilidade na reprogramação incluindo memória das células somáticas e reprogramação anômala de metilações do DNA (51). Com base nesta série de trabalhos citados, nossas piPSCs precisarão ser mais profundamente avaliadas quanto a sua integridade 
Apêndice $B$

genética e processos cada vez mais controlados de reprogramação precisarão ser aplicados.

Tendo em vista que se após o infarto do miocárdio houvesse a substituição do tecido cicatricial por novo tecido contrátil poderiam ser resolvidos grande parte dos problemas encontrados, e ressaltando que na medicina atual não existem métodos suficientemente capazes de regenerar o órgão afetado, nem mesmo o uso das células-tronco adultas, novas fontes de células capazes de gerar cardiomiócitos (CMs) tem sido estudadas. As primeiras evidências de que células humanas pluripotentes seriam capazes de se diferenciar em CMs funcionais foram observadas em hESCs $(52,53)$ e hiPSCs $(54,55)$. Contudo, estes trabalhos se baseavam em protocolos de diferenciação baseado no uso de corpos embrióides e por fim geravam número reduzido de cardiomiócitos funcionais.

Com a evolução dos conhecimentos embriológicos relacionados à formação dos cardiomiócitos, protocolos cada vez mais específicos baseados no uso de meios de cultivo definidos, livres de soro e suplementados com moléculas cada vez mais específicas tem sido propostos apresentando resultados cada vez mais reprodutíveis e homogêneos (27). Dentre estes protocolos o publicado por Lian e colaboradores se destaca e tem sido usado como base para que novos e aprimorados meios de diferenciação sejam propostos (28). Neste protocolo a via da Wnt foi manipulada em dois momentos principais. Primeiro através do uso de um inibidor de GSK3- $\beta$ (CHIR) onde as células pluripotentes são induzidas a se diferenciar em células mesodérmicas. Em um segundo momento, através da inibição de Wnt por IWP2 e 4, onde a $\beta$ - 
Apêndice $B$

catenina é degradada e as células mesodermais se transformam em células de cardiomesoderme e, posteriormente, em cardiomiócitos $(28,29)$. Recentemente, Burridge et al., com base no protocolo anteriormente citado, demonstrou que é possível obter cardiomiócitos de forma ainda mais eficiente e limpa. Neste trabalho o meio de cultura de base usado por Lian foi detalhadamente estudado. Os autores mantiveram o uso dos inibidores como proposto por Lian, porém em um meio de cultura simples e completamente definido e composto apenas por RPMI, albumina e ácido ascórbico, extremamente importante como antioxidante (30).

Para as piPSCs foi testados inicialmente o protocolo de diferenciação com meio de cultura quimicamente definido (RPMI + B27) e inibidores da via de Wnt proposto por Lian $(28,29)$. Vinte e quatro horas após o início do protocolo (quando o meio RPMI + B27) foi adicionado às placas, todas as células se encontravam mortas. O meio RPMI + B27 é suplementado com o inibidor CHIR no primeiro dia de protocolo. Para comprovar que a morte celular não estava relacionada ao uso do $\mathrm{CHIR}$, placas nas mesmas condições experimentais foram usadas como controle e à elas foi adicionado apenas RPMI + B27. Do mesmo modo que para as placas submetidas ao protocolo com meio completo, 24 horas após a troca de meio todas as células estavam mortas.

O suplemento B27 foi inicialmente proposto para uso em meio livre de soro para cultivo de neurônios do hipocampo (56). Células pluripotentes apresentam um elevado consumo de nutrientes. Células mesenquimais de porco (31) apresentam maior velocidade de duplicação do que células humanas (57). Com base nestas premissas, testamos a hipótese de que o B27 
Apêndice B

pudesse ser um suplemento muito pobre para as piPSCs que também apresentam uma velocidade de duplicação aparente, maior que as hiPSCs. Para tanto, um meio RPMI suplementado com $10 \%$ de soro fetal bovino foi testado, a despeito das já sabidas perdas de eficiência que enfrentaríamos.

Através desta combinação foi possível manter células vivas por todo o protocolo e obter a diferenciação de um pequeno número de piPSCs em células contráteis. Visto que o uso de SFB nos permitiu atingir o objetivo final do protocolo, ou seja, a obtenção de cardiomiócitos funcionais, diferentes combinações de meio com menores quantidades de SFB e adição de outros suplementos como aminoácidos não essenciais, glutamina, ácido ascórbico em diferentes combinações e doses ou ainda meios de cultura mais ricos que o RPMI foram testados. Independentemente das combinações testadas, as células continuaram a morrer. Ademais, as células que sobreviveram as 24 horas iniciais apresentaram uma resposta importante à inibição de GSK-3ß, porém essa resposta não foi sustentada mais que 48 horas. Com isso resultados superiores aos obtidos com o uso do meio RPMI + 10\% SFB não foram alcançados.

Ao passo que a tecnologia de reprogramação de células somáticas adultas é de domínio deste laboratório (humanas e porco), e que protocolos de diferenciação de hiPSCs para cardiomiócitos estão cada vez mais bem estabelecidos, novos estudos para o estabelecimento de um novo e eficaz protocolo de diferenciação de piPSCs para cardiomiócitos tem que ser estudado. Neste sentido estudos relacionados com o estresse oxidativo sofrido por essas células durante a diferenciação pode ter relevante implicação para o 
Apêndice B

futuro das células pluripotentes de porcos em cardiologia. Em um experimento pontual estas as piPSCs foram submetidas a uma variação do meio de diferenciação proposto por Burridge e colegas (30). Neste meio composto por RPMI, albumina e ácido ascórbico 5 vezes mais concentrado do que o meio usado para hiPSCs, as piPSCs sobreviveram em maior quantidade e tempo do que até aqui observado com os demais meios testados, sugerindo fortemente que a regulação do balanço oxidativo possa influenciar diretamente na sobrevida e então no sucesso da diferenciação das piPSCs. Mas esses dados ainda são preliminares e precisam ser mais bem explorados. 
Apêndice $B$

\section{Conclusões sumarizadas}

a) As piPSCs geradas a partir de pASC apresentaram expressão de marcadores de pluripotência que as caracterizam;

b) As piPSCs geradas a partir de pASC foram capazes de gerar corpos embriódes que expressaram os marcadores dos três folhetos germinativos;

c) As piPSCs geradas a partir de pASC não apresentaram aberrações cromossômicas;

d) piPSCs responderam agudamente à indução mesodérmica mas não sustentaram os níveis de expressão;

e) piPSCs originaram cardiomiócitos funcionais a despeito da baixa eficiência do protocolo.

\section{Conclusão final}

Juntos os dados apresentados permitem concluir que através da superexpressão de Oct-4, Sox-2, KLF-4 e c-Myc por um sistema de expressão lentiviral polistrônico foi possível reprograma células-tronco mesenquimais derivadas do tecido adiposo de porcos em células pluripotentes induzidas (piPSCs) e ainda que estas piPSCs foram capazes de diferenciar em cardiomiócitos funcionais através da modulação de vias relacionadas a sinalização de Wnt. A eficiência deste protocolo deve ser melhorando para obtenção de grande quantidade de cardiomiócitos funcionais. Estas células poderão ser utilizadas para o desenvolvimento de novas estratégias terapêuticas de reparo cardíaco bem como para o uso em modelos celulares de doenças. 


\section{Referências Bibliográficas}

1. Danoviz ME, Nakamuta JS, Marques FLN, dos Santos L, Alvarenga EC, dos Santos A a, et al. Rat adipose tissue-derived stem cells transplantation attenuates cardiac dysfunction post infarction and biopolymers enhance cell retention. PLOS One. 2010; 5(8):e12077.

2. Dos Santos L, Santos A a, Gonçalves G, Krieger JE, Tucci PJF. Bone marrow cell therapy prevents infarct expansion and improves border zone remodeling after coronary occlusion in rats. Int $J$ Cardiol. 2010; 145(1):34-9.

3. Mummery CL, Davis RP, Krieger JE. Challenges in using stem cells for cardiac repair. Sci Trans/ Med. 2010; 2(27):27ps17.

4. Quevedo HC, Hatzistergos KE, Oskouei BN, Feigenbaum GS, Rodriguez JE, Valdes $D$, et al. Allogeneic mesenchymal stem cells restore cardiac function in chronic ischemic cardiomyopathy via trilineage differentiating capacity. PNAS. 2009; 106(33):14022-7.

5. Nakamuta JS, Danoviz ME, Marques FLN, dos Santos L, Becker C, Gonçalves $\mathrm{G}$ a, et al. Cell therapy attenuates cardiac dysfunction post myocardial infarction: effect of timing, routes of injection and a fibrin scaffold. PLoS One. 2009; 4(6):e6005.

6. Chen D, McKearin D. Gene circuitry controlling a stem cell niche. Curr Biol. 2005; 15(2):179-84.

7. Kinnaird T, Stabile E, Burnett MS, Lee CW, Barr S, Fuchs S, et al. Marrow-derived stromal cells express genes encoding a broad spectrum of arteriogenic cytokines and promote in vitro and in vivo arteriogenesis through paracrine mechanisms. Circ Res. 2004; 94(5):678-85.

8. Wollert KC, Drexler H. Clinical applications of stem cells for the heart. Circ Res. 2005; 96(2):151-63.

9. Aicher A, Brenner W, Zuhayra M, Badorff C, Massoudi S, Assmus B, et al. Assessment of the tissue distribution of transplanted human endothelial progenitor cells by radioactive labeling. Circulation. 2003; 107(16):2134-9.

10. Gill M, Dias S, Hattori K, Rivera ML, Hicklin D, Witte L, et al. Vascular trauma induces rapid but transient mobilization of VEGFR2(+)AC133(+) endothelial precursor cells. Circ Res. 2001; 88(2):167-74. 
Apêndice $B$

11. Ivanović V, Jelkić N, Bikicki M, Petrović M, Canji T, Srdanović I. The significance of coronary collateral circulation in the preservation of myocardial function. Med Pregl. 2007; 60(5-6):287-91.

12. Regieli JJ, Jukema JW, Nathoe HM, Zwinderman AH, Ng S, Grobbee DE, et al. Coronary collaterals improve prognosis in patients with ischemic heart disease. Int J Cardiol. 2009; 132(2):257-62.

13. He A, Jiang Y, Gui C, Sun Y, Li J, Wang J. The antiapoptotic effect of mesenchymal stem cell transplantation on ischemic myocardium is enhanced by anoxic preconditioning. Can J Cardiol. 2009; 25(6):353-8.

14. Spinale FG. Myocardial matrix remodeling and the matrix metalloproteinases: influence on cardiac form and function. Physiol Rev. 2007; 87(4):1285-342.

15. Vanhoutte D, Heymans S. TIMPs and cardiac remodeling: "Embracing the MMP-independent-side of the family". J Mol Cell Cardiol. 2010; 48(3):445-53.

16. Ramkisoensing A a, Pijnappels D a, Askar SF a, Passier R, Swildens J, Goumans MJ, et al. Human embryonic and fetal mesenchymal stem cells differentiate toward three different cardiac lineages in contrast to their adult counterparts. PLoS One. 2011; 6(9):e24164.

17. Marbán E, Cingolani E. Heart to heart: Cardiospheres for myocardial regeneration. Heart Rhythm. 2012; 9(10):1727-31.

18. Malliaras K, Li T-S, Luthringer D, Terrovitis J, Cheng K, Chakravarty T, et al. Safety and efficacy of allogeneic cell therapy in infarcted rats transplanted with mismatched cardiosphere-derived cells. Circulation. 2012; 125(1):100-12.

19. Leri A, Kajstura J, Anversa P. Role of cardiac stem cells in cardiac pathophysiology: a paradigm shift in human myocardial biology. Circ Res. 2011; 109(8):941-61.

20. Zipori D. Mesenchymal stem cells: harnessing cell plasticity to tissue and organ repair. Blood Cells Mol Dis. 2004; 33(3):211-5.

21. Brehm M, Zeus T, Strauer BE. Stem cells--clinical application and perspectives. Herz. 2002; 27(7):611-20.

22. Chong JJH, Yang X, Don CW, Minami E, Liu Y-W, Weyers JJ, et al. Human embryonic-stem-cell-derived cardiomyocytes regenerate nonhuman primate hearts. Nature. 2014; 510(7504):273-7.

23. Fernandes S, Naumova A V, Zhu WZ, Laflamme MA, Gold J, Murry CE. Human embryonic stem cell-derived cardiomyocytes engraft but do not 
alter cardiac remodeling after chronic infarction in rats. $J$ Mol Cell Cardiol. 2010; 49(6):941-9.

24. Laflamme MA, Chen KY, Naumova A V, Muskheli V, Fugate JA, Dupras SK, et al. Cardiomyocytes derived from human embryonic stem cells in pro-survival factors enhance function of infarcted rat hearts. Nat Biotechnol. 2007; 25(9):1015-24.

25. Shiba Y, Fernandes S, Zhu W-Z, Filice D, Muskheli V, Kim J, et al. Human ES-cell-derived cardiomyocytes electrically couple and suppress arrhythmias in injured hearts. Nature. 2012; 489(7415):322-5.

26. Takahashi K, Yamanaka S. Induction of pluripotent stem cells from mouse embryonic and adult fibroblast cultures by defined factors. Cell. 2006; 126(4):663-76.

27. Burridge PW, Keller G, Gold JD, Wu JC. Production of de novo cardiomyocytes: human pluripotent stem cell differentiation and direct reprogramming. Cell Stem Cell. 2012; 10(1):16-28.

28. Lian X, Hsiao C, Wilson G, Zhu K, Hazeltine LB, Azarin SM, et al. Robust cardiomyocyte differentiation from human pluripotent stem cells via temporal modulation of canonical Wnt signaling. PNAS. 2012; 109(27):E1848-57.

29. Lian X, Zhang J, Azarin SM, Zhu K, Hazeltine LB, Bao X, et al. Directed cardiomyocyte differentiation from human pluripotent stem cells by modulating $W n t / \beta$-catenin signaling under fully defined conditions. Nat Protoc. 2013; 8(1):162-75.

30. Burridge PW, Matsa E, Shukla P, Lin ZC, Churko JM, Ebert AD, et al. Chemically defined generation of human cardiomyocytes. Nat Methods. $2014 ; 11(8)$.

31. Dariolli R, Bassaneze V, Nakamuta JS, Omae SV, Campos LCG, Krieger JE. Porcine Adipose Tissue-Derived Mesenchymal Stem Cells Retain Their Proliferative Characteristics, Senescence, Karyotype and Plasticity after Long-Term Cryopreservation. PLoS One. 2013; 8(7):e67939.

32. Somers A, Jean J-C, Sommer C a, Omari A, Ford CC, Mills J a, et al. Generation of transgene-free lung disease-specific human induced pluripotent stem cells using a single excisable lentiviral stem cell cassette. Stem Cells. 2010; 28(10):1728-40.

33. Fraga AM, Sukoyan M, Rajan P, Braga DP de AF, laconelli A, Franco JG, et al. Establishment of a Brazilian line of human embryonic stem cells in defined medium: implications for cell therapy in an ethnically diverse population. Cell Transplant. 2011; 20(3):431-40. 
Apêndice $B$

34. Takahashi K, Tanabe K, Ohnuki M, Narita M, Ichisaka T, Tomoda K, et al. Induction of pluripotent stem cells from adult human fibroblasts by defined factors. Cell. 2007; 131(5):861-72.

35. Yu J, Vodyanik MA, Smuga-Otto K, Antosiewicz-Bourget J, Frane JL, Tian S, et al. Induced pluripotent stem cell lines derived from human somatic cells. Science. 2007; 318(5858):1917-20.

36. Esteban MA, Xu J, Yang J, Peng M, Qin D, Li W, et al. Generation of induced pluripotent stem cell lines from Tibetan miniature pig. J Biol Chem. 2009; 284(26):17634-40.

37. Wu Z, Chen J, Ren J, Bao L, Liao J, Cui C, et al. Generation of pig induced pluripotent stem cells with a drug-inducible system. J Mol Cell Biol. 2009; 1(1):46-54.

38. Ezashi T, Telugu BPVL, Alexenko AP, Sachdev S, Sinha S, Roberts RM. Derivation of induced pluripotent stem cells from pig somatic cells. PNAS. 2009; 106(27):10993-8.

39. Roberts RM, Telugu BPVL, Ezashi T. Induced pluripotent stem cells from swine (Sus scrofa): why they may prove to be important. Cell Cycle. 2009; 8(19):3078-81.

40. Gore A, Li Z, Fung H-L, Young JE, Agarwal S, Antosiewicz-Bourget J, et al. Somatic coding mutations in human induced pluripotent stem cells. Nature. 2011; 471(7336):63-7.

41. Hussein SM, Batada NN, Vuoristo S, Ching RW, Autio R, Närvä E, et al. Copy number variation and selection during reprogramming to pluripotency. Nature. 2011; 471(7336):58-62.

42. Laurent LC, Ulitsky I, Slavin I, Tran H, Schork A, Morey R, et al. Dynamic changes in the copy number of pluripotency and cell proliferation genes in human ESCs and iPSCs during reprogramming and time in culture. Cell Stem Cell. 2011; 8(1):106-18.

43. Mayshar Y, Ben-David U, Lavon N, Biancotti J-C, Yakir B, Clark AT, et al. Identification and classification of chromosomal aberrations in human induced pluripotent stem cells. Cell Stem Cell. 2010; 7(4):521-31.

44. Ma H, Morey R, O’Neil RC, He Y, Daughtry B, Schultz MD, et al. Abnormalities in human pluripotent cells due to reprogramming mechanisms. Nature. 2014; 511(7508):177-83.

45. Steichen C, Luce E, Maluenda J, Tosca L, Moreno-Gimeno I, Desterke C, et al. Messenger RNA- versus retrovirus-based induced pluripotent stem cell reprogramming strategies: analysis of genomic integrity. Stem Cells Transl Med. 2014; 3(6):686-91. 
46. Bar-Nur O, Russ HA, Efrat S, Benvenisty N. Epigenetic memory and preferential lineage-specific differentiation in induced pluripotent stem cells derived from human pancreatic islet beta cells. Cell Stem Cell. 2011; $9(1): 17-23$.

47. Kim K, Doi A, Wen B, Ng K, Zhao R, Cahan P, et al. Epigenetic memory in induced pluripotent stem cells. Nature. 2010; 467(7313):285-90.

48. Stadtfeld M, Apostolou E, Akutsu H, Fukuda A, Follett P, Natesan S, et al. Aberrant silencing of imprinted genes on chromosome $12 \mathrm{qF} 1$ in mouse induced pluripotent stem cells. Nature. 2010; 465(7295):175-81.

49. Kim K, Zhao R, Doi A, Ng K, Unternaehrer J, Cahan P, et al. Donor cell type can influence the epigenome and differentiation potential of human induced pluripotent stem cells. Nat Biotechnol. 2011; 29(12):1117-9.

50. Polo JM, Liu S, Figueroa ME, Kulalert W, Eminli S, Tan KY, et al. Cell type of origin influences the molecular and functional properties of mouse induced pluripotent stem cells. Nat Biotechnol. 2010; 28(8):848-55.

51. Lister R, Pelizzola M, Kida YS, Hawkins RD, Nery JR, Hon G, et al. Hotspots of aberrant epigenomic reprogramming in human induced pluripotent stem cells. Nature. 2011; 471(7336):68-73.

52. He J-Q, Ma Y, Lee $Y$, Thomson JA, Kamp TJ. Human embryonic stem cells develop into multiple types of cardiac myocytes: action potential characterization. Circ Res. 2003; 93(1):32-9.

53. Kehat I, Kenyagin-Karsenti D, Snir M, Segev H, Amit M, Gepstein A, et al. Human embryonic stem cells can differentiate into myocytes with structural and functional properties of cardiomyocytes. J Clin Invest. 2001; 108(3):407-14.

54. Zhang J, Wilson GF, Soerens AG, Koonce CH, Yu J, Palecek SP, et al. Functional cardiomyocytes derived from human induced pluripotent stem cells. Circ Res. 2009; 104(4):e30-41.

55. Zwi L, Caspi O, Arbel G, Huber I, Gepstein A, Park I-H, et al. Cardiomyocyte differentiation of human induced pluripotent stem cells. Circulation. 2009; 120(15):1513-23.

56. Brewer GJ, Torricelli JR, Evege EK, Price PJ. Optimized survival of hippocampal neurons in B27-supplemented Neurobasal, a new serumfree medium combination. J Neurosci Res. 1993; 35(5):567-76.

57. Blande IS, Bassaneze V, Lavini-Ramos C, Fae KC, Kalil J, Miyakawa AA, et al. Adipose tissue mesenchymal stem cell expansion in animal serumfree medium supplemented with autologous human platelet lysate. Transfusion. 2009; 49(12):2680-5. 
